Rosangela Viana ANDRAde

\title{
A emergência da expressão comunicativa na criança com síndrome de Down
}

\author{
Tese apresentada à Faculdade de Medicina da \\ Universidade de São Paulo para obtenção do título de \\ Doutor em Ciências
}

Área de concentração: Fisiopatologia Experimental

Orientadora: Profa. Dra. Suelly Cecília Olivan Limongi

São Paulo

2006 


\section{FICHA CATALOGRÁFICA}

Preparada pela Biblioteca da Faculdade de Medicina da Universidade de São Paulo

Creprodução autorizada pelo autor

\section{Andrade, Rosangela Viana}

A emergência da expressão comunicativa na criança com síndrome de Down

/ Rosangela Viana Andrade. -- São Paulo, 2006.

Tese(doutorado)--Faculdade de Medicina da Universidade de São Paulo para obtenção do título de Doutor em Ciências.

Área de concentração: Fisiopatologia Experimental.

Orientadora: Suelly Cecília Olivan Limongi.

Descritores: 1.SÍNDROME DE DOWN 2.DESENVOLVIMENTO INFANTIL 3.DESENVOLVIMENTO DA LINGUAGEM 4.FALA 5.GESTOS 6.COGNIÇÃO 7.PRÉ-ESCOLAR

USP/FM/SBD-052/06 
A meus pais, Eurico e Maria, por todo amor que sempre me dedicaram. 


\section{AGRADECIMENTOS}

À minha orientadora, Profa. Dra. Suelly Cecília Olivan Limongi, pelas oportunidades de aprendizado profissional e, em especial, pela confiança depositada em mim, não somente durante a realização deste trabalho, mas no decorrer de todos os anos que temos trabalhado juntas.

Às professoras Dra. Débora Maria Béfi-Lopes e Dra. Fernanda Dreux Miranda Fernandes e ao amigo Dr. Zan Mustacchi pela atenção cuidadosa, observações e sugestões oferecidas no exame de qualificação.

À coordenação das APAEs de Mauá e de Santo André e às suas respectivas fonoaudiólogas: Alessandra, Ana Paula e Carla, pelo auxílio no contato com as famílias das crianças participantes deste estudo e pela atenção prestada nos dias da coleta de dados.

À Secretaria da Educação de São Bernardo do Campo por ter autorizado a realização de parte desta pesquisa junto à EMEB Antônio José Mantuan.

A todos os funcionários da EMEB Antônio José Mantuan e, em especial, à diretora Suzete Capassi Baltuilhe, pela atenção e gentileza prestadas durante o período em que discorreu a coleta de dados. 
Ao Laboratório de Investigação Fonoaudiológica em Síndromes e Alterações Sensório-Motoras do Curso de Fonoaudiologia da Faculdade de Medicina da Universidade de São Paulo, pela oportunidade do atendimento fonoaudiológico durante a realização desta pesquisa.

Às fonoaudiólogas Ângela Maria, Daniela do Val e Luciene Stivanin, por terem participado deste estudo como juizes dos dados coletados.

À fonoaudióloga Karina de Araujo, pela disponibilidade e atenção em auxiliarme nas informações de alguns conceitos da Lingüística utilizados neste trabalho.

À fonoaudióloga Ana Flávia Vidal e à minha irmã Rosemeire, pela contribuição nas filmagens das crianças.

Ao estatístico Jimmy Adans, pela atenção e disponibilidade ao trabalhar os dados coletados em resultados estatísticos.

A todas as crianças que fizeram parte desta pesquisa, cujo contato, para mim, foi o mais prazeroso durante a realização deste trabalho, e às suas respectivas mães, pela compreensão da importância deste estudo e a sua autorização.

Aos amigos e fonoaudiólogos: Christian César, Seisse Gabriela, Ivone Neves, Márcia Simões, Marília Barbieri, Renata Leite e, em especial, Dra. Cláudia Scheuer e Sandra Pires, pelo carinho, compreensão e apoio moral irrestritos durante a realização deste trabalho. 
"Vivemos com o que recebemos, mas marcamos a vida com o que damos".

Winston Churchill 
Esta tese está de acordo com:

Referências: adaptado de International Committee of Medical Journals Editors (Vancouver)

Universidade de São Paulo. Faculdade de Medicina. Serviço de Biblioteca e Documentação.

Guia de apresentação de dissertações, teses e monografias. Elaborado por Anneliese Carneiro da Cunha, Maria Julia de A. L. Freddi, Maria F. Crestana, Marinalva de Souza Aragão, Suely Campos Cardoso, Valéria Vilhena. São Paulo: Serviço de Biblioteca e Documentação; 2004.

Abreviaturas dos títulos dos periódicos de acordo com List of Journals Indexed in Index Medicus. 


\section{Sumário}

Lista de figuras

Lista de quadros

Lista de tabelas

Resumo

Summary

1. INTRODUÇÃo

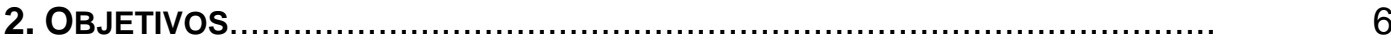

2.1. Hipótese e objetivo..............................................

2.2. Justificativa .........................................................

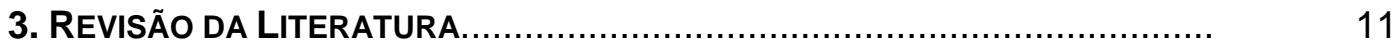

3.1. Síndrome de Down - características gerais.................... 12

3.2. A emergência da linguagem na criança com desenvolvimento típico (DT) ..................................... $\quad 24$

3.2.1. A imitação e a construção do símbolo e da linguagem segundo a Epistemologia Genética

3.2.2. A relação entre a emergência da linguagem oral, dos gestos e o jogo simbólico na criança com DT

3.2.3. O desenvolvimento lexical durante a emergência da linguagem na criança com DT.

3.3. A emergência da linguagem na criança com síndrome de Down (SD).

3.3.1. A importância da interação mãe-criança no desenvolvimento de linguagem da criança com SD. 
4. MÉTOdOS........................................................................ 61

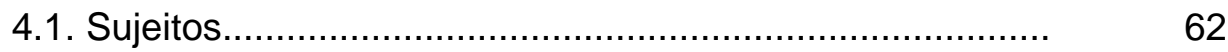

4.2. Material.......................................................... 66

4.3. Procedimento.................................................. $\quad 69$

4.3.1. Coleta de dados ............................................ 70

4.3.1.1. Coleta de dados do GP ......................... 70

4.3.1.2. Coleta de dados do GC1 ...................... 73

4.3.1.3. Coleta de dados do GC2 ….....................

4.3.2. Registro e análise dos dados $\quad 76$

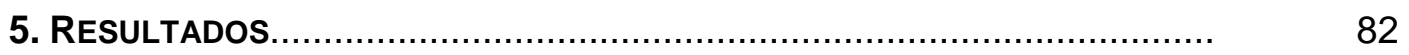

5.1. Linguagem oral (análise morfossintática)....................... 84

5.1.1. Linguagem oral (análise morfossintática) do GP 87

5.1.2. Linguagem oral (análise morfossintática) do GC1 89

5.1.3. Linguagem oral (análise morfossintática) do GC2 91

5.1.4. Análise da linguagem oral (análise morfossintática dos GP, GC1 e GC2.................. 92

5.2. Comunicação gestual........................................... 95

5.2.1. Comunicação gestual do GP.............................. 96

5.2.2. Comunicação gestual do GC1........................... 99

5.2.3. Comunicação gestual do GC2............................ 102

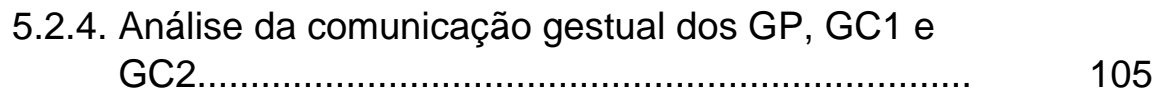

5.3. Linguagem oral e comunicação gestual simultâneas........ 106

5.3.1. Linguagem oral e comunicação gestual simultâneas do GP

5.3.1.1. Linguagem oral e comunicação gestual simultâneas de acordo com as classes de palavras (análise morfossintática)........ 108

5.3.1.2. Linguagem oral e comunicação gestual de acordo com a classificação de gestos... 
5.3.2. Linguagem oral e comunicação gestual

simultâneas do GC1

115

5.3.2.1. Linguagem oral e comunicação gestual simultâneas de acordo com as classes de palavras (análise morfossintática)......

115

5.3.2.2. Linguagem oral e comunicação gestual de acordo com a classificação de gestos...

118

5.3.3. Linguagem oral e comunicação gestual simultâneas do GC2.

122

5.3.3.1. Linguagem oral e comunicação gestual simultâneas de acordo com as classes de palavras (análise morfossintática).

122

5.3.3.2. Linguagem oral e comunicação gestual de acordo com a classificação de gestos...

124

5.3.4. Análise da linguagem oral e comunicação gestual simultâneas do GP, GC1 e GC2.

127

6. DISCUSSÃo

130

7. CONCLUSÕES.

147

8. ANEXOS

150

Anexo A: Protocolo de avaliação de linguagem e cognição

151

Anexo B: Protocolo de análise de linguagem e cognição

153

B1: Protocolo de análise de linguagem e cognição (modelo - GP).

155

B2: Protocolo de análise de linguagem e cognição (modelo - G1)

158

B3: Protocolo de análise de linguagem e cognição (modelo - G2)

161

Anexo C: Material (foto).....................................................

Anexo D: Protocolo de observação..................................... 164

Anexo E: Certificado de aprovação da comissão de ética para análise de projetos de pesquisa (CAPPesq) 166

Anexo F: Termo de consentimento livre e esclarecido 168

Modelo - GP.................................................. 169

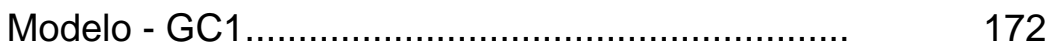

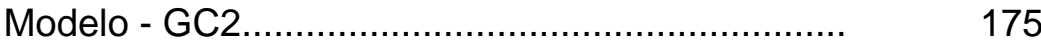

Anexo G: Autorização da instituição para a pesquisa........... 178 
Autorização - LIFSASM

179

Autorização - APAE (Mauá)

180

Autorização - APAE (Santo André).........................

181

Autorização - Secretaria da Educação de São

Bernardo do Campo.

9. REFERÊNCIAS...

183

Apêndice 


\section{LISTA DE FIGURAS}

Figura 1. Número de vocábulos diferentes presentes em GP, GC1 e GC2......

Figura 2. Número total de classes de palavras presentes em GP, GC1

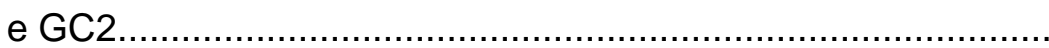

Figura 3. Número de gestos observados durante a comunicação gestual em GP, GC1 e GC2

Figura 4. Ocorrências de linguagem oral simultânea à comunicação gestual dos três grupos segundo o número de vocábulos

Figura 5. Ocorrências de linguagem oral simultânea à comunicação gestual dos três grupos segundo o número de classes de palavras

Figura 6. Ocorrências de linguagem oral e comunicação gestual simultâneas dos três grupos segundo o número de gestos..... 


\section{LISTA DE QUADROS}

Quadro 1 Observação do número de vocábulos diferentes por classe de palavras na linguagem oral dos quatro sujeitos do GP durante as três avaliações............................................

Quadro 2 Observação do número de vocábulos diferentes por classe de palavras na linguagem oral dos quatro sujeitos do GC1 durante as três avaliações

Quadro 3 Observação do número de vocábulos diferentes por classe de palavras na linguagem oral dos quatro sujeitos do GC2 durante as três avaliações

Quadro 4 Tipos diferentes de ocorrências na comunicação gestual dos quatro sujeitos do GP durante as três avaliações......

Quadro 5 Tipos diferentes de ocorrências na comunicação gestual dos quatro sujeitos do GC1 durante as três avaliações.......

Quadro 6 Tipos diferentes de ocorrências na comunicação gestual dos quatro sujeitos do GC2 durante as três avaliações.......

Quadro 7 Observação do número de vocábulos diferentes por classe de palavras na linguagem oral simultânea à comunicação gestual dos quatro sujeitos do GP durante as três avaliações

Quadro 8 Tipos diferentes de ocorrências de comunicação gestual simultânea à linguagem oral dos quatro sujeitos do GP durante as três avaliações

Quadro 9 Observação do número de vocábulos diferentes por classe de palavras na linguagem oral simultânea à comunicação gestual dos quatro sujeitos do GC1 durante as três avaliações

Quadro 10 Tipos diferentes de ocorrências de comunicação gestual simultânea à linguagem oral dos quatro sujeitos do GC1 durante as três avaliações 
Quadro 11 Observação do número de vocábulos diferentes por classe de palavras na linguagem oral simultânea à comunicação gestual dos quatro sujeitos do GC2 durante as três avaliações

Quadro 12 Tipos diferentes de ocorrências de comunicação gestual simultânea à linguagem oral dos quatro sujeitos do GC2 durante as três avaliações. 


\section{LISTA DE TABELAS}

Tabela 1. Observação da comparação dos p-valores do número de vocábulos diferentes dos três grupos......

Tabela 2. Observação da comparação dos p-valores do número total de classes de palavras dos três grupos. 


\section{RESUMO}

Andrade RV. A emergência da expressão comunicativa na criança com síndrome de Down [tese]. São Paulo: Faculdade de Medicina, Universidade de São Paulo; 2006. $206 p$.

A síndrome de Down (SD) é causada por uma alteração cromossômica, cujas características principais são a hipotonia generalizada e a defasagem cognitiva, com conseqüente atraso no desenvolvimento de linguagem. Há outros fatores que podem contribuir com este atraso: alterações neurológicas, cardiopatias, atraso no desenvolvimento neuropsicomotor, problemas respiratórios, freqüentes quadros de otite, alterações do sistema estomatognático, e alterações na qualidade da interação mãe-criança nos primeiros anos de vida. Para compensar este atraso e os fatores contribuintes, a criança com SD pode desenvolver as suas expressões comunicativas de formas diferentes para se fazer compreendida pelo interlocutor: linguagem oral, comunicação gestual ou ambas simultaneamente. Com o propósito de facilitar o melhor desenvolvimento de linguagem na criança com SD, este trabalho teve por objetivo o estudo qualitativo das diferentes formas de expressões comunicativas; a emergência da expressão oral e sua relação com os gestos durante a comunicação; a evolução dos gestos e a sua qualificação. Também se verificou a efetividade da terapia fonoaudiológica na criança com SD segundo o método dialético-didático, fundamentado no método clínico de Piaget. Este método propõe a construção do conhecimento do sujeito por meio de situações conflitivas, com a intervenção ativa do pesquisador durante este processo, auxiliando a criança a reorganizar o seu conhecimento. Participaram deste estudo 12 crianças: quatro com SD (faixa etária entre 33 e 52 meses, no início da pesquisa) constituindo o grupo pesquisa (GP); quatro com SD (mesma faixa etária que o GP) ou grupo controle um (GC1); quatro com desenvolvimento típico (DT) (faixa etárias entre 14 e 16 meses, no início da pesquisa) ou grupo controle dois (GC2). Todas as crianças apresentavam desenvolvimento cognitivo entre o final do período sensório-motor e início do pré-operatório. Todos os sujeitos foram avaliados três vezes em um período de 12 meses: inicial, após seis 
meses de estudo e aos 12 meses. As avaliações foram filmadas, transcritas e tiveram a duração de 30 minutos, cada. Foram transcritas as ações e todas as formas de comunicação das crianças. Os materiais utilizados foram brinquedos (sempre os mesmos) apropriados para a fase de desenvolvimento cognitivo apresentado pelas crianças. O processo terapêutico, apenas para o GP, constou de 40 terapias, uma por semana, com materiais semelhantes aos das avaliações. Como resultado verificou-se que o GP teve melhor evolução que GC1. Os sujeitos que melhor conseguiram se expressar, independente da forma utilizada (palavras, gestos ou ambos simultâneos), foram os que apresentaram melhor evolução no desenvolvimento cognitivo. Os sujeitos do GC2 (DT) apresentaram desenvolvimento das expressões comunicativas compatíveis com o esperado, nas três avaliações. Desse modo, foi possível confirmar a eficácia do método dialético-didático como processo terapêutico, demonstrada na evolução no desenvolvimento da linguagem do GP em relação ao GC1.

Descritores: 1. Síndrome de Down 2. Desenvolvimento Infantil 3. Desenvolvimento da Linguagem 4. Fala 5. Gestos 6. Cognição 7. Pré-escolar 


\section{SUMMARY}

Andrade RV. The emergence of communicative expression in the child with Down syndrome [thesis]. São Paulo: "Faculdade de Medicina, Universidade de São Paulo"; 2005. 206p.

Down syndrome (DS) is caused by a chromosomal alteration, whose principal characteristics are the generalized hypotonia and a cognitive imbalance, with consequent delay in language development. Other factors may contribute with this delay, such as neurological alterations, cardiopathies, a delay in the neuropsychomotor development, respiratory problems, the frequent otites, alterations in stomatognatic system, and poor mother-child interaction since the baby's birth. To compensate this delay and the contributing factors, the DS child can develop its communicative expressions in different ways, to be understood by the interlocutor: oral language, gesture communication or both simultaneously. In order to facilitate the best language development in the DS child, this qualitative study aimed to verify the different forms of communicative expressions: the emergence of oral expression and its relation to gestures during communication; gestures evolution and its qualification. It was also verified the effectiveness of speech-language therapy on the language development in DS child, according to the dialectic-didactic method, based in the clinical method of Piaget. This method proposes the subject's construction of knowledge through conflictive situations, with the active intervention of the researcher during this process, helping the child to reorganize its knowledge. Twelve children participated of this study: four with DS (ages between 33 and 52 months, in the beginning of the research); composing the research group (RG); four with DS (same age as the RG) or control group one (CG1); four with typical development (TD) (ages between 14 and 16 months, in the beginning of the research) or control group two (CG2). All children presented cognitive development between the final sensory motor and beginning of the preoperational stages. All subjects were evaluated three times in a period of 12 months: initial, after six months of the study and in the twelfth month. Evaluations were filmed, transcribed and lasted thirty (30) minutes each. Children's actions and all ways of 
communication were transcribed. Toys were utilized as materials (always the same) and were appropriate to the cognitive phase presented by these children. The therapeutic process, only for the RG, consisted of 40 therapies, once a week, with similar materials to those used in the evaluations. As result it was verified that the RG had a better evolution than the CG1. The subjects that could better express themselves, independently of the way used (words, gestures or both simultaneously), were those that presented a better evolution in the cognitive development. Subjects of the CG2 (TD) presented communicative expressions development compatible with the expected, in the three evaluations. By this means, it was possible to confirm the efficiency of the dialectic-didactic method as therapeutic process, showed in the evolution of the language development of RG in relation to CG1.

Keywords: 1.Down syndrome 2.Child Development 3.Language Development 4.Speech 5.Gestures 6.Cognition 7.Pre Scholar 
1. INTRODUCÃO 
O estudo do desenvolvimento de linguagem na criança com síndrome de Down (SD) tem sido realizado, ao longo das décadas, por muitos autores, sendo a maioria deles, internacionais.

Dentre os aspectos estudados, a maioria refere-se às diversas causas que buscam justificar o atraso do desenvolvimento de linguagem nesta população e os fatores que mais contribuem para este atraso: a defasagem cognitiva (Cunningham et al., 1985; Buckley, 1993; Franco e Wishart, 1995; Cahill e Glidden, 1996; Roach et al., 1998; Limongi et al., 2000; Clibbens, 2002; Johnson-Glenberg e Chapman, 2004; Yoder e Warren, 2004), o prejuízo na qualidade da interação mãe-criança nos primeiros anos de vida (Jones, 1977; Leifer e Lewis, 1984; Martins e Mervis, 1985; Martins et al., 1985; Fischer, 1987; Hoshino et al., 1994; Messer e Hasan, 1994; Perez e Limongi, 1998; Kumin, 1999; Pino, 2000; Andrade, 2002), o atraso do desenvolvimento neuropsicomotor (Camargo, 2000; Limongi et al., 2000; Mustacchi, 2000; Andrade, 2002), as alterações do sistema estomatognático (Schwartzman M., 1999; Andrade, 2002; Ideriha, 2005), as alterações neurológicas (Schwartzman J., 1999; Mustacchi, 2000; Spinelli et al., 2001), os quadros de otite (Kay-Raining Bird e Chapman, 1994; Roberto, 2000; Stoel-Gammon, 2002), os problemas cardíacos (Silva, 1990; Brunoni, 1999) e os respiratórios (Mustacchi e Rozone, 1990; Mustacchi, 2000).

Durante o desenvolvimento de linguagem na criança com SD, no que se refere, em particular, ao estudo da emergência das expressões comunicativas desta população, a literatura tem apresentado pesquisas que relatam tanto sobre as formas diferentes de ocorrência destas expressões 
como sobre a sua evolução (Jenkins, 1993; Franco e Wishart, 1995; Caselli et al., 1998; Ramruttun e Jenkins, 1998; Chan e Iacono, 2001; Clibbens, 2002; Iverson et al., 2003). Neste sentido, este trabalho visa contribuir com estas pesquisas, não somente buscando confirmar os dados encontrados na literatura sobre este tema, mas, também, mostrar que é possível favorecer o desenvolvimento de linguagem destas crianças, e sua expressão, por meio da intervenção terapêutica fonoaudiológica.

Para tanto, este estudo apresenta-se dividido em sete capítulos, sendo que, após a introdução, o segundo destina-se à hipótese, objetivo e justificativa. Fica estabelecida a hipótese de que o desenvolvimento da linguagem e sua expressão oral, a partir da comunicação gestual, em crianças com SD entre o final do período sensório-motor e início do préoperatório (Piaget, 1987, edição original de 1936; 1990, edição original de 1946; 1996, edição original de 1937) podem ser favorecidos por meio do método dialético-didático (Parrat-Dayan, 1996). Foi determinado como objetivo principal o estudo qualitativo do desenvolvimento das expressões comunicativas na criança com SD.

O terceiro capítulo aborda a revisão da literatura sobre:

- o estudo das características gerais da SD, referentes aos seus aspectos clínicos e genéticos;

- a emergência da linguagem na criança com desenvolvimento típico (DT). A revisão sobre esse assunto parte da teoria de Piaget sobre a cognição e a linguagem e, a seguir, são abordados alguns estudos que tratam da relação entre gestos e linguagem oral 
durante o período de emergência das expressões comunicativas na criança, a qual não pôde ser observada na teoria de Piaget. Eles foram considerados importantes de serem ressaltados por conterem informações que contribuem para a compreensão mais adequada do que pode ocorrer na evolução do desenvolvimento de linguagem na criança com SD;

- a emergência da linguagem expressiva na criança com SD. Nesta revisão são apresentados os principais trabalhos publicados nas literaturas nacional e internacional sobre este tema;

- o método dialético-didático, o qual é abordado iniciando-se pela sua definição e, a seguir, apresenta-se a sua origem histórica, e finaliza-se com a importância de seu uso durante o acompanhamento do desenvolvimento cognitivo da criança pequena.

No quarto capítulo está descrita a metodologia utilizada na seleção dos sujeitos, os materiais empregados e o procedimento adotado tanto na coleta de dados como na sua análise.

No quinto, estão os resultados obtidos sobre os três grupos que foram os sujeitos desta pesquisa com relação às suas expressões comunicativas, os quais foram divididos em: linguagem oral (análise morfossintática), comunicação gestual e linguagem oral e comunicação gestual simultâneas. A seguir, a discussão sobre os resultados obtidos, comparando-os com os trabalhos de outros autores a esse respeito, é realizada no capítulo sexto. 
O sétimo e último capítulo aborda a conclusão do estudo realizado, a partir dos resultados e sua discussão, de acordo com a hipótese e os objetivos propostos. Em seguida, são apresentados os anexos e as referências bibliográficas, finalizando o estudo. 
2. OBJETIVOS 


\subsection{Hipótese e Objetivo}

Considerando-se que:

- a defasagem cognitiva é a principal causa do atraso no desenvolvimento de linguagem na criança com SD (Cunningham et al., 1985), visto que a linguagem é estruturada pelo desenvolvimento cognitivo e dependente dele inicialmente (Piaget, 1990, edição original de 1946);

- apesar dos atrasos cognitivo e de linguagem presentes na criança com SD, observa-se que o primeiro ocorre de modo mais eficiente do que o segundo (Cunningham et al., 1985; Buckley, 1993; Caselli et al., 1998);

- no desenvolvimento de linguagem, a compreensão é melhor do que a expressão comunicativa nesta população (Cunningham et al., 1985; Franco e Wishart, 1995; Cahill e Glidden, 1996);

- para compensar o atraso na expressão oral, a criança com SD passa a desenvolver de modo significativo a comunicação gestual com o objetivo de ser melhor compreendida pelo interlocutor, de modo que os gestos podem ou não vir acompanhando a expressão oral por um longo tempo (Jenkins, 1993; Franco e Wishart, 1995; Foreman e Crews, 1998; Clibbens, 2002; JohnsonGlenberg e Chapman, 2004); 
a hipótese deste trabalho baseia-se no fato de que, por meio do método dialético-didático (Parrat-Dayan, 1996), é possível favorecer o desenvolvimento da linguagem e sua expressão oral, a partir da comunicação gestual, em crianças com SD entre o final do período sensóriomotor e início do pré-operatório (Piaget, 1987, edição original de 1936; 1990, edição original de 1946; 1996, edição original de 1937).

De acordo com esta hipótese, teve-se por objetivo o estudo qualitativo do desenvolvimento das expressões comunicativas na criança com SD, no qual pretendeu-se verificar:

- a emergência da linguagem oral e sua relação com a comunicação gestual;

- a evolução dos gestos e a sua qualificação;

- a efetividade da terapia fonoaudiológica no desenvolvimento de linguagem na criança com SD segundo o método dialético-didático (Parrat-Dayan, 1996).

\subsection{Justificativa}

A realização deste estudo justifica-se por três razões. A primeira baseia-se no fato de se tratar de uma pesquisa que busca analisar, de modo qualitativo, as diferentes formas de comunicação na criança com SD, bem como o seu processo de desenvolvimento. 
No decorrer de nossa experiência profissional temos observado que, embora a linguagem oral desenvolva-se nesta população de modo mais lento do que na com DT, a criança com SD é capaz de se comunicar por outras vias de expressão o que deseja, o que sente e o que pensa, de acordo com o contexto em que se apresenta.

Na tentativa de explicar o que ocorre com estas crianças no início do desenvolvimento de linguagem, a literatura internacional é vasta. Há estudos que se dedicam tanto em informar somente sobre o desenvolvimento da linguagem oral (período de emergência e sua relação com outras formas de expressões comunicativas) (Rondal, 1996; Berglund et al., 2001; Iverson et al., 2003), como também há outros que preferem priorizar o desenvolvimento de outras formas de comunicação acompanhando a linguagem oral ou substituindo-a (Jenkins, 1993; Franco e Wishart, 1995; Ramruttun e Jenkins, 1998; Chan e Iacono, 2001; Jonhson-Glenberg e Chapman, 2004).

A segunda razão está relacionada diretamente à primeira, que, pelo fato de quase não existirem trabalhos na literatura nacional que tratem da relação entre a emergência da linguagem oral e a comunicação gestual na criança com SD, este estudo passará, então, a contribuir.

A terceira e última razão refere-se ao uso do método dialético-didático (Parrat-Dayan, 1996) durante o acompanhamento fonoaudiológico das crianças com SD. Este método tem demonstrado, em pesquisas anteriores (Assis, 1996; Limongi et al., 2000; Alabarse, 2002; Andrade, 2002), a sua importância durante estudos clínicos como meio facilitador do desenvolvimento cognitivo e, em decorrência, da linguagem. E, por assim 
ser, os dados resultantes desta pesquisa seriam de grande relevância para se constatar a efetividade deste método durante o processo terapêutico fonoaudiológico de crianças com SD. 
3. REVISÃO DA LITERATURA 


\subsection{Síndrome de Down - características gerais}

\section{Aspectos genéticos:}

A síndrome de Down (SD) foi descrita pela primeira vez em 1838 por Juan Esquirol, ao observar uma criança que, na época, presumia-se apresentar esta síndrome.

Em 1846, Edouard Seguin descreveu um paciente com feições que sugeriam a SD, denominando-a de "idiotia furfurácea".

No ano 1866, Duncan registrou uma menina "com a cabeça pequena e arredondada, olhos parecidos com os dos chineses, uma língua grande que se projetava, e que só conhecia algumas palavras". Neste mesmo ano, John Langdon Down publicou um trabalho que descrevia algumas das características clássicas da síndrome, ao mesmo tempo que a distinguia de outras desordens com defasagem cognitiva. Por estas razões, desde então, ele mereceu o crédito da síndrome levar o seu nome (Pueschel, 1993).

Desde a sua primeira descrição, vários cientistas têm buscado respostas que justificassem a causa da SD. No início dos anos 30 do século passado, alguns médicos começaram a suspeitar que ela poderia ser resultado de alguma alteração cromossômica. Entretanto, nesta época, ainda não existiam técnicas desenvolvidas o suficiente que pudessem comprovar esta teoria.

Em 1959, Jerome Lejeune observou que os indivíduos com tal comprometimento apresentavam 47 cromossomos em cada célula ao invés 
dos esperados 46 típicos ao ser humano (22 pares de autossomos homólogos e mais dois cromossomos sexuais). Dentre estes 47, ele encontrou três cromossomos 21 ao invés de dois, o que levou à denominação do termo trissomia do 21 (Pueschel, 1993; Brunoni, 1999). Tal descoberta foi um marco no estudo da patologia humana, visto que ela foi a primeira síndrome associada a uma aberração cromossômica (Brunoni, 1999).

Mais tarde, por meio de estudos genéticos (técnicas de bandeamento), observou-se que, na SD, bastava o braço longo do cromossomo 21 apresentar-se com excesso de material gênico para caracterizar esta síndrome (Mustacchi e Rozone, 1990; Pueschel, 1993; Mustacchi, 2000). Desde então, ficou claro que, para a ocorrência da SD, não é necessário uma real trissomia completa do cromossomo 21 (Mustacchi, 2000).

A seguir, geneticistas identificaram mais dois tipos de alterações cromossômicas que envolvem o excesso de material gênico do braço longo do cromossomo 21 causando a SD. São: a translocação e o mosaicismo.

Portanto, existem três tipos de alterações cromossômicas que causam a SD:

a) Trissomia simples ou livre: ocorre em $96 \%$ dos casos e é caracterizada pela não-disjunção na meiose de um cromossomo do par 21. Segundo Mustacchi (2000), a trissomia é um acidente que ocorre na formação do gameta, sendo pouco provável a sua recorrência em outros filhos do mesmo casal. Geralmente ela está relacionada com o avanço da idade 
materna, pois, por algum motivo desconhecido, é na ovogênese que se dá a maioria dos casos de não-disjunção, a qual é favorecida pelo envelhecimento dos ovócitos. Mães com idade em torno de 30 anos apresentam um risco de terem uma criança com SD, em média, na proporção de 1 para cada 685 nascimentos, enquanto que as mães com mais de 45 anos é de 1 para cada 35.

b) Translocação: neste caso, o terceiro cromossomo 21 não é um cromossomo "livre", mas está ligado ou translocado a outro cromossomo que geralmente podem ser o 14, ou o 15, ou o 21 . A sua ocorrência está relacionada à presença da translocação em um dos pais, proveniente ou não de gerações anteriores. Segundo Pueschel (1993) e Mustacchi (2000), apesar deste pai ou desta mãe ser perfeitamente normal em todos os aspectos (físicos e mentais) e ter uma quantidade de material genético normal, dois dos cromossomos desse indivíduo estarão ligados um ao outro (translocação equilibrada), o que resulta em um número total de 45 cromossomos ao invés de 46 . Embora no portador de translocação, os cromossomos ligados não alterem as funções normais dos genes nem causem anormalidades, ele apresenta um risco maior de ter filhos com SD. Neste caso, os pais necessitarão de aconselhamento genético, visto que a recorrência desta síndrome para eles poderá ser de 20\% (Mustacchi, 2000).

c) Mosaicismo: caracteriza-se pela presença de duas ou mais populações celulares diferentes no número de cromossomos de um mesmo indivíduo, como conseqüência da não-disjunção cromossômica na 
gestação (pós-zigótica) (Mustacchi e Rozone, 1990). Quando ocorre o mosaicismo na SD, o bebê apresenta um percentual de células com 46 cromossomos e outro de células com 47 cromossomos, simulando uma forma parcial de trissomia (Mustacchi, 2000). Isto lembra um tipo de quadro em mosaico, daí o termo mosaicismo (Pueschel, 1993). Entretanto, é o tipo menos comum de ocorrer, com apenas $2 \%$ dos casos.

Segundo Pueschel (1993), vários autores relataram que algumas crianças com SD do tipo mosaicismo apresentam traços menos acentuados da síndrome e que seu desempenho intelectual é melhor do que a média para crianças com trissomia do 21. Por outro lado, vale lembrar que, independente do tipo de alteração cromossômica presente no indivíduo com SD (trissomia do 21, translocação ou mosaicismo), é sempre o cromossomo 21 o responsável pelos traços físicos específicos e função intelectual limitada observados nesta população.

Mustacchi (2000) cita estudos que relatam a identificação de anomalias em regiões deste cromossomo, as quais caracterizam as alterações encontradas nos indivíduos com esta síndrome, correlacionando o genótipo com o fenótipo. Em outras palavras, já é possível observar a íntima correlação entre grupos gênicos do cromossomo 21 e cardiopatias, leucemia e doença de Alzheimer.

\section{Aspectos clínicos:}


Das síndromes que ocorrem com maior freqüência na população, a SD é a mais registrada, juntamente com a síndrome do Sítio Frágil do cromossomo X (FRA-X). Ela ocorre em cerca de 1 a cada 600 a 800 nascimentos vivos, cuja incidência é maior na prole de pais cuja faixa etária está acima da terceira década (Mustacchi e Rozone, 1990; Pueschel, 1993; Schwartzman J., 1999). Mustacchi (2000) aponta em seus estudos que, segundo uma pesquisa realizada pela European Registry of Congenital Anomalies and Twins (EUROCAT), a freqüência de nascimentos de crianças com SD é 1 para 650.

Os sinais clínicos mais freqüentes encontrados no indivíduo com SD, segundo os estudos de Mustacchi (2000), são: comprometimento intelectual (100\%); hipotonia muscular (99\%); face achatada com fissuras palpebrais oblíquas (face que lembra uma origem oriental) (90\%); occipto achatado (80\%); mãos largas, braquidactilia (dedos curtos) (70\%); clinodactilia do $5^{\circ}$ dedo (50\%); defeitos cardíacos (40\%); microcefalia (85\%); baixa estatura (60\%); orelhas de implantação baixa (50\%); orelhas displásicas (pequenas e com hélice superior enrolada) (50\%); prega simiesca (prega única transversa) nas palmas das mãos (40\%); instabilidade rótulo-femural (10\%); instabilidade atlanto-axial (15\%); hiperextensão articular (80\%); aumento de vascularização retiniana (90\%); epicanto (prega nos cantos internos dos olhos) (40\%).

Outras características físicas também podem estar presentes: telecanto (olhos afastados); blefarite (inflamação das pálpebras); manchas 
de Brushfield; nariz pequeno e achatado, com ponte nasal baixa em conseqüência da hipoplasia do osso nasal; pés pequenos e largos; grande espaço entre o hálux e segundo artelho; sindactilia; pescoço curto, largo e com pele abundante; pênis pequeno; criptorquidia; diástese dos músculos retos abdominais; hérnia umbilical; colelitíase; dilatação dos ventrículos laterais do sistema nervoso central (SNC); baixa resistência às infecções (geralmente apresentam processos pulmonares). Manifestações orais encontradas: maxilar com crescimento menor; ângulo da boca voltado para baixo; quelite (fissura nas comissuras labiais); doença periodontal; cavidade bucal pequena com língua protrusa e geralmente com aspecto escrotal (fissurada); palato em ogiva; hipodontia ou oligodontia; germinação, fusão de dentes e microdontia; erupção dentária irregular e tardia (o primeiro dente decíduo geralmente erupciona entre os 12 e 20 meses, de modo que, até os quatro ou cinco anos, a dentição poderá ainda não estar completa. A seqüência eruptiva também poderá acontecer de forma alterada, sendo que, muitas vezes, os molares podem erupcionar antes dos incisivos); incisivos centrais em meia lua; incisivos laterais conóides; queda precoce dos dentes; hipocalcificação; maloclusão dentária; instabilidade da articulação têmporomandibular (ATM) (Mustacchi e Rozone, 1990; Mustacchi, 2000).

Das alterações que geralmente ocorrem nos diferentes sistemas e aparelhos do corpo da criança com SD, de acordo com as descrições acima, as que mais interferem diretamente no trabalho fonoaudiológico são as do aparelho cardiovascular, as do aparelho respiratório, sistema estomatognático, as do sistema gastrointestinal e as do sistema neurológico. 
A malformação cardiovascular atinge cerca de $40 \%$ das crianças com SD, sendo que: $43 \%$ correspondem ao defeito do canal atrioventricular, $32 \%$ com comunicação interventricular, $10 \%$ tem comunicação interatrial tipo fossa oval, $6 \%$ com tetralogia de Fallot, 5\% com persistência do canal arterial e 4\% a outros tipos de malformações menos freqüentes (Mustacchi, 2000).

As crianças que apresentam alterações cardíacas cansam-se facilmente ao serem manipuladas e, consequentemente, a atenção delas diminui aos estímulos provenientes do ambiente. Silva (1990) relata que as conseqüências clínicas para a criança com SD, decorrentes das alterações do aparelho cardiovascular, aparecem durante o primeiro ano de vida, manifestando-se através da insuficiência cardíaca. Os sintomas mais comuns são: crescimento deficiente e infecções respiratórias freqüentes. Em seguida, há o aparecimento de cianose ao exercício e limitação da capacidade física.

Segundo os estudos de Brunoni (1999), as cardiopatias congênitas representam a principal causa de óbito nesta população. A seguir, observamos outras, as quais estão relacionadas a defeitos congênitos de grau variado e infecções respiratórias quase sempre associadas a cardiopatias e insuficiência cardíaca como já foi citado por Silva (1990).

No que se refere ao aparelho respiratório, observa-se que as obstruções de vias aéreas superiores estão presentes em torno de $50 \%$ das crianças com SD. Segundo Mustacchi (2000), a causa está relacionada às principais bases anatomofisiológicas dos desvios fenotípicos do trato 
respiratório (vias aéreas superiores e inferiores). Mustacchi e Rozone (1990) relatam que a hipotonia presente na criança com SD é generalizada, ou seja, tanto a musculatura estriada como a lisa são acometidas. Dessa forma, como a árvore tráqueo-brônquica apresenta a musculatura lisa em sua constituição, a hipotonia dessa musculatura causa a diminuição do potencial bronco-espástico, diminuindo, por sua vez, as vibrações ciliares que movimentam o muco produzido nessa região. Consequentemente, haverá o favorecimento do acúmulo de secreção e a produção de meio adequado para a proliferação bacteriana. Além disso, ressalta-se a interferência do desenvolvimento anômalo do maciço crânio-facial (occipto e face achatados com nariz pequeno e achatado, ponte nasal baixa, hipoplasia do osso nasal, maxilar com crescimento menor e conseqüente cavidade oral pequena e palato ogival) acarretando obstruções da oronasofaringe (Mustacchi, 2000).

Desse modo, a criança com SD que possui sérias dificuldades respiratórias apresentará mais resistência na adequação de sua função respiratória do que as outras com menor dificuldade. Logo, todo o trabalho de adequação do sistema estomatognático dessas crianças também estará mais prejudicado, visto que o modo de respiração delas será basicamente oral. Em decorrência desta função alterada mais a hipotonia presente, esta criança apresentará alterações na postura de suas estruturas estomatognáticas em repouso: lábios entreabertos, língua no soalho da boca e diminuição maior do tônus de sua musculatura peri e intra-oral. Em alguns casos, ainda, registra-se a presença de sialorréia em virtude dessas alterações, aliada ao déficit no controle da coordenação sucção-deglutição 
na criança pequena. As dificuldades de sucção logo ao seu nascimento geralmente são evidentes devido ao vedamento inadequado entre lábios, língua e mamilo, aliado à insuficiente força de sucção como conseqüência da hipotonia dos músculos envolvidos neste processo (Andrade, 2002; Ideriha, 2005).

Schwartzman M. (1999) ressalta, em sua pesquisa, outros fatores que também podem interferir significativamente no desenvolvimento e na adequação do sistema estomatognático destas crianças. São: o palato duro estreito e o mole curto; o subdesenvolvimento da maxila, podendo levar a uma alteração na posição dos músculos usados na mastigação; a língua grande, ou que poderá parecer grande em relação ao tamanho da cavidade oral que, por sua vez, poderá ser pequena como decorrência da hipoplasia da parte média da face; pouco controle dos movimentos da língua; e dificuldades com a estabilidade da mandíbula. Neste último caso, vale ressaltar que, devido à frouxidão dos ligamentos e à hipotonia generalizada, a articulação têmporo-mandibular (ATM) poderá apresentar instabilidade em sua postura e mobilidade.

A presença da sialorréia observada em algumas crianças com SD poderá, ainda, não estar relacionada somente à respiração oral. Segundo Rey e Birman (1990), existem alguns fatores que favorecem a produção de saliva em alguns indivíduos desta população: significante crescimento do pH; aumento da concentração dos íons, sódio, cálcio e bicarbonato; fluxo diminuído da parótida; elevação do ácido úrico e creatinina e aumento inespecífico da atividade da enzima estearase. 
Ora, se algumas funções e estruturas estomatognáticas estiverem alteradas, consequentemente, a produção articulatória dessas crianças também estará - o que pode contribuir de forma significativa com a ininteligibilidade de fala, a qual é tão freqüentemente observada em algumas delas (Kumin, 1999; Stoel-Gammon, 2001; Andrade, 2002).

Outro fato, também importante, decorrente das freqüentes infecções de vias aéreas superiores e associado à hipotonia característica desta síndrome, é a ocorrência de quadros de otite aguda nas crianças. Roberto (2000) explica que a diminuição do tônus das estruturas da nasofaringe, mais a incompetência velo-faríngea, e as freqüentes infecções de vias aéreas superiores, associadas à conseqüente disfunção da tuba auditiva, presentes em grande parte nas crianças com SD, contribuem para a ocorrência dos quadros de otite nesta população. Como conseqüência, a criança com SD apresentará um déficit na sua função auditiva que afetará diretamente a sua linguagem. Ela será uma criança que responderá menos aos estímulos sonoros do ambiente, cuja atenção e localização aos sons estarão prejudicadas (Kay-Raining Bird e Chapman, 1994; Chapman et al., 2000; Stoel-Gammon, 2001; Andrade, 2002).

Quanto ao sistema gastrointestinal, Mustacchi (2000) relata que as anomalias do trato digestivo ocorrem de forma significativa nestes pacientes (cerca de 80\%, incluindo o refluxo gastro-esofágico e as constipações intestinais). Dentre elas, as que mais interferem durante a atuação fonoaudiológica são as que causam o refluxo gastro-esofágico, sendo que, em alguns casos, faz-se necessária a intervenção cirúrgica. Segundo o 
autor, por causa dos freqüentes refluxos, a incidência de pneumonia nos pacientes acometidos é digna de observação.

Com relação às alterações presentes no sistema neurológico dos indivíduos com SD, abaixo serão destacadas algumas, as quais são consideradas relevantes para o conhecimento do fonoaudiólogo, uma vez que interferem no desenvolvimento cognitivo e no de linguagem.

Mustacchi (2000), ao se referir a estudos realizados por Schapiro ${ }^{1}$ et al (1989), relata que, apesar do peso da massa encefálica nos indivíduos com SD, na ocasião do nascimento, ser praticamente normal, ele atinge somente $3 / 4$ do esperado durante a infância, indicando plasticidade ou velocidade de maturação neuronal reduzidas e limitadas.

Segundo Schwartzman J. (1999), nos recém-natos com SD, os pesos médios do encéfalo, tronco cerebral e cerebelo mostram-se nos limites ou inferiores aos das crianças sem alterações. Para este autor, o tamanho do cerebelo nesta população é particularmente interessante de se observar, não só por estar implicado na gênese da hipotonia da síndrome, mas pelo fato desta estrutura estar cada vez mais relacionada a processos cognitivos mais complexos, de acordo com estudos mais recentes. E isto, em parte, poderia explicar a defasagem cognitiva observada nestes indivíduos.

Por outro lado, Mustacchi (2000) relata que cerca de $20 \%$ dos neonatos com SD apresentam dilatação dos ventrículos laterais, porém, sem manifestarem qualquer propedêutica compatível com sinal de hidrocefalia.

\footnotetext{
${ }^{1}$ Scahpiro MB, Luxenberg JS, Kaye JA, Haxby JV, Friedland RP, Rapoport SI. Serial quantitative CT analysis of brain morphometrics in adult Down's syndrome at different ages. Neurology 1989; 39:1349-53.
} 
Tal fato justifica-se, provavelmente, pelo comprometimento do número e tamanho das células neuronais.

Desordens convulsivas são registradas em 8\% desta população, sendo que $40 \%$ destes indivíduos apresentam-nas antes do primeiro ano de vida (Pueschel, 1993; Mustacchi, 2000). Outros problemas neuropsiquiátricos têm sido registrados em alguns indivíduos, tais como: autismo, déficit de atenção, comportamentos oposicionais, agressivos, repetitivos e quadros de ansiedade (Shwartzman J., 1999).

Com o avanço da idade, observam-se alterações específicas relacionadas ao decréscimo de alguns neuro-transmissores sinápticos (marcadores colinérgicos e nor-adrenérgicos) presentes tanto em indivíduos com SD como na Doença de Alzheimer, os quais estão ligados ao aprendizado e à memória. Entretanto, estas alterações encontradas nem sempre podem ser correlacionadas com quadros clínicos de demência, embora existam indícios de que adultos com SD sejam mais propensos a apresentar a Doença de Alzheimer do que adultos não-Down. Além disso, antes de ser efetuado o diagnóstico da doença de Alzheimer, deve-se levar em consideração outras causas possíveis de demência, tais como quadros de disfunção da tireóide e síndromes depressivas (Schwartzman J., 1999).

A sobrevida das crianças com SD tem aumentado nos últimos anos devido à melhora no atendimento clínico-cirúrgico que vem ocorrendo de forma progressiva, resultando em um melhor tratamento com relação às cardiopatias, aos quadros infecciosos e às doenças pulmonares (Brunoni, 1999; Shwartzman J., 1999). Os programas de intervenção precoce, de um 
modo geral, os quais foram enfatizados nestas três últimas décadas, visando o máximo do desenvolvimento do potencial da criança com SD nas áreas da saúde e da educação, também têm contribuído de forma definitiva com a melhora na qualidade de vida desta população (Rice, 1983; Roth e Clark, 1987; Bud Fredericks, 1993; Zausmer, 1993; Pelchat et al, 2004).

\subsection{A emergência da linguagem na criança com desenvolvimento típico} (DT)

\subsubsection{A imitação e a construção do símbolo e da linguagem segundo a Epistemologia Genética}

Segundo os estudos de Piaget (1987, edição original de 1936; 1990, edição original de 1946; 1996, edição original de 1937), a linguagem está subordinada ao desenvolvimento da função semiótica ${ }^{2}$, a qual se manifesta no final do período sensório-motor ${ }^{3}$, juntamente com o jogo simbólico ou de

\footnotetext{
${ }^{2}$ De acordo com a terminologia dos lingüistas da escola saussuriana, Piaget (1987:19, edição original de 1936) utiliza o termo símbolo para os significantes motivados, ou seja, que apresentam uma relação de semelhança com o significado. A função semiótica consiste na diferenciação dos significantes (signos e símbolos) e dos significados (objetos ou acontecimentos, uns e outros esquemáticos ou conceitualizados), de modo que os primeiros permitam a evocação da representação dos segundos (Piaget, 1985, edição original de 1964).

${ }^{3}$ É o primeiro dos quatro períodos que dividem o desenvolvimento cognitvo, segundo a teoria de Jean Piaget (1987, edição original de 1936), e predomina na criança desde o nascimento até os vinte e quatro meses, aproximadamente. Neste período, a inteligência da criança é essencialmente prática, visto que ela vai sendo construída à medida que vão ocorrendo os processos de assimilação e acomodação como conseqüência da ação motora da criança nas diversas situações oferecidas pelo meio. A assimilação é o processo de incorporação de elementos externos aos esquemas já existentes na criança em função da sua atividade motora neste meio. À medida que os novos elementos vão sendo incorporados nos esquemas anteriores, a inteligência vai modificando incessantemente os últimos para ajustá-los aos novos dados. A esta modificação dos esquemas já existentes em função de ajustá-los aos novos dados assimilados esse autor denominou de acomodação. E quando há um
} 
imaginação ou, ainda, atividade lúdica do faz-de-conta e a imitação diferida ${ }^{4}$. Embora os três ocorram na mesma época e sejam independentes um do outro, eles são todos derivados da imitação (Piaget, 1985, edição original de 1964).

De acordo com os estudos de Piaget (1990, edição original de 1946), antes da linguagem se desenvolver, a inteligência sensório-motora já vem sendo construída desde o nascimento da criança. Ela é uma forma de inteligência que prepara, no terreno da ação elementar, o que mais tarde se converterá em operações do pensamento refletido. Segundo os estudos deste autor, desde o seu nascimento, a criança inicia a construção de seu conhecimento a partir do momento em que passa a atuar no meio, seja no sentido da ação motora propriamente dita, como também no das ações sensoriais, tais como o da visão, da audição, do tato, do gosto e do olfato. Por meio dessas ações em conjunto e coordenadas (ver e pegar, por exemplo), o indivíduo tem a oportunidade de estabelecer relações com o mundo e conhecê-lo, de modo que vão sendo construídas as noções de permanência de objeto, tempo, espaço, causalidade, classificação e seriação, favorecendo-lhe a construção de seus primeiros pré-conceitos (Scheuer e Limongi, 2003). Neste decorrer, segundo Piaget (1990, edição original de 1946), a imitação se desenvolve em direção à representação, tornando possível o desenvolvimento da linguagem e, consequentemente, a formação de conceitos.

equilíbrio entre as duas, ele o define como adaptação, cujo processo permite que o pensamento se organize e estruture as coisas.

${ }^{4}$ Em algumas traduções observa-se o termo "imitação adiada" (Pulaski, 1986, edição original de 1980) ou “imitação retardada" (Piaget, 1985, edição original de 1964). 
A imitação é fundamental para o desenvolvimento de linguagem e surge como conseqüência da repetição de ações reflexas (sucção, preensão, etc.) que a criança apresenta ao nascer, cujos exercícios contínuos se transformarão em experiência, que a tornará capaz de assimilar elementos exteriores ao próprio reflexo, diferenciando-o. Uma vez diferenciado, a criança já será capaz de reproduzi-lo, incorporando-o como um elemento novo a um esquema ${ }^{5}$ que ela já conhecia, e daí surge a imitação (como um prolongamento da acomodação dos novos elementos incorporados).

Entretanto, ressalta-se, na teoria proposta por Piaget (1990, edição original de 1946), que a imitação nada tem de automática ou de involuntária. Ela manifesta a existência de coordenações inteligentes, tanto na aprendizagem dos meios que emprega como nos seus próprios fins. A imitação evolui com o decorrer do desenvolvimento infantil, interiorizando-se, a qual se completará mais tarde quando ela assumir a forma de imitação interiorizada ou imagem mental.

Durante a $6^{\mathrm{a}}$ fase do período sensório-motor, há um momento em que a criança consegue realizar, pela primeira vez, a reprodução de um modelo de ação na sua ausência e após um intervalo mais ou menos longo de sua ocorrência. Este instante, como não foi mais necessária a sua reprodução na presença do modelo, significa que a imitação na criança desligou-se da ação

\footnotetext{
${ }^{5}$ Piaget entende por esquemas as unidades de comportamentos suscetíveis de repetição mais ou menos estável e de aplicação a situações ou objetivos diversos. A partir dos primeiros reflexos, os primeiros esquemas de ação vão se formando e a criança inicia sua busca ativa sobre os objetos. As estruturas parcialmente programadas vão se construindo e, por sua vez, estruturando novas buscas sobre o meio. (Oliveira, 1992).
} 
atual e atingiu os primórdios do nível da representação, pois, pela primeira vez, é como se ela se apoiasse numa simples recordação não acompanhada de percepção presente e, assim, o modelo percebido exteriormente é substituído por um modelo interno. A este acontecimento Piaget denominou de imitação diferida.

A imitação diferida caracteriza-se pela emancipação da acomodação diante da ação imediata dos esquemas de assimilação ao modelo, funcionando de forma autônoma e interiorizada. Com a sua ocorrência, observa-se, na criança, o nascimento da imagem mental e, consequentemente, o início da representação e de um princípio do uso de $\operatorname{signos}^{6}$. A seguir, a imitação prolongar-se-á em representação simbólica, a qual se reduzirá em imagem mental, ou seja, em evocação simbólica das realidades ausentes.

Contudo, além da imitação, a representação simbólica também deriva do desenvolvimento do jogo (ou atividade lúdica) no sexto estágio do período sensório-motor. Nos estágios anteriores deste período, ambos (imitação e jogo) desenvolvem-se paralelamente, mas com características opostas. Observa-se que, durante o desenvolvimento da imitação é a acomodação que predomina sobre a assimilação e, no desenvolvimento do jogo, por sua vez, é a assimilação que predomina.

Entretanto, tal qual a imitação, o jogo também se desenvolve da ação à representação, na medida em que evolui da sua forma inicial de exercício

\footnotetext{
${ }^{6}$ No uso corrente, o termo signo designa freqüentemente a palavra (Ferreira ABH. Novo Dicionário Aurélio da Língua Portuguesa; Editora Nova Fronteira, 1986:1584). Na definição de Piaget (1990:217, edição original de 1946), de acordo com os lingüistas da escola saussuriana, “um signo é
} 
sensório-motor (jogo de exercício) para a sua segunda forma, que é a de jogo simbólico ou jogo de imaginação. $\mathrm{Na}$ passagem do primeiro para o segundo há a interiorização de esquemas e a diferenciação entre significante e significado. O jogo simbólico desempenha um papel importante na formação do pensamento na criança por conter uma fonte de representações individuais, tanto cognitivas quanto representativas (Piaget, 1985, edição original de 1964).

No início de seu desenvolvimento, o jogo é denominado de jogo de exercício, caracterizando-se como simples assimilação funcional ou reprodutora. Neste período, Piaget ainda o denomina de assimilação pura. Ele surge quando a criança passa a atuar sobre o objeto por mero prazer funcional, sem a necessidade de realizar novas acomodações que levem à adaptação. Durante os primeiros estágios (do I ao III) do período sensóriomotor, observa-se que o jogo quase se confunde com o conjunto das condutas sensório-motoras, pelo fato de todos os esquemas serem suscetíveis de dar lugar à assimilação pura.

Por volta da quarta fase do período sensório motor, a criança realiza combinações lúdicas, as quais Piaget (1990, edição original de 1946) denominou de "ritualização" dos esquemas, que é um preparo para a formação dos jogos simbólicos. Observa-se que, durante a sua ocorrência, um determinado esquema executado pela criança manifesta-lhe algum ritual já conhecido. Por exemplo: sem estar com sono, ao ver o seu travesseiro, a criança toca-o, segura-o e chupa uma de suas extremidades. Em seguida, 
faz o seu ritual de dormir, sendo que ao final dele, e sem dormir (pois, ela não estava com sono) ela retorna à atividade precedente.

Segundo Piaget (1990, edição original de 1946), embora este ritual tivesse acontecido por meio das combinações lúdicas, ainda não pode ser considerado como símbolo porque a criança não teve consciência da ficção. A criança simplesmente repetiu o ciclo de seus movimentos habituais para dormir sem, contudo, fingir que dormia. O ato de "fingir" ou "fazer de conta" somente irá acontecer na fase VI do mesmo período.

Na sexta fase, nota-se que há um desprendimento contínuo da ação, sendo que a criança deixa de lado o ritual motor e passa a se utilizar do "fazer de conta". Piaget (1990, edição original de 1946) explica que o símbolo lúdico desliga-se do ritual sob a forma de esquemas simbólicos e, a partir de então, inicia-se a função que será a do jogo simbólico. Neste processo, a criança se utiliza de esquemas habituais e já ritualizados no decorrer dos jogos anteriores, porém, transfere-os a objetos inadequados com o único propósito de evocar os esquemas em questão por simples prazer. Por exemplo, a criança faz de conta que bebe e come não tendo nada nas mãos ou, ainda, faz de conta que bebe servindo-se de uma caixa qualquer. No entanto, vale lembrar que, antes, estes símbolos já vinham sendo preparados por uma ritualização progressiva, cujas principais fases consistiam em se divertir bebendo em copos vazios, por exemplo.

Segundo o autor, os esquemas simbólicos são a forma mais primitiva de símbolo lúdico, pois a criança limita-se a fazer de conta que realiza uma 
de suas ações habituais, sem atribuí-las a outros, nem assimilar os objetos entre si.

Como os esquemas simbólicos reproduzem apenas as ações do próprio sujeito, o símbolo ainda não é um instrumento do próprio pensamento. O que se observa é que o esquema sensório-motor ainda faz a vez de símbolo, e não tal objeto ou tal imagem particulares. Assim, a criança faz de conta que dorme, que toma banho, que come, e tantos outros esquemas. Por outro lado, também, essas reproduções do próprio sujeito não deixam de ser "auto-imitação".

Pelo fato dos esquemas simbólicos marcarem a transição entre dois grandes tipos de estruturas que caracterizam os jogos infantis, os quais são o jogo de exercício e o jogo simbólico propriamente dito, Piaget (1990, edição original de 1946) ressalta que eles apresentam características de ambos os tipos de estruturas. Do primeiro tipo, os esquemas simbólicos conservam o poder de exercitar uma conduta fora do seu contexto de adaptação atual, por simples prazer funcional (ex.: a ação de beber), enquanto que, do segundo, manifestam a capacidade de evocar essa conduta na ausência do seu objetivo habitual (ex.: fazer de conta que bebe algo), quer na presença de novos objetos concebidos como simples substitutos (ex.: uma caixa), quer na ausência de todo o suporte material. É nesse caso que se pode dizer que há a ocorrência da diferenciação entre significante (constituído por um objeto escolhido: a caixa) e significado (o próprio esquema de se satisfazer em estar bebendo algo). 
Após os esquemas simbólicos, Piaget (1990, edição original de 1946) classifica a evolução dos jogos simbólicos em fases, tipos e subtipos, nos quais observa-se, cada vez mais, o desenvolvimento do pensamento da criança por meio da sua capacidade de representação.

Assim, a inteligência prática vai gradualmente sendo substituída por uma inteligência representativa, que se manifesta em diversas atividades (jogo simbólico, gestos simbólicos e as interações sociais), cujo desenvolvimento inicial marca a passagem do período sensório-motor para o período pré-operatório ${ }^{7}$ (Assis, 1985; Case, 1989). Esse processo favorecerá o desenvolvimento da linguagem oral.

Para Piaget (1990, edição original de 1946), a linguagem oral é um sistema arbitrário de sinais, cujos signos ou palavras têm significados públicos compartilhados e compreendidos pela sociedade e serve, fundamentalmente, para comunicar aquilo que já foi compreendido. Ela se desenvolve na criança apenas com o início do uso de signos verbais na $6^{\mathrm{a}}$ fase do período sensório-motor, favorecida pela condição de diferenciação significante/significado, quando esta criança já é capaz de formar imagens mentais, após ter passado pelas experiências práticas deste período. À medida que a criança vai se desprendendo dos acontecimentos imediatos, a sua linguagem vai se caracterizando pela representação de situações passadas por meio do uso da palavra, marcando o início do período

\footnotetext{
${ }^{7}$ É o segundo dos quatro períodos que dividem o desenvolvimento cognitvo, segundo a teoria de Jean Piaget (1987, edição original de 1936), e predomina na criança dos 2 aos 7 anos, aproximadamente. Neste período, o pensamento da criança ainda é intuitivo e egocêntrico, baseando-se na contigüidade e não na lógica. Enquanto no início deste período, o seu pensamento mostra-se mais rígido, imóvel, concreto e desenvolvendo-se por meio do funcionamento simbólico, no final, ele se torna mais flexível e móvel, com uma descentração crescente (Pulaski, 1986, edição original de 1980).
} 
representativo. Aos poucos, a ação vai sendo substituída pela palavra na expressão de fatos, sentimentos ou desejos durante a comunicação.

O desenvolvimento da linguagem é estruturado pelo desenvolvimento cognitivo e depende dele. Não é por acaso que Piaget (1990, edição original de 1946) acredita que as primeiras palavras da criança pequena, emergindo do período de atividade sensório-motora, são com freqüência onomatopaicas, imitando o objeto ou a atividade descrita. Segundo Case (1989), isto acontece porque, nesta fase, as crianças ainda apresentam dificuldades em diferenciar o nome do objeto de sua função ou de parte dela. No início desse processo de produção de palavras, é muito comum observar as crianças apresentarem a compreensão de linguagem de forma muito mais vasta do que podem enunciar (Furth, 1974; Pulaski, 1986, edição original de 1980).

Após a sua emergência no desenvolvimento infantil, a linguagem auxiliará a criança na organização de suas idéias, facilitando-lhe a elaboração das estruturas cognitivas em geral, e Ihe proporcionando um salto no desenvolvimento cognitivo. Como afirmou Sinclair (1976), a linguagem é um sistema de produção que combina símbolos significativos de acordo com regras que são adquiridas e aplicadas na conversação e na compreensão. E o desenrolar deste processo é, por si mesmo, uma atividade cognitiva. 


\subsubsection{A relação entre a emergência da linguagem oral, dos gestos e o jogo simbólico na criança com DT}

Desde a década de 70, observa-se, na literatura, um número crescente de trabalhos dedicados ao estudo da relação entre o desenvolvimento de linguagem e a cognição (Nicolich,1977; Bates et al., 1979; Fenson e Ramsey, 1981; Shore et al., 1984; Acredolo e Goodwyn, 1988; Thal e Bates, 1988; Bates et al., 1989; Thal, 1991; Thal e Tobias, 1992; Thal e Tobias, 1994; Capirci et al., 1996; Bates e Dick, 2002; Capone e McGregor, 2004).

Para tanto, estes autores centralizaram as suas pesquisas entre o final do período sensório-motor e início do pré-operatório (Piaget, 1987, edição original de 1936; Piaget, 1990, edição original de 1946; Piaget, 1996, edição original de 1937), visto que, nesta fase intermediária do desenvolvimento infantil, observa-se a emergência simultânea da linguagem oral, do jogo simbólico e dos gestos.

Os estudos de Nicolich (1977) demonstraram a relação evidente entre o jogo simbólico e a emergência da linguagem expressiva, bem como enfatizaram a estruturação dessas funções como fato dependente do desenvolvimento cognitivo, resultando em um progresso significativo entre o jogo simbólico e o desenvolvimento de linguagem dos sujeitos pesquisados.

Um grupo de autores acredita que, de acordo com o jogo simbólico apresentado pela criança com desenvolvimento típico, podem ser observadas características lingüísticas correspondentes à fase específica do 
jogo simbólico em que ela está (Bates et al., 1979; Fenson e Ramsey, 1981; Shore et al., 1984; Acredolo e Goodwyn, 1988; Thal e Bates, 1988; Bates et al., 1989; Thal, 1991; Thal e Tobias, 1992; Thal e Tobias, 1994; Capirci et al., 1996; Bates e Dick, 2002).

Para exemplificar, Béfi-Lopes et al. (2000) classificaram quatro estágios diferentes do desenvolvimento do jogo simbólico, correlacionandoos com a expressão comunicativa segundo os estudos de Thal e Bates (1988), Thal (1991) e Thal e Tobias (1994):

a) Comunicação pré-simbólica (entre nove e 12 meses): neste estágio, a criança começa a expressar a intenção de perguntar ou pedir, sendo que para isto ela utiliza gestos de apontamento (gestos dêiticos), mostrando o que deseja em conjunto com vocalizações.

b) Símbolos (entre 13 e 20 meses): as primeiras palavras e gestos emergem paralelamente. Observa-se que a criança utiliza gestos convencionais associados com objetos, cuja função é de reconhecer ou classificar membros de classe de objetos. Por exemplo: beber de um copo ou cheirar uma flor. Neste estágio, geralmente, o número de gestos de reconhecimento e o de nomes de objetos existentes no vocabulário da criança estão correlacionados, pois os gestos de reconhecimento e as palavras estão emergindo ao mesmo tempo.

c) Combinações simbólicas (entre 20 e 24 meses): a criança inicia a combinação de palavras em frases e sentenças, como também a 
combinação de esquemas gestuais simples em múltiplos. Tanto as frases que se formam quanto os gestos que se combinam são mais elaborados.

d) Seqüências simbólicas (após os 28 meses): a criança começa a se utilizar da morfologia e da sintaxe. Inicia-se, então, a gramaticalização da linguagem. Entre o período de 20 e 30 meses, observa-se que a habilidade de produzir gestos simbólicos em seqüências convencionais aumenta de forma significativa, correlacionando com uma sofisticação lingüística.

Durante este período de desenvolvimento, Thal e Tobias (1992) descreveram, em seus relatos, os gestos mais utilizados pela criança: os dêiticos (apontar, mostrar, e pedidos ritualizados) e os simbólicos (beber de uma xícara vazia). Os gestos dêiticos surgem como atitude comunicativa por volta dos nove meses de idade, enquanto que os simbólicos aparecem acompanhando a emissão de palavras por volta dos doze meses, estendendo-se até os dezoito. Enquanto os primeiros não variam, estes últimos variam espontaneamente de acordo com o contexto e a intenção comunicativa da criança, desenvolvendo-se na interação com seus familiares ou por meio de sua própria interação com o objeto.

Ainda foram observadas três tipos de correlações entre gestos simbólicos e a emissão de palavras: gestos predominando sobre as palavras; palavras e gestos sendo utilizados igualmente; e palavras predominando sobre os gestos. A presença de gestos simbólicos durante o desenvolvimento de linguagem na criança, substituindo algumas palavras, 
significa que ela já é capaz de representar seu conhecimento com símbolos (Thal e Tobias, 1992).

Acredolo e Goodwyn (1988), cujos estudos abordam a influência dos gestos no início dos estágios de desenvolvimento da linguagem como fator preponderante na contribuição da comunicação da criança, afirmam que, além dos gestos descreverem melhor a função do que a forma dos objetos neste período, o uso deles está correlacionado ao desenvolvimento do vocabulário. Entretanto, quando a criança utiliza um determinado gesto durante a sua comunicação e que, por sua vez, não é compreensível para o seu interlocutor, ela simplesmente o abandona e o substitui imediatamente por outros tipos de comportamentos (ex.: vocalizações).

Dentro da categoria de gestos simbólicos, Acredolo e Goodwyn (1988) consideraram cinco subtipos:

1- gestos que denotam a presença de objetos específicos, como por exemplo, cheirar uma flor;

2- pedidos: nesta categoria, os gestos servem para indicar alguma coisa que a criança deseja para si ou de que necessita. Estes gestos baseiam-se em olhares direcionados aos pais, pareados com atitudes simultâneas do que pretendem. Além disso, também ocorrem em situações específicas e de acordo com um determinado contexto. E, por assim ser, também podem ser considerados como representativos. Por exemplo: movimentos de levantar e baixar as mãos diante de um piano e, olhando para os pais como que desejando tocá-lo; 
3- atributos: gestos que servem para representar algumas situações que envolvem qualidades ou propriedades de objetos como, por exemplo, "quente, acabou e grande";

4- respostas: as quais incluem sinais indicativos de "sim" e "não" para responder alguma questão ou, ainda, "eu não sei" por meio do gesto de encolher os ombros;

5- eventos: são gestos que correspondem ao comportamento das crianças diante de algum evento específico. Por exemplo: bater palmas em resposta à vitória de algum time em jogo ou, ainda, acenar "tchau".

Diante dos vários estudos que a literatura tem relatado sobre a relação entre o desenvolvimento da linguagem oral, gestos e jogo simbólico, a maioria dos autores enfatizou a substituição dos gestos pelas palavras à medida em que a criança pequena vai aumentando a sua capacidade de se socializar (Shore et al., 1984; Acredolo e Goodwyn, 1988; Thal e Tobias, 1992; Iverson et al., 1994; Namy e Waxman, 1998; Guidetti, 1999; Namy e Waxman, 2002; McEachern e Haynes, 2004; Iverson e Goldin-Meadow, 2005; Ozcaliskan e Goldin-Meadow, 2005).

Além do fato da criança estar iniciando a sua capacidade de representação, os gestos geralmente se desenvolvem neste período porque a criança ainda não tem o domínio suficiente da linguagem oral, visto que, a sua compreensão em relação ao sentido de palavras simples relacionadas às suas experiências apresenta-se melhor do que a sua expressão neste período. A criança passa, então, a fazer uso de gestos em substituição ao 
signo lingüístico ou acompanhando-o para facilitar a sua comunicação. À medida em que ela vai aumentando o seu repertório lingüístico em virtude de suas relações sociais e na sua interação com objetos e situações, observase que ela vai diminuindo o uso de gestos. A criança vai descobrindo que, por meio de palavras, ela tem o domínio de expressar melhor os seus pensamentos e de se fazer inteligível ao seu interlocutor (Shore et al., 1984; Acredolo e Goodwyn, 1988; Thal e Tobias, 1992; Iverson et al., 1994; Namy e Waxman, 1998; Guidetti, 1999; Namy e Waxman, 2002; McEachern e Haynes, 2004; Iverson e Goldin-Meadow, 2005; Ozcaliskan e GoldinMeadow, 2005).

Os estudos de Lyytinen et al. (1999) mostraram que, por volta dos 13 aos 18 meses de idade, o jogo simbólico apresentado pela criança tem uma maior relação com a compreensão de linguagem do que com a sua produção. É a partir dos 12 ou 13 meses, aproximadamente, que as crianças com DT iniciarão a produção de palavras. Somente depois dos 20 meses, é que a criança passa a adquirir uma diversidade semântica associada ao jogo e, então, observa-se um desenvolvimento maior do vocabulário.

McEachern e Haynes (2004) e Ozcaliskan e Goldin-Meadow (2005) relataram que o uso igual de palavras e gestos é um indício significativo de que a criança em breve estará emitindo frases compostas apenas de palavras.

Uma pesquisa realizada por Iverson e Goldin-Meadow (2005) com crianças que emitiam frases na fase de transição de uma palavra para duas, demonstrou que os gestos contribuíram fortemente para o desenvolvimento 
lexical e sintático da linguagem oral destas crianças. Segundo estes autores, um grande número de itens lexicais produzidos inicialmente apenas por meio de gestos, mais tarde, passaram a ser produzidos por meio da linguagem oral. Além disso, quando as crianças produziam frases compostas de duas expressões comunicativas simultâneas (uma palavra + um gesto), logo elas estavam emitindo frases com duas palavras.

Por outro lado, há estudos (Carpenter et al., 1998; Namy e Waxman, 2002; O'Neill et al., 2005) que relatam o quanto gestos e palavras utilizados pela mãe durante a interação com a sua criança podem influenciar significativamente durante o período de emergência das expressões comunicativas. Segundo O'Neill et al. (2005), neste período, é comum observar as mães comunicarem-se com suas crianças por meio de gestos dêiticos de apontar como apoio à fala. Agindo dessa maneira, as mães estão estimulando a atenção da criança não somente para o objeto de interação entre elas, mas, também para as expressões comunicativas que podem determiná-lo.

\subsubsection{O desenvolvimento lexical durante a emergência da linguagem na criança com DT}

Ao conseguir se expressar por meio de palavras, a criança demonstra que já é capaz de compreender o seu significado. Entretanto, segundo os estudos de Scheuer et al. (2003), observam-se diferenças individuais entre o 
desenvolvimento da compreensão das palavras e o espaço de tempo de ocorrência de sua produção.

Apesar disso, de um modo geral, por volta de um ano de idade, a criança começa a emitir as primeiras palavras, as quais são formadas por sentenças constituídas de uma palavra para designar um objeto ou uma situação. Alguns autores denominam este tipo de ocorrência como holófrases (Sinclair, 1976; Reed, 1994).

A partir dos dois anos de idade, há uma variação quanto ao relato do número de palavras aprendidas pela criança, entre os autores. Contudo, todos eles afirmam, em comum, que a partir desta idade ocorre um aumento surpreendente do vocabulário no desenvolvimento lexical da criança. Segundo os estudos de Reed (1994), dos 18 aos 24 meses, a criança passa a apresentar de 200 a 300 palavras em seu repertório lingüístico e, com dois anos e seis meses, observa-se a emissão de mais de 500 palavras.

Durante o período de aquisição do léxico, alguns estudos apontam para o fato de que, inicialmente, a criança nomeia os objetos e as ações para, mais tarde, nomear os atributos pertinentes a eles (Reed, 1994; Colombo e Burani, 2002; Abbot-Smith, 2004; Theakston et al., 2004; Blackwell, 2005; Jones e Smith, 2005; Ninio, 2005).

Para Owens (1996), a criança emite, primeiramente, nomes de objetos (substantivos). A seguir, quando ocorre o aumento de seu vocabulário, observa-se que diminui o número de aquisição de nomes de objetos e aumenta o de verbos. Paralelamente, também ocorrem algumas emissões de pronomes (pessoais, possessivos e indefinidos), preposições e 
conjunções (Owens, 1996; Theakston et al., 2004; Abbot-Smith, 2004; Blackwell, 2005; Ninio, 2005). Contudo, Barret (1997) ressalta que a diferenciação dos pronomes pessoais (eu, você, ele, ela) e dos demonstrativos (isto, aquilo, aquele, aquela) somente ocorrem por volta dos três a quatro anos de idade.

Nos estudos realizados por Maldonado (1993), no período em que se inicia a ampliação do vocabulário da criança, com o aumento de verbos, também se observa a emissão de advérbios de afirmação e de negação.

Os estudos de Veneziano (1999) demonstram que, por volta de um ano e três meses e um ano e seis meses, a criança apresenta uma maior ocorrência de substantivos e, a seguir, de verbos. Com um ano e seis meses a dois anos e dois meses, passa a ocorrer uma diminuição na emissão de substantivos, enquanto há um aumento da emissão do número de verbos no repertório lingüístico da criança. Dados semelhantes foram observados em outras pesquisas (Brown, 1973; Shi et al., 1998; Camaioni e Longobardi, 2001; Colombo e Burani, 2002).

Anisfeld (1998) afirmam que, à medida em que a criança começa a realizar a combinação de palavras para se comunicar, ela tem a necessidade de adquirir novas palavras. E, neste caso, a maioria é verbo.

Araujo (2003) realizou um estudo com crianças com DT no período da emergência da linguagem oral, o qual demonstrou a ocorrência de um número maior de verbos, seguida de substantivos, pronomes, artigos, preposições e conjunções. Segundo a autora, uma explicação para a maior 
ocorrência de verbos está no fato deles funcionarem como elementos organizadores da estrutura sintática.

Contrariamente ao que já foi exposto, os estudos de Rinaldi et al. (2004), realizado com crianças entre 18 e 30 meses, demonstraram a presença de um número maior de substantivos do que de verbos na sua emissão oral.

Goldfield (2000) e Camaioni e Longobardi (2001) relatam que o repertório lingüístico utilizado pelas mães durante a interação com suas crianças influencia significativamente no desenvolvimento de sua expressão oral. No estudo de Goldfield (2000), com díades mãe-criança (estas com um ano e oito meses), observa-se que as crianças que emitiram mais substantivos do que verbos foram aquelas cujas mães apresentaram uma quantidade maior de substantivos do que de verbos durante a interação. A mesma relação é verdadeira quando ocorreu maior número de emissão de verbos.

\subsection{A emergência da Linguagem na criança com SD}

$\mathrm{Na}$ literatura há muitos trabalhos que relatam sobre o desenvolvimento de linguagem em crianças com SD. Entretanto, foi a partir da década de 70, que este tema tornou-se mais pesquisado pelos diversos autores dedicados ao estudo da comunicação nestas crianças.

Desde então, os resultados das pesquisas têm levado os autores a observarem que a linguagem na criança com SD desenvolve-se de modo 
mais lento e atrasado quando comparada à das crianças com DT, em decorrência de sua defasagem cognitiva, a qual é inerente à síndrome.

Há outros fatores que contribuem com este atraso: a falta de estímulos adequados durante a interação mãe-criança desde o nascimento do bebê (Jones, 1977; Leifer e Lewis, 1984; Martins e Mervis, 1985; Fischer, 1987; Gomes et al., 1992; Hoshino et al., 1994; Cahill e Glidden, 1996; Perez e Limongi, 1998; Roach et al., 1998; Pino, 2000; Andrade e Limongi, 2001; Andrade, 2002; Ricci e Hodapp, 2003; Johnson-Glenberg e Chapman, 2004; Yoder e Warren, 2004); o atraso no desenvolvimento neuropsicomotor (Limongi et al., 2000; Andrade e Limongi, 2001); as alterações neurológicas (Spinelli et al., 2001; Hick et al., 2005; M Purser e Jarrold, 2005); as cardiopatias e os problemas respiratórios (Andrade, 2002), os freqüentes quadros de otite (Roberto, 2000; Andrade e Limongi, 2001; Stoel-Gammon, 2001) e as alterações do sistema estomatognático (Schwartzman M., 1999; Ideriha, 2005).

Apesar deste atraso, a literatura relata que, tanto o desenvolvimento cognitivo quanto o de linguagem ocorrem nesta população tal qual na criança com desenvolvimento típico (DT), porém de modo mais lento e atrasado, sendo que o primeiro ocorre de forma mais eficiente do que o segundo (Cunningham et al, 1985; Buckley, 1993; Messer e Hasan, 1994; Ruskin et al., 1994; Limongi et al., 2000; Andrade, 2002; Laws e Bishop, 2004). Tal fato foi registrado por Ruskin et al. (1994) ao informar que o jogo simbólico, por exemplo, demonstrado por essas crianças, é mais desenvolvido do que a sua expressão comunicativa. 
Partindo-se do pressuposto de que a linguagem é estruturada pelo desenvolvimento cognitivo e depende dele (Piaget, 1990, edição original de 1946), observa-se, segundo alguns autores, que a sua compreensão é melhor do que a sua expressão (Cunningham et al., 1985; Martins et al., 1985; Kumin, 1999; Dodd e Thompson, 2001; Chapman et al., 2002; Iverson et al., 2003; Ypsilanti et al., 2005).

Com relação aos aspectos inerentes à defasagem cognitiva nessas crianças, observa-se o atraso do desenvolvimento cognitivo com alterações significativas na atenção e na memória de curto prazo, o que dificulta a retenção de informações imediatas (Miller, 1992; Brock e Jarrold, 2004; Hick et al., 2005; MPurser e Jarrold, 2005). Dentro deste quadro estão comprometidas tanto a memória visual como a auditiva.

Observa-se, na literatura, alguns estudos (Chapman e Hesketh, 2001; Spinelli et al., 2001; Chapman et al., 2002; Yoder e Warren, 2004) apontarem para o fato de que as alterações de memória auditiva presentes nas crianças com SD contribuem de modo significativo para as alterações de desenvolvimento da sua linguagem oral, as quais se caracterizam pela ininteligibilidade de fala, alterações na compreensão e aprendizagem das regras gramaticais e sintáticas.

No que se refere à ininteligibilidade de fala, as pesquisas realizadas por Spinelli et al. (2001) demonstram que ela está relacionada diretamente, além da memória auditiva, com a habilidade práxica oral. Ambas são resultantes dos processos cerebrais, com participação cortical, devendo-se, portanto, a fatores neurológicos centrais. Segundo o autor, observa-se falhas 
na programação motora e pouca memória para seqüências motoras. Entretanto, vale lembrar que as alterações no sistema estomatognático, como a hipotonia generalizada, também podem influenciar em má qualidade de fala da criança com SD (Schwartzman M., 1999; Stoel-Gammon, 2001; Andrade, 2002; Ideriha, 2005).

Com relação às alterações na compreensão e aprendizagem das regras gramaticais e sintáticas, alguns autores relatam que o espaço de tempo que ocorre entre a compreensão inicial das palavras durante o desenvolvimento semântico-lexical e a produção oral na criança com SD é muito maior quando comparado com o da criança com DT. Enquanto esta última inicia a produção das primeiras palavras por volta dos doze meses, a criança com SD somente se expressará oralmente por volta dos vinte e quatro meses (Jenkins, 1993; Franco e Wishart, 1995; Ramruttun e Jenkins, 1998; Iverson et al., 2003).

Para Rondal (1996) e Ypsilanti et al. (2005), o uso consistente das palavras nesta população não ocorre antes dos três anos de idade cronológica, sendo que as frases compostas por mais de uma palavra ocorrerão entre os quatro e cinco anos. Dados semelhantes foram observados por Berglund et al. (2001), sendo que os resultados obtidos com as crianças com SD na faixa etária de três anos de idade são compatíveis aos das crianças com DT com idade entre um ano e quatro meses e um ano e oito meses.

Alguns estudos informam que o vocabulário das crianças com SD não se expande tão rapidamente como acontece geralmente com as crianças 
com DT (Jenkins, 1993; Franco e Wishart, 1995; Foreman e Crews, 1998; Ramruttun e Jenkins, 1998; Dodd e Thompson, 2001; Iverson et al., 2003; Hick et al., 2005).

Durante a emissão de classes de palavras, é fácil observar uma certa tendência da criança com SD a usar sentenças simples nas quais os artigos, as preposições, os pronomes, entre outros, são omitidos (Rondal, 1996). Por outro lado, Grela (2003) relata que não há diferença significativa com relação ao uso de verbos em sentenças simples entre as crianças com SD e as com DT.

Para compensar o atraso de sua produção oral, um grupo de autores acredita que muitas crianças com SD passam a desenvolver de modo significativo a comunicação gestual para se expressarem (Jenkins, 1993; Franco e Wishart, 1995; Ramruttun e Jenkins, 1998; Chan e lacono, 2001).

Na verdade, como já foi dito no capítulo anterior, o uso de gestos comunicativos acompanhando a fala é desenvolvido pelas crianças entre o final do período sensório-motor e início do pré-operatório, segundo os estudos de Piaget (1987, edição original de 1936; 1990, edição original de 1946; 1996, edição original de 1937). Franco e Wishart (1995) relatam que, na criança com SD, a comunicação gestual desenvolve-se tal qual na criança com DT, porém, observa-se que a primeira utiliza os gestos dêiticos por um período mais longo do que a segunda. A seguir, ela passa a utilizálos simultaneamente aos simbólicos.

Alguns estudos apontam para o fato de que, após esta fase de desenvolvimento, algumas crianças com SD continuam utilizando os gestos 
durante um período longo em suas vidas, variando-os conforme o contexto do ambiente em que estão, com o objetivo de se fazerem melhor compreendidas pelo interlocutor (Jenkins, 1993; Iverson et al., 1994; Franco e Wishart, 1995; Foreman e Crews, 1998; Chan e Iacono, 2001; Clibbens, 2001; Miles e Chapman, 2002; Iverson et al., 2003; Iverson e GoldinMeadow, 2005). Nestes casos, Jenkins (1993) relata que, com o desenvolvimento da linguagem oral, ao invés da fala ir predominando sobre os gestos, como acontece com a criança com DT, observa-se que as crianças com SD continuam utilizando-os simultaneamente às palavras ou, ainda, preferem usá-los predominando sobre as mesmas, como se elas fossem o apoio lingüístico, e não o contrário.

Quando a criança com SD desenvolve a sua comunicação neste sentido, os gestos utilizados por elas não são pré-estabelecidos ou padronizados por ninguém. Eles são individuais, próprios de cada criança, e são totalmente compreensíveis pelo interlocutor (Franco e Wishart, 1995; Foreman e Crews, 1998; Clibbens, 2001; Iverson et al., 2003).

Os gestos mais freqüentes utilizados pela criança com SD foram classificados por Franco \& Wishart (1995) em quatro categorias:

1- apontar: braço e dedo indicador estendidos;

2- indicar: braço estendido, sendo que os dedos podem estar fechados;

3- alcançar: braço estendido com a palma da mão para baixo em uma postura de querer pegar; 
4- outros: gestos expressivos (bater palmas, por ex.), gestos com conteúdo semântico (balançar os braços segurando uma boneca imitação, por ex.), gestos convencionais (acenar "tchau", por ex.).

Há ainda o gesto de "dê-me" (palmas das mãos voltadas para cima com os dedos abrindo e fechando), mas, segundo os autores, este gesto pode ser classificado na categoria de alcançar.

Foreman e Crews (1998) e Clibbens (2001) explicam que algumas crianças com SD desenvolvem melhor a sua comunicação gestual (gestos representativos, em sua maioria) do que a linguagem oral pelo fato de que, os sistemas visual e motor, envolvidos na produção dos gestos e sinais nestas crianças, amadurecem mais rapidamente do que os sistemas envolvidos na produção lingüística oral.

Há pesquisas que justificam o uso de gestos pela criança com SD durante a comunicação, tanto acompanhando a emissão de palavras como usados preferencialmente, devido à sua ininteligibilidade de fala, cuja causa está relacionada às alterações do sistema estomatognático aliadas às dificuldades de compreensão e aprendizagem das regras gramaticais e sintáticas (Buckley, 1993; Kumin, 1999; Schwartzman M., 1999; Chan e Iacono, 2001; Dodd e Thompson, 2001; Stoel-Gammon, 2001; Chapman et al., 2002; Miles e Chapman, 2002; Laws e Bishop, 2004; Hick et al., 2005; Iverson e Goldin-Meadow, 2005; Ypsilanti et al., 2005).

Além desses fatores, Chapman et al (2000) referem que a variação na habilidade da linguagem expressiva nesta população de crianças pode estar 
relacionada a variáveis sócio-econômicas, grau de escolaridade das mães e freqüência de quadros de otites agudas.

\subsubsection{A importância da interação mãe-criança no desenvolvimento de linguagem da criança com SD}

Para complementar os estudos sobre o desenvolvimento de linguagem na criança com SD e suas alterações, vale ressaltar a importância da interação mãe-criança como fonte de estímulos cognitivo e lingüístico durante este período (Jones, 1977; Martins e Mervis, 1985; Fischer, 1987; Gomes et al., 1992; Hoshino et al., 1994; Cahill e Glidden, 1996; Perez e Limongi, 1998; Roach et al, 1998; Hauser-Cram et. al, 1999; Limongi et al, 2000; Pino, 2000; Andrade e Limongi, 2001; Andrade, 2002; Moore et al, 2002; Ricci e Hodapp, 2003; Johnson-Glenberg e Chapman, 2004).

Segundo esses autores, a falta de estímulos adequados durante a interação mãe-criança com SD pode ser significativo para o seu desenvolvimento, visto que a mãe é a mediadora das ações da criança com o ambiente (pessoas, objetos e situações).

Hauser-Cram et al. (1999) relatam que o desenvolvimento adequado de linguagem da criança com SD, bem como a sua socialização satisfatória, dependem do modo como a família interpreta os estímulos ambientais para a sua criança, principalmente quando estes estímulos são favorecidos pela interação mãe-criança. 
Segundo Jones (1977), durante a interação mãe-criança com SD, as crianças iniciam menos as interações com suas mães, como também apresentam dificuldades em mantê-las. O autor refere que elas são mais lentas em responderem aos estímulos do ambiente por dois motivos importantes, sendo que um é conseqüente ao outro. O primeiro motivo está no fato de que as crianças com SD são mais lentas devido à presença da hipotonia generalizada, a qual é inerente à síndrome, contribuindo, portanto, com uma atuação motora mais lenta no ambiente (Camargo, 2000). Há, ainda, outros fatores que podem contribuir com esta lentidão, tais como: os problemas respiratórios, cardíacos, auditivos e de atenção, os quais podem interferir conjuntamente entre si (Andrade, 2002).

O segundo motivo está no fato de que as mães podem se sentir menos incentivadas a estimularem as suas crianças devido ao atraso de suas respostas (Jones, 1977; Martins e Mervis, 1985; Fischer, 1987; Perez e Limongi, 1998; Roach et al, 1998; Andrade, 2002).

Ramruttun e Jenkins (1998) referem que, no início do desenvolvimento da criança com SD, o sorriso reflexo presente no nascimento é observado com cinco semanas de atraso em relação à criança com DT, cuja possível explicação está no baixo estado de alerta característico dessa população nas primeiras semanas de vida. O sorriso social, por sua vez, somente aparecerá com o desenvolvimento do contato de olho, como resposta a um estímulo oferecido. O início do contato de olho mais prolongado ocorrerá em torno dos quatro ou cinco meses de idade. Observa-se a emergência do balbucio por volta dos nove meses, 
manifestando-se com um atraso de dois meses quando comparada com a criança com DT. Esta mesma observação foi relatada nos estudos de StoelGammon (2001).

Fischer (1987) demonstra, em estudo realizado com crianças com SD no período pré-lingüístico, que a interação mãe-criança pode ser prejudicada desde o primeiro mês de vida da criança. Segundo o autor, isto se deve, principalmente, ao fato de algumas mães saberem desde o nascimento de seus bebês que eles apresentarão alterações no decorrer do desenvolvimento (atrasos cognitivo, de linguagem e motor) conseqüentes do quadro sindrômico. Desse modo, essas mães interagem menos com seus filhos que, por sua vez, tornam-se menos espontâneos para iniciar alguma comunicação social.

Foi observado, também, que estas mães costumavam ser menos diretivas com suas crianças durante as atividades que exigiam estímulos comunicativos para a adequação da linguagem. Por outro lado, as mães que já estavam de alguma forma engajadas com suas crianças em algum programa de intervenção desde cedo, respondiam à maioria dos sinais comunicativos apresentados por suas crianças durante a interação, principalmente diante da emissão de alguma vocalização. Com isso, notouse que estas crianças apresentavam desenvolvimentos cognitivo e de linguagem melhores do que as outras.

Roach et al (1998) realizaram um estudo no qual compararam a interação de mães e crianças com SD de três a dezessete meses de idade com a interação de mãe e crianças com defasagem cognitiva com idade 
cronológica de dezesseis a trinta meses, mas com idade mental em torno de três a dezessete meses, e com crianças com DT com a mesma idade cronológica (três a dezessete meses). Todas as mães de crianças com SD já estavam fazendo parte de algum programa de intervenção.

Segundo os autores, durante o estudo foi observado que as mães das crianças com SD foram mais diretivas com seus filhos durante as brincadeiras livres (espontâneas) do que as mães dos outros dois grupos, como também durante as brincadeiras que envolviam objetos. Desta forma, foi observado que as crianças com SD respondiam com mais freqüência aos estímulos de suas mães do que as outras crianças, embora estas também respondessem.

Legerstee et al. (2002) salientam que, à medida que a mãe atende às necessidades de sua criança com SD durante o período pré-lingüístico, direcionando a sua atenção para as estratégias interativas propostas e a comunicação, há um melhor desenvolvimento na sua produção de gestos e palavras.

As mães devem, inclusive, oferecer oportunidades para as suas crianças iniciarem a comunicação, tornando-as mais ativas do que reativas neste processo. Também, faz-se necessário o desenvolvimento de estratégias que facilitem a criança com SD a melhorar a sua expressão comunicativa, tanto qualitativa quanto quantitativamente (Jenkins, 1993; Stoel-Gammon, 2001).

Yoder e Warren (2004) sugerem, em seus estudos, o esforço contínuo dos pais de crianças com SD em maximizar o desenvolvimento de 
linguagem de suas crianças por meio do aumento de respostas às suas solicitações durante a interação.

Por outro lado, Andrade (2002) ressalta que a interação mãe-criança ainda poderá ser prejudicada, inicialmente, devido ao impacto que a família sofre, logo após o nascimento de sua criança, ao saber que ela tem SD.

O nascimento de uma criança com SD geralmente leva a família a se deparar, inicialmente, com um bebê fisicamente diferente do esperado. Para a maioria dos pais, esta situação causa-Ihes um impacto em suas vidas acompanhado de sentimentos de orgulho ferido, culpa e depressão, até que ocorra uma reorganização familiar (Murphy, 1993; Perez e Limongi, 1998; Mustacchi, 2000; Andrade, 2002).

Para alguns autores (Seltzer et al., 2001; Andrade, 2002; Trute e Hiebert-Murphy, 2002), o impacto que as famílias sofrem diante da situação inusitada de terem uma criança com alterações não é um acontecimento que envolve apenas o período do diagnóstico, mas um processo de frustração que reaparece em determinadas fases da vida da criança, à medida que as suas dificuldades vão surgindo e sendo enfrentadas. Quanto mais grave a alteração, mais difícil torna-se essa reorganização familiar.

Portanto, o trabalho de intervenção precoce nestes casos é imprescindível, bem como o acompanhamento fonoaudiológico (Jones, 1977; Leifer e Lewis, 1984; Martins et al. 1985; Martins e Mervis, 1985; Gomes et al., 1992; Hoshino et al., 1994; Nilholm, 1996; Perez e Limongi, 1998; Roach et al., 1998; Limongi et al., 2000; Stoel-Gammon, 2001; 
Andrade, 2002; Legerstee et al., 2002; Ricci e Hodapp, 2003; JonhsonGlenberg e Chapman, 2004; Yoder e Warren, 2004).

Resumidamente, o trabalho fonoaudiológico direcionado a esta população, no período da intervenção precoce, geralmente é baseado em orientações às mães quanto à adequação do sistema estomatognático e ao desenvolvimento de linguagem e cognição de sua criança. O seu objetivo é proporcionar o desenvolvimento máximo do potencial desta criança em relação às áreas referidas, cuja efetividade somente será possível se a interação mãe-criança ocorrer de forma satisfatória. Além disso, por meio dele, as mães vão compreendendo as dificuldades e necessidades apresentadas por suas crianças enquanto, ao mesmo tempo, elas vão se sentindo mais autoconfiantes nestes cuidados. Consequentemente, a interação da díade melhora aos poucos e, juntamente com isto, o desenvolvimento de linguagem da criança (Martins e Mervis, 1985; Gomes et al., 1992; Buckley, 1993; Hoshino et al., 1994; Nilholm, 1996; Perez e Limongi, 1998; Ramruttun e Jenkins, 1998; Roach et al, 1998; Schwartzman M., 1999; Limongi et al., 2000; Stoel-Gammon, 2001; Andrade, 2002; Yoder e Warren, 2004).

\subsection{O método dialético-didático}

O método dialético-didático foi proposto por Parrat-Dayan no ano de 1996, e foi totalmente baseado no método clínico de Piaget, diferenciandose deste apenas no fato de que o examinador intervém ativamente durante 
as situações conflitivas entre o sujeito e o objeto de conhecimento, com o objetivo de desenvolver o estado atual de raciocínio da criança, e não se detendo somente no estudo da evolução deste raciocínio.

No entanto, para uma maior compreensão deste método, faz-se necessária a síntese do percurso histórico do método clínico segundo os estudos de Castorina et al. (1984).

O uso do método clínico teve o seu início em 1926, empregado originalmente por Piaget. Segundo Castorina et al. (1984), a partir de então, ele sofreu modificações históricas desde os objetos de investigação às peculiaridades da situação experimental.

Os autores relatam que, no início, a principal característica deste método baseava-se na indagação clínica dirigida ao indivíduo, no sentido de determinar a sua capacidade de conhecer ("funcionamento cognoscitivo"). Em outras palavras, ele era constituído com base na conversa com a criança por meio de perguntas ao acaso, as quais eram questionadas a partir das suas respostas, mas, também, de acordo com as hipóteses que o experimentador formulava previamente a respeito do comportamento infantil. Neste início, o método foi criado por analogia com o exame psiquiátrico porque, segundo os autores, o psiquiatra levanta problemas para si, formulando hipóteses e as comprovando por meio do contato (conversas e reações) com o paciente.

No entanto, neste método, era imprescindível que o interrogador soubesse observar, permitindo que a criança falasse à vontade enquanto, ao mesmo tempo, ele soubesse obter informações precisas por meio de suas 
hipóteses de trabalho. Neste sentido, as respostas obtidas dão lugar a novas perguntas para completar a informação ou promover uma verificação ou reformulação da mesma.

Após um período de experiências com o procedimento da indagação clínica, Castorina et al. (1984) ainda relatam uma modificação no método: o diálogo é substituído por uma série de observações, sendo que, às vezes, são puras, enquanto que, ao mesmo tempo, é substituído pela ação. Nestes casos, primeiramente a observação é realizada sem qualquer interferência do observador durante a atividade da criança em uma situação livre e, depois, provocada, sendo realizada com a inclusão de situações experimentais conforme as respostas das atividades da criança e de acordo com as hipóteses do observador.

Neste período, a preocupação maior de Piaget foi o estudo da formação do conhecimento pela criança, buscando entender como as ações do bebê se constituíam. As suas hipóteses partiram das idéias de Poincaré sobre os grupos de deslocamentos na Geometria, nos quais envolviam algumas propriedades espaciais invariantes em um sistema de transformações. Piaget, por sua vez, preparou situações experimentais selecionando os comportamentos dos bebês com o objetivo de entender como as suas ações (dos bebês) coordenavam-se em forma de sistemas. Foi, inclusive, nesta época, que a seqüência de observações realizadas por este autor em seus filhos proporcionou-lhe comprovar, cada vez mais, as suas hipóteses: a criança constrói progressivamente o seu conhecimento, o qual, no início, é exclusivamente sensório-motor. 
Em 1947, Piaget passa a adotar um método misto, que consiste na análise da construção do pensamento a partir de operações efetivas e concretas, sem deixar de considerar a linguagem, fazendo-a intervir do modo mais espontâneo possível, em função da ação. Nesta perspectiva, Piaget elabora uma grande variedade de provas acerca das noções de número, conservação, classificação, seriação, tempo, velocidade, espaço e acaso (causalidade), as quais envolvem a manipulação de objetos, produzindo transformações (alongar, encurtar, decompor, recompor, deslocamentos em sentido contrário, etc.). O objetivo deste procedimento era o de analisar como as crianças pensavam as transformações do material, como elas argumentavam e como sustentavam as suas conclusões.

Entretanto, os princípios fundamentais da interrogação clínica permanecem os mesmos, uma vez que se baseia numa conversa livre com o sujeito sobre uma ação concreta, em lugar de limitar-se a perguntas ao acaso. O que se pergunta às crianças, como se pergunta, em que direção e o que se valoriza do interrogatório dependem dos problemas e das hipóteses que orientam a formulação dessas questões. Isto implica no fato de que o pesquisador deverá conhecer teoricamente a temática em questão, visto que a origem das transformações realizadas pelas crianças tem uma interpretação determinada e, assim sendo, o pesquisador estará tentando elucidar. Nesta nova situação, a conversação livre tem a vantagem de poder ser adaptada a cada criança e de permitir-lhe refletir sobre as suas ações e afirmações (Assis, 1996). 
$\mathrm{Na}$ interpretação dos resultados obtidos durante as provas operatórias, Castorina et al. (1984) ressaltam o cuidado que se deve ter para não as considerar como uma medida do nível estrutural da criança e sim, como o seu indicador. As provas oferecem algumas noções do nível estrutural, mas não garantem que tal nível estenda-se a todas as situações.

Segundo Vinh-Bang (1990), a partir de então, as respostas das crianças são consideradas significativas, pois já indicam um estado de conhecimento do indivíduo, além de que, todas elas, dependem da natureza e da forma da pergunta realizada.

De acordo com as declarações de Assis (1996), o método clínico permite captar o processo de pensamento do sujeito e a estrutura característica de seu estágio de desenvolvimento, uma vez que possibilita a construção e a conscientização dos sistemas lógicos subjacentes aos sistemas de significação na organização intelectual. Neste sentido, torna-se imprescindível que o examinador se deixe orientar de acordo com as respostas, tanto originais como as imprevistas pelos sujeitos da pesquisa e, assim, ir adaptando as suas próximas questões de acordo com os resultados que vão surgindo.

Em 1996, a educadora Parrat-Dayan realiza um estudo em que levanta uma hipótese acerca do processo de construção do conhecimento do sujeito na atuação com os objetos, o qual implica, segundo a autora, na reorganização de conhecimentos como todo processo construtivo.

Para tanto, ela elaborou dois métodos de aprendizagem com base no método clínico, visto que ele Ihe permitiria compreender e analisar o 
processo de construção de conhecimento do sujeito, os quais são: método por conflito cognitivo e o método dialético-didático. O primeiro baseou-se no conflito cognitivo, como o próprio nome o diz, e the permitiria ver de que maneira o objeto "guia" o sujeito na explicação de suas propriedades. O segundo combina a ação do sujeito sobre o objeto com a intervenção ativa do examinador facilitando a resolução do problema da criança sobre o objeto de atuação, enquanto que Ihe permitiria avaliar a troca de informações entre a criança e o examinador durante a resolução.

Com relação ao método dialético-didático, a sua hipótese baseou-se no fato de que o confronto de argumentos permitiria à criança uma melhor compreensão da realidade, além de que o fato de uma criança receber informações sobre o seu objeto de atuação não a impediria de construir o seu conhecimento a respeito dele. Entretanto, a autora ressalta que essas informações não seriam de conteúdo escolar porque trata-se de um contexto dialético de discussão entre a criança e o examinador.

O método dialético-didático generaliza as sugestões positivas do método clínico piagetiano, diferenciando deste apenas no fato de que a discussão entre criança e examinador é valorizada com o objetivo de se construir um conhecimento comum, ao passo que no método clínico clássico o objetivo é o estudo da evolução do estado atual do pensamento da criança.

Quanto ao método por conflito cognitivo, as situações de aprendizagem propostas deveriam provocar interações conflitivas entre o sujeito e o objeto físico. E então, foram observadas pela autora as reações 
da criança diante do problema proposto: se houve antecipação, constatação e explicação.

Como resultado de seu estudo, Parrat-Dayan (1996) observou que o método dialético-didático permitiu uma melhor evolução no raciocínio da construção de conhecimento das crianças do que o por conflito cognitivo, cuja causa está no fato de que, neste último, o examinador não incitava a criança a buscar explicações mais elaboradas diante do problema proposto, visto que ela tinha que resolvê-lo sozinha. Por meio do método dialéticodidático, ao contrário, o examinador auxiliava a criança a delimitar o problema proposto e a orientava de modo que ela pudesse encontrar uma solução. Além disso, as orientações que o examinador sugeria à criança suscitavam-lhe a reflexão mais elaborada sobre o problema proposto, fazendo-a buscar a explicação na sua resolução de uma forma dialética.

Contudo, o interveniente ou examinador deve: procurar respeitar e encorajar o papel ativo do sujeito, lembrar-se que o conhecimento é construído, obedecer a hierarquia da psicogênese, cuidar para que cada aquisição seja estruturada e considerar os erros tratando-os com profundidade.

Para Parrat-Dayan (1996), o confronto de argumentos distintos diante da resolução de um determinado problema faz do método dialético-didático um método que colabora definitivamente com o progresso do raciocínio da criança e, assim, com a construção de seu conhecimento sobre a realidade. 
4. MÉTODOS 


\subsection{Sujeitos}

O estudo foi realizado com doze crianças distribuídas em três grupos distintos, sendo um de pesquisa e dois de controle:

- Grupo 1 (grupo de pesquisa - GP): quatro crianças com síndrome de Down (SD) em processo terapêutico fonoaudiológico, com idades entre três e quatro anos, no início da pesquisa, com desenvolvimento cognitivo entre o final do período sensório-motor e início do pré-operatório segundo Piaget (1987, edição original de 1936; 1990, edição original de 1946; 1996, edição original de 1937):

S1: RFC - data de nascimento: 06/11/2000 - gênero: feminino;

S2: MZ - data de nascimento: 09/10/2000 - gênero: masculino;

S3: HAV - data de nascimento: 29/ 03/2000 - gênero: masculino;

S4: SCA - data de nascimento: 23/12/1999 - gênero: feminino.

Todas as crianças deste grupo já estavam em processo terapêutico fonoaudiológico no Laboratório de Investigação Fonoaudiológica em Síndromes e Alterações Sensório-Motoras (LIFSASM) do Departamento de Fisioterapia, Fonoaudiologia e Terapia Ocupacional da Faculdade de Medicina da Universidade de São Paulo. 
O critério de seleção das crianças deste grupo, com relação ao desenvolvimento cognitivo, baseou-se nas informações obtidas por meio de seus respectivos prontuários e avaliação inicial, realizada pela pesquisadora.

- $\underline{\text { Grupo } 2}$ (grupo controle 1 - GC1): quatro crianças com SD que receberam acompanhamento fonoaudiológico por pelo menos três anos consecutivos, com idades entre três e quatro anos no início da pesquisa, e desenvolvimento cognitivo entre o final do período sensório-motor e início do pré-operatório segundo Piaget (1987, edição original de 1936; 1990, edição original de 1946; 1996, edição original de 1937):

S5: LHSP - data de nascimento: 22/04/2000 - gênero masculino;

S6: MMFV - data de nascimento: 20/08/2000 - gênero feminino;

S7: ATSN - data de nascimento: 28/11/2000 - gênero masculino;

S8: EBM - data de nascimento: 19/05/2000 - gênero feminino.

Os sujeitos deste grupo estavam no final do atendimento fonoaudiológico precoce na Associação de Pais e Amigos dos Excepcionais (APAE) de Santo André (três crianças) e na APAE de Mauá (uma criança). O critério de determinação das instituições escolhidas para a seleção do GC1 baseou-se no fato de oferecerem atendimento gratuito à população, tal como no LIFSASM, e de serem de acesso fácil para a pesquisadora.

A seleção das crianças que compõem este grupo deu-se por meio de entrevistas com as fonoaudiólogas responsáveis por seu atendimento nas 
instituições e, a seguir, por meio dos dados obtidos na avaliação inicial, realizada pela pesquisadora.

Este grupo foi considerado de controle neste estudo porque, além dessas crianças apresentarem SD e idades cronológicas próximas às do GP, a intervenção fonoaudiológica que recebiam era diversa, do ponto de vista teórico-metodológico, daquela desenvolvida com o GP.

- $\underline{\text { Grupo3 }}$ (grupo controle 2 - GC2): quatro crianças com desenvolvimento típico (DT), com idades entre um e dois anos, no início da pesquisa, sendo que o desenvolvimento cognitivo era compatível com a idade cronológica, ou seja, final do período sensório-motor e início do préoperatório segundo Piaget (1987, edição original de 1936; 1990, edição original de 1946; 1996, edição original de 1937):

S9: LBV - data de nascimento: 10/06/2002 - gênero feminino;

S10: FBCB - data de nascimento: 13/05/2002 - gênero masculino;

S11: ACUR - data de nascimento: 08/04/2002 - gênero masculino;

S12: JOA - data de nascimento: 15/04/2002 - gênero feminino.

Os sujeitos deste grupo foram selecionados de uma creche municipal da cidade de São Bernardo do Campo (autorização no anexo J). O critério de seleção das crianças baseou-se nas informações obtidas pela diretoria da creche sobre o desempenho de cada uma delas quanto ao desenvolvimento global esperado para uma criança com DT e, em seguida, por meio da 
avaliação inicial. Optou-se por uma creche municipal da região do $A B C$ paulista por oferecer atendimento gratuito, ter proximidade física com as instituições da APAE e por ser de acesso fácil para a pesquisadora.

A utilização de um segundo grupo controle fez-se necessária para a realização desta pesquisa pelo fato dos sujeitos deste grupo apresentarem os desenvolvimentos cognitivo e o de linguagem adequados à idade cronológica e que, portanto, são fundamentais enquanto parâmetros de observação e análise dos dados dos outros grupos.

Durante a seleção dos sujeitos para a pesquisa, levou-se em consideração alguns critérios de exclusão e inclusão para os GP e GC1.

Os critérios de exclusão referem-se às seguintes características:

1. presença de alterações de saúde: cardiopatias, quadros respiratórios;

2. quadros associados como a deficiência auditiva, deficiência visual, distúrbios psiquiátricos e/ou psicológicos, de origem neurológica.

Ressalta-se que, qualquer um desses critérios, quando presentes na criança com SD, poderia interferir de modo significativo no seu desenvolvimento global e, consequentemente, alterar os dados da pesquisa (Mustacchi e Rozone, 1990; Pueschel, 1993; Mustacchi, 2000, Andrade, 2002).

Por outro lado, são classificados como critérios de inclusão para GP e GC1: 
desenvolvimento cognitivo entre o final do período sensório-motor e início do pré-operatório, segundo a teoria de Piaget (1987, edição original de 1936; 1990, edição original de 1946; 1996, edição original de 1937);

presença de intenção comunicativa observável;

ter realizado acompanhamento de estimulação precoce em algum serviço fonoaudiológico, ou, pelo menos, estar no final dele, para o GC1 e freqüentar o LIFSASM para o GP;

ambos os gêneros, sendo dois sujeitos com gênero masculino e outros dois com gênero feminino em cada grupo.

\subsection{Material:}

Durante a realização das avaliações foi utilizado, para os sujeitos de todos os grupos, um protocolo de avaliação de linguagem e cognição (anexo A) e um protocolo de análise (anexos: B, B1, B2 e B3), elaborados pela pesquisadora e baseados na teoria de Piaget (1987, edição original de 1936; 1990, edição original de 1946; 1996, edição original de 1937).

O protocolo de avaliação de linguagem e cognição contém as seguintes informações:

$\checkmark$ dados de identificação da criança (nome, data de nascimento e idade);

$\checkmark$ tipo de grupo (GP, GC1 ou GC2) a que pertencesse;

$\checkmark$ instituição;

$\checkmark$ data da avaliação; 
$\checkmark$ observação ( 1,2 ou 3, correspondendo à primeira, segunda ou terceira avaliação);

$\checkmark$ um quadro para a anotação das informações obtidas quanto ao desenvolvimento da criança contendo os seguintes itens:

- objeto (anexo C): este item identifica o brinquedo utilizado pela criança durante as avaliações. Os brinquedos são compatíveis para a criança que apresenta desenvolvimento cognitivo entre o final do período sensório-motor e início do pré-operatório e possuem tamanhos variáveis, partindo desde miniaturas a um tamanho que caiba nos braços da criança. São eles: utensílios de cozinha em miniatura (quatro pires, quatro xícaras, três colheres, quatro panelas de tamanho e profundidade diferentes com tampa, três copos, um fogão, uma cesta); uma boneca, um berço, um urso de pelúcia, um cachorro de pelúcia, animais de plástico em miniatura (uma girafa, um leão, um tigre, um elefante, um gorila, um cavalo, um cachorro), dois carrinhos, um caminhão, um telefone, um jogo de encaixe de argolas (arca de Noé), um jogo de encaixe de dez canecas e um brinquedo de encaixe de formas (um carro).

- ação: neste item foi descrito o desenrolar das ações da criança com o objeto, ou seja, quais os brinquedos de sua preferência e como ela brincava com eles. As informações deste item permitiram identificar em qual fase do desenvolvimento cognitivo ela estava.

- linguagem oral: corresponde às produções orais emitidas pela criança durante a realização das ações. Neste caso, foram 
consideradas desde repetições de palavras ou frases até emissões espontâneas (incluindo vocalizações).

- comunicação gestual: neste item, registrou-se todas as produções gestuais da criança (gestos, expressões faciais, contato de olho, etc.), as quais poderiam ou não vir acompanhadas da linguagem oral.

- observação: refere-se a alguma informação importante como dado de pesquisa, mas que não se aplicava a nenhum dos itens já mencionados.

O protocolo de análise, por sua vez, contém informações semelhantes às do protocolo de avaliação de linguagem e cognição, porém, diferindo em alguns itens do quadro, os quais, retirou-se objeto e observação, e acrescentou-se linguagem oral simultânea à comunicação gestual e comunicação gestual simultânea à linguagem oral. Neste protocolo foram sintetizados os dados das crianças descritos nos protocolos de avaliação de linguagem e cognição.

Como a efetividade da terapia fonoaudiológica no desenvolvimento de linguagem foi um dos aspectos observados durante a realização desta pesquisa, as sessões terapêuticas do GP foram registradas em um protocolo de observação (anexo D), também semelhante ao utilizado para a avaliação de linguagem e cognição, diferindo apenas na exclusão do item número da observação. 
Os materiais utilizados durante as sessões, por sua vez, também foram semelhantes aos da avaliação, visto que, dessa forma, permitiriam o acompanhamento da evolução do desenvolvimento de linguagem e cognição do GP.

Foram utilizadas filmadoras (JVC GR-AXM237 ou Panasonic PV-IQ 305) e fitas de vídeo.

\subsection{Procedimento}

Para a efetivação da pesquisa, foi necessária sua aprovação pela Comissão de Ética para Análise de Projetos de Pesquisa da Diretoria Clínica do Hospital das Clínicas e da Faculdade de Medicina da Universidade de São Paulo - CAPpesq (protocolo de pesquisa no 076/03, datado de 14 de maio de 2003 - anexo E). Além disso, solicitou-se aos responsáveis de cada criança o preenchimento do termo de consentimento livre e esclarecido, o qual se apresenta em três modelos distintos, de acordo com os diferentes grupos citados neste estudo (anexos: F1, F2 e F3).

Durante o processo de realização deste trabalho, todas as crianças foram avaliadas pela mesma fonoaudióloga, conforme o procedimento adotado.

A pesquisa foi fundamentada no modelo teórico proposto pela Epistemologia Genética e utilizado o método dialético-didático (ParratDayan, 1996). 


\subsubsection{Coleta de dados}

Após a seleção dos sujeitos, de acordo com os critérios de inclusão e exclusão, a coleta de dados foi realizada em três fases, as quais, três avaliações intercaladas entre si por um período de seis meses, resultando em um ano de pesquisa. Ressalta-se que a seleção dos sujeitos do GP e GC1 foi realizada com base nas informações obtidas dos processos terapêuticos que já estavam sendo realizados em suas respectivas instituições de origem, por meio de entrevistas com as fonoaudiólogas responsáveis pelo atendimento de cada sujeito, mas comprovada mediante a avaliação inicial, realizada pela pesquisadora. Os sujeitos do GC2, por sua vez, foram selecionados a partir de entrevistas com a diretora da instituição e as professoras responsáveis por eles, informando sobre o desenvolvimento de cada um nas atividades desenvolvidas na creche, cujos dados também foram comprovados na avaliação inicial.

\subsubsection{Coleta de dados do GP:}

Após a avaliação inicial, as crianças deste grupo passaram a ser atendidas pela pesquisadora. Todas foram atendidas semanalmente, em sessões terapêuticas com 45 (quarenta e cinco) minutos de duração, por um período de doze meses, resultando em 40 (quarenta) sessões, aproximadamente. 
O atendimento fonoaudiológico foi individual e a terapeuta atuou diretamente com cada sujeito, com o objetivo de trabalhar os aspectos referentes aos desenvolvimentos cognitivo e de linguagem. Para tanto, cada criança foi atendida em uma sala que continha: uma mesa pequena, duas cadeiras, um colchonete e brinquedos semelhantes aos utilizados no período da avaliação. As terapias foram filmadas quinzenalmente para garantir a objetividade nas observações, cujos dados seriam trabalhados qualitativamente (Thiollent, 1985; Lee e Goldman, 1989; Hays et al., 1990; Baum e Gray, 1992; Cordes, 1994; Scarcellone, 1998; Elder, 1999; Steinke, 2001). Em seguida, foram transcritas no protocolo de observação. Ressaltase que, nos períodos de gravação da pesquisa, a filmadora era posicionada sobre um tripé, em torno de dois metros de distância do local destinado à avaliação.

Durante as terapias, a pesquisadora oferecia à criança, no máximo, três tipos diferentes de brinquedo (semelhantes aos utilizados nas avaliações), sendo um de cada vez. Inicialmente, após a oferta do brinquedo, observava-se a ação espontânea da criança com o objeto, que poderia variar de acordo com o tipo oferecido, bem como a presença ou não de: linguagem oral, comunicação gestual e observações que fossem úteis à pesquisa.

Após alguns minutos de brincadeira espontânea, a pesquisadora passava a intervir nas atividades da criança propondo-Ihe situações conflitivas entre ela e o brinquedo, com o objetivo de trabalhar o seu desenvolvimento cognitivo, tal qual propõe o método dialético-didático 
(Parrat-Dayan, 1996). À medida que a criança ia resolvendo as suas dificuldades, a pesquisadora passava a propor outras situações conflitivas. Por exemplo: durante a atividade de encaixar canecas, ao notar que a criança já dominava o encaixe de um determinado número delas, a terapeuta oferecia-Ihe mais uma caneca com tamanho mais próximo ao das canecas anteriores, aumentando, assim, o número de canecas a serem encaixadas. A partir de então, a criança tentaria encaixá-la entre as outras, até dominar o encaixe das que já Ihe tinham sido oferecidas. Enquanto a criança tentava encaixá-la, a terapeuta poderia ou não intervir no processo, facilitando ou não a atividade da criança de acordo com a sua capacidade de realizá-la. Mais uma vez dominada a tarefa proposta, mais uma caneca com tamanho diferente lhe era entregue e, assim, repetia-se todo o processo.

Durante as terapias, também buscou-se favorecer a comunicação da criança, principalmente a linguagem oral, incentivando o seu uso, por meio de questões simples e diretas, elaboradas dentro de um determinado contexto, por nomeações de objetos ou ações durante as atividades propostas, e, ainda, por meio de situações em que a criança pudesse sentir a necessidade de se expressar.

No final, a cada seis meses transcorridos (20 sessões terapêuticas realizadas por semestre), após a primeira avaliação, as crianças deste grupo foram submetidas a duas reavaliações, totalizando três avaliações no período de doze meses, aproximadamente.

Para a avaliação, utilizou-se os brinquedos selecionados e o mesmo ambiente de terapia. Entretanto, somente nos dias destinados à avaliação, o 
período da atividade foi de 30 (trinta) minutos, tal qual ocorreu com os outros dois grupos (GC1 e GC2), cujas coletas serão descritas a seguir.

Durante a realização das avaliações, todos os brinquedos foram dispostos no colchonete de modo que a criança pudesse vê-los de uma vez assim que entrasse na sala e pudesse manuseá-los espontaneamente. Um pouco mais adiante do colchonete, a filmadora estava posicionada sobre um tripé dirigida ao local a ser filmado.

A atuação da pesquisadora durante as avaliações foi semelhante à sua atuação durante as terapias.

Após as avaliações serem filmadas, elas foram transcritas no protocolo de avaliação de linguagem e cognição e, depois, realizada a análise.

O estudo com este grupo, incluindo processo terapêutico e avaliações semestrais, foi realizado no Laboratório de Investigação Fonoaudiológica em Síndromes e Alterações Sensório-Motoras (LIFSASM) do Departamento de Fisioterapia, Fonoaudiologia e Terapia Ocupacional da Faculdade de Medicina da Universidade de São Paulo, mediante a autorização da docente responsável (anexo G).

\subsubsection{Coleta de dados do GC1:}

As crianças deste grupo não conheciam a pesquisadora. Entretanto, desde a primeira avaliação, elas foram conduzidas tranqüilamente para o espaço físico destinado pelas instituições (autorizações das APAE Santo 
André e APAE Mauá segundo os anexos $\mathrm{H}$ e I) para a realização da pesquisa, após alguns momentos de interação com a pesquisadora em outro recinto. Este procedimento tornou-se necessário pelo fato de algumas delas demonstrarem, inicialmente, um pouco de timidez diante da pesquisadora. Em seguida, com a certeza da descontração da criança, deu-se início ao processo de avaliação. Molini-Alvejonas (2004) aborda em seus estudos sobre o perfil funcional da comunicação de crianças autistas, com SD e com DT, que as com SD apresentam uma grande habilidade social quando comparadas às outras crianças, facilitando, assim, o desenvolvimento de seus aspectos funcionais da comunicação.

O espaço físico utilizado para a avaliação na APAE de Santo André foi uma sala que continha: uma mesa de escritório, duas cadeiras, um armário e um tapete. O espaço físico cedido pela APAE de Mauá, por sua vez, continha: uma mesa de escritório, três cadeiras, uma mesa pequena com duas cadeiras também pequenas, um espelho, um armário, uma lousa e um colchonete.

Quando a criança entrava na sala, os brinquedos já estavam dispostos no tapete (APAE Santo André) ou no colchonete (APAE Mauá), de tal modo que ela os via de uma vez, como também a filmadora já estava posicionada, tal qual era realizado com o GP.

Durante o período de 30 (trinta) minutos, a cada seis meses de intervalo entre as avaliações, as quais totalizaram três avaliações no prazo de doze meses, o procedimento utilizado para a coleta de dados deste grupo foi exatamente o mesmo utilizado com o GP. 


\subsubsection{Coleta de dados do GC2:}

Pelo fato das crianças deste grupo serem muito novas e não terem conhecido previamente a pesquisadora, bem como, para evitar situações de timidez ou qualquer constrangimento que pudesse causar algum tipo de viés à pesquisa, optou-se pela presença de uma das cuidadoras da creche na sala cedida para a avaliação. Em nenhum momento a cuidadora interferiu diretamente no processo de avaliação. A sua presença apenas contribuiu para que a criança se sentisse confiante na presença de uma pessoa que Ihe era estranha.

No espaço físico cedido pela instituição para as avaliações tinha: um tapete, algumas almofadas grandes e outras pequenas, alguns livros distribuídos em prateleiras baixas, uma pia com uma torneira, e, das paredes que formavam a sala, uma delas era de vidro com uma janela que dava para um jardim.

Quando a criança adentrava a sala, os brinquedos já estavam dispostos no tapete tal qual nos ambientes de avaliação dos grupos anteriores e a filmadora posicionada a alguns metros do tapete. Assim, em seguida, dava-se início ao processo de avaliação também da mesma forma que se realizou nos outros grupos, respeitando-se o intervalo de seis meses entre uma avaliação e outra. 


\subsubsection{Registro e análise dos dados}

O processo terapêutico do GP foi filmado e os dados obtidos foram transcritos nos protocolos de observação com o propósito de se garantir a objetividade nas observações com relação ao processo de evolução terapêutica das crianças (Thiollent, 1985; Lee e Goldman, 1989; Hays et al., 1990; Baum e Gray, 1992; Cordes, 1994; Scarcellone, 1998; Elder, 1999; Steinke, 2001).

Do mesmo modo, as avaliações de cada criança de todos os grupos foram filmadas em vídeo-tape por um período de 30 (trinta) minutos e os dados obtidos foram transcritos nos protocolos de avaliação.

Após realizadas as transcrições das avaliações, de acordo com os itens do protocolo, os dados obtidos foram sintetizados em um protocolo de análise (anexos B, B1, B2 e B3). Além disso, ressalta-se que, antes da realização da síntese dos dados no protocolo de análise, parte dos protocolos de avaliação de linguagem e cognição de todos os grupos foram conferidos por três juizes capacitados de acordo com a mesma abordagem teórica da pesquisadora. Tal procedimento fez-se necessário para se garantir a precisão e a confiabilidade dos dados obtidos na pesquisa (Fleiss, 1981; Siegel e Castellan, 1988; Lee e Goldman, 1989; Scarcellone, 1998).

Para que os dados fossem sintetizados no protocolo de análise, buscou-se observar, no protocolo de avaliação de linguagem e cognição, as ações espontâneas de cada criança com os objetos de sua preferência, bem 
como o uso de vocábulos ou frases, e a presença das expressões gestuais isoladas ou acompanhando a linguagem oral.

Com relação às ações espontâneas de cada criança com os objetos, analisou-se:

a) utensílios de cozinha: observava-se a organização dos objetos quanto à sua disposição na superfície (p.ex.: uso de classificação, seriação e correspondência termo a termo) e a presença ou não de jogo simbólico.

b) boneca, urso de pelúcia, cachorro de pelúcia e berço: foi observado se a criança representou ações vividas em si e/ou nos outros (boneca, animais de pelúcia), bem como as seqüências das ações, ou, então, se ela somente manipulou as propriedades físicas dos objetos (ex:: apertou-os, cheirou-os, levou-os à boca, etc.).

c) carrinhos e caminhão: foi observado se a criança simplesmente manipulou as propriedades físicas dos objetos (ex.: fazer o carrinho andar para ouvir o ruído que ele provoca), se realizou ações motoras (empurrar o carrinho) ou se ela apresentou ou não jogo simbólico.

d) miniatura de animais de plástico: observou-se o que as crianças eram capazes de realizar com eles (classificação, seriação, exclusão ou inclusão nas atividades anteriores).

e) telefone: observou-se se a criança apenas manipulou as propriedades físicas do objeto, ou se o utilizou de modo 
convencional (apenas levando-o à orelha), ou ainda, se representou situações vividas por si mesma ou por outros dialogando ao telefone.

f) brinquedos de encaixe (argolas, formas geométricas, jogo de canecas de tamanhos diferentes): de um modo geral, foram observadas as tentativas de encaixe (por experimentação, comparação ou aleatoriamente). Para o jogo de canecas, de modo mais específico, além das tentativas de encaixe, observou-se a ordenação tanto no sentido horizontal quanto no vertical e o número de canecas utilizadas com êxito na ação a que se propôs.

A seguir, com base nas informações acima, no item ação do protocolo de análise, foram sintetizadas as fases do desenvolvimento cognitivo em que o sujeito estava naquele semestre, as quais incluíam: a presença da imitação diferida, nível do jogo simbólico, tipos de seriação e de classificação de objetos.

No item linguagem oral do protocolo de avaliação de linguagem e cognição observou-se a produção oral da criança, a qual foi sintetizada no item linguagem oral do protocolo de análise, considerando-se somente as situações em que os sujeitos produziram-na de modo espontâneo para designar objetos ou ações. Isto significa que, as palavras emitidas juntamente com qualquer tipo de gesto utilizado pela criança para facilitar a sua expressão não foram analisadas neste item. 
Desse modo, as palavras emitidas pelos sujeitos foram descritas no protocolo de análise de acordo com a sua função, a qual é explicada pela classe e posição que ocupa dentro da oração (análise morfossintática ${ }^{1}$ ). Assim, tem-se as seguintes classes de palavras:

1- substantivo;

2- adjetivo;

3- pronome;

4- verbo;

5- advérbio;

6- artigo;

7- preposição;

8- conjunção;

9- numeral;

10- interjeição.

Ressalta-se que, neste item, também considerou-se as expressões orais vocálicas ou silabadas emitidas com sentido de palavra conforme a sua relação sintagmática ${ }^{2}$ na oração, ou seja, as palavras emitidas dentro de um determinado contexto, foram analisadas como pertencentes às classes as

\footnotetext{
${ }^{1}$ Pelo fato dos conceitos da Morfologia e da Sintaxe sobreporem-se em muitos aspectos de suas respectivas descrições científicas, os lingüistas da atualidade, desde Saussure, preferem não distinguilos como faziam os da gramática tradicional, considerando mais apropriado o termo Morfossintaxe (Carone, 1986).

${ }^{2}$ As relações sintagmáticas, segundo Cabral (1988:95), “decorrem do caráter linear da linguagem articulada”, visto que o signo lingüístico pode estabelecer relações de vários tipos dependendo da unidade que vem antes ou depois ou, ainda, de ambas simultaneamente, ao ser transmitido em uma sucessão de linha, no tempo. Cada unidade determina os padrões gramaticais dos morfemas (unidade mínima de significado) que a constitui, bem como a sua ordem e posição. Desse modo, fica estabelecida a estrutura nos diversos níveis (palavra, locução, oração, período) dentro da linguagem articulada.
} 
quais estavam representando. Por exemplo: se um dos sujeitos emitiu /a/ para "alô" em um determinado contexto e, em outro, ele emitiu /a/ para "água", então, enquanto no primeiro caso a palavra foi classificada como interjeição, no segundo, foi como substantivo.

Na síntese do item comunicação gestual do protocolo de avaliação de linguagem e cognição para o de análise, os gestos descritos (apontar, p.ex.) no primeiro foram classificados em duas categorias: dêiticos ou representativos. Esta classificação foi adaptada pela pesquisadora com base nos estudos de Franco e Wishart (1995) e de Iverson et al. (2003), com o objetivo de facilitar a sua compreensão e a análise.

Desse modo, tem-se os seguintes tipos de gestos, referentes a cada categoria:

тм Gestos dêiticos:

1. apontar: braço e dedo indicador estendidos;

2. mostrar: indicar um objeto perto do ouvinte tocando-o, segurando-o ou agarrando-o;

3. alcançar: braço estendido com a palma da mão para baixo em uma postura de querer pegar.

тм Gestos representativos:

1. de conteúdo semântico: apresenta características específicas de conteúdo semântico de acordo com o contexto (ex.: abanar as mãos para "muito quente"); 
2. convencionais: gestos culturalmente definidos (ex.: acenar a cabeça para designar "sim", acenar "tchau", etc.);

3. expressivos: expressões faciais de um modo geral (ex.: beijo, sorrisos, demonstrações de: tristeza, raiva, insatisfação, etc.).

Neste item, considerou-se somente os gestos que os sujeitos apresentaram de modo espontâneo, ou seja, que não foram acompanhados por qualquer emissão oral durante a comunicação.

$\mathrm{Na}$ análise dos dados obtidos com relação à linguagem oral simultânea à comunicação gestual e comunicação gestual simultânea à linguagem oral, considerou-se apenas as situações em que os sujeitos comunicaram-se utilizando a linguagem oral acompanhada de gestos, segundo a análise morfossintática e os tipos de gestos já classificados anteriormente, observando-se a ocorrência simultânea de ambas expressões no protocolo de análise . Por exemplo:

1 - o enquanto o sujeito diz "não", abana a cabeça convencionalmente;

2 - o sujeito diz "olha" enquanto mostra um objeto;

3 - durante uma atividade de jogo simbólico, enquanto o sujeito leva uma colher em miniatura à boca, diz "gostoso".

Nesta análise não foram consideradas as situações em que ocorreu apenas a emissão da linguagem oral e nem apenas os gestos. 
5. RESULTADOS 
Os dados obtidos serão apresentados a partir da análise qualitativa dos sujeitos de cada grupo (GP, GC1 e GC2), sendo seguida do estudo estatístico dos grupos entre si. Este tipo de opção deve-se a dois fatos: por tratar-se de uma pesquisa longitudinal, cuja amostra estudada é pequena, e pelo fato de que um dos objetivos propostos no estudo é acompanhar o processo evolutivo da comunicação gestual para a linguagem oral na criança com SD.

Para tanto, os resultados serão apresentados na seguinte ordem: linguagem oral (análise morfossintática), cujo critério de classificação das palavras emitidas baseou-se em conceitos lingüísticos; comunicação gestual (gestos e expressões faciais), segundo os critérios utilizados por Franco e Wishart (1995) e de Iverson et al. (2003); e, por último, linguagem oral e comunicação gestual simultâneas. Desse modo, será possível a realização das análises intra e inter-grupos.

Ressalta-se que os dados intra-grupos, referentes à linguagem oral (análise morfossintática), foram tratados, estatisticamente, por meio dos testes de Kruskal-Wallis (Conover, 1971), para as comparações entre todas as classes simultaneamente e pelo teste de Mann-Whitney (Conover, 1971) para a consideração do p-valor nas comparações gerais. Como estatisticamente esses dados não foram considerados significantes, optouse por apresentá-los em quadros e descrevê-los, o que possibilitou a análise qualitativa dos sujeitos. Tal escolha refere-se à importância do estudo nessa área voltada à população com SD em nosso país. 
Para a análise estatística intergrupal foram utilizados os testes não paramétricos de Mann-Whitney, Kruskal-Wallis, Friedman e Wilcoxon (Conover, 1971), complementados, descritivamente, pelo uso da técnica de intervalo de confiança (Spiegel, 1993; Fonseca e Martins, 1996). O intervalo de significância utilizado foi determinado em 10\%.

\subsection{Linguagem oral (análise morfossintática)}

Para a avaliação da linguagem oral, levou-se em consideração somente as situações em que os sujeitos produziram-na de modo isolado para designar objetos ou ações. Isto significa que, as palavras emitidas juntamente com qualquer tipo de gesto utilizado pela criança para facilitar a sua expressão, não foram analisadas neste item.

Desse modo, as expressões orais vocálicas ou silábicas emitidas com significado dentro de um determinado contexto foram analisadas como palavras pertencentes às classes as quais estavam representando. Por exemplo: se um dos sujeitos emitiu la/ para "alô" em um determinado contexto e, em outro, ele emitiu /a/ para "água", então, enquanto no primeiro caso a palavra foi classificada como interjeição, no segundo, foi como substantivo.

Além disso, para a apresentação dos dados relacionados a este item, as palavras que compuseram cada classe foram contadas somente uma vez quando emitidas durante a expressão oral na data da avaliação, para se ter uma base do conhecimento da criança em relação às classes de palavras e 
ao seu uso durante a sua comunicação. Por exemplo: /bô/ e /abô/, emitidos para expressar o vocábulo "acabou", do verbo "acabar", foram contados somente uma vez dentro de sua classe, mesmo que ela tivesse sido emitida outras vezes no decorrer da avaliação. Portanto, as formas diferentes que o sujeito utilizou para expressar oralmente um mesmo vocábulo não foram consideradas.

Assim, após a coleta de dados e sua organização nos protocolos de avaliação de linguagem e cognição (anexo 1), as palavras emitidas pelos sujeitos dos três grupos foram classificadas no protocolo de análise (anexos $2 a, 2 b$ e $2 c$ ) de acordo com as classes pertencentes, da seguinte forma:

Exemplo 1: S4 realiza, silenciosamente, uma atividade, quando T. interfere, estimulando-a a falar:

T.: Quem te deu essa blusa?

S4: Mãe.

T.: Foi sua mãe que te deu?

S4: É.

Conforme o exemplo, tem-se as seguintes classes de palavras: substantivo (Mãe) e verbo (é, do verbo ser).

Exemplo 2: Durante uma atividade que envolvia um brinquedo de encaixe, S7 tenta encaixar as peças por tentativa e erro, enquanto emite:

S7: Num cabu. (= não cabe) 
De acordo com o exemplo acima, observa-se as seguintes classes de palavras: advérbio (num = não) e verbo (cabu = cabe do verbo caber).

Exemplo 3: Em um determinado momento da avaliação, S12 vê o telefone e, antes de o pedir, diz:

S12: Eu quelo dá alô...

De acordo com o exemplo, tem-se as seguintes classes de palavras: pronome $(E u)$, verbo (quelo = quero do verbo querer; dá do verbo dar), interjeição (alô). Portanto, S12 apresentou três classes de palavras.

Seguem, abaixo, os resultados obtidos dos GP, GC1 e GC2, respectivamente. Para facilitar a sua compreensão, os dados dos sujeitos dos três grupos foram organizados em três quadros, um para cada grupo, sendo que, em cada um observa-se o número diferente de vocábulos emitidos pelos quatro sujeitos de cada um deles em cada uma das dez classes de palavras, durante as três avaliações realizadas.

Optou-se por juntar os dados obtidos dos sujeitos dos três grupos em seus respectivos quadros para uma melhor visualização e comparação entre os quatro sujeitos de cada um dos grupos e a sua evolução no decorrer das avaliações realizadas. 


\subsubsection{Linguagem oral (análise morfossintática) do GP}

Quadro 1: Observação do número de vocábulos diferentes por classe de palavras na linguagem oral dos quatro sujeitos do GP durante as três avaliações.

\begin{tabular}{|l|c|c|c|c|c|c|c|c|c|c|c|c|}
\cline { 2 - 15 } \multicolumn{1}{c|}{} & \multicolumn{4}{|c|}{$\mathbf{1}^{\mathbf{0}}$ avaliação } & \multicolumn{4}{c|}{$\mathbf{2}^{\mathbf{0}}$ avaliação } & \multicolumn{3}{c|}{$\mathbf{3}^{\mathbf{0}}$ avaliação } \\
\hline Classes de palavras & $\mathbf{S 1}$ & $\mathbf{S 2}$ & $\mathbf{S 3}$ & $\mathbf{S 4}$ & $\mathbf{S 1}$ & $\mathbf{S 2}$ & $\mathbf{S 3}$ & $\mathbf{S 4}$ & $\mathbf{S 1}$ & $\mathbf{S 2}$ & $\mathbf{S 3}$ & S4 \\
\hline substantivo & 5 & 0 & 0 & 0 & 2 & 0 & 0 & 4 & 7 & 0 & 1 & 3 \\
\hline adjetivo & 0 & 0 & 0 & 0 & 0 & 0 & 0 & 0 & 0 & 0 & 0 & 0 \\
\hline pronome & 3 & 0 & 0 & 0 & 0 & 0 & 0 & 2 & 0 & 0 & 0 & 0 \\
\hline verbo & 3 & 0 & 0 & 2 & 3 & 0 & 0 & 5 & 8 & 0 & 0 & 4 \\
\hline advérbio & 3 & 0 & 0 & 1 & 1 & 1 & 0 & 1 & 1 & 1 & 1 & 1 \\
\hline artigo & 0 & 0 & 0 & 0 & 1 & 0 & 0 & 0 & 2 & 0 & 0 & 0 \\
\hline preposição & 0 & 0 & 0 & 0 & 0 & 0 & 0 & 0 & 0 & 0 & 0 & 0 \\
\hline conjunção & 0 & 0 & 0 & 0 & 0 & 0 & 0 & 0 & 1 & 0 & 0 & 0 \\
\hline numeral & 0 & 0 & 0 & 0 & 0 & 0 & 0 & 0 & 0 & 0 & 0 & 0 \\
\hline interjeição & 1 & 0 & 0 & 0 & 0 & 0 & 0 & 1 & 1 & 0 & 0 & 1 \\
\hline $\begin{array}{l}\mathbf{n}^{\circ} \text { total de palavras } \\
\text { diferentes emitidas } \\
\text { por classe }\end{array}$ & $\mathbf{1 5}$ & $\mathbf{0}$ & $\mathbf{0}$ & $\mathbf{3}$ & $\mathbf{7}$ & $\mathbf{1}$ & $\mathbf{0}$ & $\mathbf{1 3}$ & $\mathbf{2 0}$ & $\mathbf{1}$ & $\mathbf{2}$ & $\mathbf{9}$ \\
\hline $\begin{array}{l}\mathbf{n}^{\circ} \text { total de classes } \\
\text { de palavras }\end{array}$ & $\mathbf{5}$ & $\mathbf{0}$ & $\mathbf{0}$ & $\mathbf{2}$ & $\mathbf{4}$ & $\mathbf{1}$ & $\mathbf{0}$ & $\mathbf{5}$ & $\mathbf{6}$ & $\mathbf{1}$ & $\mathbf{2}$ & $\mathbf{4}$ \\
\hline
\end{tabular}

Observa-se no quadro acima que, durante a primeira avaliação, somente dois sujeitos apresentaram a emissão de classes de palavras em seus respectivos repertórios lingüísticos, os quais foram S1 e S4, sendo que o primeiro apresentou um número maior do que o segundo.

As classes de palavras presentes durante esta avaliação pelos sujeitos são: substantivo, pronome, verbo, advérbio e interjeição. Já as classes adjetivo, artigo, preposição, conjunção e numeral não foram emitidas por nenhum deles. Entre elas, apenas as classes verbo e advérbio foram comuns às emissões orais de S1 e S4.

Durante a segunda avaliação, observa-se que apenas S3 não apresentou a emissão oral de nenhuma classe de palavras, ao passo que S4 
foi o que emitiu um número maior delas, sendo seguido de S1 e, por último, S2. Em relação à primeira avaliação, enquanto S2 e S4 apresentaram evolução na ocorrência do número de classes por sujeito, S1 diminuiu uma e S3 manteve-se com a mesma quantidade.

A classe advérbio esteve presente no repertório lingüístico dos três sujeitos, sendo que todos apresentaram o mesmo número de palavras nesta classe. As classes não emitidas oralmente por nenhum sujeito foram: adjetivo, preposição, conjunção e numeral.

As classes presentes nesta avaliação pelos sujeitos, no total, foram: substantivo, pronome, verbo, advérbio, artigo e interjeição. As classes substantivo e verbo foram emitidas somente por S1 e S2. Já as classes pronome e interjeição só foram emitidas apenas por S4 e a classe artigo por S1.

Na terceira avaliação, todos os sujeitos apresentaram emissão oral de classes de palavras, sendo que S1 foi o que esteve mais à frente, sendo seguido de S4, S3 e, por último, S2. Em relação à avaliação anterior, S1 e S3 produziram um número maior de classes de palavras, enquanto que S2 manteve-se e S4 diminuiu uma.

A única classe emitida oralmente pelos quatro sujeitos foi advérbio, a qual ocorreu com o mesmo número em todos eles. A classe substantivo foi emitida por três sujeitos (S1, S3 e S4), verbo e interjeição por dois deles (S1 e S4) e as classes artigo e conjunção por apenas um sujeito (S1). Por outro lado, as classes adjetivo, pronome, preposição e numeral não foram emitidas por nenhum dos sujeitos. 


\subsubsection{Linguagem oral (análise morfossintática) do GC1}

Quadro 2: Observação do número de vocábulos diferentes por classe de palavras na linguagem oral dos quatro sujeitos do GC1 durante as três avaliações.

\begin{tabular}{|c|c|c|c|c|c|c|c|c|c|c|c|c|}
\hline & \multicolumn{4}{|c|}{$1^{\circ}$ avaliação } & \multicolumn{4}{|c|}{$2^{\circ}$ avaliação } & \multicolumn{4}{|c|}{$3^{\circ}$ avaliação } \\
\hline Classes de palavras & S5 & S6 & S7 & S8 & S5 & S6 & S7 & S8 & S5 & S6 & S7 & S8 \\
\hline substantivo & 0 & 0 & 0 & 0 & 0 & 0 & 0 & 4 & 0 & 1 & 1 & 7 \\
\hline adjetivo & 0 & 0 & 0 & 0 & 0 & 0 & 0 & 2 & 0 & 0 & 0 & 0 \\
\hline pronome & 0 & 0 & 0 & 0 & 0 & 0 & 0 & 1 & 0 & 0 & 0 & 0 \\
\hline verbo & 0 & 0 & 0 & 2 & 0 & 0 & 1 & 5 & 1 & 1 & 0 & 5 \\
\hline advérbio & 0 & 0 & 0 & 0 & 0 & 0 & 1 & 3 & 0 & 1 & 0 & 3 \\
\hline artigo & 0 & 0 & 0 & 1 & 0 & 0 & 0 & 1 & 0 & 1 & 0 & 0 \\
\hline preposição & 0 & 0 & 0 & 0 & 0 & 0 & 0 & 0 & 0 & 0 & 0 & 1 \\
\hline conjunção & 0 & 0 & 0 & 0 & 0 & 0 & 0 & 0 & 0 & 0 & 0 & 0 \\
\hline numeral & 0 & 0 & 0 & 0 & 0 & 0 & 0 & 0 & 0 & 0 & 0 & 0 \\
\hline interjeição & 0 & 0 & 0 & 0 & 0 & 0 & 0 & 0 & 0 & 0 & 0 & 2 \\
\hline $\begin{array}{l}n^{0} \text { total de palavras } \\
\text { diferentes emitidas } \\
\text { por classe }\end{array}$ & 0 & 0 & 0 & 3 & 0 & 0 & 2 & 16 & 1 & 4 & 1 & 18 \\
\hline $\begin{array}{l}n^{\circ} \text { total de classes } \\
\text { de palavras }\end{array}$ & 0 & 0 & 0 & 2 & 0 & 0 & 2 & 6 & 1 & 4 & 1 & 5 \\
\hline
\end{tabular}

Durante a primeira avaliação, observa-se no Quadro 2 que S8 foi o único sujeito que apresentou emissão de classes de palavras, sendo que os demais não apresentaram. Sendo assim, somente as classes verbo e artigo foram emitidas oralmente nesta avaliação.

$\mathrm{Na}$ segunda avaliação, observa-se que apenas dois sujeitos apresentaram emissões de classes de palavras, os quais foram S7 e S8. Este último apresentou um número maior delas do que o primeiro.

Somente as classes verbo e advérbio foram comuns na emissão oral de ambos os sujeitos, sendo que S8 foi o que apresentou um número maior de palavras em ambas as classes do que $\mathrm{S} 7$. 
As classes presentes na emissão oral dos sujeitos nesta avaliação foram: substantivo, adjetivo, pronome, verbo, advérbio e artigo. Por outro lado, as classes que não foram emitidas oralmente por nenhum deles foram: preposição, conjunção, numeral e interjeição.

Em relação à avaliação anterior, observa-se que, enquanto S7 e S8 apresentaram evolução quanto ao número de classes de palavras presentes em seus respectivos repertórios lingüísticos, S5 e S6 mantiveram-no.

$\mathrm{Na}$ terceira avaliação, nota-se que todos os sujeitos apresentaram emissões orais. S8 foi o sujeito que mais apresentou classes diferentes em seu repertório lingüístico, sendo seguido por S6 e, por último, S5 e S7 com o mesmo número. De acordo com a avaliação anterior, S5 e S6 aumentaram a quantidade de classes, enquanto que S7 e S8 diminuíram uma. Não houve classes de palavras comuns presentes na emissão oral de todos os sujeitos.

As classes substantivo e verbo, por sua vez, foram emitidas oralmente por três sujeitos (a primeira por S6, S7 e S8, enquanto que a segunda por $\mathrm{S} 5, \mathrm{~S} 6$ e S8), a classe advérbio por dois sujeitos (S6 e S8) e as classes preposição e interjeição por um sujeito (S8). Por outro lado, as classes adjetivo, pronome, conjunção e numeral não foram emitidas por nenhum dos sujeitos. 


\subsubsection{Linguagem oral (análise morfossintática) do GC2}

Quadro 3: Observação do número de vocábulos diferentes por classe de palavras na linguagem oral dos quatro sujeitos do GC2 durante as três avaliações.

\begin{tabular}{|c|c|c|c|c|c|c|c|c|c|c|c|c|}
\hline & \multicolumn{4}{|c|}{$1^{\circ}$ avaliação } & \multicolumn{4}{|c|}{$2^{\circ}$ avaliação } & \multicolumn{4}{|c|}{$3^{\circ}$ avaliação } \\
\hline Classes de palavras & S9 & S10 & S11 & S12 & S9 & S10 & S11 & S12 & S9 & S10 & S11 & S12 \\
\hline substantivo & 0 & $\overline{0}$ & 2 & 4 & 10 & 2 & 12 & 4 & 14 & 3 & 6 & 8 \\
\hline adjetivo & 0 & 0 & 0 & 0 & 1 & 0 & 0 & 3 & 2 & 1 & 1 & 0 \\
\hline pronome & 0 & 0 & 0 & 0 & 1 & 0 & 1 & 2 & 4 & 3 & 2 & 8 \\
\hline verbo & 0 & 0 & 0 & 3 & 4 & 1 & 4 & 6 & 8 & 6 & 7 & 13 \\
\hline advérbio & 0 & 0 & 0 & 0 & 4 & 0 & 3 & 2 & 5 & 2 & 1 & 5 \\
\hline artigo & 0 & 0 & 0 & 0 & 2 & 1 & 1 & 1 & 2 & 1 & 1 & 2 \\
\hline preposição & 0 & 0 & 0 & 0 & 0 & 0 & 0 & 0 & 2 & 0 & 1 & 4 \\
\hline conjunção & 0 & 0 & 0 & 0 & 0 & 0 & 1 & 0 & 1 & 1 & 1 & 0 \\
\hline numeral & 0 & 0 & 0 & 0 & 0 & 0 & 0 & 0 & 1 & 0 & 1 & 0 \\
\hline interjeição & 0 & 0 & 0 & 0 & 2 & 0 & 1 & 2 & 1 & 1 & 1 & 1 \\
\hline $\begin{array}{l}n^{0} \text { total de palavras } \\
\text { diferentes emitidas } \\
\text { por classe }\end{array}$ & 0 & 0 & 2 & 7 & 24 & 4 & 23 & 20 & 40 & 18 & 22 & 41 \\
\hline $\begin{array}{l}n^{\circ} \text { total de classes } \\
\text { de palavras }\end{array}$ & 0 & 0 & 1 & 2 & 7 & 3 & 7 & 7 & 10 & 8 & 10 & 7 \\
\hline
\end{tabular}

Observa-se no Quadro 3 que, durante a primeira avaliação, somente S11 e S12 apresentaram emissão oral, sendo que S12 teve uma quantidade maior de classes de palavras do que o outro. O número total de classes de palavras observadas entre estes sujeitos foram duas: substantivo e verbo, sendo que substantivo foi a classe comum de ocorrência aos dois.

Durante a segunda avaliação, observa-se que todos os sujeitos apresentaram emissão oral, sendo que S9, S11 e S12 apresentaram um maior número de classes de palavras e com igual quantidade. Com relação à avaliação anterior, todos os sujeitos apresentaram evolução quanto ao número de classes de palavras. 
As classes de palavras de ocorrência comum aos quatro sujeitos foram: substantivo, verbo e artigo. Por outro lado, as classes que não foram produzidas oralmente por nenhum dos sujeitos foram: preposição e numeral. Observa-se, ainda, que as classes pronome, advérbio e interjeição foram emitidas apenas por S9, S11 e S12, enquanto que adjetivo somente por S9 e S12 e conjunção por S11. Ao todo, os sujeitos apresentaram oito classes de palavras

$\mathrm{Na}$ terceira avaliação, nota-se que S9 e S11 foram os únicos que apresentaram todas as classes de palavras em seus repertórios lingüísticos, sendo seguidos por S10 e S12, respectivamente, com relação ao maior número de emissão oral de classes.

Nesta avaliação, as classes de palavras comuns de ocorrência aos quatro sujeito foram: substantivo, pronome, verbo, advérbio, artigo e interjeição. Já as classes adjetivo, preposição e conjunção somente foram emitidas oralmente por três sujeitos, enquanto que numeral, somente por dois sujeitos.

\subsubsection{Análise da linguagem oral (análise morfossintática) dos GP, GC1 e GC2}

Neste item será mostrada a análise morfossintática referente aos resultados da linguagem oral dos três grupos, de acordo com o estudo estatístico realizado, na seguinte ordem: número de vocábulos diferentes e, a seguir, conforme o número total de classes de palavras. 
Figura 1: Número de vocábulos diferentes presentes em GP, GC1 e GC2

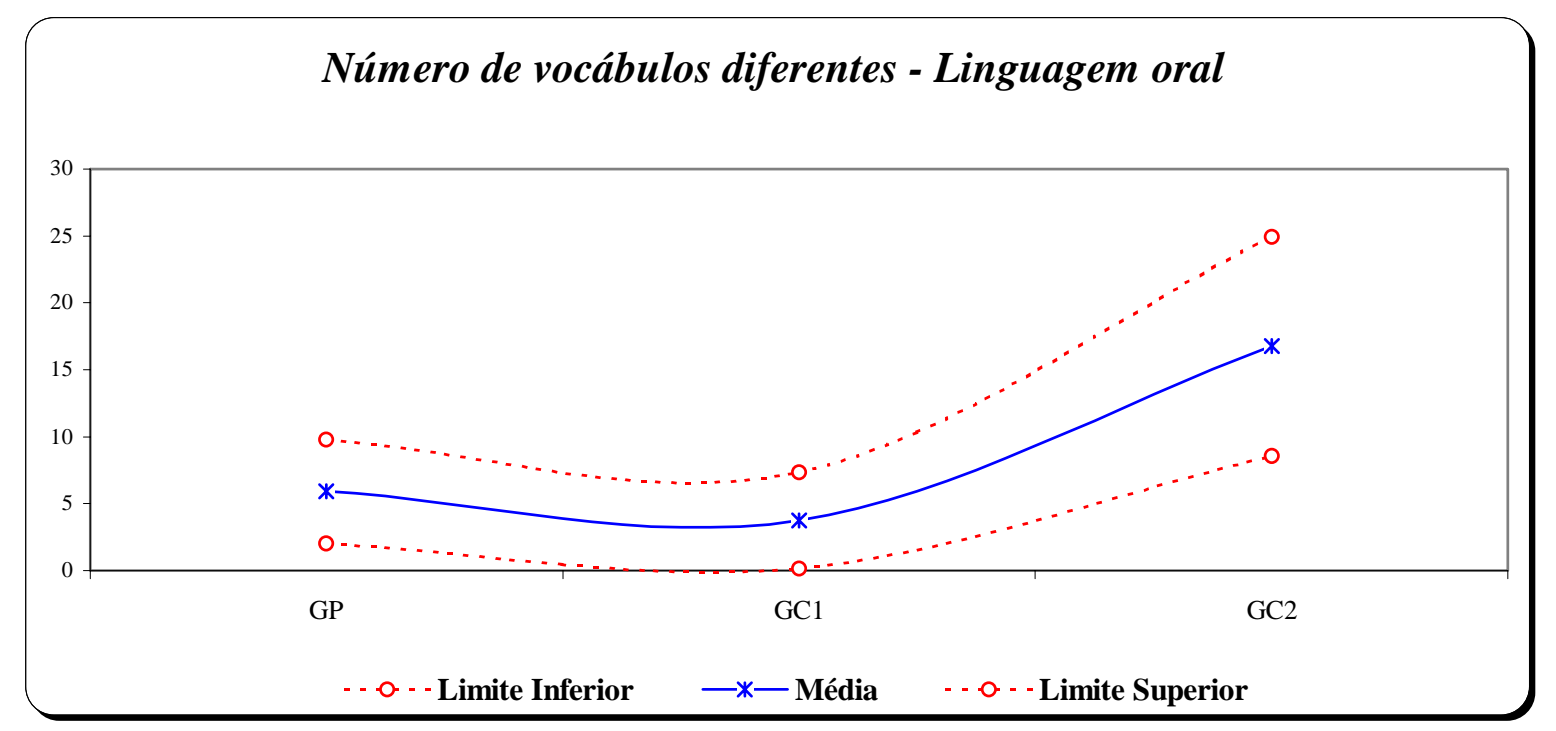

\begin{tabular}{|l|c|c|c|}
\hline \multicolumn{1}{|c|}{ Ling. Oral } & $G P$ & $G C 1$ & $G C 2$ \\
\hline Limite Inferior & 2,03 & 0,16 & 8,58 \\
\hline Média & 5,92 & 3,75 & 16,75 \\
\hline Limite Superior & 9,8 & 7,34 & 24,92 \\
\hline
\end{tabular}

$p$-valor $=0,024$

Observa-se que existe diferença média estatisticamente significante entre os grupos, segundo o p-valor obtido dos três grupos. Sendo assim, para se especificar onde está localizada esta diferença, considerou-se necessária a comparação entre todos os grupos dois a dois, como se observa na Tabela 1, na qual estão somente os p-valores dessas comparações. 
Tabela 1: Observação da comparação dos p-valores do número de vocábulos diferentes dos três grupos

\begin{tabular}{ccc}
\hline $\begin{array}{c}\text { Ling. } \\
\text { Oral }\end{array}$ & GP & GC1 \\
\hline GC1 & 0,361 & \\
\hline GC2 & $0,052^{*}$ & $0,011^{*}$ \\
\hline p-valores
\end{tabular}

Verifica-se que o GC2 é considerado estatisticamente diferente dos demais grupos que, por sua vez, são iguais entre si.

Figura 2: Número total de classes de palavras presentes em GP, GC1 e GC

Número total de classes de palavras - Linguagem oral

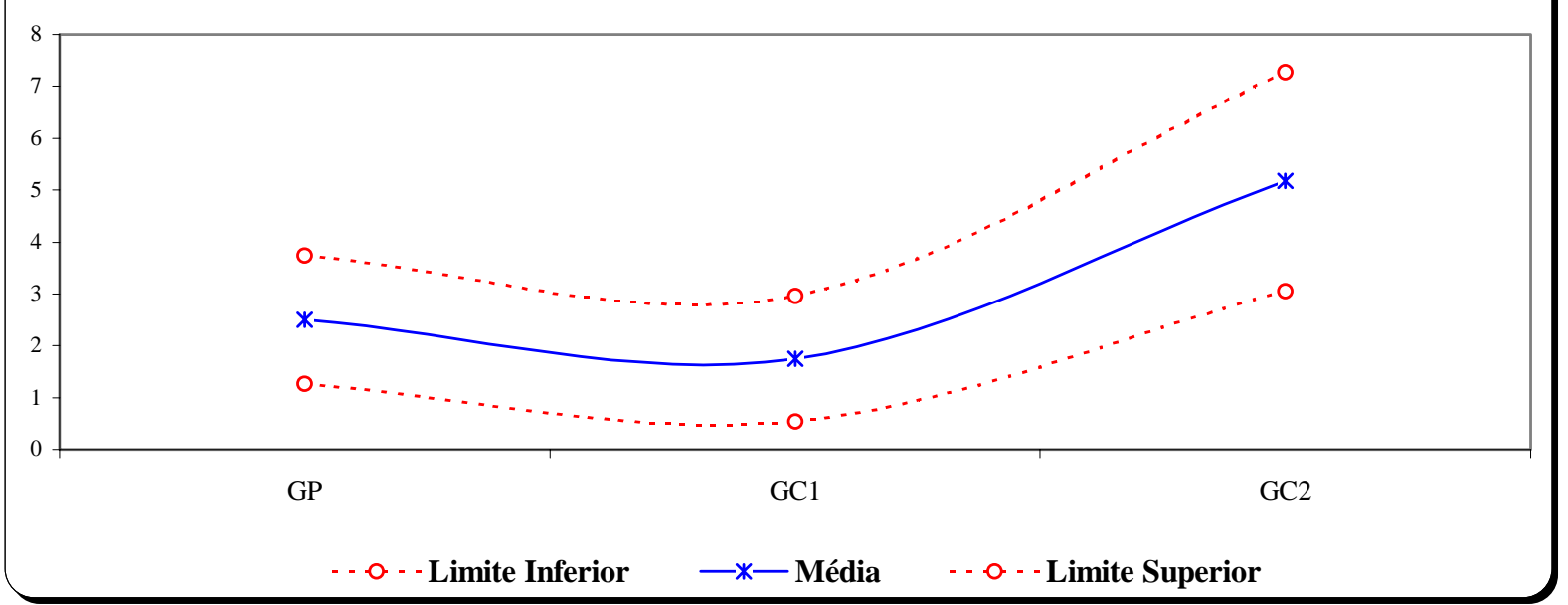

\begin{tabular}{|l|c|c|c|}
\hline Ling. Oral - Classe & GP & GC1 & GC2 \\
\hline Limite Inferior & 1,26 & 0,54 & 3,05 \\
\hline Média & 2,5 & 1,75 & 5,17 \\
\hline Limite Superior & 3,74 & 2,96 & 7,28 \\
\hline
\end{tabular}

$p$-valor $=0,037$ 
De acordo com o p-valor obtido da análise dos três grupos, verifica-se que ocorreu diferença média estatisticamente significante entre os grupos. Portanto, para se especificar esta diferença, foi necessário comparar os $p$ valores de todos os grupos dois a dois, como se observa na Tabela 2.

Tabela 2: Observação da comparação dos $p$-valores do número total de classes de palavras dos três grupos

\begin{tabular}{ccc}
\hline $\begin{array}{c}\text { Ling. Oral - } \\
\text { Classe }\end{array}$ & GP & GC1 \\
\hline GC1 & 0,374 & \\
\hline GC2 & $0,062^{*}$ & $0,019^{*}$ \\
\hline p-valores & &
\end{tabular}

Conclui-se, então, que o GC2 novamente é considerado estatisticamente diferente dos demais grupos que, por sua vez, são iguais entre si.

\subsection{Comunicação gestual}

Para a classificação dos dados obtidos neste item, os critérios adotados foram adaptados pela pesquisadora com base nos estudos de Franco e Wishart (1995) e de Iverson et al. (2003), com o objetivo de facilitar a sua compreensão e a análise. Entretanto, somente foram considerados os gestos que os sujeitos expressaram de modo espontâneo (isolado), ou seja, que não foram acompanhados por qualquer emissão oral durante a sua comunicação.

Com o objetivo de estudar a variação de gestos demonstrados pelos sujeitos durante a comunicação, ressalta-se que os dados obtidos a cada 
avaliação foram considerados de modo qualitativo e não quantitativo. Em outras palavras, durante as avaliações, não foi considerado o número de vezes que cada gesto era apresentado por cada sujeito da pesquisa, e sim, quantos tipos diferentes de gestos dentro de suas respectivas categorias os sujeitos apresentaram nas suas expressões comunicativas.

Seguem abaixo as avaliações realizadas a cada semestre por cada sujeito de cada grupo. Tal qual na análise da linguagem oral (análise morfossintática), após a coleta de dados e sua organização nos protocolos de avaliação de linguagem e cognição (anexo 1), os gestos apresentados pelos sujeitos dos três grupos foram classificados nos protocolos de análise (anexo 2a, 2b e 2c). Optou-se por juntar os dados obtidos no mesmo quadro para facilitar a visualização e a comparação entre os quatro sujeitos de cada grupo e a evolução de cada um deles no decorrer das avaliações realizadas.

\subsubsection{Comunicação gestual do GP}

Quadro 4: Tipos diferentes de ocorrências na comunicação gestual dos quatro sujeitos do GP durante as três avaliações.

\begin{tabular}{|c|c|c|c|c|c|c|c|c|c|c|c|c|}
\hline \multirow[b]{2}{*}{ Comunicação Gestual } & \multicolumn{4}{|c|}{$1^{\text {a }}$ avaliação } & \multicolumn{4}{|c|}{$2^{\mathrm{a}}$ avaliação } & \multicolumn{4}{|c|}{$3^{\mathrm{a}}$ avaliação } \\
\hline & S1 & S2 & S3 & S4 & S1 & S2 & S3 & S4 & S1 & S2 & S3 & S4 \\
\hline Gestos dêiticos: & & & & & & & & & & & & \\
\hline apontar & 0 & 0 & 0 & 1 & 0 & 0 & 0 & 0 & 0 & 0 & 0 & 0 \\
\hline mostrar & 0 & 0 & 0 & 0 & 0 & 0 & 0 & 2 & 0 & 0 & 0 & 0 \\
\hline alcançar & 0 & 0 & 0 & 0 & 0 & 0 & 0 & 0 & 0 & 0 & 0 & 0 \\
\hline Gestos representativos: & & & & & & & & & & & & \\
\hline de conteúdo semântico: & 10 & 13 & 1 & 4 & 0 & 19 & 4 & 7 & 10 & 11 & 6 & 4 \\
\hline convencionais & 1 & 1 & 0 & 0 & 0 & 1 & 1 & 0 & 1 & 2 & 1 & 1 \\
\hline expressivos & 0 & 3 & 1 & 0 & 0 & 4 & 1 & 1 & 0 & 3 & 2 & 3 \\
\hline$n^{\circ}$ total de gestos & 11 & 17 & 2 & 5 & 0 & 24 & 6 & 10 & 11 & 16 & 9 & 8 \\
\hline $\begin{array}{l}n^{\circ} \text { total de tipos } \\
\text { diferentes de gestos }\end{array}$ & 2 & 3 & 2 & 2 & 0 & 3 & 3 & 3 & 2 & 3 & 3 & 3 \\
\hline
\end{tabular}


Durante a primeira avaliação, observa-se no quadro acima que, com relação à categoria de gestos dêiticos, somente S4 apresentou um dos tipos (apontar), sendo que os outros não apresentaram nenhum.

Quanto à categoria dos gestos representativos, S2 foi o único que apresentou todos os tipos. Os gestos de conteúdo semântico foram apresentados por todos os sujeitos, sendo S2 o que apresentou um maior número deles e, a seguir, S1, S4 e S3 respectivamente. Os gestos convencionais foram apresentados somente por S1 e S2 (ambos com número igual de gestos), ao passo que, os expressivos somente por S2 e S3 (o primeiro sujeito apresentou um número maior).

Com relação ao número total de gestos apresentados, S2 foi o que apresentou um maior número, sendo seguido por S1, S4 e S3, respectivamente. Quanto ao número total de tipos diferentes de gestos, S2 também foi o que apresentou o maior número, ao passo que os demais apresentaram a mesma quantidade.

Na segunda avaliação, somente S4 apresentou gestos dêiticos (gesto de mostrar). Quanto aos gestos representativos, S2 e S3 apresentaram todos os tipos, ao passo que S4 apresentou apenas dois deles.

Os gestos de conteúdo semântico e os expressivos foram apresentados somente por S2, S3 e S4, sendo que S2 apresentou um número maior dos primeiros e, a seguir, S4 e S3, respectivamente. Os gestos expressivos, por sua vez, foram apresentados em maior número por $\mathrm{S} 2$, sendo seguidos por S3 e S4, os quais apresentaram a mesma 
quantidade. Já os gestos convencionais somente foram apresentados, com a mesma quantidade, por S2 e S3.

S1 não apresentou nenhuma das categorias de gestos.

Com relação ao número total de gestos apresentados, S2 foi o que apresentou um maior número, e a seguir, S4 e S3, respectivamente. Quanto ao número total de tipos diferentes de gestos, os três sujeitos (S2, S3 e S4) apresentaram a mesma quantidade.

Comparando os dados da primeira avaliação com os da segunda, observa-se que S1 diminuiu a variedade do número de tipos diferentes de gestos (de dois tipos para zero), enquanto que S2 manteve-se e, S3 e S4 aumentaram (de dois para três, cada um). Quanto ao número total de gestos, somente S1 diminuiu, ao passo que os outros três aumentaram.

$\mathrm{Na}$ terceira avaliação, observa-se que nenhum dos sujeitos apresentou gestos dêiticos. Por outro lado, todos eles apresentaram gestos representativos, de modo que os de conteúdo semântico e os convencionais foram apresentados por todos os sujeitos. Com relação ao primeiro tipo, S2 foi o que apresentou um maior número deles, sendo seguido por S1, S3 e S4, respectivamente. Os gestos convencionais, por sua vez, foram apresentados em maior número por S2, enquanto que os outros três sujeitos apresentaram a mesma quantidade. Os gestos expressivos somente foram apresentados por S2, S4 (ambos com mesma quantidade) e S3, respectivamente.

Com relação ao número total de gestos apresentados, S2 foi o que apresentou um maior número, e a seguir, S1, S3 e S4, respectivamente. 
Quanto ao número total de tipos diferentes de gestos, observa-se que S2, S3 e S4 apresentaram a mesma quantidade e, a seguir, S1.

Ao se comparar os dados desta avaliação com os da segunda, verifica-se que S1 aumentou o número de tipos diferentes de gestos (de zero para dois), enquanto que os demais sujeitos mantiveram-se. Quanto ao número total de gestos, somente S1 e S3 aumentaram, enquanto que S2 e S4 diminuíram.

\subsubsection{Comunicação gestual do GC1}

Quadro 5: Tipos diferentes de ocorrências na comunicação gestual dos quatro sujeitos do GC1 durante as três avaliações.

\begin{tabular}{|c|c|c|c|c|c|c|c|c|c|c|c|c|}
\hline & \multicolumn{4}{|c|}{$1^{\text {a }}$ avaliação } & \multicolumn{4}{|c|}{$2^{\mathrm{a}}$ avaliação } & \multicolumn{4}{|c|}{$3^{\text {a }}$ avaliação } \\
\hline Comunicação Gestual & S5 & 56 & S7 & S8 & S5 & $\overline{S 6}$ & S7 & 58 & $\mathrm{S5}$ & 56 & S7 & S8 \\
\hline Gestos dêiticos: & & & & & & & & & & & & \\
\hline apontar & 0 & 0 & 0 & 0 & 0 & 1 & 0 & 0 & 0 & 1 & 0 & 1 \\
\hline mostrar & 0 & 0 & 0 & 1 & 0 & 1 & 0 & 0 & 0 & 1 & 0 & 2 \\
\hline alcançar & 0 & 0 & 0 & 0 & 0 & 2 & 0 & 0 & 0 & 0 & 0 & 1 \\
\hline Gestos representativos: & & & & & & & & & & & & \\
\hline de conteúdo semântico: & 2 & 13 & 9 & 15 & 4 & 5 & 8 & 10 & 5 & 9 & 7 & 10 \\
\hline convencionais & 0 & 0 & 0 & 0 & 0 & 0 & 2 & 0 & 0 & 0 & 1 & 1 \\
\hline expressivos & 0 & 1 & 0 & 3 & 0 & 0 & 5 & 2 & 3 & 0 & 1 & 1 \\
\hline$n^{\circ}$ total de gestos & 2 & 14 & 9 & 19 & 4 & 9 & 15 & 12 & 8 & 13 & 9 & 16 \\
\hline $\begin{array}{l}n^{\circ} \text { total de tipos } \\
\text { diferentes de gestos }\end{array}$ & 1 & 2 & 1 & 3 & 1 & 4 & 3 & 2 & 2 & 3 & 3 & 6 \\
\hline
\end{tabular}

Durante a primeira avaliação, observa-se no quadro acima que S8 foi o único sujeito a apresentar gestos dêiticos (mostrar).

Por outro lado, todos os sujeitos apresentaram gestos representativos. Dentre os gestos desta categoria, os convencionais não foram apresentados por nenhum sujeito, enquanto que os de conteúdo 
semântico os foram por todos eles, sendo que S8 apresentou o maior número, e em seguida, S6, S7 e S5, respectivamente. Os gestos expressivos somente foram apresentados por S6 e S8, de modo que este último teve o maior número.

De acordo com os dados observados no Quadro 5, S8 foi o sujeito que apresentou o maior número de gestos diferentes com relação à totalidade de gestos por sujeito, sendo seguido por S6, S7 e S5, respectivamente. Quanto ao número total de tipos diferentes de gestos, S8 foi o que apresentou o maior número, sendo seguido por S6 e, por último, S5 e S7 (ambos com a mesma quantidade).

Na segunda avaliação, S6 foi o único sujeito a apresentar a categoria de gestos dêiticos (apontar, mostrar e alcançar), enquanto que todos os outros apresentaram a de gestos representativos. Nestes, S7 foi o único a apresentar todos os tipos diferentes.

Os gestos representativos de conteúdo semântico foram apresentados em maior número por S8, S7, S6 e S5, respectivamente. Os gestos expressivos somente foram apresentados por S7 e S8, sendo que o primeiro apresentou o número maior deles. E, os gestos convencionais foram apresentados apenas por S7.

Em relação à variedade dos tipos diferentes de gestos, S6 foi o sujeito que apresentou o número maior (quatro) e, a seguir, S7 (três), S8 (dois) e S5 (um), respectivamente. Comparando-se os dados obtidos nesta avaliação com os da primeira, no que se refere ao número total de tipos diferentes de gestos, observa-se que S6 e S7 aumentaram, S8 diminuiu e S5 manteve-se. 
Já com relação ao número total de gestos, S5 e S7 aumentaram o seu número enquanto que S6 e S8 diminuíram-no.

$\mathrm{Na}$ terceira avaliação, observa-se que apenas dois sujeitos apresentaram a categoria de gestos dêiticos: S6 e S8, sendo que este último apresentou os três tipos, enquanto que S6 apresentou apenas dois (apontar e mostrar). Além disso, S8 apresentou um número maior de gestos no tipo mostrar em relação aos outros dois tipos, os quais teve o mesmo número. S6 também apresentou o mesmo número de gestos nos dois tipos.

Todos os sujeitos apresentaram a categoria de gestos representativos, sendo que S7 e S8 apresentaram os três tipos, enquanto que S5 apresentou dois (gestos de conteúdo semântico e expressivos) e S6 apenas um (gestos de conteúdo semântico).

Os gestos representativos de conteúdo semântico foram apresentados em maior número por S8, S6, S7 e S5, respectivamente. Os convencionais por S7 e S8, sendo que ambos apresentaram o mesmo número. E os expressivos por S5, S7 e S8 (estes últimos com o mesmo número de gestos).

Segundo o número total de gestos, os sujeitos que mais os apresentaram foram S8, S6, S7 e S5, respectivamente. Com relação ao número total de tipos diferentes de gestos, S8 apresentou o maior número e, a seguir, S6 e S7 (estes com a mesma quantidade) e S5, respectivamente.

Ao se comparar os dados obtidos nesta avaliação com os da segunda, em relação à variedade de tipos diferentes de gestos, observa-se que S5 e S8 aumentaram, S7 manteve-se e S6 diminuiu. Já com relação ao 
número total de gestos, apenas S7 diminuiu, enquanto que os demais aumentaram-no.

\subsubsection{Comunicação gestual do GC2}

Quadro 6: Tipos diferentes de ocorrências na comunicação gestual dos quatro sujeitos do GC2 durante as três avaliações.

\begin{tabular}{|c|c|c|c|c|c|c|c|c|c|c|c|c|}
\hline & \multicolumn{4}{|c|}{$1^{\text {a }}$ avaliação } & \multicolumn{4}{|c|}{$2^{\mathrm{a}}$ avaliação } & \multicolumn{4}{|c|}{$3^{\mathrm{a}}$ avaliação } \\
\hline Comunicação Gestual & S9 & S10 & S11 & S12 & S9 & $\mathbf{S 1 0}$ & S11 & S12 & S9 & S10 & S11 & $\mathbf{S 1 2}$ \\
\hline Gestos dêiticos: & & & & & & & & & & & & \\
\hline apontar & 0 & 1 & 1 & 0 & 1 & 0 & 1 & 0 & 0 & 0 & 3 & 0 \\
\hline mostrar & 0 & 0 & 0 & 0 & 0 & 1 & 1 & 0 & 0 & 0 & 3 & 0 \\
\hline alcançar & 0 & 0 & 0 & 0 & 2 & 1 & 0 & 1 & 0 & 0 & 1 & 0 \\
\hline Gestos representativos: & & & & & & & & & & & & \\
\hline de conteúdo semântico: & 2 & 4 & 2 & 16 & 9 & 10 & 7 & 7 & 5 & 4 & 1 & 6 \\
\hline convencionais & 0 & 0 & 1 & 0 & 1 & 2 & 1 & 2 & 0 & 0 & 0 & 1 \\
\hline expressivos & 0 & 1 & 0 & 0 & 2 & 2 & 0 & 1 & 0 & 1 & 0 & 1 \\
\hline$n^{\circ}$ total de gestos & 2 & 6 & 4 & 16 & 15 & 16 & 10 & 11 & 5 & 5 & 8 & 8 \\
\hline $\begin{array}{l}n^{\circ} \text { total de tipos } \\
\text { diferentes de gestos }\end{array}$ & 1 & 3 & 3 & 1 & 5 & 5 & 4 & 4 & 1 & 2 & 4 & 3 \\
\hline
\end{tabular}

Na primeira avaliação observa-se, no quadro acima, que somente S10 e S11 apresentaram a categoria de gestos dêiticos (apontar) e em quantidade igual. Por outro lado, todos os sujeitos apresentaram a categoria de gestos representativos, sendo que os de conteúdo semântico foram apresentados por todos, enquanto que os convencionais apenas por S11 e os expressivos por S10.

O número maior de tipos diferentes de gestos representativos de conteúdo semântico foram apresentados por S12, S10, S9 e S11 (estes dois últimos com a mesma quantidade), respectivamente. 
Com relação ao número total de gestos, observa-se que S12 apresentou o maior número e, a seguir, S10, S11 e \$9, respectivamente. Quanto ao número total de tipos diferentes de gestos, S10 e S11 apresentaram o maior número e em igual quantidade (três), sendo seguidos por S9 e S12, também com a mesma quantidade (um).

$\mathrm{Na}$ segunda avaliação, observa-se que todos os sujeitos apresentaram tanto gestos dêiticos quanto representativos, diferenciando-se apenas nos tipos apresentados.

Com relação aos gestos dêiticos, o de alcançar foi apresentado por três sujeitos: S9, S10 e S12, sendo que S9 o apresentou em maior número, enquanto que S10 e S12 apresentaram-no na mesma quantidade. O gesto de apontar foi apresentado apenas por S9 e S11 (em quantidade igual) e o de mostrar somente por S10 e S11 (em quantidade igual).

No que se refere aos gestos representativos, os de conteúdo semântico e os convencionais foram apresentados por todos os sujeitos, sendo que o primeiro tipo foi apresentado em maior número por S10 e, a seguir, S9, S11 e S12 (estes dois com o mesmo número), respectivamente. Já os gestos convencionais foram apresentados em maior número por S10 e S12 (ambos com a mesma quantidade) e, depois, por S9 e S11 (número igual). Os expressivos, por sua vez, somente não foram apresentados por S11, enquanto que S9 e S10 apresentaram o maior número (dois) deste tipo de gesto, e, a seguir, S12 (um).

Nesta avaliação, observa-se que S9 e S10 apresentaram o número maior de tipos diferentes de gestos (cinco), enquanto que S11 e S12 
apresentaram um número menor (quatro). Quanto ao número total de gestos, S10 esteve à frente dos outros sujeitos, sendo seguido por S9, S12 e S11, respectivamente. Já, com relação ao número total de tipos diferentes de gestos, S9 e S10 estiveram à frente dos outros dois, com número igual (cinco), sendo que S11 e S12 também apresentaram a mesma quantidade (quatro). Ao se comparar estes dados com os da primeira avaliação, observa-se, quanto à variedade de tipos diferentes de gestos, que todos os sujeitos aumentaram o número. E, com relação à quantidade total de gestos, S9, S10 e S11 aumentaram-na, enquanto que S12 a diminuiu.

$\mathrm{Na}$ terceira avaliação, observa-se que somente S11 apresentou a categoria de gestos dêiticos (todos os tipos), ao passo que a de representativos foram apresentados por todos, variando apenas nos tipos.

Desse modo, com relação aos gestos dêiticos, S11 apresentou, em ordem decrescente de tipos diferentes os seguintes gestos: apontar, mostrar (ambos na mesma quantidade) e alcançar.

Quanto à categoria de gestos representativos, os de conteúdo semântico foram apresentados por todos os sujeitos, sendo que, S12 foi o sujeito que teve o número maior de tipos diferentes deles e, a seguir, S9, S10 e S11, respectivamente. Os gestos convencionais foram apresentados somente por S12, enquanto que os expressivos foram apresentados apenas por S10 e S12 e, em igual quantidade.

Nesta avaliação, S11 apresentou uma maior variedade de tipos diferentes de gestos, sendo seguido de S12, S10 e S9, respectivamente. Quanto ao número total de gestos, S11 e S12 apresentaram um número 
maior (oito) e, a seguir, S9 e S10 (cinco). Com relação à segunda avaliação, no que se refere à variedade de tipos diferentes de gestos, S9, S10 e S12 diminuíram-na, enquanto que S11 manteve-se. Quanto ao número total de gestos, todos os sujeitos diminuíram-no.

\subsubsection{Análise da comunicação gestual dos GC, GC1 e GC2}

Figura 3: Número de gestos observados durante a comunicação gestual em GP, GC1 e GC2

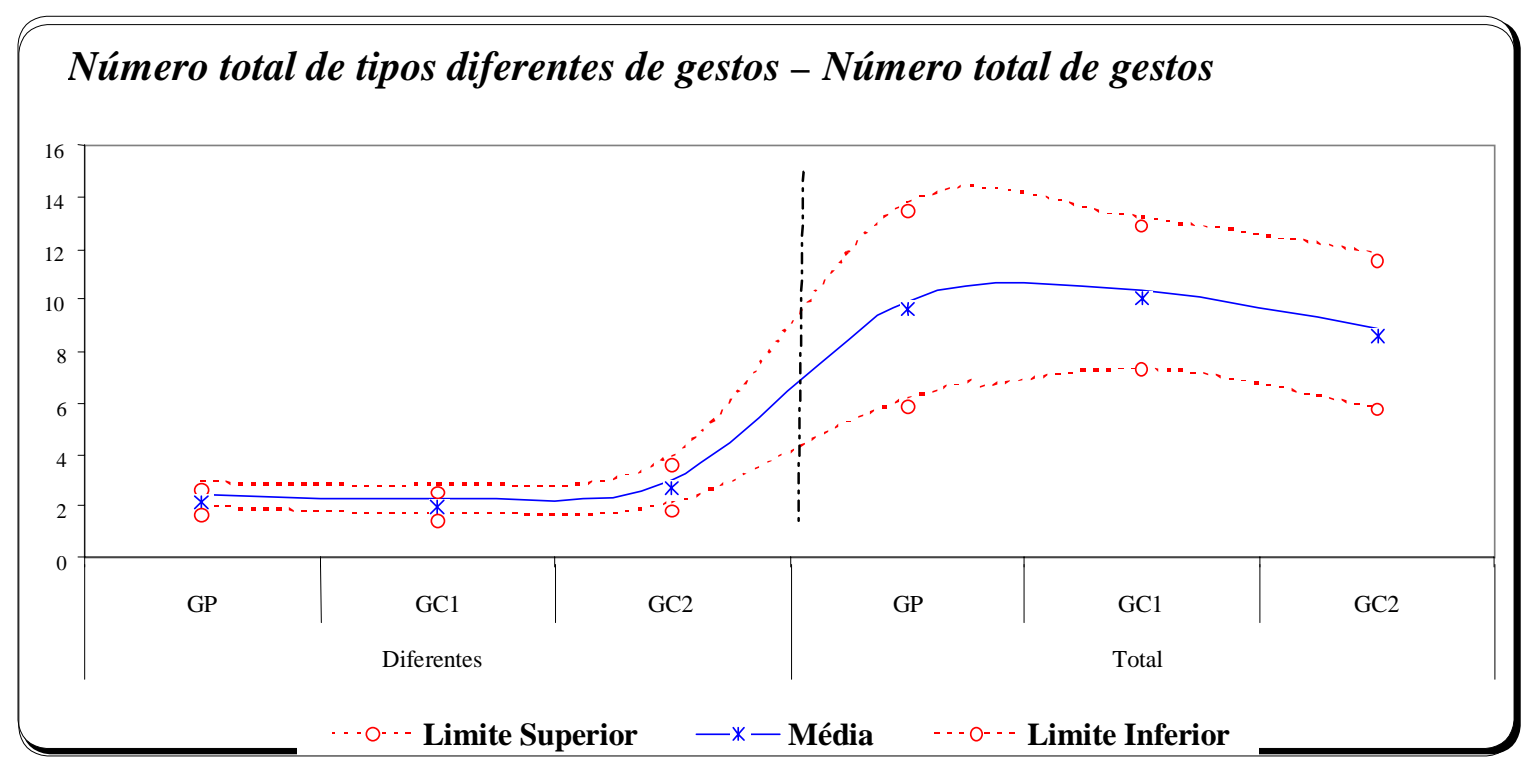

\begin{tabular}{|l|c|c|c|c|c|c|}
\hline \multirow{2}{*}{} & \multicolumn{3}{|c|}{$\begin{array}{c}\text { Número total de tipos } \\
\text { diferentes de gestos }\end{array}$} & \multicolumn{3}{c|}{ Número total de gestos } \\
\cline { 2 - 7 } & GP & GC1 & GC2 & GP & GC1 & GC2 \\
\hline Limite Superior & 2,93 & 2,84 & 3,88 & 13,7 & 13,14 & 11,77 \\
\hline Média & 2,42 & 2,27 & 3 & 9,92 & 10,36 & 8,91 \\
\hline Limite Inferior & 1,91 & 1,7 & 2,12 & 6,13 & 7,59 & 6,05 \\
\hline
\end{tabular}

Ao se observar os p-valores, tanto com relação aos tipos diferentes de gestos como para o número total de gestos apresentados pelos três grupos, 
verifica-se que não foram encontradas diferenças médias entre os grupos que pudessem ser consideradas estatisticamente significantes.

Portanto, pode-se dizer que os três grupos comportaram-se estatisticamente iguais quanto à comunicação gestual.

\subsection{Linguagem oral e comunicação gestual simultâneas}

Durante a classificação dos dados obtidos neste item, considerou-se apenas as situações em que os sujeitos comunicaram-se utilizando a linguagem oral acompanhada de gestos, segundo os tipos de gestos já classificados anteriormente.

Os dados obtidos durante cada avaliação realizada com os sujeitos foram considerados de acordo com o número de tipos diferentes de ocorrência (linguagem oral acompanhada de comunicação gestual) e não o número de vezes que cada emissão oral acompanhada de gesto(s) era produzida.

Assim, após a coleta de dados e sua organização nos protocolos de avaliação de linguagem e cognição (anexo 1), as palavras emitidas acompanhadas de gestos pelos sujeitos dos três grupos foram classificadas nos protocolos de análise (anexos 2a, 2b e 2c). Os dados deste item foram analisados da seguinte forma: 
(Durante uma atividade de jogo simbólico, S12 pega uma boneca)

S12: Tá chorando, ó! O meu nenê...

T.: Tá chorando? E agora?

S12: Agora põe ele dumi (=dormir).

De acordo com o exemplo, S12 apresentou duas situações diferentes em que ocorrem a linguagem oral simultânea à comunicação gestual:

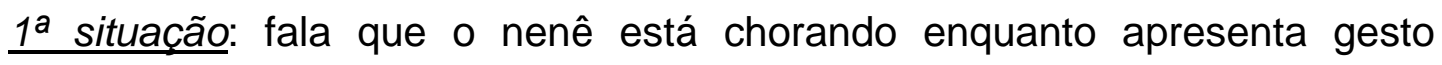
representativo de conteúdo semântico ao segurar a boneca;

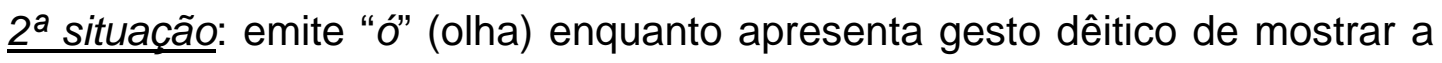
boneca para o interlocutor.

Seguem abaixo as avaliações realizadas por sujeito de cada grupo, sendo que, tal qual nos itens anteriores, os dados obtidos das três avaliações de cada sujeito serão mostrados em um mesmo quadro para facilitar a visualização e a comparação entre os quatro sujeitos de cada grupo e a evolução de cada um deles no decorrer das avaliações.

Ressalta-se que, primeiramente, os dados que serão apresentados, por grupo, referem-se à linguagem oral e comunicação gestual simultâneas de acordo com as classes de palavras (análise morfossintática) e, a seguir, de acordo com a classificação gestual. 


\subsubsection{Linguagem oral e comunicação gestual simultâneas do GP}

5.3.1.1. Linguagem oral e comunicação gestual simultâneas de acordo com as classes de palavras (análise morfossintática)

Quadro 7: Observação do número de vocábulos diferentes por classe de palavras na linguagem oral simultânea à comunicação gestual dos quatro sujeitos do GP durante as três avaliações.

\begin{tabular}{|c|c|c|c|c|c|c|c|c|c|c|c|c|}
\hline & \multicolumn{4}{|c|}{$1^{\circ}$ avaliação } & \multicolumn{4}{|c|}{$2^{\circ}$ avaliação } & \multicolumn{4}{|c|}{$3^{\circ}$ avaliação } \\
\hline Classes de palavras & S1 & S2 & S3 & S4 & S1 & $\mathrm{S2}$ & S3 & S4 & S1 & S2 & S3 & S4 \\
\hline substantivo & 12 & 0 & 1 & 1 & 16 & 0 & 2 & 6 & 10 & 0 & 0 & 11 \\
\hline adjetivo & 0 & 0 & 0 & 0 & 0 & 0 & 0 & 0 & 5 & 0 & 0 & 0 \\
\hline pronome & 2 & 0 & 0 & 0 & 4 & 1 & 0 & 2 & 2 & 0 & 0 & 1 \\
\hline verbo & 3 & 1 & 0 & 0 & 4 & 0 & 0 & 3 & 5 & 0 & 1 & 7 \\
\hline advérbio & 2 & 1 & 1 & 1 & 1 & 1 & 1 & 2 & 2 & 1 & 0 & 4 \\
\hline artigo & 0 & 0 & 0 & 0 & 1 & 0 & 0 & 0 & 1 & 0 & 0 & 0 \\
\hline preposição & 0 & 0 & 0 & 0 & 1 & 0 & 0 & 1 & 1 & 0 & 0 & 1 \\
\hline conjunção & 0 & 0 & 0 & 0 & 0 & 0 & 0 & 0 & 0 & 0 & 0 & 0 \\
\hline numeral & 0 & 0 & 0 & 0 & 4 & 0 & 0 & 0 & 0 & 0 & 0 & 0 \\
\hline interjeição & 3 & 0 & 0 & 0 & 4 & 2 & 0 & 0 & 2 & 1 & 1 & 3 \\
\hline $\begin{array}{l}n^{\circ} \text { total de palavras } \\
\text { diferentes emitidas } \\
\text { por classe }\end{array}$ & 20 & 2 & 2 & 2 & 35 & 4 & 3 & 14 & 28 & 2 & 2 & 27 \\
\hline $\begin{array}{l}n^{\circ} \text { total de classes } \\
\text { de palavras }\end{array}$ & 5 & 2 & 2 & 2 & 8 & 3 & 2 & 5 & 8 & 2 & 2 & 6 \\
\hline
\end{tabular}

Observa-se, no quadro acima, que todos os sujeitos deste grupo apresentaram linguagem oral simultânea à comunicação gestual em todas as avaliações, variando apenas quanto ao número de classes de palavras e ao número das palavras dentro de suas respectivas classes.

Durante a primeira avaliação, observa-se que S1 foi o que apresentou um número maior de classes de palavras seguido dos demais, os quais com o mesmo número. 
As classes de palavras presentes durante esta avaliação pelos sujeitos são: substantivo, pronome, verbo, advérbio e interjeição. Entre elas, somente a classe advérbio foi comum a todos os sujeitos, sendo que substantivo foi comum a S1, S3 e S4, verbo a S1 e S2 e as classes pronome e interjeição foram emitidas apenas por S1. Já as palavras pertencentes às classes adjetivo, artigo, preposição, conjunção e numeral não foram emitidas por nenhum deles.

Com relação ao número total de palavras diferentes emitidas juntamente com a comunicação gestual, observa-se que $\mathrm{S} 1$ foi o sujeito que apresentou o maior número (20) enquanto que os demais sujeitos apresentaram, cada um, apenas duas.

$\mathrm{Na}$ segunda avaliação, S1 também foi o sujeito que apresentou o maior número de classes de palavras, sendo seguido por S4, S2 e S3, respectivamente. Em relação à primeira avaliação, S1, S2 e S4 aumentaram o seu número de classes enquanto que S3 manteve-se.

Observa-se, ainda, que apenas as palavras pertencentes às classes adjetivo e conjunção não foram emitidas por nenhum sujeito, ao passo que a classe advérbio esteve presente em todos eles. Em relação às demais classes, tem-se que: a classe substantivo esteve presente no repertório lingüístico de S1, S3 e S4; a classe pronome em S1, S2 e S4; verbo e preposição em S1 e S4; artigo e numeral somente por S1; e interjeição por S1 e S2.

Com relação ao número total de palavras diferentes emitidas simultâneas à comunicação gestual, nota-se que S1 (com 35 palavras) foi o 
sujeito que apresentou o número maior delas em relação aos outros sujeitos, sendo seguido por S4 (14), S2 (quatro) e S3 (três). Ao se comparar estes dados com os da primeira avaliação, todos os sujeitos aumentaram o seu número de palavras diferentes.

Na terceira avaliação, S1 foi o sujeito que apresentou o maior número de classes em relação aos outros sujeitos, sendo seguido por S4 e por S2 e S3 com o mesmo número. Em relação ao semestre anterior, S4 aumentou o seu número de classes de palavras, enquanto que S2 diminuiu e S1 e S3 mantiveram o mesmo número.

As palavras que pertencem às classes conjunção e numeral não foram emitidas por nenhum sujeito, ao passo que as da classe interjeição foram por todos. As palavras pertencentes às classes substantivo, pronome e preposição foram emitidas apenas por S1 e S4; as das classes adjetivo e artigo por S1, apenas; verbo por S1, S3 e S4; e advérbio por S1, S2 e S4.

Nesta avaliação, com relação ao número total de palavras diferentes emitidas simultâneas à comunicação gestual, S1 (com 28 palavras) foi quem apresentou um número maior, sendo seguido por S4 (27) e, por último, S2 e S3 com o mesmo número (duas). Comparando estes dados com os da segunda avaliação, observa-se que S1, S2 e S3 diminuíram o número de palavras, enquanto que S4 aumentou. 
5.3.1.2. Linguagem oral e comunicação gestual simultâneas de acordo com a classificação de gestos

Quadro 8: Tipos diferentes de ocorrências de comunicação gestual simultânea à linguagem oral dos quatro sujeitos do GP durante as três avaliações.

\begin{tabular}{|c|c|c|c|c|c|c|c|c|c|c|c|c|}
\hline \multirow{2}{*}{$\begin{array}{l}\text { Lgg oral e comunicação } \\
\text { gestual simultâneas }\end{array}$} & \multicolumn{4}{|c|}{$1^{\mathrm{a}}$ avaliação } & \multicolumn{4}{|c|}{$2^{\mathrm{a}}$ avaliação } & \multicolumn{4}{|c|}{$3^{a}$ avaliação } \\
\hline & S1 & S2 & S3 & S4 & S1 & S2 & S3 & S4 & S1 & S2 & S3 & S4 \\
\hline \multicolumn{13}{|l|}{ Gestos dêiticos: } \\
\hline apontar & 0 & 1 & 1 & 0 & 1 & 1 & 1 & 1 & 1 & 1 & 1 & 0 \\
\hline mostrar & 4 & 1 & 0 & 0 & 3 & 1 & 0 & 1 & 8 & 0 & 0 & 3 \\
\hline alcançar & 0 & 0 & 0 & 0 & 0 & 1 & 0 & 0 & 0 & 0 & 0 & 1 \\
\hline \multicolumn{13}{|l|}{ Gestos representativos: } \\
\hline de conteúdo semântico: & 15 & 0 & 4 & 1 & 9 & 4 & 2 & 4 & 12 & 0 & 2 & 4 \\
\hline convencionais & 2 & 1 & 1 & 0 & 3 & 1 & 1 & 1 & 2 & 0 & 0 & 1 \\
\hline expressivos & 1 & 0 & 0 & 0 & 3 & 1 & 0 & 0 & 1 & 2 & 3 & 1 \\
\hline$n^{\circ}$ total de gestos & 22 & 3 & 6 & 1 & 19 & 9 & 4 & 7 & 24 & 3 & 6 & 10 \\
\hline $\begin{array}{l}\mathrm{n}^{\circ} \text { total de tipos } \\
\text { diferentes de gestos }\end{array}$ & 4 & 3 & 3 & 1 & 5 & 6 & 3 & 4 & 5 & 2 & 3 & 5 \\
\hline
\end{tabular}

Durante a primeira avaliação observa-se, no quadro acima que, com relação à categoria de gestos dêiticos, nenhum dos sujeitos apresentou o gesto de alcançar simultâneo à emissão de palavras. Por outro lado, S2 e S3 apresentaram o gesto de apontar (mesma quantidade de situações) simultâneo às palavras, enquanto que S1 e S2 apresentaram o de mostrar, sendo que S1 apresentou-o em um número maior de ocorrências diferentes do que S2.

Com relação à categoria de gestos representativos, os quatro sujeitos apresentaram-nos simultâneos às palavras, sendo que ocorreu um maior número de ocorrências de gestos de conteúdo semântico e de 
convencionais (três sujeitos) do que de expressivos (um sujeito). No que se refere ao número de ocorrências diferentes de gestos de conteúdo semântico acompanhando as palavras, S1 foi quem as apresentou em um número maior, sendo seguido por S3 e S4, respectivamente. Na ocorrência de gestos convencionais simultâneos às palavras, foi S1 quem também os apresentou em maior número de ocorrências diferentes, sendo seguido por S2 e S3 (com número igual). E, com relação aos gestos expressivos, somente S1 o apresentou em uma única ocorrência acompanhando a linguagem oral.

Quanto à variedade de tipos diferentes de gestos que acompanham a linguagem oral, S1 é quem apresenta um número maior, sendo seguido por S2, S3 (estes dois com o mesmo número de ocorrências diferentes) e S4, respectivamente. Com relação ao número total de gestos que acompanham a linguagem oral, observa-se, primeiramente S1 e, a seguir, S3, S2 e S4, respectivamente.

Na segunda avaliação, observa-se no Quadro 8 que tanto a categoria de gestos dêiticos quanto a de representativos acompanharam a linguagem oral de todos os sujeitos, variando apenas nos tipos diferentes de situações. Assim, o gesto de apontar foi apresentado por todos os sujeitos com o mesmo número de ocorrências diferentes; o gesto de mostrar, apenas foi apresentado por S1, S2 e S4 (estes dois últimos apresentaram número igual de ocorrências diferentes), respectivamente; e o gesto de alcançar foi apresentado somente por S2. 
Quanto aos gestos representativos, os de conteúdo semântico acompanharam a linguagem oral dos quatro sujeitos, sendo que S1 apresentou um número maior de ocorrência deste gesto em situações diferentes, sendo seguido por S2, S4 (estes com o mesmo número de ocorrência em situações diferentes) e S3, respectivamente. Os gestos convencionais também acompanharam a linguagem oral dos quatro sujeitos, sendo que também foi S1 quem apresentou um número maior de ocorrência deste gesto em situações diferentes, sendo seguido por S2, S3 e S4 (os três com o mesmo número de ocorrências diferentes). Já os gestos expressivos acompanharam a linguagem oral somente de dois sujeitos: S1 e S2, respectivamente.

Com relação à variedade de tipos diferentes de gestos que acompanham a linguagem oral, S2 esteve à frente dos outros sujeitos, sendo seguido por S1, S4 e S3, respectivamente. E, quanto ao número total de gestos que acompanham a linguagem oral, S1 foi quem esteve à frente dos outros sujeitos, sendo seguido por S2, S4 e S3, respectivamente.

Ao se comparar esta avaliação com a primeira, observa-se, quanto à variedade de tipos diferentes de gestos que acompanham a linguagem oral, que S1, S2 e S4 aumentaram-na, enquanto S3 manteve-se. Com relação ao número total de gestos que acompanham a linguagem oral, S2 e S4 aumentaram, enquanto que S1 e S3 diminuíram.

Durante a terceira avaliação, nota-se que todos os sujeitos apresentaram tanto a categoria de gestos dêiticos como a de representativos 
acompanhando a linguagem oral, variando somente quanto aos tipos diferentes de situações.

Assim, com relação aos gestos dêiticos, somente S1, S2 e S3 apresentaram o gesto de apontar acompanhando a linguagem oral (os três com a mesma quantidade de ocorrências em situações diferentes), enquanto que S1 e S4, respectivamente, apresentaram o gesto de mostrar acompanhando a linguagem oral e somente S4 apresentou o gesto de alcançar.

No que se refere à categoria de gestos representativos, observa-se que todos os sujeitos (S3, S2, S1 e S4, respectivamente, sendo que os dois últimos com o mesmo número de ocorrências em situações diferentes), apresentaram os gestos expressivos acompanhando a emissão oral; três (S1, S4 e S3, respectivamente) apresentaram gestos de conteúdo semântico acompanhando a linguagem oral; e dois (S1 e S4) apresentaram gestos convencionais acompanhando a linguagem oral.

Com relação à variedade de tipos diferentes de gestos que acompanham a linguagem oral, observa-se que S1 e S4 estiveram à frente dos outros sujeitos com o mesmo número, sendo seguido por S3 e S2, respectivamente. Quanto ao número total de gestos que acompanham a linguagem oral, foi S1 quem esteve à frente, sendo seguido de S4, S3 e S2, respectivamente.

Comparando-se os dados obtidos nesta avaliação com os da segunda, observa-se, quanto à variedade de tipos diferentes de gestos que acompanham a linguagem oral, que S4 a aumentou, S1 e S3 mantiveram- 
na, enquanto que S2 a diminuiu. Com relação ao número total de gestos que acompanham a emissão oral, S1, S3 e S4 aumentaram, enquanto que S2 diminuiu.

\subsubsection{Linguagem oral e comunicação gestual simultâneas do GC1}

5.3.2.1. Linguagem oral e comunicação gestual simultâneas de acordo com as classes de palavras (análise morfossintática)

Quadro 9: Observação do número de vocábulos diferentes por classe de palavras na linguagem oral simultânea à comunicação gestual dos quatro sujeitos do GC1 durante as três avaliações.

\begin{tabular}{|c|c|c|c|c|c|c|c|c|c|c|c|c|}
\hline & \multicolumn{4}{|c|}{$1^{\circ}$ avaliação } & \multicolumn{4}{|c|}{$2^{\circ}$ avaliação } & \multicolumn{4}{|c|}{$3^{\circ}$ avaliação } \\
\hline Classes de palavras & S5 & S6 & S7 & S8 & S5 & S6 & S7 & S8 & S5 & S6 & S7 & S8 \\
\hline substantivo & $\overline{0}$ & 0 & 0 & 4 & 0 & 4 & 1 & 11 & 0 & 3 & 5 & 10 \\
\hline adjetivo & 0 & 0 & 0 & 1 & 0 & 0 & 0 & 0 & 0 & 0 & 0 & 0 \\
\hline pronome & 0 & 0 & 0 & 0 & 0 & 0 & 0 & 1 & 0 & 0 & 0 & 3 \\
\hline verbo & 0 & 2 & 0 & 9 & 0 & 2 & 0 & 5 & 0 & 2 & 0 & 7 \\
\hline advérbio & 0 & 0 & 0 & 0 & 0 & 0 & 0 & 0 & 0 & 1 & 0 & 5 \\
\hline artigo & 0 & 0 & 0 & 0 & 0 & 0 & 1 & 1 & 0 & 0 & 0 & 1 \\
\hline preposição & 0 & 0 & 0 & 0 & 0 & 0 & 0 & 1 & 0 & 0 & 0 & 0 \\
\hline conjunção & 0 & 0 & 0 & 0 & 0 & 0 & 0 & 0 & 0 & 0 & 0 & 0 \\
\hline numeral & 0 & 0 & 0 & 0 & 0 & 0 & 0 & 0 & 0 & 0 & 0 & 0 \\
\hline interjeição & 0 & 2 & 0 & 3 & 1 & 2 & 0 & 2 & 1 & 3 & 1 & 1 \\
\hline $\begin{array}{l}\mathrm{n}^{\circ} \text { total de palavras } \\
\text { diferentes emitidas } \\
\text { por classe }\end{array}$ & 0 & 4 & 0 & 17 & 1 & 8 & 2 & 21 & 1 & 9 & 6 & 27 \\
\hline $\begin{array}{l}n^{\circ} \text { total de classes } \\
\text { de palavras }\end{array}$ & 0 & 2 & 0 & 4 & 1 & 3 & 2 & 6 & 1 & 4 & 2 & 6 \\
\hline
\end{tabular}

Durante a primeira avaliação, observa-se no Quadro 9, que somente S6 e S8 apresentaram a emissão de palavras simultâneas à comunicação gestual, sendo que S8 apresentou um número maior do que S6. As palavras emitidas por estes sujeitos foram as pertencentes às classes: substantivo, 
adjetivo, verbo e interjeição, sendo que verbo e interjeição estiveram presentes no repertório lingüístico de ambos os sujeitos, enquanto que substantivo e adjetivo estiveram presentes apenas no de S8.

As classes pronome, advérbio, artigo, preposição, conjunção e numeral não foram emitidas por nenhum deles.

Quanto ao número total de palavras diferentes emitidas simultâneas à comunicação gestual, observa-se que S8 (com 17 palavras) apresentou-as em número maior do que S6 (quatro). O mesmo observa-se com relação ao número total de classes de palavras, sendo que S8 apresentou quatro classes diferentes em seu repertório lingüístico enquanto que S6, duas.

$\mathrm{Na}$ segunda avaliação, pode-se observar que todos os sujeitos apresentaram linguagem oral simultânea à comunicação gestual. Com relação ao número de classes de palavras, nota-se que S8 foi o que apresentou o maior número, sendo seguido por S6, S7 e S5, respectivamente. Ao se comparar estes dados com os da primeira avaliação, observa-se que todos os sujeitos apresentaram um número maior de classes, aumentando o seu número de palavras simultâneas à comunicação gestual.

As palavras pertencentes à classe substantivo estiveram presentes no repertório lingüístico de S6, S7 e S8; as das classes pronome e preposição somente estiveram presentes no repertório lingüístico de S8; verbo no de S6 e S8; artigo no de S7 e S8; e interjeição no de S5, S6 e S8.

As classes de palavras que não foram emitidas oralmente por nenhum dos sujeitos foram: adjetivo, advérbio, conjunção e numeral. 
Ao se comparar o número total da emissão de palavras diferentes simultâneas à comunicação gestual desta avaliação com a primeira, verificase que todos os sujeitos aumentaram o seu número, sendo que S8 (com 21 palavras) foi o que apresentou o maior número e, a seguir, S6 (oito), S7 (duas) e S5 (uma), respectivamente.

$\mathrm{Na}$ terceira avaliação, nota-se que todos os sujeitos apresentaram a emissão de palavras simultâneas à comunicação gestual, sendo que S8 foi o que apresentou o número maior de classes e, a seguir, S6, S7 e S5, respectivamente. Nota-se também que, em relação à segunda avaliação, S6 foi o único que aumentou o seu número de classes, enquanto que os demais mantiveram-no.

Nesta avaliação, as palavras pertencentes às classes adjetivo, preposição, conjunção e numeral não foram emitidas simultâneas à comunicação gestual por nenhum sujeito, sendo que, a classe interjeição esteve presente no repertório lingüístico de todos os sujeitos.

As palavras pertencentes à classe substantivo foram emitidas simultâneas à comunicação gestual por S6, S7 e S8. As classes verbo e advérbio estiveram presentes no repertório lingüístico de S6 e S8, ao passo que as classes pronome e artigo, por sua vez, estiveram presentes somente no de S8.

Quanto ao número total de palavras diferentes emitidas simultâneas à comunicação gestual, S8 (com 27 palavras) é quem apresentou o número maior, comparando-o com os outros sujeitos, sendo seguido por S6 (nove), S7 (seis) e S5 (uma), respectivamente. Em relação à segunda avaliação, 
somente S5 manteve o seu número de palavras emitidas simultâneas à comunicação gestual, enquanto que os demais aumentaram-no.

5.3.2.2. Linguagem oral e comunicação gestual simultâneas de acordo com a classificação de gestos

Quadro 10: Tipos diferentes de ocorrências de comunicação gestual simultânea à linguagem oral dos quatro sujeitos do GC1 durante as três avaliações.

\begin{tabular}{|c|c|c|c|c|c|c|c|c|c|c|c|c|}
\hline \multirow{2}{*}{$\begin{array}{l}\text { Lgg oral e comunicação } \\
\text { gestual simultâneas }\end{array}$} & \multicolumn{4}{|c|}{$1^{\mathrm{a}}$ avaliação } & \multicolumn{4}{|c|}{$2^{\mathrm{a}}$ avaliação } & \multicolumn{4}{|c|}{$3^{\mathrm{a}}$ avaliação } \\
\hline & $\mathrm{S5}$ & 56 & S7 & S8 & S5 & 56 & S7 & S8 & S5 & S6 & S7 & S8 \\
\hline Gestos dêiticos: & & & & & & & & & & & & \\
\hline apontar & 1 & 1 & 0 & 1 & 0 & 2 & 1 & 0 & 0 & 4 & 0 & 0 \\
\hline mostrar & 0 & 3 & 0 & 5 & 2 & 3 & 2 & 5 & 1 & 4 & 1 & 2 \\
\hline alcançar & 0 & 2 & 0 & 2 & 0 & 2 & 0 & 0 & 0 & 2 & 0 & 3 \\
\hline Gestos representativos: & & & & & & & & & & & & \\
\hline de conteúdo semântico: & 3 & 5 & 0 & 11 & 3 & 14 & 1 & 3 & 3 & 3 & 2 & 5 \\
\hline convencionais & 0 & 0 & 0 & 1 & 0 & 0 & 0 & 0 & 0 & 0 & 2 & 0 \\
\hline expressivos & 0 & 3 & 0 & 4 & 0 & 1 & 0 & 0 & 0 & 1 & 0 & 0 \\
\hline$n^{\circ}$ total de gestos & 4 & 14 & 0 & 24 & 5 & 22 & 4 & 8 & 4 & 14 & 5 & 10 \\
\hline $\begin{array}{l}\mathrm{n}^{\mathbf{0}} \quad \text { total de tipos } \\
\text { diferentes de gestos }\end{array}$ & 2 & 4 & 0 & 6 & 2 & 5 & 3 & 2 & 2 & 22 & 4 & 8 \\
\hline
\end{tabular}

Na primeira avaliação, observa-se no quadro acima, que três sujeitos, S5, S6 e S8 apresentaram tanto a categoria de gestos dêiticos quanto a de representativos acompanhando a linguagem oral. Por outro lado, S7 não apresentou nenhuma delas.

Com relação à categoria de gestos dêiticos, observa-se que os três sujeitos apresentaram o gesto de apontar acompanhando a linguagem oral, com o mesmo número de ocorrências. Os gestos de mostrar e alcançar foram apresentados apenas por S6 e S8, sendo que enquanto S8 
apresentou o gesto de mostrar em um número maior de ocorrências acompanhando a linguagem oral do que S6 e ambos apresentaram o gesto de alcançar na mesma quantidade de situações.

Quanto à ocorrência de gestos representativos simultâneos à linguagem oral, S8 foi o que apresentou um número maior em todos os tipos desta categoria do que os outros sujeitos. No que se refere às situações em que ocorreram os gestos de conteúdo semântico, após S8, seguem-se S6 e S5, respectivamente. Somente S8 apresentou gestos convencionais acompanhando a linguagem oral, enquanto que, os expressivos, foram apresentados por S6 e S8.

De acordo tanto com a variedade de tipos diferentes de gestos que acompanham a linguagem oral, quanto com o número total de ocorrências em que os gestos acompanham a linguagem oral, observa-se que S8 esteve à frente dos outros sujeitos, sendo seguido por S6 e S5, respectivamente.

Durante a segunda avaliação, observa-se que todos os sujeitos apresentaram tanto a categoria de gestos dêiticos como a de representativos acompanhando a linguagem oral. Com relação aos dêiticos, somente S6 e S7 apresentaram gestos de apontar, sendo que o primeiro apresentou um número maior de ocorrências deste gesto do que o segundo. Os gestos de mostrar, por sua vez, esteve presente durante a linguagem oral dos quatro sujeitos, sendo que S8 foi o que apresentou o maior número de ocorrências e, a seguir, S6, S5 e S7 (estes dois últimos com o mesmo número de ocorrências), respectivamente. Quanto ao gesto de alcançar, somente S8 o apresentou acompanhando a linguagem oral. 
Quanto à categoria de gestos representativos, todos os sujeitos apresentaram os de conteúdo semântico acompanhando a linguagem oral, sendo que S6 foi o que apresentou um maior número de ocorrências e, em seguida, S5 e S8 (ambos com o mesmo número de ocorrências) e S7, respectivamente. Por outro lado, nenhum dos sujeitos apresentou gestos convencionais acompanhando a linguagem oral, e somente S6 apresentou gestos expressivos.

Ao se analisar a variedade dos tipos diferentes de gestos que acompanham a emissão oral, observa-se que S6 é quem apresenta o número maior, sendo seguido de S7, S5 e S8 (estes dois com o mesmo número), respectivamente. Quanto ao número total de gestos que acompanham a linguagem oral, S6 também apresenta um número maior e, a seguir, S8, S5 e S7, respectivamente.

Comparando estes dados com os da primeira avaliação, observa-se, quanto à variedade de tipos diferentes de gestos que acompanham a linguagem oral, que S6 e S7 aumentaram o seu número, S8 diminuiu-o e S5 o manteve. Quanto ao número total de gestos que acompanham a linguagem oral, S5, S6 e S7 aumentaram-no enquanto que S8 o diminuiu.

Na terceira avaliação, tal como a segunda, observa-se que todos os sujeitos apresentaram tanto a categoria de gestos dêiticos como a de representativos acompanhando a linguagem oral. Com relação aos gestos dêiticos de apontar, nota-se que somente S6 o apresentou. Os gestos de mostrar foram apresentados por todos os sujeitos, de modo que S6 foi quem o apresentou em maior número, sendo seguido por S8 e S5 e S7 (estes dois 
últimos com a mesma quantidade), respectivamente. Os gestos de alcançar, por sua vez, somente foram apresentados por S2 e S8, sendo que este último apresentou o maior número.

Ao se observar a categoria de gestos representativos acompanhando a linguagem oral, os de conteúdo semântico ocorreram durante a comunicação de todos os sujeitos, sendo que S8 foi quem o apresentou em maior número e, a seguir, S5 e S6 (ambos com o mesmo número) e S7, respectivamente. Por outro lado, os gestos convencionais apenas acompanharam a linguagem oral de S7 enquanto que os expressivos, somente a de S6.

Quanto ao número total de tipos diferentes de gestos, bem como o número total deles que ocorreu simultaneamente à linguagem oral, observase que $\mathrm{S6}$ esteve à frente de todos os sujeitos, sendo seguido de S8, S7 e S5, respectivamente.

Comparando-se estes dados com os da segunda avaliação, verificase, quanto à variedade de tipos diferentes de gestos que acompanham a linguagem oral, que apenas S5 diminuiu o seu número, enquanto que os demais sujeitos aumentaram-no. Com relação ao número total de gestos que acompanham a linguagem oral, enquanto S5 e S6 diminuíram-no, S7 e S8 o aumentaram. 


\subsubsection{Linguagem oral e comunicação gestual simultâneas do GC2}

5.3.3.1. Linguagem oral e comunicação gestual simultâneas de acordo com as classes de palavras (análise morfossintática)

Quadro 11: Observação do número de vocábulos diferentes por classe de palavras na linguagem oral simultânea à comunicação gestual dos quatro sujeitos do GC2 durante as três avaliações.

\begin{tabular}{|c|c|c|c|c|c|c|c|c|c|c|c|c|}
\hline & \multicolumn{4}{|c|}{$1^{\circ}$ avaliação } & \multicolumn{4}{|c|}{$2^{\circ}$ avaliação } & \multicolumn{4}{|c|}{$3^{\circ}$ avaliação } \\
\hline Classes de palavras & S9 & S10 & S11 & S12 & S9 & S10 & S11 & S12 & S9 & S10 & S11 & S12 \\
\hline substantivo & 0 & $\overline{0}$ & 0 & 5 & 4 & 3 & 13 & 14 & $\overline{9}$ & 2 & 4 & 12 \\
\hline adjetivo & 0 & 0 & 0 & 0 & 0 & 0 & 1 & 0 & 0 & 0 & 0 & 1 \\
\hline pronome & 0 & 0 & 0 & 1 & 2 & 1 & 1 & 8 & 2 & 0 & 3 & 4 \\
\hline verbo & 0 & 0 & 0 & 6 & 13 & 5 & 5 & 10 & 17 & 4 & 10 & 11 \\
\hline advérbio & 0 & 0 & 0 & 1 & 5 & 1 & 0 & 4 & 3 & 0 & 5 & 3 \\
\hline artigo & 0 & 0 & 0 & 0 & 1 & 1 & 1 & 1 & 0 & 0 & 1 & 0 \\
\hline preposição & 0 & 0 & 0 & 0 & 2 & 0 & 0 & 3 & 1 & 0 & 2 & 2 \\
\hline conjunção & 0 & 0 & 0 & 0 & 1 & 0 & 0 & 0 & 1 & 0 & 0 & 1 \\
\hline numeral & 0 & 0 & 0 & 0 & 1 & 0 & 0 & 0 & 1 & 0 & 0 & 3 \\
\hline interjeição & 0 & 0 & 0 & 1 & 1 & 1 & 0 & 4 & 1 & 0 & 1 & 3 \\
\hline $\begin{array}{l}n^{\circ} \text { total de palavras } \\
\text { diferentes emitidas } \\
\text { por classe }\end{array}$ & 0 & 0 & 0 & 14 & 30 & 12 & 21 & 44 & 35 & 6 & 26 & 40 \\
\hline $\begin{array}{l}n^{\circ} \text { total de classes } \\
\text { de palavras }\end{array}$ & 0 & 0 & 0 & 5 & 9 & 6 & 5 & 7 & 8 & 2 & 7 & 9 \\
\hline
\end{tabular}

Durante a primeira avaliação observa-se, no quadro acima, que somente S12 apresentou linguagem oral simultânea à comunicação gestual, emitindo palavras pertencentes a cinco classes: substantivo, pronome, verbo, advérbio e interjeição. No total, este sujeito apresentou a emissão de 14 palavras diferentes distribuídas nas classes, acompanhando a comunicação gestual.

$\mathrm{Na}$ segunda avaliação, observa-se que todos os sujeitos apresentaram linguagem oral simultânea à comunicação gestual, variando somente quanto às classes apresentadas pelos sujeitos. 
S9 foi o sujeito que apresentou o número maior de classes de palavras simultâneas aos gestos quando comparado com os demais, sendo seguido por S12, S10 e S11, respectivamente.

As palavras pertencentes às classes substantivo, pronome, verbo e artigo foram emitidas por todos os sujeitos; as pertencentes à classe adjetivo, somente por S11; advérbio e interjeição por S9, S10 e S11; preposição por S9 e S12; e conjunção e numeral por S9, apenas.

Comparando os dados obtidos desta avaliação com os da primeira, no que se refere ao número total de palavras emitidas simultaneamente à comunicação gestual, observa-se que todos os sujeitos aumentaram o seu número, sendo que S12 (com 44 palavras) foi o que apresentou o maior número e, a seguir, S9 (30 palavras), S11 (21 palavras) e S10 (12 palavras), respectivamente.

Na terceira avaliação, observa-se que todos os sujeitos deste grupo apresentaram a emissão de palavras simultâneas à comunicação gestual, sendo que S12 foi o sujeito que apresentou o número maior de classes de palavras, sendo seguido por S9, S11 e S10, respectivamente. Em relação à segunda avaliação, vê-se também que S11 e S12 aumentaram o seu número de classes de palavras no repertório lingüístico, enquanto que S9 e S10 o diminuíram.

Observa-se a presença de palavras pertencentes às classes substantivo e verbo na linguagem oral de todos os sujeitos deste grupo. A classe adjetivo esteve presente somente no repertório lingüístico de S12, enquanto que pronomes, advérbios, preposições e interjeições foram 
emitidos por S9, S11 e S12; artigo somente por S11; e conjunções e numerais por S9 e S12.

Com relação ao número total de palavras diferentes emitidas simultaneamente à comunicação gestual, o sujeito que apresentou o número maior foi S12 (40 palavras), sendo seguido por S9 (35 palavras), S11 (26 palavras) e S10 (seis), respectivamente.

Comparando estes dados com os da segunda avaliação, S9 e S11 aumentaram o seu número de palavras emitidas simultaneamente à linguagem oral, enquanto que S10 e S12 o diminuíram.

5.3.3.2. Linguagem oral e comunicação gestual simultâneas de acordo com a classificação de gestos

Quadro 12: Tipos diferentes de ocorrências de comunicação gestual simultânea à linguagem oral dos quatro sujeitos do GC2 durante as avaliações.

\begin{tabular}{|c|c|c|c|c|c|c|c|c|c|c|c|c|}
\hline \multirow{2}{*}{$\begin{array}{l}\text { Lgg oral e comunicação } \\
\text { gestual simultâneas }\end{array}$} & \multicolumn{4}{|c|}{$1^{\mathrm{a}}$ avaliação } & \multicolumn{4}{|c|}{$2^{\mathrm{a}}$ avaliação } & \multicolumn{4}{|c|}{$3^{a}$ avaliação } \\
\hline & S9 & $\mathbf{S 1 0}$ & S11 & S12 & S9 & S10 & S11 & $\mathbf{S 1 2}$ & S9 & S10 & S11 & S12 \\
\hline \multicolumn{13}{|l|}{ Gestos dêiticos: } \\
\hline apontar & 0 & 0 & 0 & 0 & 3 & 1 & 1 & 3 & 0 & 1 & 3 & 0 \\
\hline mostrar & 0 & 0 & 0 & 5 & 5 & 10 & 10 & 9 & 11 & 2 & 3 & 11 \\
\hline alcançar & 0 & 0 & 0 & 0 & 2 & 0 & 1 & 0 & 0 & 0 & 1 & 0 \\
\hline \multicolumn{13}{|l|}{ Gestos representativos: } \\
\hline de conteúdo semântico: & 0 & 0 & 0 & 2 & 14 & 1 & 13 & 8 & 8 & 3 & 8 & 9 \\
\hline convencionais & 0 & 0 & 0 & 0 & 2 & 0 & 0 & 1 & 1 & 0 & 0 & 1 \\
\hline expressivos & 0 & 0 & 0 & 1 & 2 & 1 & 0 & 2 & 0 & 0 & 3 & 3 \\
\hline$n^{o}$ total de gestos & 0 & 0 & 0 & 8 & 28 & 13 & 25 & 23 & 20 & 6 & 18 & 24 \\
\hline $\begin{array}{l}\mathrm{n}^{\circ} \text { total de tipos } \\
\text { diferentes de gestos }\end{array}$ & 0 & 0 & 0 & 3 & 6 & 4 & 4 & 4 & $\overline{3}$ & 3 & 5 & 4 \\
\hline
\end{tabular}


Durante a primeira avaliação observa-se, no quadro acima, que somente S12 apresentou gestos simultâneos à linguagem oral.

Desse modo, com relação à ocorrência da categoria de gestos dêiticos acompanhando a linguagem oral, observa-se que S12 apresentou apenas o de mostrar, enquanto que da categoria de representativos, foram apresentados os de conteúdo semântico e os expressivos. Ao todo, S12 apresentou três tipos diferentes de gestos simultâneos às palavras.

$\mathrm{Na}$ segunda avaliação, observa-se que todos os sujeitos apresentaram tanto gestos dêiticos quanto representativos durante a linguagem oral. Com relação à categoria de gestos dêiticos, todos os sujeitos apresentaram o de apontar, sendo que S9 e S12 apresentaram o mesmo número de ocorrências e, também, um número maior do que S10 e S11, os quais também com número igual entre si. O mesmo ocorreu com relação ao gesto de mostrar, porém, S10 e S11 apresentaram o mesmo número de ocorrências, sendo seguidos por S12 e S9, respectivamente. Por outro lado, quanto ao gesto de alcançar, somente S9 e S11 os apresentaram.

No que se refere à categoria de gestos representativos, todos os sujeitos apresentaram os de conteúdo semântico, sendo que, pela ordem decrescente em relação ao número de ocorrências, temos: S9, S11, S12 e S10, respectivamente. Os gestos convencionais somente foram apresentados por S9 e S12 e os expressivos por S9, S12 (ambos com o mesmo número de ocorrências) e S10, respectivamente. 
Comparando os dados desta avaliação com os da primeira, verifica-se que todos os sujeitos aumentaram tanto o número de tipos diferentes de gestos que acompanham a linguagem oral, como também o número total deles.

Durante a terceira avaliação, observa-se que todos os sujeitos apresentaram gestos dêiticos e gestos representativos acompanhando a linguagem oral. Com relação à categoria de gestos dêiticos, somente S10 e S11 apresentaram gestos de apontar, sendo que o último apresentou um número maior do que o primeiro. Todos os sujeitos apresentaram gestos de mostrar, de modo que S9 e S12 estiveram à frente dos outros com o mesmo número de ocorrências deste gesto acompanhando palavras e, a seguir, S11 e S10, respectivamente. Quanto aos gestos de alcançar, somente S11 os apresentou.

Com relação à categoria de gestos representativos, S12 foi quem apresentou o número maior de ocorrências de gestos de conteúdo semântico acompanhando a linguagem oral e, a seguir, S9, S11 (ambos com o mesmo número de ocorrência), e S10, respectivamente. Os gestos convencionais foram apresentados somente por S9 e S12, os quais com o mesmo número de ocorrência. Os gestos expressivos, por sua vez, apenas foram apresentados acompanhando a linguagem oral por S11 e S12, também com o mesmo número de ocorrência.

Ao se comparar os dados obtidos nesta avaliação com os da segunda, observa-se, quanto aos tipos diferentes de gestos que acompanham a linguagem oral, que S9 e S10 diminuíram o número, S11 
aumentou-o e S12 manteve-se. Quanto ao número total dos gestos que acompanham a emissão oral, S9, S10 e S11 diminuíram-no, enquanto que S12 o aumentou.

\subsubsection{Análise da linguagem oral e comunicação gestual simultâneas dos GP, GC1 e GC2}

A análise da linguagem oral e comunicação gestual simultâneas dos três grupos será mostrada, a seguir, de modo inter-grupal e de acordo com o estudo estatístico realizado. Para uma melhor compreensão, os dados serão apresentados na seguinte ordem: o número de vocábulos diferentes, número total de classes de palavras e número de gestos.

Figura 4: Ocorrências de linguagem oral simultânea à comunicação gestual dos três grupos segundo o número de vocábulos

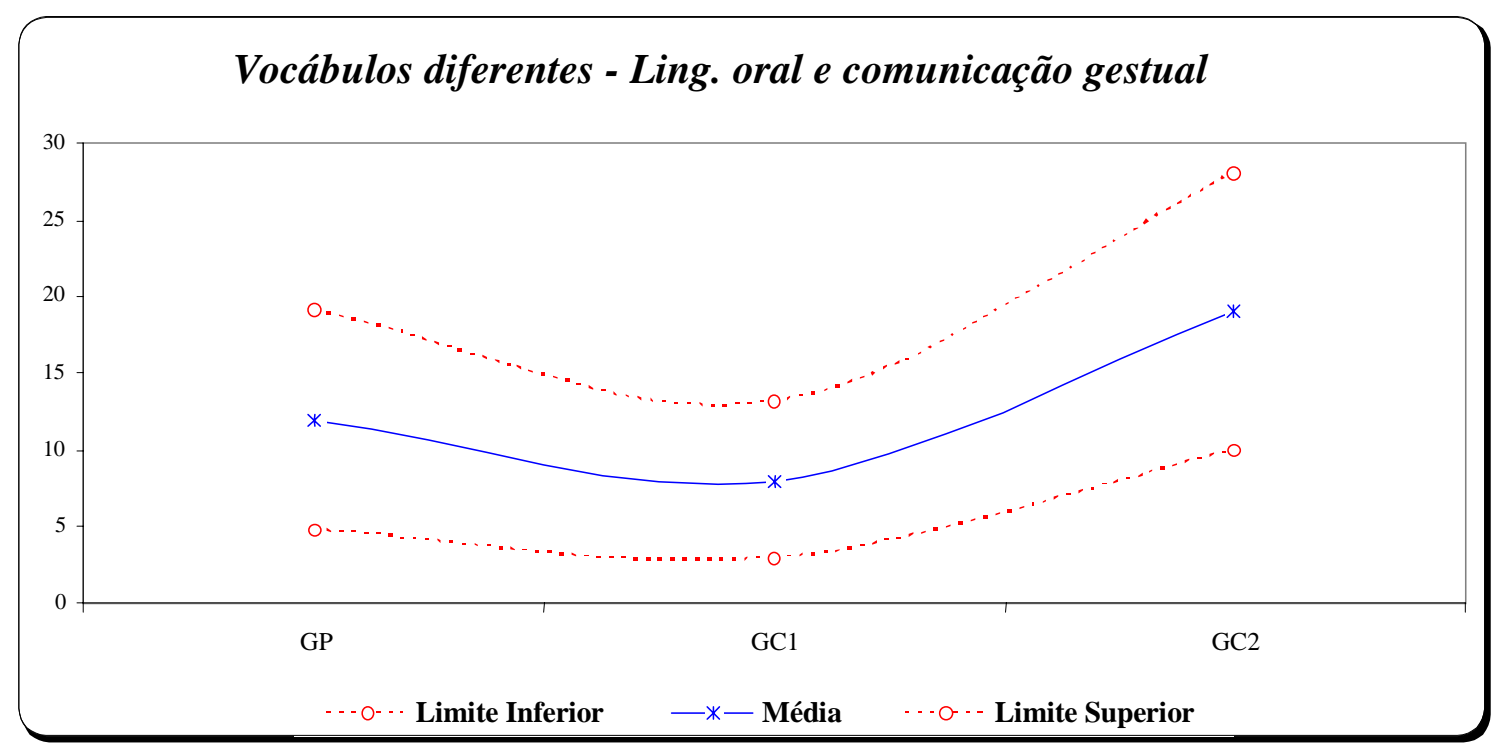




\begin{tabular}{|l|c|c|c|}
\hline Ambas - Vocábulo & GP & GC1 & GC2 \\
\hline Limite Inferior & 4,76 & 2,9 & 9,94 \\
\hline Média & 11,92 & 8 & 19 \\
\hline Limite Superior & 19,07 & 13,1 & 28,06 \\
\hline
\end{tabular}

$p$-valor $=0,300$

Segundo o $p$-valor, verifica-se que as diferenças encontradas entre os grupos não podem ser consideradas estatisticamente significantes.

Figura 5: Ocorrências de linguagem oral simultânea à comunicação gestual dos três grupos segundo o número de classes de palavras

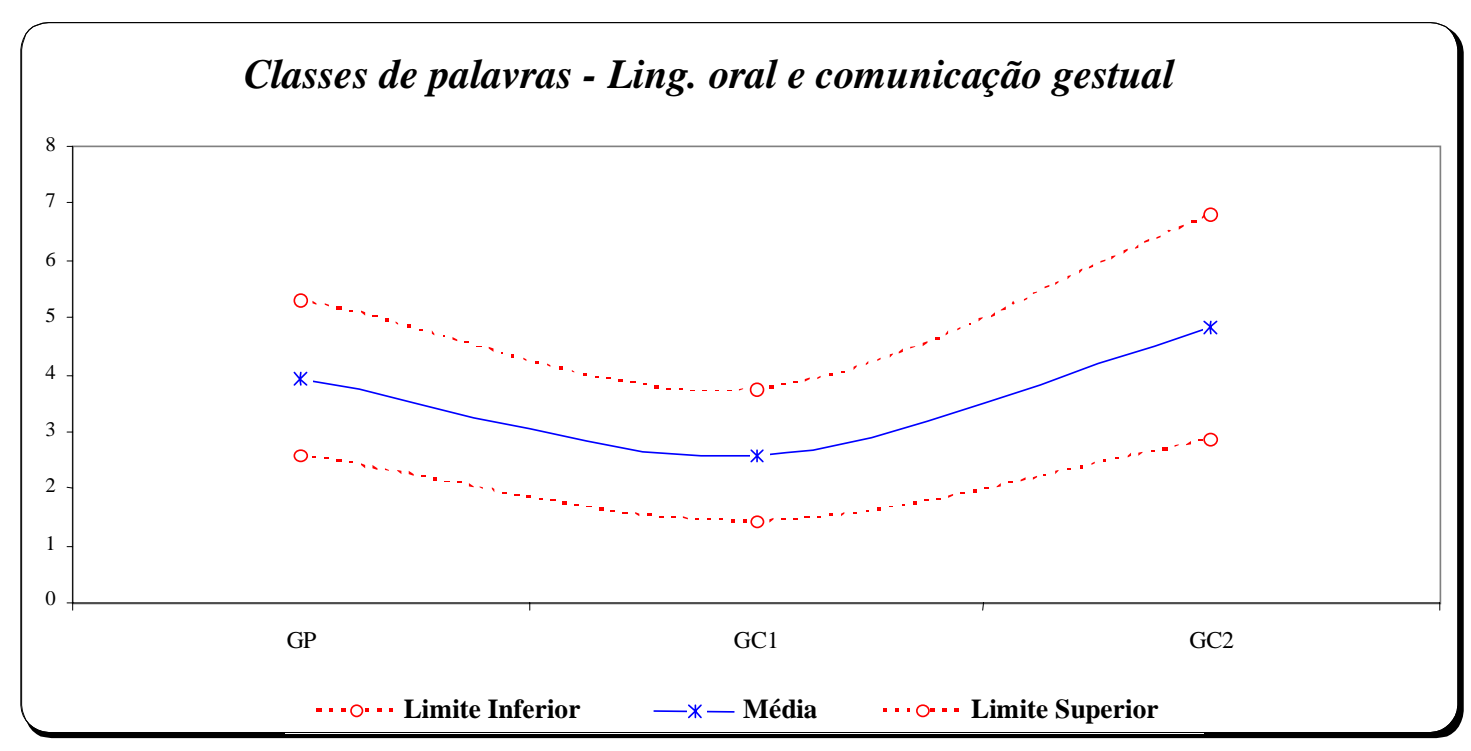

\begin{tabular}{|l|r|r|r|}
\hline Ambas - Classe & GP & GC1 & \multicolumn{1}{c|}{ GC2 } \\
\hline Limite Inferior & 2,56 & 1,41 & 2,86 \\
\hline Média & 3,92 & 2,58 & 4,83 \\
\hline Limite Superior & 5,27 & 3,75 & 6,81 \\
\hline
\end{tabular}

$p$-valor $=0,193$

De acordo com o p-valor observado, verifica-se que não foram encontradas diferenças significantes entre os grupos. 
Figura 6: Ocorrências de linguagem oral e comunicação gestual simultâneas dos três grupos segundo o número de gestos

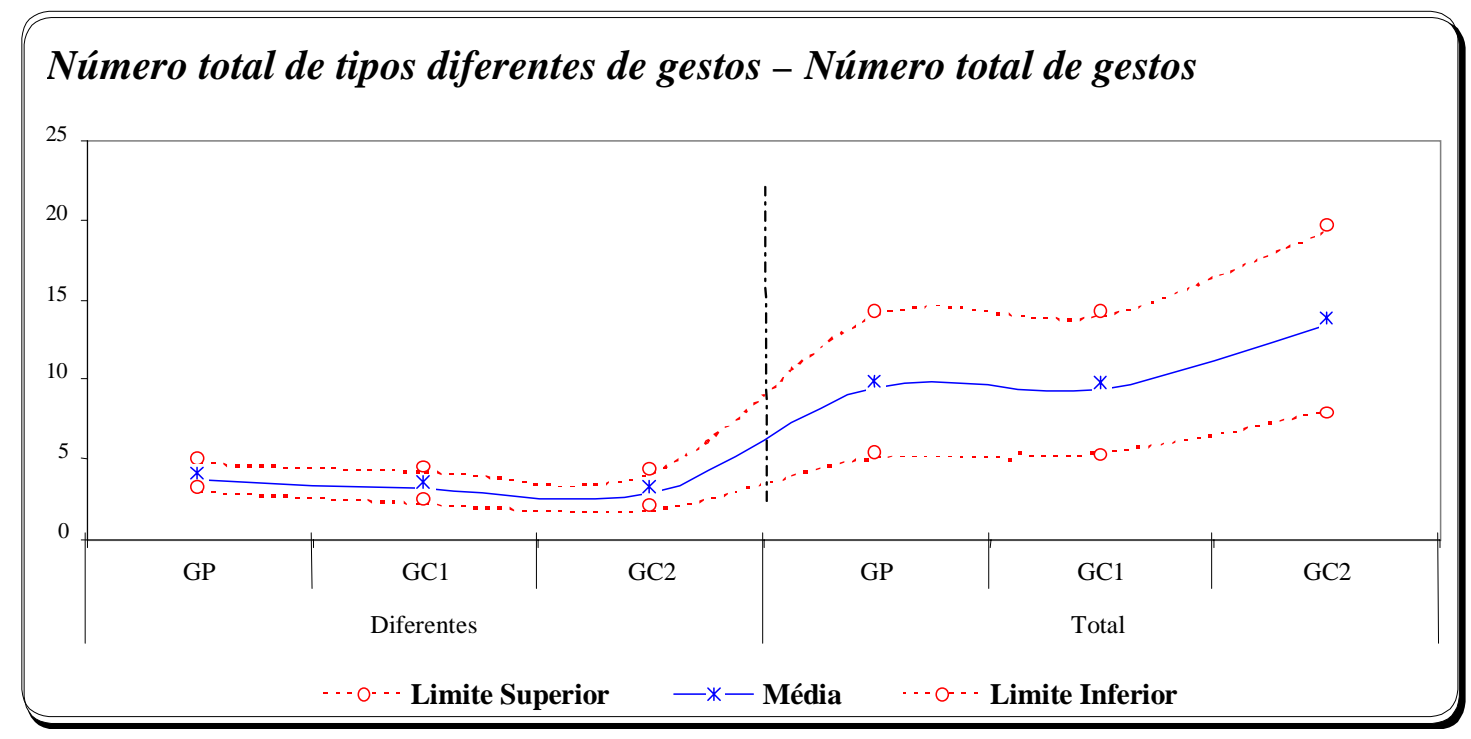

\begin{tabular}{|l|c|c|c|c|c|c|}
\hline \multirow{2}{*}{} & \multicolumn{3}{|c|}{$\begin{array}{c}\mathbf{N}^{\circ} \text { total de tipos } \\
\text { diferentes de gestos }\end{array}$} & \multicolumn{3}{c|}{$\mathbf{N}^{\circ}$ total de gestos } \\
\cline { 2 - 7 } & GP & GC1 & GC2 & GP & GC1 & GC2 \\
\hline Limite Superior & 4,62 & 4,09 & 4,08 & 13,93 & 13,95 & 19,31 \\
\hline Média & 3,75 & 3,09 & 2,91 & 9,5 & 9,45 & 13,45 \\
\hline Limite Inferior & 2,88 & 2,1 & 1,74 & 5,07 & 4,96 & 7,59 \\
\hline
\end{tabular}

Ao se observar os p-valores acima, verifica-se que não existe média estatisticamente significante entre os grupos.

Desse modo, conclui-se que, em todas as análises para a linguagem oral e comunicação gestual simultâneas, não foram encontradas diferenças significantes entre os grupos, sendo que, os três grupos comportaram-se estatisticamente iguais. 
6. DISCUSSÃO 
A discussão dos resultados obtidos será abordada a partir da comparação intra-grupal dos GP, GC1 e GC2 e, a seguir, inter-grupal.

$\mathrm{Na}$ comparação intra-grupal, para facilitar a compreensão dos resultados obtidos de acordo com a hipótese e objetivos propostos, dar-se-á início à discussão a partir do GC2, visto que os seus sujeitos apresentavam DT e, em seguida, os outros grupos por serem constituídos por sujeitos com SD.

\section{Comparação intra-grupal do GC2}

De um modo geral, pode-se dizer que os dados obtidos com os sujeitos do GC2 referentes à emergência de sua comunicação expressiva, considerando-se as três avaliações, estiveram de acordo com a literatura. Observou-se que, durante a emergência da comunicação expressiva dos sujeitos deste grupo, ocorreu a evolução da comunicação gestual para a linguagem oral e comunicação gestual simultâneas e, desta, para a linguagem oral espontânea.

Durante a primeira avaliação, a forma predominante de comunicação de todos os sujeitos deste grupo foi a gestual, de modo que os gestos representativos de conteúdo semântico foram os mais apresentados pela maioria dos sujeitos. Tais dados foram compatíveis tanto com as pesquisas de Acredolo e Goodwyn (1988) quando ressaltaram a influência dos gestos no início dos estágios de desenvolvimento da linguagem, como as de Thal e 
Tobias (1992) sobre a presença de gestos representativos, denominados pelos autores de simbólicos, neste mesmo período. Entretanto, S12 foi o único a apresentar palavras e gestos simultâneos com predomínio dos gestos dêiticos, ao invés dos representativos de conteúdo semântico, contrariando os estudos de Thal e Tobias (1992).

Nesta avaliação, embora a metade destes sujeitos não tivesse emitido palavras espontaneamente, S11 e S12 apresentaram algumas emissões de substantivos, sendo que S12 ainda apresentou algumas de verbos. Tais dados confirmam, não somente os estudos de alguns autores sobre a presença de substantivos no início do desenvolvimento lexical (Reed, 1994; Colombo e Burani, 2002; Theakston et al., 2004; Blackwell, 2005; Jones e Smith, 2005; Ninio, 2005), como também indicam que S12 estava um pouco mais adiantado que os outros sujeitos de seu grupo com relação ao desenvolvimento da linguagem oral. Tal fato justifica-se por este sujeito apresentar a emissão de alguns verbos em seu repertório lingüístico, segundo as observações de Owens (1996) e Veneziano (1999) sobre a ocorrência desta classe de palavras durante a expansão vocabular da criança.

$\mathrm{Na}$ segunda avaliação, foi observado que todos os sujeitos apresentaram evolução tanto em relação ao número de classes de palavras quanto ao de gestos, quando produzidos espontaneamente, porém, a maioria deles apresentou maior evolução na ocorrência da linguagem oral e comunicação gestual simultâneas. A exceção foi feita para S10, o qual ainda se comunicava predominantemente por meio de gestos. 
$\mathrm{Na}$ ocorrência desta forma de comunicação, basicamente houve distribuição semelhante entre gestos dêiticos de mostrar e os representativos de conteúdo semântico, bem como entre as classes substantivos e verbos, tal qual afirmaram McEachern e Haynes (2004) e Ozcaliskan e Goldin-Meadow (2005) sobre o uso igual de gestos e palavras como o indício de que, em breve, a criança estaria emitindo frases compostas apenas de palavras.

Após as classes substantivos e verbos, foi observado, em alguns sujeitos, o aumento do número de pronomes e advérbios, confirmando os estudos de Maldonado (1993) a respeito do desenvolvimento dessas classes de palavras paralelo ao das duas primeiras.

Por outro lado, tal qual ocorreu com S12 na primeira avaliação, ao ser observada a linguagem oral espontânea dos sujeitos, a emissão de substantivos esteve presente na maioria deles, predominando sobre as outras classes de palavras, bem como a presença maior de gestos representativos de conteúdo semântico quando apresentados espontaneamente. S12 foi o único a apresentar, de maneira espontânea, mais verbos do que substantivos, confirmando que ele esteve mais adiante do que os outros sujeitos de seu grupo em relação ao desenvolvimento da emergência da comunicação expressiva e de acordo com a literatura (Brown, 1973; Maldonado, 1993; Owens, 1996; Shi et al., 1998; Veneziano, 1999; Camaioni e Longobardi, 2001; Colombo e Burani, 2002; Abbot-Smith, 2004; Theakston et al., 2004; Blackwell, 2005; Ninio, 2005). 
$\mathrm{Na}$ terceira avaliação, todos os sujeitos do GC2 apresentaram a diminuição de gestos e o aumento do número de palavras, passando a se comunicarem, predominantemente, por meio da linguagem oral espontânea, confirmando as pesquisas encontradas na literatura sobre a substituição dos gestos pelas palavras durante o desenvolvimento da linguagem na criança com DT à medida em que o seu vocabulário vai se expandindo (Acredolo e Goodwyn, 1988; Thal e Tobias, 1992; Lyytinen et al., 1999; McEachern e Haynes, 2004; Iverson e Goldin-Meadow, 2005; Ozcaliskan e GoldinMeadow, 2005). Metade dos sujeitos deste grupo apresentou a emissão de todas as classes de palavras e a outra metade, de quase todas, de modo que foi possível visualizar a presença de mais verbos do que das outras classes. Tais resultados demonstraram a evolução crescente deste grupo em relação à sua expansão vocabular de acordo com a literatura (Reed, 1994; Owens, 1996; Colombo e Burani, 2002; Araújo, 2003; Abbot-Smith, 2004; Theakston et al., 2004; Blackwell, 2005; Jones e Smith, 2005; Ninio, 2005), .

Nesta avaliação, ressalta-se que, na ocorrência de palavras e gestos simultâneos, além da quantidade de palavras ter sido maior do que a de gestos, foi observada uma maior variação de tipos diferentes de gestos do que quando eles ocorreram espontaneamente, indicando que estes sujeitos apenas utilizaram os gestos como apoio lingüístico, como referiram Thal e Tobias (1992), McEachern e Haynes (2004) e Iverson e Goldin-Meadow (2005) em seus estudos. 


\section{Comparação intra-grupal do GP}

Diferentemente do GC2, a discussão do GP será abordada iniciandose pelos dados mais gerais sobre o grupo e, depois, sobre a evolução de cada sujeito no decorrer das três avaliações. Justifica-se este procedimento pelo fato de que os sujeitos apresentaram tanto características comunicativas comuns entre eles, como individuais, as quais valem ser ressaltadas.

Na observação da seqüência dos resultados obtidos nas avaliações realizadas, pôde-se verificar que a maioria dos sujeitos partiu, basicamente, de uma comunicação predominantemente gestual e, a seguir, enquanto metade deles evoluiu para a emissão de palavras e gestos simultâneos, a outra metade evoluiu para uma maior variação na comunicação gestual.

Tal qual ocorreu com o GC2, inicialmente, os gestos apresentados em maior número pelos sujeitos deste grupo foram os representativos de conteúdo semântico, ao passo que, quando simultâneos às palavras, além dos representativos já mencionados, ocorreram alguns dêiticos. Observa-se que estes dados estão de acordo com as pesquisas de Acredolo e Goodwyn (1988) e de Thal e Tobias (1992) no que se refere ao desenvolvimento da comunicação gestual durante a emergência das expressões comunicativas.

Quanto à emissão de palavras, substantivo foi a classe mais emitida por alguns sujeitos do GP, sendo seguida de verbo, durante a ocorrência da linguagem oral e comunicação gestual simultâneas, durante as três avaliações. Tais dados estão de acordo com a literatura sobre a presença de 
substantivos no início do desenvolvimento lexical (Reed, 1994; Colombo e Burani, 2002; Theakston et al., 2004; Blackwell, 2005; Jones e Smith, 2005; Ninio, 2005), bem como indicam que este grupo apresentou desenvolvimento de linguagem mais atrasado e mais lento quando comparado com as crianças com DT, segundo os estudos de alguns autores (Jones, 1977; Cunningham et al., 1985; Gomes et al., 1992; Franco e Wishart, 1995; Cahill e Glidden, 1996; Clibbens, 2001; Andrade, 2002; Johanson-Glenberg e Chapman, 2004; Yoder e Warren, 2004).

Por outro lado, na ocorrência da linguagem oral espontânea, a situação apresentada foi oposta, ou seja, verbo foi a classe mais emitida pelos sujeitos, sendo seguida de substantivo. Este fato difere dos resultados obtidos no GC2, visto que a maioria dos sujeitos deste último apresentou mais verbos do que substantivos, nesta forma de comunicação, somente na última avaliação (Camaioni e Longobardi, 2001; Colombo e Burani, 2002; Grela, 2003; Jones e Smith, 2005).

No decorrer das avaliações de S1, foi observado que este sujeito apresentou, predominantemente, linguagem oral e comunicação gestual simultâneas para se expressar. Na primeira avaliação, ele apresentou basicamente a mesma quantidade de gestos e palavras, indicando, a princípio, que S1 já estava prestes a emitir frases compostas apenas de palavras, como afirmaram McEachern e Haynes (2004) e Ozcaliskan e Goldin-Meadow (2005) em seus estudos, visto que os gestos contribuem para o desenvolvimento lexical e sintático da linguagem oral, mas, à medida em que a criança vai aumentando a sua capacidade de se socializar, ela vai 
substituindo, aos poucos, os gestos pelas palavras (Shore et al., 1984; Acredolo e Goodwyn, 1988; Thal e Tobias, 1992; Iverson et al. 1994; Namy e Waxman, 1998; Guidetti, 1999; Namy e Waxman, 2002; McEachern e Haynes, 2004; Iverson e Goldin-Meadow, 2005; Oscaliskan e GoldinMeadow, 2005).

Na segunda avaliação, os gestos diminuíram e a emissão do número de classes de palavras aumentou quando ocorreu a linguagem oral e comunicação gestual simultâneas. Na terceira avaliação, por sua vez, o número de emissões de palavras diminuiu e aumentou o de gestos durante a mesma forma de comunicação. Por outro lado, durante a emissão de linguagem oral espontânea, S1 apresentou o aumento do número de classes de palavras. Estes dados confirmam, mais uma vez, que S1 estava prestes a emitir frases compostas apenas por palavras.

Com relação à emissão de palavras, ressalta-se que, diferente do que ocorreu na evolução da linguagem oral dos sujeitos do GC2, S1 apresentou maior número de substantivos na ocorrência da linguagem oral e comunicação gestual simultâneas no decorrer das três avaliações, enquanto que, na linguagem oral espontânea, o número maior foi de verbos durante as duas últimas avaliações.

Dentre os sujeitos do GP, S2 foi o único a apresentar a evolução predominante da comunicação gestual durante as três avaliações realizadas, cujos gestos variaram de acordo com o contexto em que se desenrolaram as situações e de modo compreensível para o interlocutor. As poucas palavras emitidas por S2 tiveram, somente, a função de acompanhar 
os gestos como apoio lingüístico. Os resultados apresentados por este sujeito confirmaram os estudos abordados na literatura sobre a preferência de alguns sujeitos com SD desenvolverem a sua comunicação neste sentido (Jenkins, 1993; Franco e Wishart, 1995; Foreman e Crews, 1998; Ramruttun e Jenkins, 1998; Chan e Iacono, 2001; Clibbens, 2001; Iverson et al., 2003; Iverson e Goldin-Meadow, 2005).

S3 iniciou a sua comunicação predominantemente por meio da linguagem oral e comunicação gestual simultâneas e evoluiu para a comunicação gestual, porém de modo mais atrasado do que S2.

S4, por sua vez, apresentou a sua comunicação partindo da predominância de gestos e evoluiu para a linguagem oral e comunicação gestual simultâneas, cujo desenvolvimento de linguagem esteve aproximado do de S1 na terceira avaliação. Com relação à emissão de classes de palavras, durante as três avaliações, S4 apresentou número maior de verbos do que substantivos na ocorrência da linguagem oral espontânea, enquanto que, na linguagem oral e comunicação gestual simultâneas, ocorreu a situação inversa. Observa-se que estes resultados diferem do que ocorreu com os sujeitos do GC2 e do que geralmente ocorre no desenvolvimento da linguagem oral da criança com DT, segundo a literatura (Reed, 1994; Owens, 1996; Camaioni e Longobardi, 2001; Colombo e Burani, 2002; Grela, 2003; Abbot-Smith, 2004; Jones e Smith, 2005). 


\section{Comparação intra-grupal do GC1}

Antes de dar início à discussão dos dados obtidos do GC1, vale ressaltar que os seus sujeitos não receberam atendimento fonoaudiológico na mesma instituição que o GP, bem como o processo terapêtico não era fundamentado no método dialético-didático (Parrat-Dayan, 1996) como o foi com o GP.

Os sujeitos do GC1 apresentaram o desenvolvimento de suas expressões comunicativas semelhante ao do GP, porém, de modo mais lento e atrasado do que o GP e do que este em relação ao GC2.

No decorrer das avaliações, observou-se que, embora a maioria dos sujeitos deste grupo tivessem desenvolvido a sua comunicação predominantemente por meio de gestos, a sua evolução não ocorreu da mesma forma que a do GP. Os gestos apresentados pelos sujeitos do GC1 apresentaram-se em menor número do que o do GP, bem como, menos variados. A razão para este fato pode estar relacionada, de um modo geral, à defasagem cognitiva destes sujeitos, a qual, apresentou-se mais comprometida do que para o GP, nas duas últimas avaliações, visto que, no início, ambos apresentavam a mesma fase de desenvolvimento cognitivo. Consequentemente, estas alterações podem ter interferido de forma significativa no desenvolvimento de suas expressões comunicativas. Tais resultados confirmam os estudos de alguns autores sobre o atraso de linguagem na criança com SD e a relação existente entre os desenvolvimentos cognitivo e de linguagem nesta população (Cunningham 
et al.,1985; Buckley, 1993; Messer e Hasan, 1994; Ruskin, 1994; Limongi et al., 2000; Andrade, 2002; Laws e Bishop, 2004).

Vale lembrar que Piaget (1990, edição original de 1946) já havia explicado sobre a estruturação e a dependência do desenvolvimento de linguagem em relação ao desenvolvimento cognitivo.

Os gestos de maior ocorrência observados nas expressões comunicativas dos sujeitos do GC1 foram os representativos de conteúdo semântico quando ocorria somente a comunicação gestual. Por outro lado, na ocorrência da linguagem oral e comunicação gestual simultâneas, além dos primeiros, a presença dos gestos dêiticos foi maior do que quando ocorria somente a comunicação gestual, tal como aconteceu com o GP e de acordo com as pesquisas de Franco e Wishart (1995) sobre o uso prolongado dos gestos dêiticos na criança com SD.

As classes de palavras mais presentes no repertório lingüístico de alguns sujeitos do GC1 foram substantivo e verbo, de modo que a primeira classe foi mais emitida do que a segunda na ocorrência da linguagem oral e comunicação gestual simultâneas ao passo que, durante a linguagem oral espontânea, foram verbo e substantivo, respectivamente. Observa-se que este fato está de acordo com os resultados do GP, porém, tal qual este último, também difere dos dados obtidos no GC2 e dos achados da literatura (Reed, 1994; Owens, 1996; Camaioni e Longobardi, 2001; Colombo e Burani, 2002; Grela, 2003; Abbot-Smith, 2004; Jones e Smith, 2005).

Durante as três avaliações dos sujeitos do GC1, foi observado que dois deles (S6 e S8), embora tivessem apresentado um número maior de 
ocorrências de linguagem oral e comunicação gestual simultâneas do que a comunicação gestual espontânea, S6 apresentou mais gestos do que palavras desde a primeira avaliação, ao passo que S8 evoluiu do número maior de gestos para o de palavras. Tais dados indicam que, enquanto S6 apresentou as palavras como apoio lingüístico aos gestos, S8 teve um desenvolvimento semelhante aos dos sujeitos do GP que evoluíram a sua comunicação neste sentido. Ressalta-se que, no primeiro caso, os resultados diferem do que ocorre com a criança com DT, visto que para estas os gestos é que servem de apoio às palavras na emergência da linguagem (Jenkins, 1993; Franco e Wishart, 1995; Foreman e Crews, 1998; Ramruttun e Jenkins, 1998; Chan e lacono, 2001; Clibbens, 2001; Iverson et al., 2003; Iverson e Goldin-Meadow, 2005). Por outro lado, assemelha-se aos resultados de alguns sujeitos do GP, bem como está de acordo com as citações de Jenkins (1993), sobre a preferência de algumas crianças com SD desenvolverem a sua linguagem desta forma.

S5 e S7, por sua vez, apresentaram o predomínio da comunicação gestual, indicando que, para eles, foi mais fácil comunicarem-se assim e de se fazerem melhor compreendidos pelo interlocutor, tal qual ocorreu com alguns sujeitos do GP e de acordo com alguns trabalhos relatados na literatura (Jenkins, 1993; Franco e Wishart, 1995; Stoel-Gammon, 2001; Chapman et al., 2002; Foreman et al. , 2003; Johnson-Glenberg e Chapman, 2004). 


\section{Comparação inter-grupal dos GP, GC1 e GC2}

De acordo com o estudo estatístico sobre a comparação entre os grupos, no decorrer das três avaliações realizadas, foi observado que somente existiu diferença significante no p-valor do GC2 em relação à expressão oral, demonstrando a evolução crescente deste grupo nesta forma de comunicação quando comparado com os demais grupos, os quais, estatisticamente, comportaram-se de modo semelhante para todos os aspectos avaliados na pesquisa.

Por outro lado, não ocorreram diferenças estatísticas significantes entre os $p$-valores para os três grupos no que se referiu à comunicação gestual e na linguagem oral e comunicação gestual simultâneas. A análise mais cuidadosa sobre esses fatos mostra que são dados complementares e que se justificam por si mesmos, pois o GC2 não apresentou diferenças estatísticas significantes com relação aos demais grupos justamente por ter evoluído na sua expressão oral, indicando que os seus sujeitos estavam diminuindo o número de gestos à medida em que aumentavam o de palavras, tal qual apontou a literatura (Acredolo e Goodwyn, 1988; Thal e Tobias, 1992; Iverson et al., 1994; Namy e Waxman, 1998; Guidetti, 1999; Namy e Waxman, 2002; McEachern e Haynes, 2004; Ozcaliskan e GoldinMeadow, 2005; Iverson e Goldin-Meadow, 2005).

Segundo as comparações intra-grupais realizadas anteriormente e os estudos de alguns autores (Cunningham et al., 1985; Johnson-Glenberg e Chapman, 2004; Laws e Bishop; 2004), verifica-se que, apesar dos GP e 
GC1 serem constituídos por sujeitos com SD e de apresentarem idades cronológicas aproximadas entre si e estarem na mesma fase do desenvolvimento cognitivo, no início da pesquisa, este desenvolvimento apresentou-se diferente em ambos os grupos, o que, consequentemente, interferiu no desenvolvimento de suas expressões comunicativas.

Estas diferenças podem ser justificadas por meio da própria evolução das expressões comunicativas apresentada pelos sujeitos de ambos os grupos, independente se foram realizadas predominantemente por meio de gestos, palavras e gestos simultâneos ou somente palavras. Como exemplo, pode-se citar o fato de que, embora alguns sujeitos do GP tivessem se comunicado predominantemente por meio de gestos, foi observado que as suas expressões comunicativas foram mais variadas e inteligíveis do que as de alguns sujeitos do GC1. Tais resultados estão de acordo com a literatura, confirmando que, apesar dos atrasos cognitivo e de linguagem presentes na criança com SD, o desenvolvimento cognitivo ocorre de modo mais eficiente do que o de linguagem e que, nesta, a compreensão é melhor do que a expressão (Cunningham et al., 1985; Martins et al., 1985; Buckley, 1993; Messer e Hasan, 1994; Ruskin et al., 1994; Kumin, 1999; Limongi et al., 2000; Dodd e Thompson, 2001; Andrade, 2002; Chapman et al., 2002; Iverson et al., 2003; Laws e Bishop, 2004; Ypsilanti et al., 2005).

Outro fato que contribui para justificar a melhor evolução do GP em relação ao GC1 fundamenta-se na utilização do método dialético-didático (Parrat-Dayan, 1996) realizado durante o processo terapêutico fonoaudiológico com o primeiro grupo. No decorrer deste processo, diante 
de cada dificuldade apresentada pelos sujeitos na realização das atividades propostas pela terapeuta, ocorria a intervenção desta última, incentivando-os a resolver o "problema", mostrando-lhes parte de sua resolução para que eles percebessem o seu processo e, a seguir, repetia-se a ação realizada naquele momento e nas terapias seguintes, até que a terapeuta tivesse a certeza da compreensão e aprendizado dos sujeitos sobre o que Ihes tinha sido proposto.

Ressalta-se que toda atividade apresentada aos sujeitos era iniciada a partir do seu conhecimento já construído sobre o objeto de atuação, de acordo com a sua fase de desenvolvimento cognitivo, em direção à próxima fase. Neste sentido, a terapeuta foi capaz de intervir respeitando o limite de resposta de cada sujeito, de acordo com o seu potencial naquele momento. Desse modo, foi possível observar, por exemplo, que S3 costumava resolver as suas dificuldades diante das atividades propostas de forma mais lenta e por um tempo mais longo do que S2.

Durante a realização das atividades propostas aos sujeitos, independente de sua forma de expressão comunicativa, a terapeuta também incentivava a emissão oral destes sujeitos, de acordo com o contexto em que se desenvolviam as ações. Eram apresentadas situações em que os sujeitos sentiam-se estimulados a se comunicarem como, por exemplo: pedindo algo, mostrando objetos ou ações, respondendo questões que lhes eram formuladas, e cantando, sempre fundamentado nos princípios do método dialético-didático e como proposto por Hoshino et al. (1994), Perez e 
Limongi (1998), Limongi et al. (2000), Alabarse (2002) e Andrade (2002), cujos estudos reforçam os achados da pesquisa ora discutida.

Quando algum dos sujeitos respondia às solicitações da terapeuta por meio de gestos, como ocorreu diversas vezes com S2, a terapeuta repetia a atividade, realizando-a junto com o sujeito, enquanto nomeava os objetos e descrevia as ações envolvidas.

Foi observado que todos estes procedimentos adotados pela terapeuta, em relação ao GP, favoreceram os resultados desta pesquisa em confirmação aos estudos de Piaget (1987, edição original de 1936; 1996, edição original de 1937; 1990, edição original de 1946), que a criança constrói o seu conhecimento agindo sobre o objeto (ação motora e sensorial), observando as transformações que é capaz de operar com ele e, assim, estabelecer relações entre as suas propriedades físicas. Agindo dessa forma, a criança raciocina sobre o objeto e, com o passar do tempo, ela reorganiza o seu conhecimento a respeito dele, de acordo com os estímulos que o meio the oferece e, principalmente, com a sua fase de desenvolvimento cognitivo.

Por meio do método dialético-didático, foi possível observar a capacidade que os sujeitos do GP tiveram de construir representações, segundo o desenvolvimento cognitivo de cada um, as quais manifestaram-se pelos gestos, palavras ou ambos (Piaget, 1990, edição original de 1946; Iverson et al., 2003; Iverson e Goldin-Meadow, 2005).

No decorrer do processo terapêutico e das três avaliações realizadas, foi observada, à medida que as sessões eram filmadas, transcritas e 
analisadas, a possibilidade de acompanhamento da evolução dos desenvolvimentos cognitivo e de linguagem dos sujeitos dos três grupos, verificando-se que, aos poucos, as suas dificuldades eram compreendidas e o seu conhecimento reorganizado. Assim, pode-se afirmar que o uso de filmadora e a transcrição das situações possibilitaram a comparação dos dados obtidos, tal qual sugeriram Thiollent (1985), Baum e Gray (1992), Cordes (1994), Elder (1999) e Steinke (2001) favorecendo, também, maior objetividade na análise das situações, o que se mostrou muito importante por se tratar de estudo qualitativo.

A confirmação dessas observações foi feita pela contribuição dada por meio da utilização de juizes, que corroboraram esta análise (Fleiss, 1981; Siegel e Castellan, 1988; Lee e Goldman, 1989; Scarsellone, 1998). 
7. CONCLUSÕES 
De acordo com a análise e a discussão dos resultados obtidos durante a pesquisa, confirma-se a hipótese que originou este estudo: por meio do método dialético-didático é possível favorecer o desenvolvimento da linguagem e sua expressão oral, a partir da expressão gestual, em crianças com SD entre o final do período sensório-motor e o início do pré-operatório.

A confirmação desta hipótese está baseada no estudo qualitativo realizado e que cumpriu os objetivos inicialmente propostos:

- quanto à emergência da linguagem oral e sua relação com a comunicação gestual, verificou-se que na criança com SD, os gestos desenvolveram-se antes da linguagem oral, tal qual ocorre com a criança com DT, mas se prolongaram por mais tempo. Em alguns casos foi observado que os gestos foram utilizados acompanhando as palavras e, com o decorrer do desenvolvimento lexical, houve diminuição do seu número de ocorrências; em outros, sua utilização foi em substituição à linguagem oral, mas de modo compreensível para o interlocutor, por variarem de acordo com o contexto.

- no que se refere à evolução dos gestos e à sua qualificação, foi verificado que as crianças com SD que apresentaram linguagem oral e comunicação gestual simultâneas diminuíram a quantidade de gestos à medida que ampliaram o seu vocabulário sem, contudo, deixá-los de apresentar por um período longo. Por outro lado, outras ampliaram a quantidade de gestos em detrimento do desenvolvimento da linguagem oral e, neste caso, a comunicação gestual apresentou variedade tanto com relação ao número de gestos quanto aos tipos apresentados. 
- o método dialético-didático favoreceu o desenvolvimento de linguagem e sua expressão oral nas crianças com SD, a partir da comunicação gestual, o que foi verificado ao se constatar a evolução apresentada pelo GP durante e após o período a que se submeteram à intervenção fonoaudiológica, comparando-se seu desempenho com as crianças do GC1. 
8. ANEXOS 


\section{$\underline{\text { ANEXOA }}$}

Protocolo de avaliação de linguagem e cognição 
PROTOCOLO DE AVALIAÇÃO DE LINGUAGEM E COGNIÇÃO

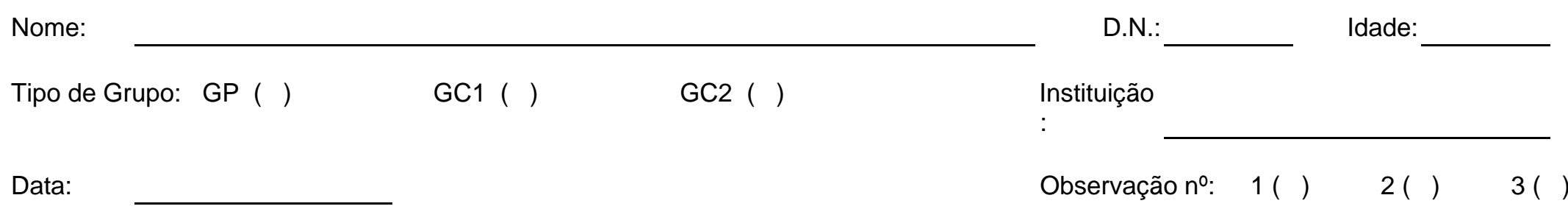

\begin{tabular}{|c|c|c|c|c|}
\hline OBJETO & AÇÃO & LGG ORAL & COMUNICAÇÃO GESTUAL & OBS. \\
\hline & & & & \\
\hline & & & & \\
\hline & & & & \\
\hline & & & & \\
\hline & & & & \\
\hline & & & & \\
\hline & & & & \\
\hline & & & & \\
\hline & & & & \\
\hline & & & & \\
\hline & & & & \\
\hline & & & & \\
\hline & & & & \\
\hline
\end{tabular}




\section{ANEXO B}

\section{Protocolo de análise de linguagem e cognição}

B1. Protocolo de análise de linguagem e cognição (modelo - GP)

B2. Protocolo de análise de linguagem e cognição (modelo - GC1)

B3. Protocolo de análise de linguagem e cognição (modelo - GC2) 
PROTOCOLO DE ANÁLISE DE LINGUAGEM E COGNIÇÃO

NOME:

Tipo de Grupo: GP ( )

Data:
D.N.:

GC2（） 2()$\quad 3()$

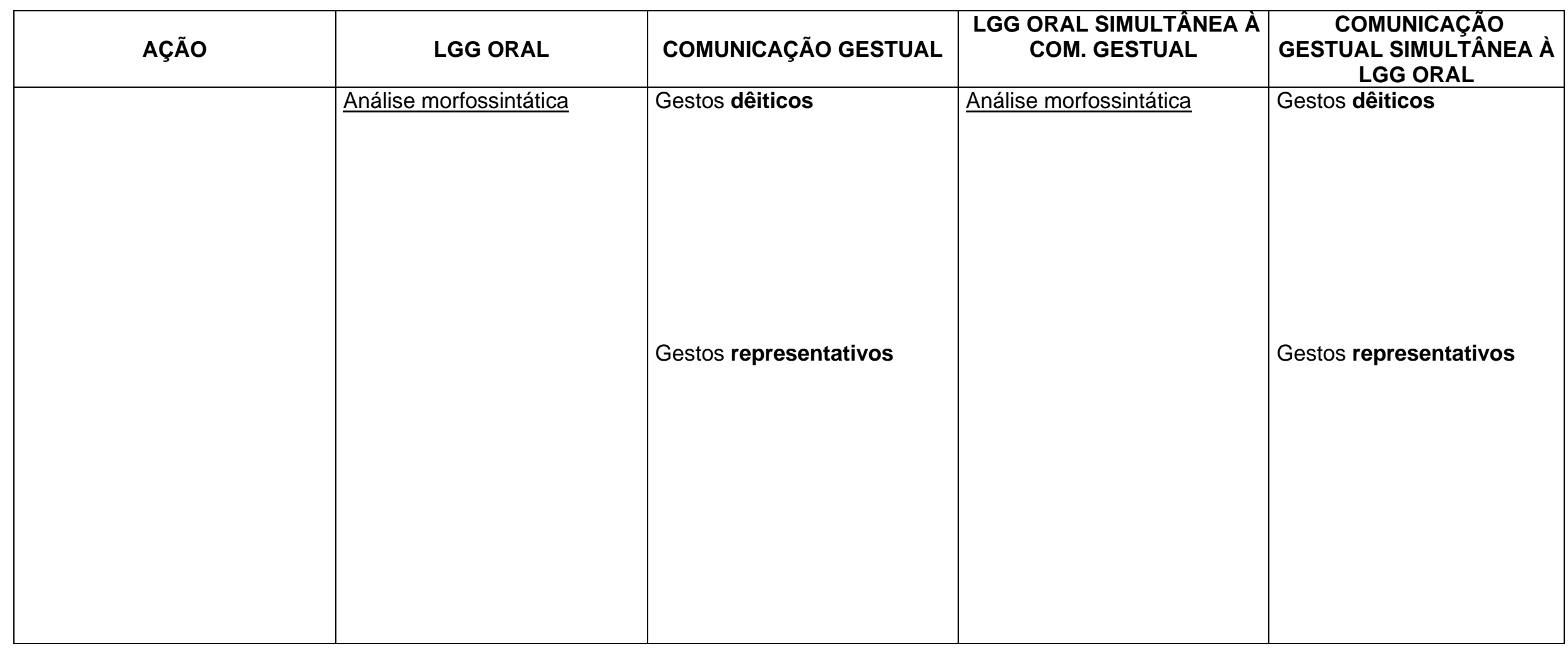




\section{B1 - PROTOCOLO DE ANÁLISE DE LINGUAGEM E COGNIÇÃO}

NOME: R.F.C.

$$
\text { D.N.: 06/11/2000 }
$$

\section{Tipo de Grupo: GP (X) GC1（ ) GC2（） Instituição: LIFSASM}

Data: $16 / 12 / 2003$

Observação $n^{\circ}: 1(X) \quad 2() \quad 3($ )

\begin{tabular}{|c|c|c|c|c|}
\hline AÇÃO & LGG ORAL & COMUNICAÇÃO GESTUAL & 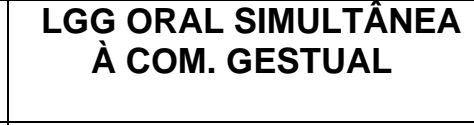 & $\begin{array}{c}\text { COMUNICAĈ̃̃O } \\
\text { GESTUAL SIMULTÂNEA À } \\
\text { LGG ORAL }\end{array}$ \\
\hline $\begin{array}{l}\text { Imitação: } \\
\text { - } \quad \text { VI fase: imitação diferida. } \\
\text { Jogo simbólico: } \\
\text { - } \quad \text { esquemas simbólicos; } \\
\text { - } \quad \text { projeção dos esquemas } \\
\text { nos objetos novos (Fase I, } \\
\text { tipo IA). } \\
\text { projeção de esquemas de } \\
\text { imitação em novos objetos } \\
\text { (Fase I, tipo IB). } \\
\text { Início da assimilação } \\
\text { simples de um objeto a um } \\
\text { outro (Fase I, tipo IIA). } \\
\text { Início da assimilação do } \\
\text { corpo do sujeito ao de } \\
\text { outrem ou a quaisquer } \\
\text { objetos (Fase I, tipo IIB). }\end{array}$ & 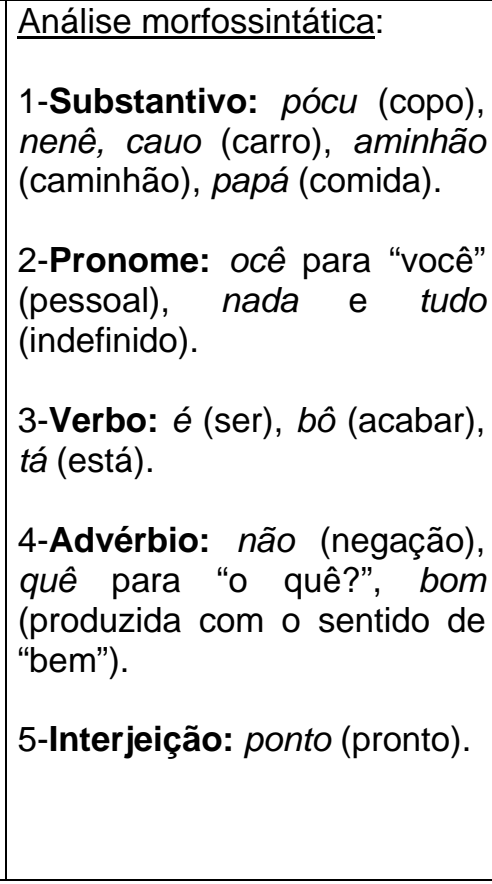 & $\begin{array}{l}\text { Gestos dêiticos } \\
\text { Gestos representativos: } \\
\text { - de conteúdo semântico: } \\
\text { 1. mexe uma colher dentro } \\
\text { da panela; } \\
\text { 2. faz o carrinho andar, } \\
\text { imitando, ao mesmo } \\
\text { tempo, o som do carro; } \\
\text { 3. abre e fecha a porta do } \\
\text { carrinho, imitando o som } \\
\text { da batida da porta, como } \\
\text { se alguém tivesse saído } \\
\text { de dentro dele; } \\
\text { coloca duas canecas com } \\
\text { colheres sobre o fogão } \\
\text { para fazer "comida"; } \\
\text { dá "comida" para a }\end{array}$ & $\begin{array}{l}\text { Análise morfossintática: } \\
\text { 1- Substantivo: pócu } \\
\text { (copo), ié (colher), papai, } \\
\text { nenê, cauo (carro), mamãe, } \\
\text { giafa (girafa), lão (leão), tigui } \\
\text { (tigre), taco (macaco), tuto } \\
\text { (suco), aanja (laranja), usso } \\
\text { (urso). } \\
\text { Pronome: tudo } \\
\text { (indefinido), cê para "você" } \\
\text { (pessoal). } \\
\text { 3-Verbo: cabô e abô } \\
\text { (acabar), vô e i (ir), ábi } \\
\text { (abrir). } \\
\text { 4-Advérbio: aqui e qui para } \\
\text { "aqui" (lugar), num } \\
\text { (negação). }\end{array}$ & $\begin{array}{l}\text { Gestos dêiticos: } \\
\text { - mostrar: } \\
\text { 1. à medida em que vai } \\
\text { tirando os objetos da cesta, } \\
\text { olha para a terapeuta e os } \\
\text { nomeia; } \\
\text { 2. olha para o berço e, em } \\
\text { seguida para a terapeuta } \\
\text { dizendo, ao mesmo tempo } \\
\text { "nenê"; } \\
\text { à medida que junta os } \\
\text { animais de brinquedo, } \\
\text { nomeia-os mostrando-os à } \\
\text { terapeuta; } \\
\text { toca com os dedos na porta } \\
\text { do carrinho e diz "cauo" } \\
\text { (carro), enquanto olha, ao } \\
\text { mesmo tempo, para a } \\
\text { terapeuta. }\end{array}$ \\
\hline
\end{tabular}




\begin{tabular}{|c|c|c|c|}
\hline 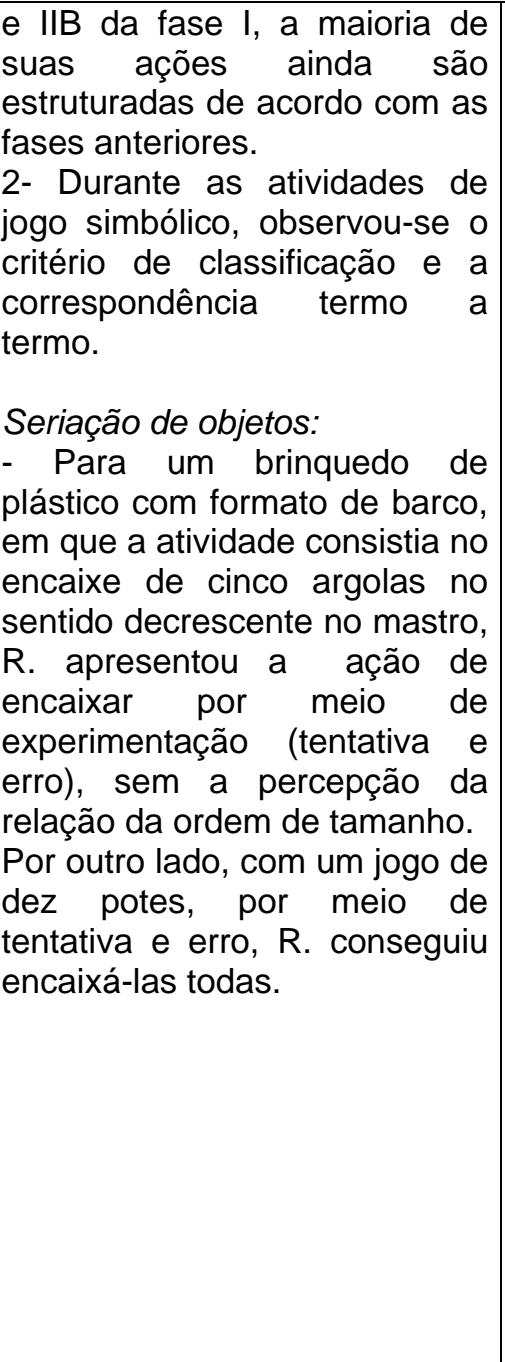 & \begin{tabular}{|l} 
boneca, levando a colher \\
da caneca para a boca da \\
boneca; \\
6. leva a colher com \\
"comida" para a sua boca; \\
7. oferece a "comida" na \\
colher para a terapeuta; \\
8. faz carinho na cabeça do \\
"nenê"; \\
9. limpa a boca do "nenê" \\
com o babador depois de \\
dar-lhe a comida; \\
10. leva o copo à boca da \\
boneca. \\
- convencional: \\
1. lacena "não" com a \\
cabeça.
\end{tabular} & $\begin{array}{l}\text { 5-Interjeição: aô (alô), oi, } \\
\text { gada (obrigada). }\end{array}$ & $\begin{array}{l}\text { Gestos representativos: } \\
\text { de conteúdo semântico: } \\
\text { 1. fala ao telefone; } \\
\text { 2. oferece o telefone à } \\
\text { terapeuta; } \\
\text { 3. tenta tampar a panela } \\
\text { sobre o fogão; } \\
\text { 4. faz movimentos de vai e } \\
\text { vem com o carro; } \\
\text { 5. segura um dos carrinhos e } \\
\text { diz "papai"; } \\
\text { 6. coloca a colher dentro do } \\
\text { copo; } \\
\text { 7. mexe a colher dentro da } \\
\text { caneca; } \\
\text { 8. tenta tampar as panelas } \\
\text { para levá-las ao fogão; } \\
\text { 9. segura a boneca ninando- } \\
\text { a; } \\
\text { 11. pega um copo e faz-de- } \\
\text { conta que coloca suco } \\
\text { nele; }\end{array}$ \\
\hline
\end{tabular}




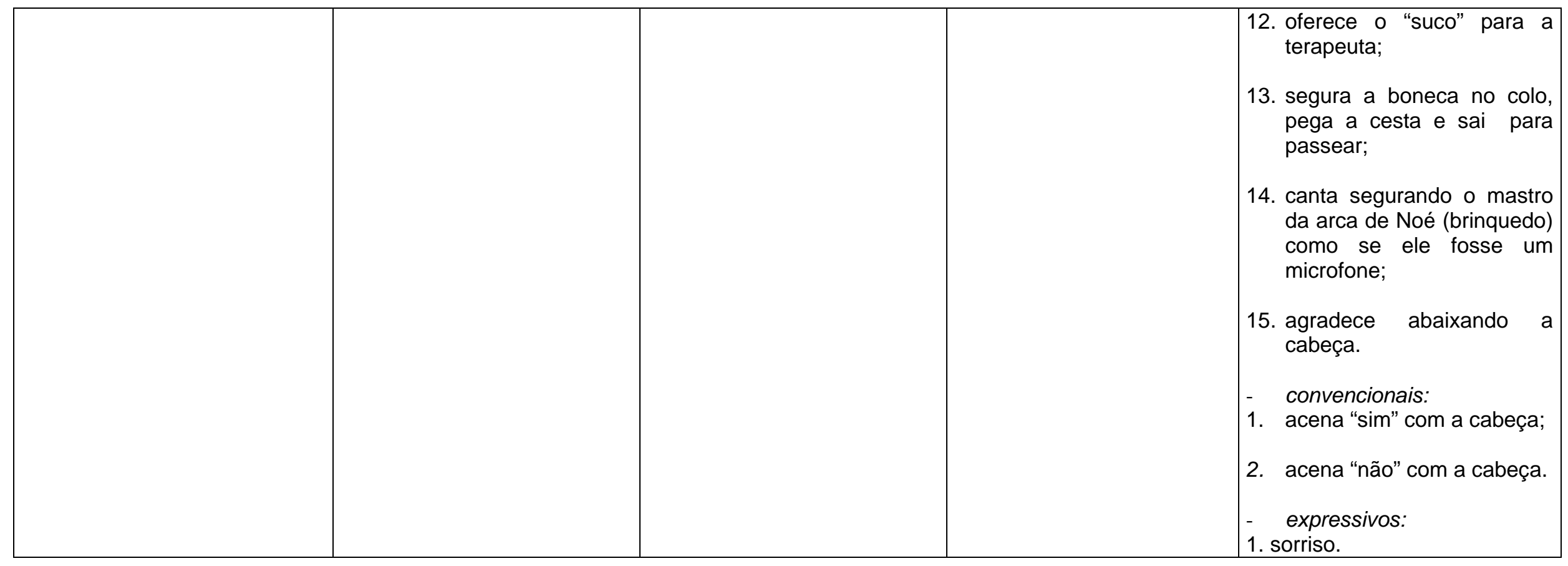




\section{B2 - PROTOCOLO DE ANÁLISE DE LINGUAGEM E COGNIÇÃO}

NOME: E.B.M.

Tipo de Grupo: GP ( )

D.N.: 19/05/2000

Idade: $3 a 6 m$

Data: $20 / 11 / 2003$
$\operatorname{GC1}(\mathbf{X}) \quad \mathrm{GC} 2(\quad)$

$\operatorname{GC1}(\mathbf{X}) \quad \mathrm{GC} 2(\quad)$

Instituição: APAE (Santo André)

\begin{tabular}{|c|c|c|c|c|}
\hline AÇÃO & LGG ORAL & COMUNICAÇÃO GESTUAL & $\begin{array}{c}\text { LGG ORAL SIMULTÂNEA À } \\
\text { COM. GESTUAL }\end{array}$ & $\begin{array}{c}\text { COMUNICAÇÃO } \\
\text { GESTUAL SIMULTÂNEA À } \\
\text { LGG ORAL }\end{array}$ \\
\hline 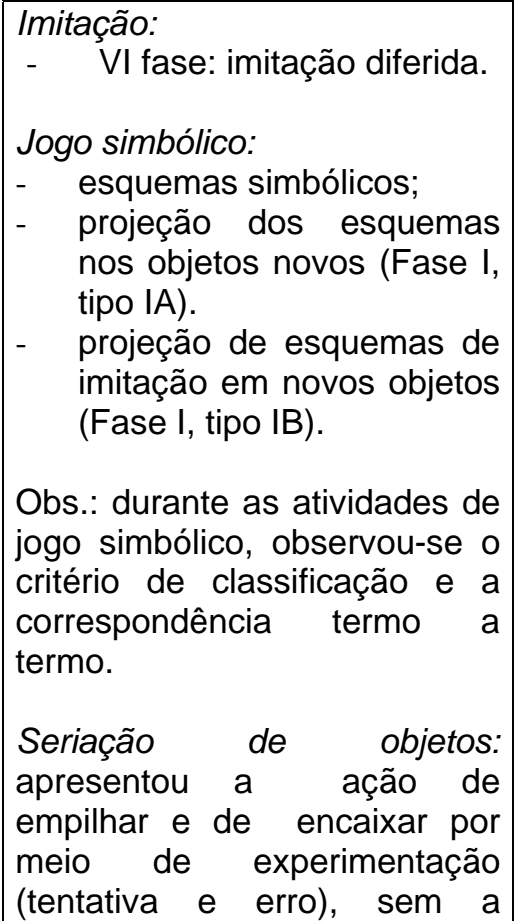 & $\begin{array}{l}\text { Análise morfossintática: } \\
\text { 1-Verbo: cai (cair), vamu (ir). } \\
\text { 2-Artigo: } 0 .\end{array}$ & $\begin{array}{l}\text { Gestos dêiticos: } \\
\text { - mostrar: } \\
\text { 1. segura uma colher, } \\
\text { mostrando-a à avaliadora. } \\
\text { Gestos representativos: } \\
\text { - de conteúdo semântico: } \\
\text { 1. segura a boneca e a } \\
\text { coloca no berço; } \\
\text { 2. leva uma xícara à boca } \\
\text { da boneca; } \\
\text { 3. leva a colher à boca da } \\
\text { boneca; } \\
\text { 4. mexe uma colher na } \\
\text { panela; } \\
\text { 5. leva uma colher à sua } \\
\text { boca; } \\
\text { 6. retira a "comida" da }\end{array}$ & $\begin{array}{l}\text { Análise morfossintática: } \\
\text { 1-Substantivo: nenê, pé, } \\
\text { bezo (beijo), ca e cau (carro). } \\
\text { 2-Adjetivo: tosu (gostoso). } \\
\text { 3-Verbo: iu (cair), tá (tomar), } \\
\text { é (ser), tá (estar), dá (dar), } \\
\text { umí (dormir), ábi (abrir), essô } \\
\text { (fechou), tó ("toma", sentido } \\
\text { de oferecer algo). } \\
\text { 4-Interjeição: eh, ah, iô (alô). }\end{array}$ & 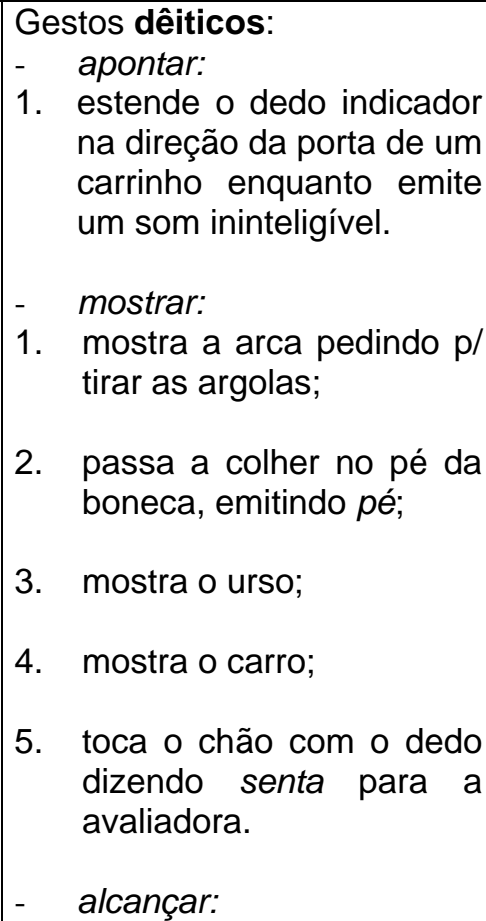 \\
\hline
\end{tabular}




\begin{tabular}{|c|c|c|}
\hline $\begin{array}{l}\text { percepção da relação da } \\
\text { ordem de tamanho. Observou- } \\
\text { se o mesmo no sentido } \\
\text { horizontal. }\end{array}$ & $\begin{array}{l}\text { panela e a leva à boca da } \\
\text { boneca; } \\
\text { 7. limpa a boca da boneca } \\
\text { com a sua toalha; } \\
\text { 8. leva um copo à boca da } \\
\text { boneca; } \\
\text { 9. mexe uma colher no copo } \\
\text { e a leva à boca da } \\
\text { boneca; } \\
\text { 10. segura a boneca em seu } \\
\text { colo; } \\
\text { 11. faz a boneca cavalgar } \\
\text { sobre um elefante; } \\
\text { 12. mexe uma panela com o } \\
\text { seu dedo e o leva à sua } \\
\text { boca; } \\
\text { 13. pega uma tampa e tampa } \\
\text { uma panela; } \\
\text { 14. imita a avaliadora } \\
\text { empurrando um carrinho; } \\
\text { 15. empurra um caminhão. }\end{array}$ & $\begin{array}{l}\text { 1. } \begin{array}{l}\text { estende o braço para } \\
\text { pegar o caminhão } \\
\text { dizendo dá; }\end{array} \\
\text { 2. } \begin{array}{l}\text { estende os dois braços, } \\
\text { dizendo dá. }\end{array} \\
\text { Gestos representativos: } \\
\text { - de conteúdo semântico: } \\
\text { 1. } \begin{array}{l}\text { retira a boneca do berço } \\
\text { dizendo nenê; }\end{array} \\
\text { 2. leva a panela à boca da } \\
\text { boneca; } \\
\text { 3. leva a xícara à boca da } \\
\text { boneca, dizendo bebe; } \\
\text { 4. leva o prato diretamente à } \\
\text { boca da boneca; } \\
\text { 5. leva o copo à boca da } \\
\text { boneca; } \\
\text { 6. fala ao telefone; } \\
\text { 7. destampa a panela, mexe } \\
\text { com a colher dentro e a } \\
\text { leva à boca da avaliadora } \\
\text { dizendo tá; } \\
\text { toma a sua toalha da mão } \\
\text { da avaliadora, dizendo dá } \\
\text { e cobre a boneca com } \\
\text { ela; }\end{array}$ \\
\hline
\end{tabular}




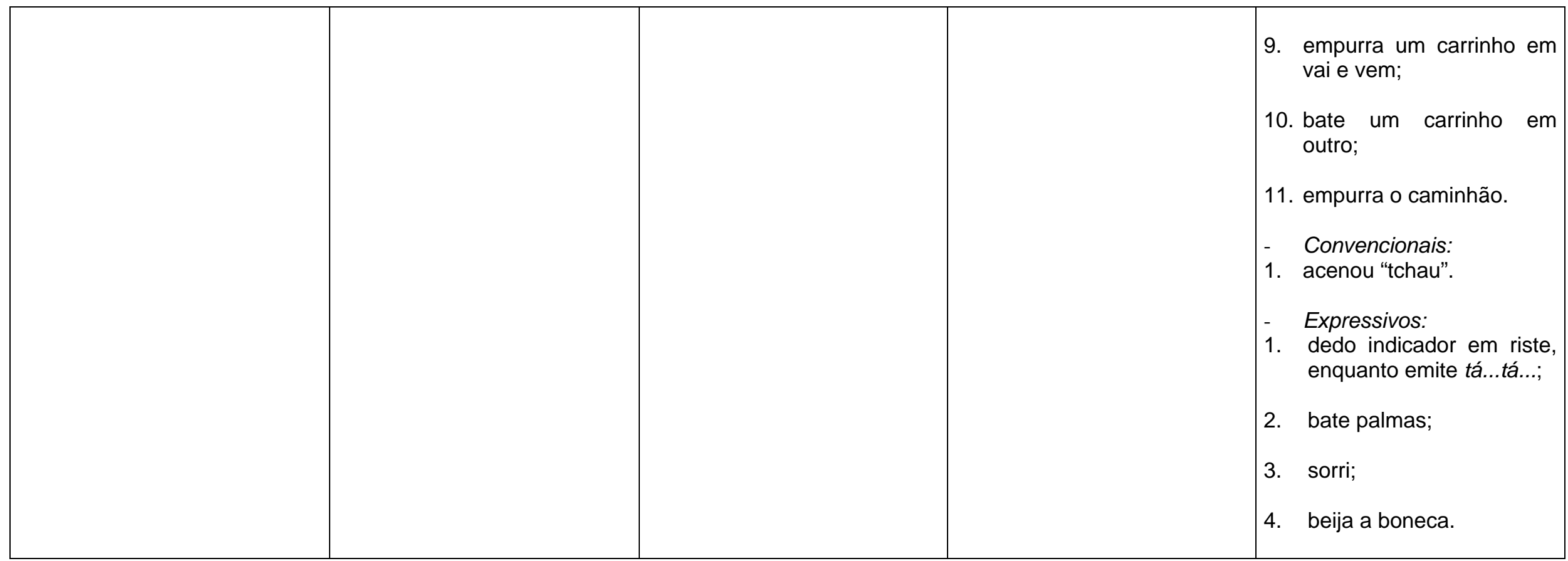




\section{B3 - PROTOCOLO DE ANÁLISE DE LINGUAGEM E COGNIÇÃO}

NOME: A. C. U. R.

D.N.: 08/04/2002

Idade: $1 \mathrm{a} 7 \mathrm{~m}$

Tipo de Grupo: GP ( ) GC1( ) GC2 (X)

Instituição: EMEB

Data: $13 / 11 / 2003$

Observação $n^{\circ}: 1(X)$

$2($ )

3()

\begin{tabular}{|c|c|c|c|c|}
\hline AÇÃO & LGG ORAL & COMUNICAÇÃO GESTUAL & $\begin{array}{l}\text { LGG ORAL SIMULTÂNEA À } \\
\text { COM. GESTUAL }\end{array}$ & $\begin{array}{c}\text { COMUNICAÇÃO } \\
\text { GESTUAL SIMULTÂNEA À } \\
\text { LGG ORAL }\end{array}$ \\
\hline $\begin{array}{l}\text { Imitação: } \\
\text { - VI fase: imitação diferida. }\end{array}$ & $\begin{array}{l}\text { Análise morfossintática: } \\
\text { 1-Substantivo: mãe, au-au }\end{array}$ & $\begin{array}{l}\text { Gestos dêiticos: } \\
-\quad \text { apontar: }\end{array}$ & Análise morfossintática & Gestos dêiticos \\
\hline $\begin{array}{l}\text { Seriação de objetos: } \\
\text { apresentou a ação de } \\
\text { empilhar e de encaixar } \\
\text { algumas canecas (duas) por } \\
\text { meio de experimentação } \\
\text { (tentativa e erro), sem a } \\
\text { percepção da relação da } \\
\text { ordem de tamanho. }\end{array}$ & & $\begin{array}{l}\text { animais. } \\
\text { Gestos representativos: } \\
-\quad \text { de conteúdo semântico: } \\
\text { 1. empurra um carrinho; } \\
\text { 2. empurra dois } \\
\begin{array}{l}\text { carrinhos ao mesmo } \\
\text { tempo. }\end{array} \\
\text { convencionais: } \\
\text { 1. acena "sim" com a cabeca. }\end{array}$ & & \\
\hline
\end{tabular}


ANEXOC

$\underline{\text { Material - (foto) }}$ 


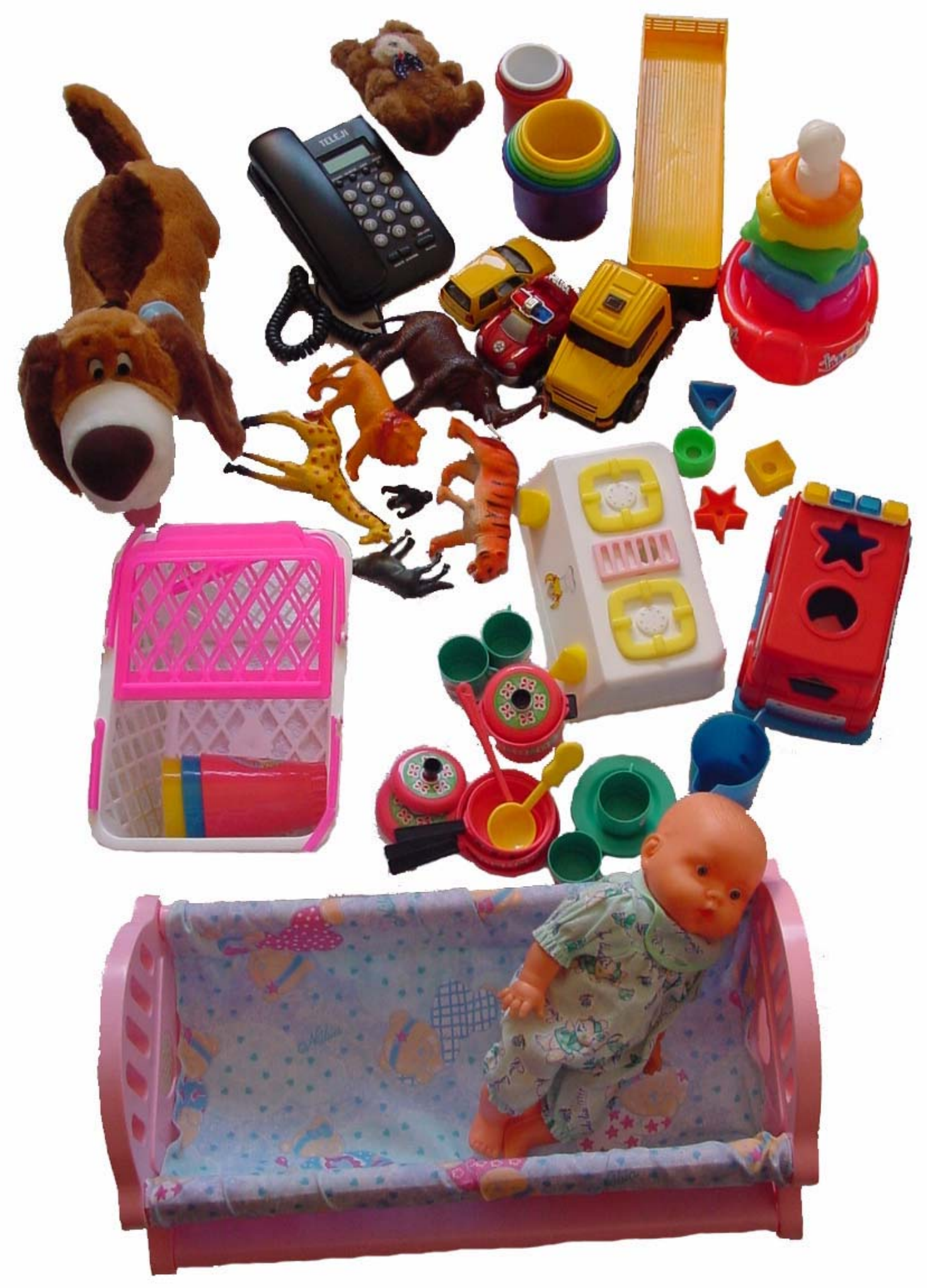




\section{ANEXO D}

Protocolo de observação 
PROTOCOLO DE OBSERVAÇÃO

Nome:

Tipo de Grupo: GP
Instituição: LIFSASM

\begin{tabular}{|l|l|l|l|}
\hline OBJETO & AÇ̃̃O & LGG ORAL & COMUNICAÇÃO GESTUAL \\
\hline & & & \\
\hline & & & \\
\hline & & & \\
\hline & & & \\
\hline & & & \\
\hline & & & \\
\hline & & & \\
\hline & & & \\
\hline & & & \\
\hline & & & \\
\hline & & & \\
\hline & & & \\
\hline
\end{tabular}

D.N.

Idade

Data: 


\section{ANEXOE}

Certificado de aprovação da comissão de ética para análise de projetos de pesquisa (CAPPesq) 


\section{$\underline{\text { ANEXOF }}$}

Termo de consentimento livre e esclarecido

F1. Modelo - GP

F2. Modelo - GC1

F3. Modelo - GC2 


\section{TERMO DE CONSENTIMENTO LIVRE E ESCLARECIDO (modelo GP)}

I - DADOS DE IDENTIFICAÇÃO DO SUJEITO DA PESQUISA OU RESPONSÁVEL
LEGAL
PACIENTE. DO

\section{II - DADOS SOBRE A PESQUISA CIENTÍFICA}

1. TÍTULO DO PROTOCOLO DE PESQUISA: A Emergência da Linguagem Expressiva na Criança com Síndrome de Down

PESQUISADOR: Rosangela Viana Andrade

CARGO/FUNÇÃO: Fonoaudióloga INSCRIÇÃO CONSELHO REGIONAL Nº 5574/SP UNIDADE DO HCFMUSP: Departamento de Fisioterapia, Fonoaudiologia e Terapia Ocupacional

3. AVALIAÇÃO DO RISCO DA PESQUISA:

$\begin{array}{lll}\text { SEM RISCO } & \text { XRISCO MÍNIMO } & \text { RISCO MÉDIO } \\ \text { RISCO BAIXO } & \text { RISCO MAIOR } & \end{array}$

(probabilidade de que o indivíduo sofra algum dano como consequência imediata ou tardia do estudo)

4.DURAÇÃO DA PESQUISA : 12 (doze) meses consecutivos 


\section{III - REGISTRO DAS EXPLICAÇÕES DO PESQUISADOR AO PACIENTE OU SEU REPRESENTANTE LEGAL SOBRE A PESQUISA, CONSIGNANDO:}

1. justificativa e os objetivos da pesquisa;

Pelo fato da criança com síndrome de Down apresentar o seu desenvolvimento global mais atrasado do que as crianças normais, inclusive o seu desenvolvimento de linguagem (a fala e a compreensão), o qual interfere na sua comunicação com as pessoas, esta pesquisa tem o objetivo de estudar as maneiras que a criança com síndrome de Down usa para comunicar-se com os outros (fala e/ou gestos).

2. procedimentos que serão utilizados e propósitos, incluindo a identificação dos procedimentos que são experimentais;

Para a realização desta pesquisa serão utilizados 3 (três) grupos de crianças, sendo que um deles é o de crianças com síndrome de Down que estão sendo beneficiadas por algum tipo de trabalho fonoaudiológico voltado à estimulação precoce. Cada criança será avaliada separada das outras, sendo que ela passará por três avaliações: uma avaliação inicial, a segunda avaliação depois de 6 (seis) meses da avaliação inicial e, a terceira avaliação, depois de 6 (seis) meses da segunda avaliação. No total, serão 3 (três) avaliações dentro do prazo de 1 (um) ano. Em cada avaliação será observado como a criança brinca e como ela se comunica: se é por palavras, se é por gestos ou se é pelos dois (palavras e gestos). Depois, os resultados de todas as crianças serão comparados com os das crianças dos outros grupos. Os materiais que serão utilizados para esta pesquisa serão somente brinquedos (carrinhos, jogo de panelinhas, canecas de encaixe e outros apropriados para a idade da criança).

3. desconfortos e riscos esperados;

A pesquisa não oferece nenhum tipo de desconforto ou risco para a criança.

4. benefícios que poderão ser obtidos;

Através desta pesquisa, será possível favorecer o desenvolvimento geral e principalmente o de linguagem da criança com síndrome de Down.

5. procedimentos alternativos que possam ser vantajosos para o indivíduo;

Caso seja descoberto qualquer problema com qualquer uma das crianças, os pais ou a família será comunicada imediatamente para que se possa tomar as providências necessárias, como por exemplo, o encaminhamento da criança a um profissional da saúde se ela precisar.

\section{IV - ESCLARECIMENTOS DADOS PELO PESQUISADOR SOBRE GARANTIAS DO SUJEITO DA PESQUISA:}

1. acesso, a qualquer tempo, às informações sobre procedimentos, riscos e benefícios relacionados à pesquisa, inclusive para dirimir eventuais dúvidas.

Qualquer dúvida que os pais ou o responsável pela criança tenham, eles poderão perguntar à fonoaudióloga. Também, caso eles queiram um relatório sobre os dados da pesquisa, eles poderão obtê-lo quando desejarem.

2. liberdade de retirar seu consentimento a qualquer momento e de deixar de participar do estudo, sem que isto traga prejuízo à continuidade da assistência.

Caso os pais ou o responsável pela criança desejarem não consentir mais a participação de sua criança na pesquisa, a sua vontade será respeitada sem qualquer prejuízo.

3. salvaguarda da confidencialidade, sigilo e privacidade.

Os pais ou a pessoa responsável pela criança podem estar certos de que a identidade da criança que está sendo pesquisada será preservada, tanto durante a pesquisa como após a 
publicação dos resultados. Somente a fonoaudióloga estará sabendo, além dos pais ou responsáveis pela criança sobre os seus resultados na pesquisa.

4. disponibilidade de assistência no HCFMUSP, por eventuais danos à saúde, decorrentes da pesquisa.

Esta pesquisa não oferece riscos à saúde da criança.

5. viabilidade de indenização por eventuais danos à saúde decorrentes da pesquisa.

Esta pesquisa não oferece riscos à saúde da criança.

\section{INFORMAÇÕES DE NOMES, ENDEREÇOS E TELEFONES DOS RESPONSÁVEIS PELO ACOMPANHAMENTO DA PESQUISA, PARA CONTATO EM CASO DE INTERCORRÊNCIAS CLÍNICAS E REAÇÕES ADVERSAS.}

Qualquer problema de saúde que venha a surgir na criança durante a pesquisa que a impossibilite de continuar participando, os pais ou o responsável pela criança poderá entrar em contato com:

NOME: Rosangela Viana Andrade

ENDEREÇO: Rua Cipotânea n 53, Cidade Universitária, São Paulo.

CEP: 05360-160 Telefone: 3091-7453 Celular: 9121-9899

\section{OBSERVAÇÕES COMPLEMENTARES:}

A partir da primeira avaliação, as crianças com síndrome de Down que farão parte da pesquisa e que já estavam em atendimento fonoaudiológico no Laboratório de Investigação Fonoaudiológica em Síndromes e Alterações Sensório-Motoras (LIFSASM), passarão a ser atendidas pela pesquisadora durante uma vez por semana, por um período de 1 (um) ano.

A criança que já estava em atendimento fonoaudiológico no LIFSASM não poderá ter mais do que três faltas (todas justificadas), senão será desligada do serviço, conforme os critérios adotados pelo LIFSASM.

\section{VII - CONSENTIMENTO PÓS-ESCLARECIDO}

Declaro que, após convenientemente esclarecido pelo pesquisador e ter entendido o que me foi explicado, consinto em participar do presente Protocolo de Pesquisa

São Paulo, de de 2003 . 


\section{TERMO DE CONSENTIMENTO LIVRE E ESCLARECIDO (modelo GC1)}

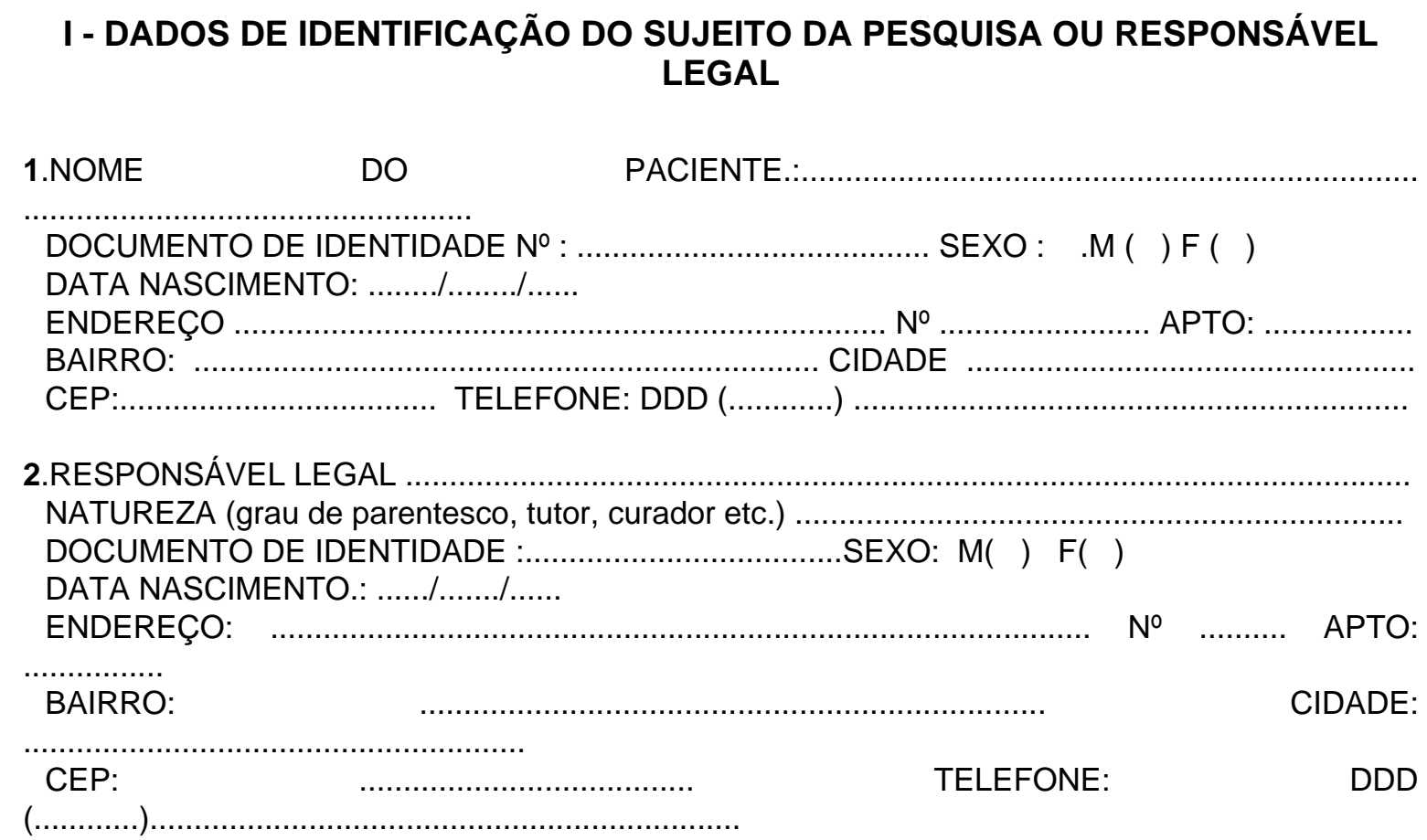

2.RESPONSÁVEL LEGAL

NATUREZA (grau de parentesco, tutor, curador etc.)

DOCUMENTO DE IDENTIDADE :.

DATA NASCIMENTO.: .....................

SEXO: $M(\quad) F(\quad)$

ENDEREÇO:

$\mathrm{N}^{\mathrm{O}}$

APTO:

BAIRRO:

CIDADE:

CEP:

TELEFONE:

DDD $(\ldots \ldots \ldots \ldots) . .$.

\section{II - DADOS SOBRE A PESQUISA CIENTÍFICA}

6. TÍTULO DO PROTOCOLO DE PESQUISA: A Emergência da Linguagem Expressiva na Criança com Síndrome de Down

PESQUISADOR: Rosangela Viana Andrade CARGO/FUNÇÃO: Fonoaudióloga INSCRIÇÃO CONSELHO REGIONAL No 5574/SP UNIDADE DO HCFMUSP: Departamento de Fisioterapia, Fonoaudiologia e Terapia Ocupacional

3. AVALIAÇÃO DO RISCO DA PESQUISA:

$\begin{array}{lll}\text { SEM RISCO } & \text { XRISCO MÍNIMO } & \text { RISCO MÉDIO } \\ \text { RISCO BAIXO } & \text { RISCO MAIOR } & \end{array}$

(probabilidade de que o indivíduo sofra algum dano como consequência imediata ou tardia do estudo)

4.DURAÇÃO DA PESQUISA : 12 (doze) meses consecutivos 


\section{III - REGISTRO DAS EXPLICAÇÕES DO PESQUISADOR AO PACIENTE OU SEU REPRESENTANTE LEGAL SOBRE A PESQUISA, CONSIGNANDO:}

6. justificativa e os objetivos da pesquisa;

Pelo fato da criança com síndrome de Down apresentar o seu desenvolvimento global mais atrasado do que as crianças normais, inclusive o seu desenvolvimento de linguagem (a fala e a compreensão), o qual interfere na sua comunicação com as pessoas, esta pesquisa tem o objetivo de estudar as maneiras que a criança com síndrome de Down usa para comunicar-se com os outros (fala e/ou gestos).

7. procedimentos que serão utilizados e propósitos, incluindo a identificação dos procedimentos que são experimentais;

Para a realização desta pesquisa serão utilizados 3 (três) grupos de crianças, sendo que um deles é o de crianças com síndrome de Down que estão sendo beneficiadas por algum tipo de trabalho fonoaudiológico voltado à estimulação precoce. Cada criança será avaliada separada das outras, sendo que ela passará por três avaliações: uma avaliação inicial, a segunda avaliação depois de 6 (seis) meses da avaliação inicial e, a terceira avaliação, depois de 6 (seis) meses da segunda avaliação. No total, serão 3 (três) avaliações dentro do prazo de 1 (um) ano. Em cada avaliação será observado como a criança brinca e como ela se comunica: se é por palavras, se é por gestos ou se é pelos dois (palavras e gestos). Depois, os resultados de todas as crianças serão comparados com os das crianças dos outros grupos. Os materiais que serão utilizados para esta pesquisa serão somente brinquedos (carrinhos, jogo de panelinhas, canecas de encaixe e outros apropriados para a idade da criança).

8. desconfortos e riscos esperados;

A pesquisa não oferece nenhum tipo de desconforto ou risco para a criança.

9. benefícios que poderão ser obtidos;

Através desta pesquisa, será possível favorecer o desenvolvimento geral e principalmente o de linguagem da criança com síndrome de Down.

10. procedimentos alternativos que possam ser vantajosos para o indivíduo;

Caso seja descoberto qualquer problema com qualquer uma das crianças, os pais ou a família será comunicada imediatamente para que se possa tomar as providências necessárias, como por exemplo, o encaminhamento da criança a um profissional da saúde se ela precisar.

\section{IV - ESCLARECIMENTOS DADOS PELO PESQUISADOR SOBRE GARANTIAS DO SUJEITO DA PESQUISA:}

1. acesso, a qualquer tempo, às informações sobre procedimentos, riscos e benefícios relacionados à pesquisa, inclusive para dirimir eventuais dúvidas.

Qualquer dúvida que os pais ou o responsável pela criança tenham, eles poderão perguntar à fonoaudióloga. Também, caso eles queiram um relatório sobre os dados da pesquisa, eles poderão obtê-lo quando desejarem.

7. liberdade de retirar seu consentimento a qualquer momento e de deixar de participar do estudo, sem que isto traga prejuízo à continuidade da assistência.

Caso os pais ou o responsável pela criança desejarem não consentir mais a participação de sua criança na pesquisa, a sua vontade será respeitada sem qualquer prejuízo.

8. salvaguarda da confidencialidade, sigilo e privacidade.

Os pais ou a pessoa responsável pela criança podem estar certos de que a identidade da criança que está sendo pesquisada será preservada, tanto durante a pesquisa como após a 
publicação dos resultados. Somente a fonoaudióloga estará sabendo, além dos pais ou responsáveis pela criança sobre os seus resultados na pesquisa.

9. disponibilidade de assistência no HCFMUSP, por eventuais danos à saúde, decorrentes da pesquisa.

Esta pesquisa não oferece riscos à saúde da criança.

10. viabilidade de indenização por eventuais danos à saúde decorrentes da pesquisa.

Esta pesquisa não oferece riscos à saúde da criança.

\section{INFORMAÇÕES DE NOMES, ENDEREÇOS E TELEFONES DOS RESPONSÁVEIS PELO ACOMPANHAMENTO DA PESQUISA, PARA CONTATO EM CASO DE INTERCORRÊNCIAS CLÍNICAS E REAÇÕES ADVERSAS.}

Qualquer problema de saúde que venha a surgir na criança durante a pesquisa que a impossibilite de continuar participando, os pais ou o responsável pela criança poderá entrar em contato com:

NOME: Rosangela Viana Andrade

ENDEREÇO: Rua Cipotânea n 53, Cidade Universitária, São Paulo.

CEP: 05360-160 Telefone: 3091-7453 Celular: 9121-9899

\section{OBSERVAÇÕES COMPLEMENTARES:}

\section{VII - CONSENTIMENTO PÓS-ESCLARECIDO}

Declaro que, após convenientemente esclarecido pelo pesquisador e ter entendido o que me foi explicado, consinto em participar do presente Protocolo de Pesquisa

São Paulo, de de 2003 . 


\section{TERMO DE CONSENTIMENTO LIVRE E ESCLARECIDO (modelo GC2)}

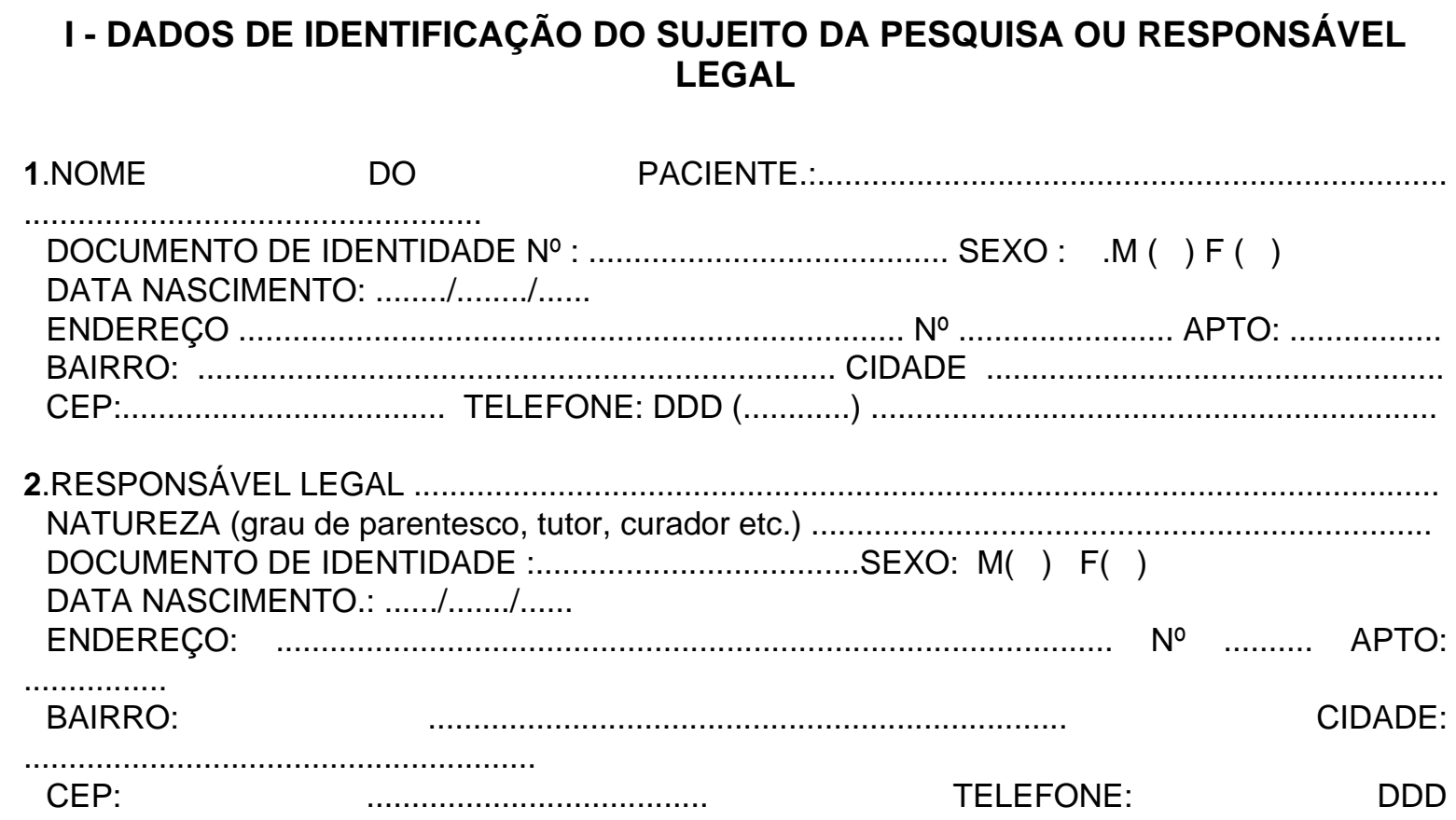

2.RESPONSÁVEL LEGAL

NATUREZA (grau de parentesco, tutor, curador etc.)

DOCUMENTO DE IDENTIDADE :.

DATA NASCIMENTO.: .....................

SEXO: $M(\quad) F(\quad)$

ENDEREÇO:

$\mathrm{N}^{\mathrm{O}}$

APTO:

BAIRRO:

CIDADE:

CEP:

TELEFONE:

DDD

\section{II - DADOS SOBRE A PESQUISA CIENTÍFICA}

11. TÍTULO DO PROTOCOLO DE PESQUISA: A Emergência da Linguagem Expressiva na Criança com Síndrome de Down

PESQUISADOR: Rosangela Viana Andrade

CARGO/FUNÇÃO: Fonoaudióloga INSCRIÇÃO CONSELHO REGIONAL No 5574/SP

UNIDADE DO HCFMUSP: Departamento de Fisioterapia, Fonoaudiologia e Terapia Ocupacional

3. AVALIAÇÃO DO RISCO DA PESQUISA:

$\begin{array}{lll}\text { SEM RISCO } & \text { XRISCO MÍNIMO } & \text { RISCO MÉDIO } \\ \text { RISCO BAIXO } & \text { RISCO MAIOR } & \end{array}$

(probabilidade de que o indivíduo sofra algum dano como consequência imediata ou tardia do estudo)

4.DURAÇÃO DA PESQUISA : 12 (doze) meses consecutivos 


\section{III - REGISTRO DAS EXPLICAÇÕES DO PESQUISADOR AO PACIENTE OU SEU REPRESENTANTE LEGAL SOBRE A PESQUISA, CONSIGNANDO:}

11. justificativa e os objetivos da pesquisa;

Pelo fato da criança com síndrome de Down apresentar o seu desenvolvimento global mais atrasado do que as crianças normais, inclusive o seu desenvolvimento de linguagem (a fala e a compreensão), o qual interfere na sua comunicação com as pessoas, esta pesquisa tem o objetivo de estudar as maneiras que a criança com síndrome de Down usa para comunicar-se com os outros (fala e/ou gestos).

12. procedimentos que serão utilizados e propósitos, incluindo a identificação dos procedimentos que são experimentais;

Para a realização desta pesquisa serão utilizados 3 (três) grupos de crianças, sendo que um deles é o de crianças normais com idade entre 10 (dez) e 18 (dezoito) meses. Cada criança será avaliada separada das outras, sendo que ela passará por três avaliações: uma avaliação inicial, a segunda avaliação depois de 6 (seis) meses da avaliação inicial e a terceira avaliação depois de 6 (seis) meses da segunda avaliação. No total, serão 3 (três) avaliações dentro do prazo de 1 (um) ano. Depois, os resultados de todas as crianças serão comparados com os das crianças dos outros grupos. Os materiais que serão utilizados para esta pesquisa serão somente brinquedos (carrinhos, jogo de panelinhas, canecas de encaixe e outros apropriados para a idade da criança).

13. desconfortos e riscos esperados;

A pesquisa não oferece nenhum tipo de desconforto ou risco para a criança.

14. benefícios que poderão ser obtidos;

Por meio desta pesquisa, será possível favorecer o desenvolvimento geral e principalmente o de linguagem da criança com síndrome de Down.

15. procedimentos alternativos que possam ser vantajosos para o indivíduo;

Caso seja descoberto qualquer problema com qualquer uma das crianças, os pais ou a família será comunicada imediatamente para que se possa tomar as providências necessárias, como por exemplo, o encaminhamento da criança a um profissional da saúde se ela precisar.

\section{IV - ESCLARECIMENTOS DADOS PELO PESQUISADOR SOBRE GARANTIAS DO SUJEITO DA PESQUISA:}

1. acesso, a qualquer tempo, às informações sobre procedimentos, riscos e benefícios relacionados à pesquisa, inclusive para dirimir eventuais dúvidas.

Qualquer dúvida que os pais ou o responsável pela criança tiverem, eles poderão perguntar à fonoaudióloga. Também, caso eles queiram um relatório sobre os dados da pesquisa, eles poderão obtê-lo quando desejarem.

12. liberdade de retirar seu consentimento a qualquer momento e de deixar de participar do estudo, sem que isto traga prejuízo à continuidade da assistência.

Caso os pais ou o responsável pela criança desejarem não consentir mais a participação de sua criança na pesquisa, a sua vontade será respeitada sem qualquer prejuízo.

13. salvaguarda da confidencialidade, sigilo e privacidade.

Os pais ou a pessoa responsável pela criança podem estar certos de que a identidade da criança que está sendo pesquisada será preservada, tanto durante a pesquisa como após a publicação dos resultados. Somente a fonoaudióloga estará sabendo, além dos pais ou responsáveis pela criança sobre os seus resultados na pesquisa.

14. disponibilidade de assistência no HCFMUSP, por eventuais danos à saúde, decorrentes da pesquisa. 
Esta pesquisa não oferece riscos à saúde da criança.

15. viabilidade de indenização por eventuais danos à saúde decorrentes da pesquisa.

Esta pesquisa não oferece riscos à saúde da criança.

V. INFORMAÇÕES DE NOMES, ENDEREÇOS E TELEFONES DOS RESPONSÁVEIS PELO ACOMPANHAMENTO DA PESQUISA, PARA CONTATO EM CASO DE INTERCORRÊNCIAS CLÍNICAS E REAÇÕES ADVERSAS.

Qualquer problema de saúde que venha a surgir na criança durante a pesquisa que a impossibilite de continuar participando, os pais ou o responsável pela criança poderão entrar em contato com:

NOME: Rosangela Viana Andrade

ENDEREÇO: Rua Cipotânea nº 53, Cidade Universitária, São Paulo.

CEP: 05360-160 Telefone: 3091-7453 Celular: 9121-9899

\section{OBSERVAÇÕES COMPLEMENTARES:}

\section{VII - CONSENTIMENTO PÓS-ESCLARECIDO}

Declaro que, após convenientemente esclarecido pelo pesquisador e ter entendido o que me foi explicado, consinto em participar do presente Protocolo de Pesquisa

São Paulo, de de 2003 . 


\section{ANEXO G}

\section{Autorização da instituição para a pesquisa}

G1. Autorização - LIFSASM

G2. Autorização - APAE (Mauá)

G3. Autorização - APAE (Santo André)

G4. Autorização - Secretaria da Educação de São Bernardo do Campo 
7. REFERÊNCIAS 
Abbot-Smith K, Lieven E, Tomasello M. Training 2;6-years-old to produce the transitive construction: the role of frequency, semantic similarity and shared syntatic distribution. Dev Sci. 2004 Feb; 7(1): 48-55.

Acredolo L, Goodwyn S. Symbolic gesturing in normal infants. Child Development. 1988, 59:450-66.

Alabarse VM. Estudo do desenvolvimento cognitivo e da linguagem em crianças com síndrome de Down [dissertação]. São Paulo: Faculdade de Medicina, Universidade de São Paulo; 2002.

Andrade RV, Limongi SCO. O processo terapêutico fonoaudiológico de crianças pequenas portadoras de síndrome de Down e a orientação à família. Revista da Sociedade Brasileira de Fonoaudiologia 2001; 2:29-33.

Andrade RV. Trabalho de reeducação quanto à comunicação oral de crianças com alterações sensório-motoras de origem sindrômica (0 a 3 anos): enfoque na orientação às mães [dissertação]. São Paulo: Faculdade de Educação, Universidade de São Paulo; 2002.

Anisfeld (1998) M. Lexical acceleration coincides with the onset of combinatorial speech. First Language 1998; 18:165-84. 
Araujo K. Aspectos do desempenho gramatical de crianças pré-escolares em desenvolvimento normal de linguagem [dissertação]. São Paulo: Faculdade de Filosofia, Letras e Ciências Humanas, Universidade de São Paulo; 2003.

Assis OZM. A pesquisa na perspectiva piagetiana. In: Assis MC, Assis OZM, Ramozzi-Chiarottino Z. (orgs.) - Piaget: Teoria e Prática - IV Simpósio Internacional de Epistemologia Genética, XIII Encontro Nacional de Professores do PROEPRE; 1996. p.257-265.

Barret M. Desenvolvimento lexical inicial. In: Fletcher $\mathrm{P}, \mathrm{McWhinney} \mathrm{B.}$ Compêndio da Linguagem da Criança. Porto Alegre: Artes Médicas; 1997.

Bates E, Snyder L, Bretherton I, Volterra V. The emergence of symbols in language and action: similarities and differences. Papers and Reports on Child Language Development. 1979; 17:106-18.

Bates E, Thal D, Fenson L, Whitsell K, Oakes. Integrating language and gesture in infancy. Developmental Psychology 1989; 25(6):1004-19.

Bates E, Dick F. Language, gesture, and the developing brain. Dev. Psychobiol. 2002 Apr; 40(3):293-310. 
Baum BE, Gray JJ. Experting modeling, self-observation using videotape, and acquisition basic therapy skills. Professional Psychology Research and Practice1992; 23(3):220-5.

Berglund E, Eriksson M, Johansson I. Parental reports of spoken language skills in children with Down syndrome. Journal of Speech, Language, and Hearing Research 2001 February; 44:179-91.

Béfi-Lopes DM, Takiuchi N, Araújo K. Avaliação da maturidade simbólica nas alterações do desenvolvimento da linguagem. Jornal Brasileiro de Fonoaudiologia 2000; 3:6-15.

Blackwell AA. Acquiring the english adjective lexicon: relationships with input properties and adjectival semantic typology. J Child Lang. 2005 Aug; 32(3): $535-62$.

Brock J, Jarrold C. Language influences on verbal short-memory performance in Down syndrome: item and order recognition. J Speech Lang Hear Res. 2004 Dec; 47(6):1334-46.

Brown R. A first language: the early stages. Cambridge, MA: Harvard University Press; 1973. 
Brunoni D. Aspectos epidemiológicos e genéticos. In: Schwartzman JS e col. Síndrome de Down. São Paulo: Editora Mackenzie; 1999. p. 32-43.

Buckley S. Language development in children with Down's syndrome reasons for optimism. The Down Syndrome Educational Trust Down Syndrome Research and Practice 1993; 1(1):3-9.

Bud Fredericks HD. A educação da criança e do adolescente. In: Pueschel S (org.). Síndrome de Down - guia para pais e educadores. Campinas: Papirus; 1993. p. 183-206.

Cabral LS. Introdução à lingüística. 7a ed. Rio de Janeiro: Globo; 1988.

Cahill BM, Glidden LM. Influence of child diagnosis on family and parental functioning: Down syndrome versus other disabilities. American Journal on Mental Retardation 1996; 101(2):149-160.

Camaioni L, Longobardi E. Noun versus verb emphasis in italian mother-tochild speech. J Child Lang. 2001 Oct; 28(3): 773-85.

Camargo PFF. Síndromes genéticas, evolução humana e fisioterapia. In: Mustacchi Z, Peres S (org.). Genética Baseada em Evidências - Síndromes e Heranças. São Paulo: CID Editora; 2000. p.1011-24. 
Capirci O, Iverson JM, Pizzuto E, Volterra V. Gestures and words during the transition to two-word speech. Journal Child Language 1996; 23:645-73.

Capone NC, McGregor KK. Gesture development: a review for clinical and research practices. Journal Speech Language Hearing Research 2004 Feb; 47(1):173-86.

Carone FB. Morfossintaxe. São Paulo: Ática; 1986.

Carpenter M, Nagell K, Tomasello M. Social cognition, joint attention, and communicative competence from 9 to 15 months of age. Monogr Soc Res Child Dev. 1998; 63(4):i-vi, 1-143.

Case R. El desarrollo intelectual del nacimiento a la edad madura. Barcelona: Paidós Ibérica S.A.; 1989.

Caselli MC, Vicari S, Longobardi E, Lami L, Pizzoli C. Stella G. Gestures and words in early development of children with Down syndrome. J Speech Lang Hearing Research 1998 Oct; 41(5):1125-35.

Castorina JA, Lenzi A, Fernández S. Alcances do método de exploração crítica em psicologia genética. In: Castorina JA e col. Psicologia genética: aspectos metodológicos e implicações pedagógicas. Porto Alegre: Artes Médicas. 1984. 
Chan JB \& lacono T. Gesture and production in children with Down syndrome. AAC Augmentative and Alternative Communication 2001 June; 17:73-87.

Chapman RS, Hesketh LJ. Language, cognition, and short-term memory in individuals with Down Syndrome. Down Syndrome Research and Practice 2001; 7(1):1-7.

Chapman RS, Seung HK, Schwartz SE, Bird EKR. Predicting language production in children and adolescents with Down syndrome: the role of comprehension. Journal of Speech, Language and Hearing Research 2000 April; 43:340-350.

Chapman RS, Hesketh LJ, Kistler DJ. Predicting longitudinal change in language production and comprehension in individuals with Down syndrome: hierarchial linear modeling. Journal of Speech, Language, and Hearing Research 2002 October; 45:902-15.

Clibbens J. Signing and lexical development in children with Down syndrome. Down Syndrome Research and Practice 2001; 7(3):101-5. 
Colombo L, Burani C. The influence of age of acquisition, root frequency, and context availability in processing nouns and verbs. Brain Lang. 2002 Apr-Jun; 81(1-3):398-411.

Conover WU. Pratical Nonparametric Statistics. New York: John Willy \& Sons; 1971.

Cordes AK. The reability of observational data: theories and methods for speech-language pathology. Journal of Speech and Hearing Research 1994; $37: 264-278$.

Cunningham CC, Glenn SM, Wilkinson P, Sloper P. - Mental ability, symbolic play and receptive and expressive language of young children with Down's syndrome. Journal of Child Psychology and Psychiatry 1985; 26(2):255-265.

Dodd B, Thompson L. Speech disorder in children with Down's syndrome. J Intellect Disabil Res. 2001 Aug; 45(Pt 4):308-16.

Elder JH. Videotaped behavioral observations: enhancing validity and realiability. Appl Nurs Res. 1999 Nov; 12(4):206-9.

Fenson L, Ramsay D. Effects of modeling action sequences on the play of twelve, fifteen, and nineteen month old children. Child Development 1981; 32:1028-36. 
Fischer MA. Mother-child interaction in preverbal children with Down syndrome. Journal of Speech and Hearing Disorders 1987; 52:179-190.

Fleiss JL. Statistical methods for rates and proportions. New York: John Willy; 1981. p.212-36.

Fonseca JS, Martins GA. Curso de estatística. 6ª ed. São Paulo:Atlas; 1996.

Foreman P, Crews G. Using augmentative communication with infants and young children with Down syndrome. Down Syndrome Research and Practice 1998; 5(1):16-25.

Franco F, Wishart JG. Use of pointing and other gestures by young chidren with Down syndrome. American Journal on Mental Retardation 1995; 100(2):160-82.

Furth HG. Piaget e o conhecimento. $2^{\mathrm{a}}$ edição. Rio de Janeiro: ForenseUniversitária; 1974.

Goldfield BA. Nouns before verbs in comprehension vs. Production: the view from pragmatics. J Child Lang. 2000 Oct; 27(3):501-20. 
Gomes RCG, Andrade RV, Limongi SCO. Trabalho de orientação fonoaudiológica a mães de crianças com síndrome de Down (0 a 3 anos) estudo clínico de dois casos. Pró-Fono Revista de Atualização Científica 1992; 4(2):22-28.

Grela BG. Do children with Down syndrome have difficulty with argument structure?. J Commun. Disord. 2003 Jul-Aug; 36(4):263-79.

Guidetti M. Les gestes conventionnels chez l'enfant: approche pragmatique. Archives de Psychologie 1999; 67:3-20.

Hauser-Cram P, Warfield ME, Shonkoff JP, Krauss MW, Upshur CC, Sayer A. Family influences on adaptive development in young children with Down syndrome. Child Development 1999 Jul-Aug; 70(4):979-89.

Hays RB, Jones BF, Adkins PB, McKain PJ. Analysis of videotaped consultations to certify competence. Med J Aust. 1990 Jun 4; 152(11):60911.

Hick RF, Botting N, Conti-Ramsden G. Short-term memory and vocabulary development in children with Down syndrome and children with specific language impairment. Dev Med Child Neurol. 2005 Aug; 47(8):532-8. 
Hoshino AC, Andrade, RV, Perez, VM, Limongi SCO. Mães de crianças portadoras de síndrome de Down e o trabalho de orientação em fonoaudiologia. In: Tópicos em Fonoaudiologia - Marchesan IQ, Bolaffi C, Gomes ICD, Zorzi J L (org.). São Paulo: Editora Lovise; 1994. p.193-8.

Ideriha PN. Eficácia do tratamento fonoaudiológico em síndrome de Down: avaliação eletromiográfica de superfície [dissertação]. São Paulo: Faculdade de Medicina, Universidade de São Paulo; 2005.

Iverson JM, Capirci O, Caselli MC. From communication to language in two modalities. Cognitive Development 1994; 9:23-43.

Iverson JM, Longobardi E, Caselli MC. Relationship between gestures and words in children with Down's syndrome and typically developing children in the early stges of communicative development. Int. J. Lang. Comm. Dis. 2003; 38(2):179-97.

Iverson JM, Goldin-Meadow S. Gesture paves the way for language development. Psychol Sci. 2005 May; 16(5):367-71.

Jenkins C. Expressive language delay in Children with Down Syndrome - A specific causa for concern. The Down Syndrome Eductional Trust Down Syndrome Research ande Practice 1993; 1(1):10-14. 
Johnson-Glenberg MC, Chapman RS. Predictors of parent-child language during novel task play: comparison between typically developing children and individual with Down syndrome. J Intellect Disabil. Res. 2004 Mar; 48(Pt 3):225-38.

Jones O. Mother child communication with prelinguistic Down's syndrome and normal infants. In: R. Schaffer (Ed.). Studies in Mother-Infanct interacration. New York: Academic Press; 1977.

Jones SS, Smith LB. Object name learning and object perception: a deficit in late talkers. J Child Lang. 2005 Feb; 32(1):223-40.

Kay-Raining Bird E, Chapman R. S. Sequential recall in individuals with Down syndrome. Journal of Speech and Hearing Research 1994 December; $37: 1369-80$

Kumin L. Comprehensive speech and language treatment for infants, toddlers, and children with Down syndrome. In: Hassold TJ, Patterson D. Down Syndrome: a promising future, together. New York: Wiley - Liss; 1999. p. $145-54$.

Laws G, Bishop DV. Verbal deficits in Down's syndrome and specific language impairment: a comparison. Int J Lang Commun Disord. 2004 OctDec; 39(4):423-51. 
Lee TH, Goldman L. Development and analysis of observational data bases. Journal Am. Coll. Cardiol. 1989 Sep; 14(13):44-7.

Legerstee M, Varghese J, van Beek Y. Effects of maintaining and redirecting infant attention on the production of referential communication in infants with and without Down syndrome. J Child Lang. 2002 Feb; 29(1):23-48.

Leifer JS, Lewis M. Acquisition of conversational response skills by young Down syndrome and nonretarded young children. American Journal of Medical Deficiency 1984; 88(6):610-18.

Limongi SCO, Andrade RV, Lima FAGF, Alabarse VM, Perez VM. Processo terapêutico fonoaudiológico realizado com um par de gêmeos portadores de síndrome de Down. Pró-Fono Revista de Atualização Científica 2000; 12(1):24-33.

Lyytinen P, Laakso ML, Poikkeus AM, Rita N. The development and predictive relations of play and language across the second year. Scandinavian Journal of Psychology 1999, 40:177-86.

McEachern D, Haynes WO. Gesture-speech combinations as a transition to multiword utterances. American Journal Speech Language Pathol. 2004 Aug; 13(3):227-35. 
Maldonado DJ. Early lexical development in spanish-speaking infants and toddlers. Journal of Child Language 1993; 20:523-49.

Martins CC, Mervis CB. Maternal speech to prelinguistic children with Down syndrome. American Journal of Mental Deficiency 1985; 89(5):451-8.

Martins CC, Mervis CB, Mervis CA. Early vocabulary acquisition by children with Down syndrome. American Journal of Mental Deficiency 1985; 90(2):177-84.

Messer DJ, Hasan PJ. Early communication and cognition in children with Down's syndrome. The Down Syndrome Educational Trust Down Syndrome Research and Practice 1994; 2(1):3-10.

Miles S, Chapman RS. Narrative content as described by individuals with Down syndrome and typically developing children. Journal of Speech, Language, and Hearing Research Februry 2002; 45:175-89.

Miller JF. Development of speech and language in children with Down syndrome. In: Lott JY, McCoy EE (ed). Clinical care for persons with Down syndrome. New York: Academic Press; 1992. p. 39-50. 
Molini-Alvejonas DR. Perfil funcional da comunicação de crianças com autismo, síndrome de Down e normais pareadas pelo desempenho sóciocognitivo [tese]. São Paulo: Faculdade de Medicina, Universidade de São Paulo; 2004.

Moore DG, Oates JM, Hobson RP, Goodwin J. Cognitive and social factors in the development of infants with Down syndrome. Downs Syndrome Research and Practice 2002 Sep; 8(2):43-52.

M Purser HR, Jarrold C. Impaired verbal short-term memory in Down syndrome reflects a capacity limitation rather than atypically rapid forgetting. J Exp Child Psychol. 2005 May; 91(1):1-23.

Murphy A. Nasce uma criança com síndrome de Down. In: Pueschel S (org.). Síndrome de Down - guia para pais e educadores. Campinas: Papirus; 1993. p. 23-31.

Mustacchi Z, Rozone G. A clínica da síndrome de Down. In: Mustacchi Z, Rozone G (org.). Síndrome de Down - aspectos clínicos e odontológicos. São Paulo: CID ; 1990. p.51-98.

Mustacchi Z. Síndrome de Down. In: Mustacchi Z , Peres S. (orgs.). Genética baseada em evidências - síndromes e heranças. São Paulo: CID editora; 2000. p. 817-94. 
Namy LL, Waxman SR. Words and gestures: infants' interpretations of different forms of symbolic reference. Child Development April 1998; 69(2):295-308.

Namy LL, Waxman SR. Patterns of spontaneous production of novel words and gestures within an experimental setting in children ages 1;6 and 2;2. $\mathrm{J}$ Child Lang. 2002 Nov; 29(4): 911-21.

Nicolich LMC. Beyond sensorimotor intelligence: assessment of symbolic maturity through analysis of pretend play. Merril-Palmer Quarterly 1977; 23(2):89-99.

Nilholm C. Early intervention with children with Down syndrome - past and future issues. Down Syndrome Research and Practice 1996; 4(2)51-8.

Ninio A. Testing the role of semantic similarity in syntatic development. $J$ Child Lang. 2005 Feb; 32(1):35-61.

Oliveira VB. O símbolo e o brinquedo. Rio de Janeiro: Vozes; 1992.

O'Neill M, Bard KA, Linnell M, Fluck M. Maternal gestures with 20-months-old infants in two contexts. Dev Sci. 2005 Jul; 8(4):352-9. 
Owens RE Jr. Language development. $4^{\text {th }}$ ed. Needhan Height; 1996. Cap. 3, p.66-107: Child development.

Ozcaliskan S, Goldin-Meadow S. Gesture is at the cutting edge of early language development. Cognition 2005 Jul; 96(3):B101-13.

Parrat-Dayan S. - Processos internos y externos en la construcción de una explicación causal. In: Assis MC, Assis OZM, Ramozzi-Chiarottino Z. (org.). Piaget: Teoria e Prática - IV Simpósio Internacional de Epistemologia Genética, XIII Encontro Nacional de Professores do PROEPRE; 1996. p.2845.

Pelchat D, Lefebvre H, Proulx M, Reidy M. Parental satisfaction with an early family intervention program. J Perinat Neonatal Nurs 2004 Apr-Jun; 18(2):128-44.

Perez VM, Limongi SCO. Mães de crianças portadoras de síndrome de Down e o trabalho fonoaudiológico. In: Limongi SCO (org.). Fonoaudiologia \& Pesquisa São Paulo: Lovise; 1998. p.253-67.

Piaget J. Seis estudos de psicologia. Rio de Janeiro: Forense-Universitária; 1985, edição original de 1964.

Piaget J. O nascimento da inteligência na criança. Rio de Janeiro: Guanabara;1987, edição original de 1936. 
Piaget J. A formação do símbolo na criança. Rio de Janeiro: LTC; 1990, edição original de 1946.

Piaget J. A construção do real na criança. São Paulo: Ática; 1996, edição original de 1937.

Pino O. The effect of context on mother's interaction style with Down's syndrome and typically developing children. Research Development Disabilit. 2000 Sep-Oct; 21(15): 329-46.

Pueschel SM. Questões médicas. In: Pueschel S (org.). Síndrome de Down - guia para pais e educadores. Campinas: Papirus; 1993. p. 85-98.

Pulaski MAS. Compreendendo Piaget: uma introdução ao desenvolvimento cognitivo da criança. Rio de Janeiro: LTC; 1986, edição original de 1980.

Ramruttun B, Jenkins C. - Prelinguistic communication and Down syndrome. Down Syndrome Research and Practice. 1998; 5(2):53-62.

Reed VA. An introduction to children with language disorders. $2^{\text {nd }}$ ed. McMillan; 1994. 
Rey SC, Birman EG. Odontologia e síndrome de Down: aspectos craniofaciais. In: Mustacchi Z, Rozone G (org.). Síndrome de Down aspectos clínicos e odontológicos. São Paulo: CID; 1990. p. 197-221.

Ricci LA, Hodapp RM. Fathers of children with Down's syndrome versus other types of intellectual disability: perceptions, stress and involvement. $J$. Intellect Disabil Res 2003 May-Jun; 47(Pt 4-5):273-84.

Rice ML. Contemporary accounts of the cognition/language relationship: implications for speech-language clinicians. Journal of Speech and Hearing Disorders 1983 Nov; 48:347-59.

Rinaldi P, Barca L, Burani C. A database for semantic, grammatical, and frequency properties of the first words acquired by Italian children. Behav Res Methods Instrum Comput. 2004 Aug; 36(3):525-30.

Roach MA, Barrant MS, Miller JF, Leavitt LA. The structure of mother-child play: young children with Down syndrome and typically developing children. Developmental Psychology 1998; 34(1):77-87.

Roberto MP. Audiologia clínica como e quando avaliar - achados nas principais síndromes genéticas. In: Mustacchi Z, Peres S. (orgs.). Genética baseada em evidências - síndromes e heranças. São Paulo: CID; 2000. p. 963-94. 
Rondal JA. Oral language in Down's syndrome. In: Rondal JA. e col. (ed.). Down's syndrome: psychological, psychobiological, and socio-educational perspectives. England: Whurr Publishers; 1996.

Roth FP, Clark DM. Symbolic play and social participation abilities of language-impaired and normally developing children. Journal of Speech and Hearing Disorders 1987 February; 52:17-29.

Ruskin EM, Kasari C, Mundy P, Sigman M. Attention to people and toys during social and object mastery in children with Down syndrome. American Journal on Mental Retardation. 1994, 99(1):103-111.

Scarcellone JM. Analysis of observational data in speech and language research using generalizability theory. Journal of Speech, Language and Hearing Research 1998 Dec; 41:1341-7.

Scheuer Cl, Befi-Lopes DM, Wertzner HF. Desenvolvimento da linguagem: uma introdução. In: Limongi SCO (org.). Fonoaudiologia - informação para a formação. Rio de Janeiro: Guanabara Koogan; 2003. p. 1-18.

Scheuer $\mathrm{Cl}$, Limongi SCO. Distúrbios cognitivos. In: Limongi SCO (org.). Fonoaudiologia - informação para a formação. Rio de Janeiro: Guanabara Koogan; 2003. p. 139-57. 
Schwartzman JS. O sistema nervoso na síndrome de Down. In: Schwartzman JS e col. Síndrome de Down. São Paulo: Mackenzie; 1999. p. 44-81.

Schwartzman MLC. Aspectos do desenvolvimento motor oral e da alimentação. In: Schwartzman JS e col. Síndrome de Down. São Paulo: Mackenzie; 1999. p. 155-66.

Seltzer MM, Grennberg JS, Floyd FJ, Pettee Y, Hong J. Life course impacts of parenting a child with a disabilitiy. American Journal on Mental Retardation 2001 May; 103(3):265-86.

Shi R, Morgan JL, Allopenna P. Phonological and acoustic bases for early grammatical category assignment: a cross-linguistic perspective. Journal of Child Language 1998; 25:169-201.

Shore C, O'Connell B, Bates E. First sentences in language and symbolic play. Developmental Psychology 1984; 20:881-92.

Siegel S, Castellan N. Nonparametric Statistics for the Behavioral Sciences. 2.ed. New York: McGraw-Hill; 1988. p 284-5. 
Silva MVD. O coração na síndrome de Down. In: Mustacchi Z, Rozone G (org.). Síndrome de Down - aspectos clínicos e odontológicos. São Paulo: CID; 1990. p. 118-46.

Sinclair H. Development psycholinguistics. In: Barbel I, Harold C. Piaget and his school. New York: Springer-Verlag; 1976.

Spiegel MR. Estatística coleção schaum. 3a ed. São Paulo: Afiliada; 1993. (Coleção Schaum).

Spinelli M, Garcez EMCBM, Sarruf M, Endsfeldz AA, Marin A, Ayuso MTSC et al. Inteligibilidade da fala em portadores da síndrome de Down: relações com praxia motora oral, memória auditiva verbal, idade, sexo e nível intelectual. Distúrbios da Comunicação 2001 Jun; 12(2):141-60.

Steinke EE. Use of videotaped interventions in research. West J Nurs Res. 2001 Oct; 23(6): 627-43.

Stoel-Gammon C. Down syndrome phonology: developmental patterns and intervention strategies. Down Syndrome Research and Practice 2001; 7(3):93-100.

Thal DJ, Bates E. Language and gesture in late talkers. Journal of Speech and Hearing Research 1988; 31:115-23. 
Thal DJ. Language and cognition in normal and late-talking toddlers. Top Lang Disord 1991; 11(4):33-42.

Thal DJ, Tobias S. Communicative gestures in children with delayed onset of oral expressive vocabulary. Journal of Speech and Hearing Research 1992 Dec; 35:1281-9.

Thal DJ, Tobias S. Relationship between language and gesture in normally developing and late-talking toddlers. Speech Hearing Research 1994; 37:157-70.

Theakston AL, Lieven EV, Pine JM, Rowland CF. Semantic generality, input frequency and the acquisition of syntax. J Child Lang. 2004 Feb; 31(1): 6199.

Thiollent MJ - Método de pesquisa-ação. São Paulo: Cortez; 1985.

Trute B, Hiebert-Murphy D. Family adustment to childhood development disability: a measure of parent appraisal of family impacts. Journal Pediatr Psycholog 2002 Apr-May; 27(3):271-80. 
Veneziano E. Early lexical, morphological and syntatic development in French: some complex relations. The International Journal of Bilinguism 1999; 3(2-3): 183-217.

Vinh-Bang. L'Intervention psychopédagogique. Archives de Psychologic. 1990; 58:123-35.

Yoder PJ, Warren SF. Early predictors of language in children with and without Down syndrome. American Journal on Mental Retardation 2004; 109(4):285-300.

Ypsilantii A, Grouios G, Alevriadou A, Tsapkini K. Expressive and receptive vocabulary in children with Williams and Down syndromes. J Intellect Disabil Res. 2005 May; 49(Pt 5): 353-64.

Zausmer E. Estimulação precoce do desenvolvimento. In: Pueschel S (org.). Síndrome de Down - guia para pais e educadores. Campinas: Papirus; 1993. p. $115-126$. 


\section{APÊNDICE}

Cópia do artigo sobre o trabalho desenvolvido enviada para a publicação 


\section{Título do trabalho}

A emergência da comunicação expressiva na criança com síndrome de Down The emergence of communicative expression in the child with Down syndrome

\section{Instituição}

Departamento de Fisioterapia, Fonoaudiologia e Terapia Ocupacional da Faculdade de Medicina da Universidade de São Paulo

\section{Resumo}

Tema: expressões comunicativas na criança com SD. Objetivo: estudo qualitativo das diferentes formas de expressões comunicativas na criança com SD para verificar: a relação entre a emissão oral e o uso de gestos e, a efetividade do método dialéticodidático como terapia fonoaudiológica. Método: oito crianças com SD e quatro com DT avaliadas três vezes. Ações e comunicação foram filmadas e transcritas. Resultados: os sujeitos apresentaram linguagem oral e comunicação gestual simultâneas ou comunicação gestual. Conclusão: emergência de linguagem da SD tal qual do DT, mas atrasada; confirmou-se a eficácia do método dialético-didático.

Palavras-Chaves: Síndrome de Down; Linguagem Oral; Gestos

Abstract

Theme: communicative expressions in the child with DS. Objective: qualitative study of the different forms of communication in child with DS, to verify: the relation between oral emission and the use of gestures and the effectiveness of the dialecticdidactic method as speech-language therapy. Method: eight children with DS and 4 with TD, were evaluated three times. Actions and communication were filmed and 
transcribed. Results: subjects presented oral language and gesture communication simultaneously or gesture communication. Conclusion: emergence of language in DS just as of TD is more delayed; the efficiency of the dialectic-didactic method was confirmed.

Key Words: Down Syndrome; Oral Language; Gestures 


\section{Introdução}

A síndrome de Down (SD) é causada por uma alteração cromossômica, cujas características principais são a hipotonia generalizada e a defasagem cognitiva, com conseqüente atraso no desenvolvimento de linguagem (Limongi et al., 2000; Johnson-Glenberg e Chapman, 2004; Laws e Bishop, 2004).

Há outros fatores que contribuem com este atraso: a importância da interação mãe-criança como estímulo fundamental desde o nascimento do bebê (Gomes et al., 1992; Andrade e Limongi, 2001; Andrade, 2002; Johnson-Glenberg e Chapman, 2004), o atraso no desenvolvimento neuropsicomotor (Limongi et al., 2000; Andrade, 2002), as alterações neurológicas (Spinelli et al., 2001; Hick et al., 2005; MPurser e Jarrold, 2005), as cardiopatias e os problemas respiratórios (Mustacchi, 2000), os freqüentes quadros de otite (Yoder e Warren, 2004) e as alterações do sistema estomatognático (Ideriha, 2005).

Apesar deste atraso, a literatura relata que, tanto o desenvolvimento cognitivo quanto o de linguagem ocorrem nesta população tal qual na criança com desenvolvimento típico (DT), porém de modo mais lento e atrasado, sendo que o primeiro ocorre de forma mais eficiente do que o segundo (Limongi et al., 2000; Andrade, 2002; Laws e Bishop, 2004). Partindo-se do pressuposto de que a linguagem é estruturada pelo desenvolvimento cognitivo e depende dele (Piaget, 1990, edição original de 1946), observa-se, segundo alguns autores (Iverson et al., 2003), que a sua compreensão é melhor do que a sua expressão.

Segundo os estudos de Iverson et al. (2003), o espaço de tempo que ocorre entre a compreensão inicial das palavras durante o desenvolvimento semântico- 
lexical e a produção oral na criança com SD é muito maior quando comparado com o da criança com DT. Nestas, as primeiras palavras desenvolvem-se por volta dos 12 meses, as quais são nomes e, à medida que o seu vocabulário se expande, elas passam a emitir mais verbos do que nomes (Camaioni e Longobardi, 2001; Colombo e Burani, 2002; Abbot-Smith et al., 2004; Jones e Smith, 2005; Ninio, 2005; Theakston et al., 2004; Blackwell, 2005). Araujo (2003) explica que a maior ocorrência de verbos está no fato deles funcionarem como elementos organizadores da estrutura sintática. Paralelamente à esta ocorrência, ainda observa-se a emissão de alguns pronomes e advérbios (Araujo, 2003).

Quanto à produção de classes de palavras no repertório lingüístico da criança com SD, Dodd e Thompson (2001) e Grela (2003) relatam que não há diferença significativa com relação ao uso de verbos em sentenças simples entre estas crianças e as com DT.

Segundo Ypsilant et al. (2005), observa-se uma certa tendência da criança com SD a usar sentenças mais simples nas quais os artigos, as preposições, os pronomes, entre outros são omitidos.

Este autor ainda afirma que o uso consistente de palavras na criança com SD não ocorre antes dos três anos de idade, sendo que as frases compostas por mais de uma palavra estarão presentes entre os quatro e cinco anos. Dados semelhantes foram observados por Berglund et al. (2001), além de que, os resultados obtidos em sua pesquisa mostram que as crianças com SD na faixa etária de três anos de idade são compatíveis aos das crianças com DT com idade entre um ano e quatro meses e um ano e oito meses. 
As pesquisas de Iverson et al. (2003), Brock e Jarrold (2004) e de Hick et al. (2005) indicam que o vocabulário das crianças com SD não se expande tão rapidamente como acontece geralmente com as crianças com DT.

Para compensar o atraso de sua produção oral, alguns autores afirmam que muitas crianças com SD passam a desenvolver de modo significativo a comunicação gestual para se expressarem (Chan e Iacono, 2001).

Franco e Wishart (1995) esclarecem que, na criança com SD, a comunicação gestual desenvolve-se tal qual na criança com DT durante o período de emergência das expressões comunicativas, porém, observa-se que a primeira utiliza os gestos dêiticos por um tempo mais longo do que a segunda. A seguir, ela passa a utilizá-los simultaneamente aos simbólicos.

Os estudos de Miles e Chapman (2002) apontam para o fato de que, após esta fase de desenvolvimento, algumas crianças com SD continuam utilizando os gestos durante muito tempo em suas vidas, variando-os conforme o contexto do ambiente em que estão, com o objetivo de se fazerem melhor compreendidas pelo interlocutor. Nestes casos, observa-se que, ao invés da fala ir predominando sobre os gestos, como acontece com as crianças com DT, as com SD continuam utilizando os gestos simultâneos à emissão de palavras ou, ainda, utilizam-nos predominando sobre as mesmas, como se elas é que fossem o apoio lingüístico, e não o contrário (Chan e Iacono, 2001; Namy e Waxman, 2002; Iverson et al., 2003; McEachern e Haynes, 2004; Iverson e Goldin-Meadow, 2005; Ozcaliskan e Goldin-Meadow, 2005).

Quando a criança com SD desenvolve a sua comunicação neste sentido, os gestos utilizados por elas não são pré-estabelecidos ou padronizados por ninguém. 
Eles são individuais, próprios de cada criança, e são totalmente compreensíveis pelo interlocutor (Franco e Wishart, 1995).

Os gestos mais freqüentes utilizados pela criança com SD foram classificados por Franco e Wishart (1995) em quatro categorias: apontar; indicar; alcançar e outros (gestos expressivos: bater palmas, por ex.; gestos com conteúdo semântico: "ninar” uma boneca; gestos convencionais: acenar "tchau”).

Além das explicações acima, há autores que ainda justificam o uso de gestos pela criança com SD por outras razões: a ininteligibilidade de fala decorrente das alterações do sistema estomatognático, aliadas às dificuldades de compreensão e aprendizagem das regras gramaticais e sintáticas decorrentes de fatores neurológicos e cognitivos (Chapman et al., 2002; Jonhson-Glenberg e Chapman, 2004).

Com o propósito de facilitar o melhor desenvolvimento de linguagem na criança com SD, este trabalho teve por objetivo o estudo qualitativo das diferentes formas de expressões comunicativas neste tipo de população, em que se pretendeu verificar: a emergência da expressão oral e sua relação com os gestos durante a comunicação; a evolução dos gestos e a sua qualificação; a efetividade da terapia fonoaudiológica no desenvolvimento de linguagem na criança com SD segundo o método dialético-didático (Parrat-Dayan, 1996), o qual foi fundamentado no método clínico de Piaget e propõe a construção do conhecimento do sujeito por meio de situações conflitivas, mas, com a intervenção ativa do pesquisador durante este processo, auxiliando a criança a reorganizar o seu conhecimento.

\section{Método}


Esta pesquisa foi aprovada pela Comissão de Ética para Análise de Projetos de Pesquisa (CAPPesq) da Diretoria Clínica do Hospital das Clínicas e da Faculdade de Medicina da Universidade de São Paulo, por meio do protocolo 076/03. Os responsáveis pelos sujeitos que participaram deste trabalho consentiram com a pesquisa e a publicação de seus resultados por meio do Termo de Consentimento Livre e Esclarecido, conforme a Resolução 196/96 do Ministério da Saúde/Conselho Nacional de Saúde/Comissão Nacional de Ética em Pesquisa (MS/CNS/CNEP).

Pelo fato da pesquisa ter sido realizada nas instituições as quais os sujeitos pertenciam, também foi adquirida a sua autorização: Associação de Pais e Amigos dos Excepcionais (APAE) de Mauá, APAE de Santo André, Secretaria da Educação da cidade de São Bernardo do Campo e o Laboratório de Investigação Fonoaudiológica em Síndromes e Alterações Sensório-Motoras (LIFSASM) do Curso de Fonoaudiologia da Faculdade de Medicina da Universidade de São Paulo (FMUSP).

Para a sua realização, foram selecionadas 12 crianças: oito com SD (faixa etária entre 33 e 52 meses, no início da pesquisa), as quais, metade formaram o grupo pesquisa (GP) e a outra metade, o grupo controle um (GC1); e quatro com desenvolvimento típico (DT) (faixa etárias entre 14 e 16 meses, no início da pesquisa), constituindo o grupo controle dois (GC2). Todas apresentavam desenvolvimento cognitivo entre o final do período sensório-motor e início do préoperatório.

Os critérios de exclusão dos GP e GC1 utilizados foram: presença de alterações de saúde (cardiopatias, quadros respiratórios) e os quadros associados como a deficiência auditiva, deficiência visual, distúrbios psiquiátricos e/ou 
psicológicos, de origem neurológica. Como critérios de inclusão considerou-se: desenvolvimento cognitivo entre o período sensório-motor e início do pré-operatório, segundo a teoria de Piaget (1990, edição original de 1946); presença de intenção comunicativa observável; ter realizado acompanhamento de estimulação precoce em algum serviço fonoaudiológico, ou, pelo menos, estar no final dele, para o GC1 e freqüentar o LIFSASM para o GP; ambos os gêneros, sendo dois sujeitos masculinos e dois femininos em cada grupo.

Os sujeitos do GC1 foram considerados de controle para este estudo porque, além deles apresentarem SD e idades cronológicas próximas às do GP, a intervenção fonoaudiológica que recebiam era diversa, do ponto de vista teórico-metodológico, daquela desenvolvida com o GP.

A utilização de um segundo grupo controle (GC2) fez-se necessária por se tratarem de crianças que apresentavam os desenvolvimentos cognitivo e o de linguagem adequados à idade cronológica e que, portanto, são fundamentais enquanto parâmetros de observação e análise dos dados dos outros dois grupos.

Como procedimento, estes sujeitos passaram por três avaliações no período de 12 meses: uma inicial, uma após seis meses de estudo e uma final, com a duração de 30 minutos, cada. Todas foram filmadas e transcritas, como sugere Steinke (2001) para garantir a objetividade nas observações, cujos dados obtidos seriam trabalhados qualitativamente.

Para o GP, o processo terapêutico constou, no total, de 40 terapias, realizadas durante uma vez por semana, a partir da primeira avaliação. No decorrer das terapias, foi utilizado o método dialético-didático (Parrat-Dayan, 1996), e buscou-se favorecer a comunicação da criança, principalmente a linguagem oral, dentro de um 
determinado contexto, incentivando o seu uso por meio de nomeações de objetos ou ações e de situações em que a criança sentisse a necessidade de se expressar. Quinzenalmente, as terapias também eram filmadas e transcritas.

Os materiais utilizados, tanto para as avaliações como durante o processo terapêutico do GP, foram brinquedos apropriados para a fase de desenvolvimento cognitivo apresentado pelas crianças, sendo sempre os mesmos para as avaliações e outros, semelhantes a estes, para as terapias.

Os dados obtidos eram registrados em protocolos de análise elaborados pela pesquisadora, de modo que se visualizasse facilmente os momentos em que os sujeitos se expressaram somente por meio da linguagem oral ou da comunicação gestual, ou, ainda, por meio da linguagem oral e comunicação gestual simultâneas. Ressalta-se que, antes da síntese dos dados nos protocolos de análise, parte das transcrições realizadas foram conferidos por três juizes capacitados de acordo com a mesma abordagem teórica da pesquisadora. Tal procedimento fez-se necessário para se garantir a precisão e a confiabilidade das informações obtidas na pesquisa (Scarsellone, 1998).

Os dados obtidos foram analisados de forma qualitativa e quantitativa.

Para a análise qualitativa, os critérios utilizados na linguagem oral basearamse nos conceitos da Lingüística (análise morfossintática); os da comunicação gestual (gestos e expressões faciais), nos estudos de Franco e Wishart (1995) e de Iverson et al. (2003); e os da linguagem oral e comunicação gestual simultâneas, em ambos os critérios. Para a comparação dos dados de forma quantitativa, utilizou-se os testes não paramétricos de Kruskal-Wallis, Mann-Whithney, Friedman e Wilcoxon, complementados, descritivamente, pelo uso da técnica de intervalo de confiança 
(Fonseca e Martins, 1996). O intervalo de significância utilizado foi determinado em $10 \%$.

\section{Resultados}

A ordem de apresentação dos resultados será a seguinte: dados referentes à linguagem oral (análise morfossintática), comunicação gestual e linguagem oral e comunicação gestual simultâneas, sempre relativos às três avaliações dos três grupos (GP, GC1 e GC2). Assim, será possível a realização das análises intra-grupos apresentadas por meio dos quadros e as inter-grupos por meio de figuras.

\section{Linguagem oral (análise morfossintática)}

Quadro 1: observação do número de vocábulos diferentes por classe de palavras na linguagem oral dos quatro sujeitos do GP durante as três avaliações.

\begin{tabular}{|l|c|c|c|c|c|c|c|c|c|c|c|c|}
\multicolumn{1}{c|}{} & \multicolumn{4}{c}{$\mathbf{1}^{\mathbf{0}}$ avaliação } & \multicolumn{3}{c|}{$\mathbf{2}^{\mathbf{0}}$ avaliação } & \multicolumn{3}{c|}{$\mathbf{3}^{\circ}$ avaliação } \\
\hline Classes de palavras & $\mathbf{S 1}$ & $\mathbf{S 2}$ & $\mathbf{S 3}$ & $\mathbf{S 4}$ & $\mathbf{S 1}$ & $\mathbf{S 2}$ & $\mathbf{S 3}$ & $\mathbf{S 4}$ & $\mathbf{S 1}$ & $\mathbf{S 2}$ & $\mathbf{S 3}$ & $\mathbf{S 4}$ \\
\hline substantivo & 5 & 0 & 0 & 0 & 2 & 0 & 0 & 4 & 7 & 0 & 1 & 3 \\
\hline adjetivo & 0 & 0 & 0 & 0 & 0 & 0 & 0 & 0 & 0 & 0 & 0 & 0 \\
\hline pronome & 3 & 0 & 0 & 0 & 0 & 0 & 0 & 2 & 0 & 0 & 0 & 0 \\
\hline verbo & 3 & 0 & 0 & 2 & 3 & 0 & 0 & 5 & 8 & 0 & 0 & 4 \\
\hline advérbio & 3 & 0 & 0 & 1 & 1 & 1 & 0 & 1 & 1 & 1 & 1 & 1 \\
\hline artigo & 0 & 0 & 0 & 0 & 1 & 0 & 0 & 0 & 2 & 0 & 0 & 0 \\
\hline preposição & 0 & 0 & 0 & 0 & 0 & 0 & 0 & 0 & 0 & 0 & 0 & 0 \\
\hline conjunção & 0 & 0 & 0 & 0 & 0 & 0 & 0 & 0 & 1 & 0 & 0 & 0 \\
\hline numeral & 0 & 0 & 0 & 0 & 0 & 0 & 0 & 0 & 0 & 0 & 0 & 0 \\
\hline interjeição & 1 & 0 & 0 & 0 & 0 & 0 & 0 & 1 & 1 & 0 & 0 & 1 \\
\hline $\begin{array}{l}\mathbf{n}^{\circ} \text { total de palavras } \\
\text { diferentes emitidas por } \\
\text { classe }\end{array}$ & $\mathbf{1 5}$ & $\mathbf{0}$ & $\mathbf{0}$ & $\mathbf{3}$ & $\mathbf{7}$ & $\mathbf{1}$ & $\mathbf{0}$ & $\mathbf{1 3}$ & $\mathbf{2 0}$ & $\mathbf{1}$ & $\mathbf{2}$ & $\mathbf{9}$ \\
\hline $\begin{array}{l}\mathbf{n}^{\circ} \text { total de classes de } \\
\text { palavras }\end{array}$ & $\mathbf{5}$ & $\mathbf{0}$ & $\mathbf{0}$ & $\mathbf{2}$ & $\mathbf{4}$ & $\mathbf{1}$ & $\mathbf{0}$ & $\mathbf{5}$ & $\mathbf{6}$ & $\mathbf{1}$ & $\mathbf{2}$ & $\mathbf{4}$ \\
\hline
\end{tabular}


Quadro 2: observação do número de vocábulos diferentes por classe de palavras na linguagem oral dos quatro sujeitos do GC1 durante as três avaliações.

\begin{tabular}{|c|c|c|c|c|c|c|c|c|c|c|c|c|}
\hline \multirow[b]{2}{*}{ Classes de palavras } & \multicolumn{4}{|c|}{$1^{\circ}$ avaliação } & \multicolumn{4}{|c|}{$2^{\circ}$ avaliação } & \multicolumn{4}{|c|}{$3^{\circ}$ avaliação } \\
\hline & S5 & S6 & S7 & S8 & S5 & 56 & S7 & 58 & S5 & S6 & S7 & 58 \\
\hline substantivo & 0 & 0 & 0 & 0 & 0 & 0 & 0 & 4 & 0 & 1 & 1 & 7 \\
\hline \begin{tabular}{|l|} 
adjetivo \\
\end{tabular} & 0 & 0 & 0 & 0 & 0 & 0 & 0 & 2 & 0 & 0 & 0 & 0 \\
\hline pronome & 0 & 0 & 0 & 0 & 0 & 0 & 0 & 1 & 0 & 0 & 0 & 0 \\
\hline verbo & 0 & 0 & 0 & 2 & 0 & 0 & 1 & 5 & 1 & 1 & 0 & 5 \\
\hline advérbio & 0 & 0 & 0 & 0 & 0 & 0 & 1 & 3 & 0 & 1 & 0 & 3 \\
\hline artigo & 0 & 0 & 0 & 1 & 0 & 0 & 0 & 1 & 0 & 1 & 0 & 0 \\
\hline preposição & 0 & 0 & 0 & 0 & 0 & 0 & 0 & 0 & 0 & 0 & 0 & 1 \\
\hline conjunção & 0 & 0 & 0 & 0 & 0 & 0 & 0 & 0 & 0 & 0 & 0 & 0 \\
\hline numeral & 0 & 0 & 0 & 0 & 0 & 0 & 0 & 0 & 0 & 0 & 0 & 0 \\
\hline interjeição & 0 & 0 & 0 & 0 & 0 & 0 & 0 & 0 & 0 & 0 & 0 & 2 \\
\hline $\begin{array}{l}\mathrm{n}^{\circ} \text { total de palavras } \\
\text { diferentes emitidas por } \\
\text { classe }\end{array}$ & 0 & 0 & 0 & 3 & 0 & 0 & 2 & 16 & 1 & 4 & 1 & 18 \\
\hline $\begin{array}{l}n^{\circ} \text { total de classes de } \\
\text { palavras }\end{array}$ & 0 & 0 & 0 & 2 & 0 & 0 & 2 & 6 & 1 & 4 & 1 & 5 \\
\hline
\end{tabular}

Quadro 3: observação do número de vocábulos diferentes por classe de palavras na linguagem oral dos quatro sujeitos do GC2 durante as três avaliações.

\begin{tabular}{|c|c|c|c|c|c|c|c|c|c|c|c|c|}
\hline \multirow[b]{2}{*}{ Classes de palavras } & \multicolumn{4}{|c|}{$1^{\circ}$ avaliação } & \multicolumn{4}{|c|}{$2^{\circ}$ avaliação } & \multicolumn{4}{|c|}{$3^{\circ}$ avaliação } \\
\hline & S9 & $\mathrm{S10}$ & $\mathrm{S11}$ & $\mathrm{S} 12$ & S9 & $\mathrm{S} 10$ & S11 & $\mathrm{S} 12$ & S9 & $\mathrm{S10}$ & S11 & $\mathrm{S} 12$ \\
\hline substantivo & 0 & 0 & 2 & 4 & 10 & 2 & 12 & 4 & 14 & 3 & 6 & 8 \\
\hline adjetivo & 0 & 0 & 0 & 0 & 1 & 0 & 0 & 3 & 2 & 1 & 1 & 0 \\
\hline pronome & 0 & 0 & 0 & 0 & 1 & 0 & 1 & 2 & 4 & 3 & 2 & 8 \\
\hline verbo & 0 & 0 & 0 & 3 & 4 & 1 & 4 & 6 & 8 & 6 & 7 & 13 \\
\hline advérbio & 0 & 0 & 0 & 0 & 4 & 0 & 3 & 2 & 5 & 2 & 1 & 5 \\
\hline artigo & 0 & 0 & 0 & 0 & 2 & 1 & 1 & 1 & 2 & 1 & 1 & 2 \\
\hline preposição & 0 & 0 & 0 & 0 & 0 & 0 & 0 & 0 & 2 & 0 & 1 & 4 \\
\hline conjunção & 0 & 0 & 0 & 0 & 0 & 0 & 1 & 0 & 1 & 1 & 1 & 0 \\
\hline numeral & 0 & 0 & 0 & 0 & 0 & 0 & 0 & 0 & 1 & 0 & 1 & 0 \\
\hline interjeição & 0 & 0 & 0 & 0 & 2 & 0 & 1 & 2 & 1 & 1 & 1 & 1 \\
\hline $\begin{array}{l}\mathrm{n}^{\circ} \text { total de palavras } \\
\text { diferentes emitidas por } \\
\text { classe }\end{array}$ & 0 & 0 & 2 & 7 & 24 & 4 & 23 & 20 & 40 & 18 & 22 & 41 \\
\hline $\begin{array}{l}n^{\circ} \text { total de classes de } \\
\text { palavras }\end{array}$ & 0 & 0 & 1 & 2 & 7 & 3 & 7 & 7 & 10 & 8 & 10 & 7 \\
\hline
\end{tabular}


Figura 1: Número de vocábulos diferentes presentes em GP, GC1 e GC2

Número de vocábulos diferentes - Linguagem oral

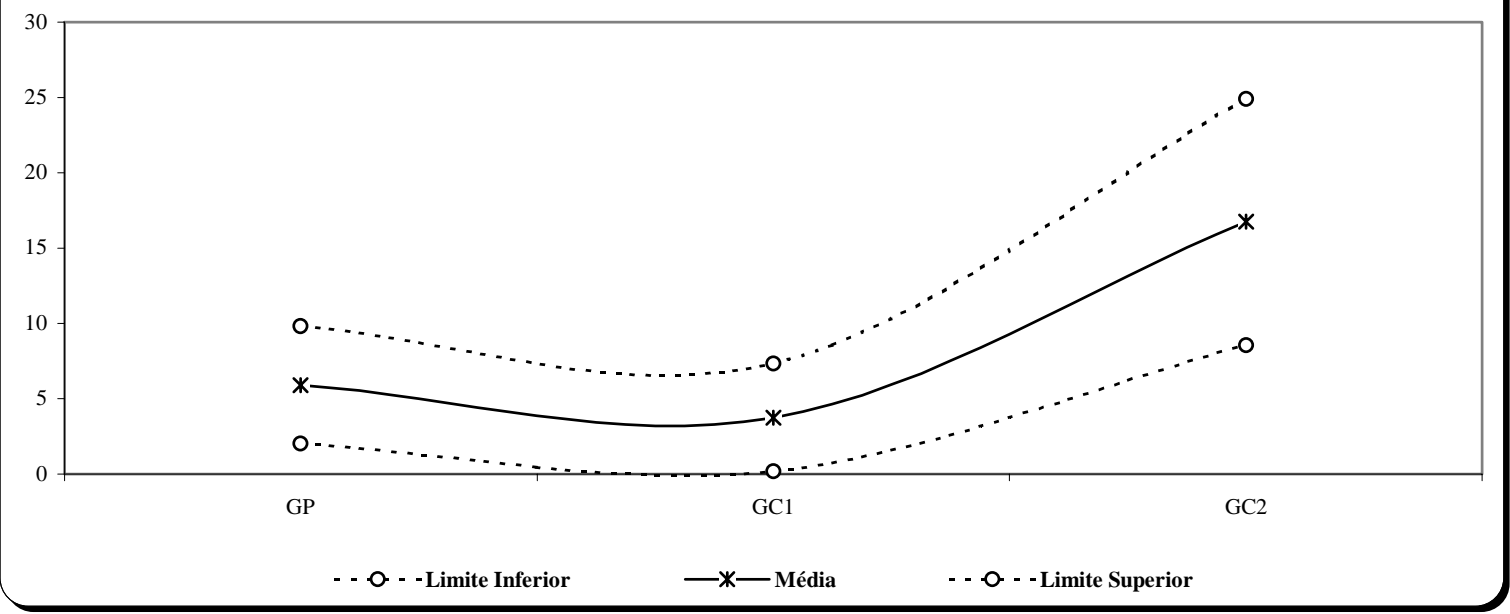

\begin{tabular}{|l|c|c|c|}
\hline Ling. Oral & \multicolumn{1}{|l|}{ GP } & GC1 & GC2 \\
\hline Limite Inferior & 2,03 & 0,16 & 8,58 \\
\hline Média & 5,92 & 3,75 & 16,75 \\
\hline Limite Superior & 9,8 & 7,34 & 24,92 \\
\hline
\end{tabular}

$\mathrm{p}$-valor $=0,024$

Observa-se que existe diferença média estatisticamente significante entre os grupos, segundo o p-valor obtido dos três grupos. Sendo assim, para se especificar onde está localizada esta diferença, considerou-se necessário a comparação entre todos os grupos dois a dois, como se observa na Tabela 1, na qual estão somente os p-valores dessas comparações.

Tabela 1: Observação da comparação dos p-valores do número de vocábulos diferentes dos três grupos

\begin{tabular}{ccc}
\hline Ling. Oral & GP & GC1 \\
\hline GC1 & 0,361 & \\
\hline GC2 & $0,052^{*}$ & $0,011^{*}$ \\
\hline p-valores & & \\
\end{tabular}


Verifica-se que o GC2 é considerado estatisticamente diferente dos demais grupos que, por sua vez, são iguais entre si.

Figura 2: Número total de classes de palavras presentes em GP, GC1 e GC2

Número total de classes de palavras - Linguagem oral

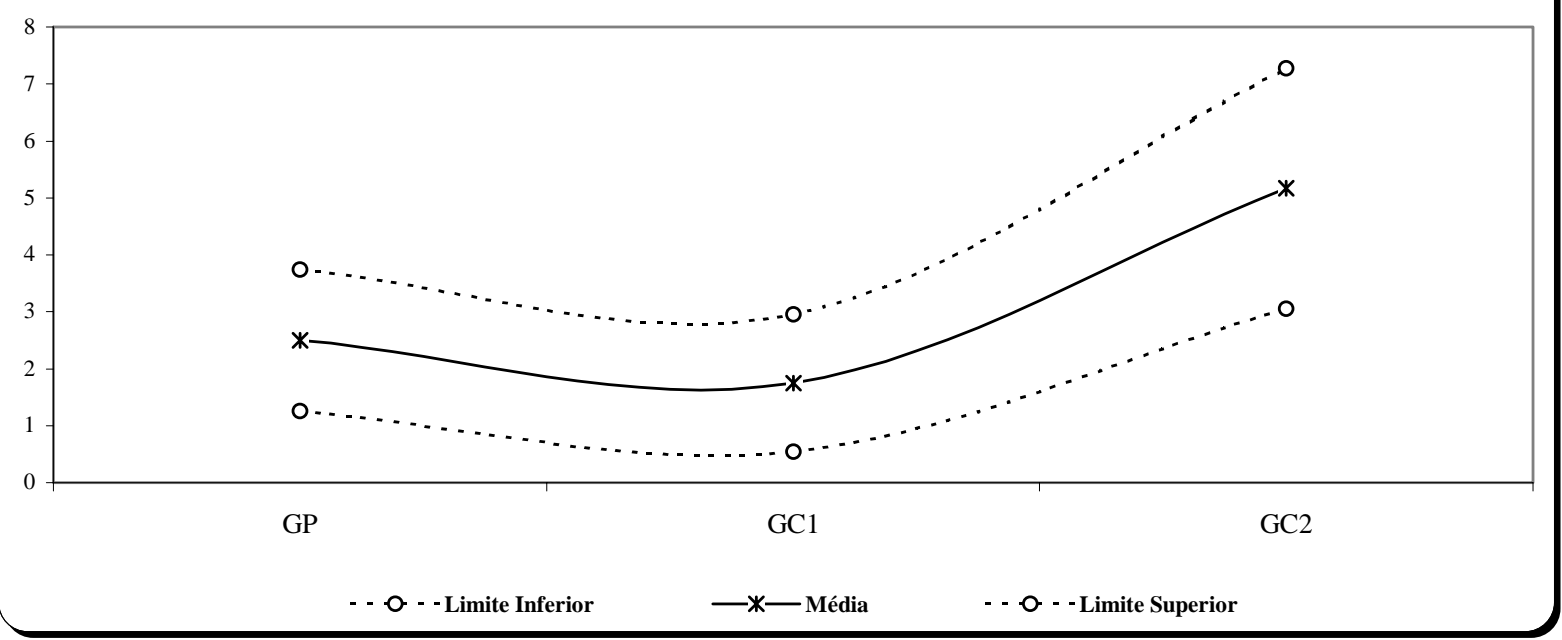

\begin{tabular}{|l|c|c|c|}
\hline Ling. Oral - Classe & GP & GC1 & GC2 \\
\hline Limite Inferior & 1,26 & 0,54 & 3,05 \\
\hline Média & 2,5 & 1,75 & 5,17 \\
\hline Limite Superior & 3,74 & 2,96 & 7,28 \\
\hline
\end{tabular}

p-valor $=0,037$

De acordo com o p-valor obtido na análise dos três grupos, verifica-se que ocorreu diferença média estatisticamente significante entre os grupos. Portanto, para se especificar esta diferença, foi necessário comparar os p-valores de todos os grupos dois a dois, como se observa na Tabela 2. 
Tabela 2: Observação da comparação dos p-valores do número total de classes de palavras dos três grupos

\begin{tabular}{ccc}
\hline $\begin{array}{c}\text { Ling. Oral - } \\
\text { Classe }\end{array}$ & GP & GC1 \\
& & \\
\hline GC1 & 0,374 & \\
\hline GC2 & $0,062^{*}$ & $0,019^{*}$ \\
\hline p-valores & & \\
\end{tabular}

Conclui-se, então, que o GC2 novamente é considerado estatisticamente diferente dos demais grupos que, por sua vez, são iguais entre si.

\section{Comunicação gestual}

Quadro 4: Tipos diferentes de ocorrências na comunicação gestual dos quatro sujeitos do GP durante as avaliações.

\begin{tabular}{|c|c|c|c|c|c|c|c|c|c|c|c|c|}
\hline & \multicolumn{4}{|c|}{$1^{\mathrm{a}}$ avaliação } & \multicolumn{4}{|c|}{$2^{\mathrm{a}}$ avaliação } & \multicolumn{4}{|c|}{$3^{\mathrm{a}}$ avaliação } \\
\hline Comunicação Gestual & S1 & $\mathrm{S2}$ & S3 & S4 & S1 & S2 & S3 & S4 & S1 & $\mathbf{S 2}$ & S3 & S4 \\
\hline \multicolumn{13}{|l|}{ Gestos dêiticos: } \\
\hline apontar & 0 & 0 & 0 & 1 & 0 & 0 & 0 & 0 & 0 & 0 & 0 & 0 \\
\hline mostrar & 0 & 0 & 0 & 0 & 0 & 0 & 0 & 2 & 0 & 0 & 0 & 0 \\
\hline alcançar & 0 & 0 & 0 & 0 & 0 & 0 & 0 & 0 & 0 & 0 & 0 & 0 \\
\hline \multicolumn{13}{|l|}{ Gestos representativos: } \\
\hline de conteúdo semântico: & 10 & 13 & 1 & 4 & 0 & 19 & 4 & 7 & 10 & 11 & 6 & 4 \\
\hline convencionais & 1 & 1 & 0 & 0 & 0 & 1 & 1 & 0 & 1 & 2 & 1 & 1 \\
\hline expressivos & 0 & 3 & 1 & 0 & 0 & 4 & 1 & 1 & 0 & 3 & 2 & 3 \\
\hline$n^{\circ}$ total de gestos & 11 & 17 & 2 & 5 & $\overline{0}$ & $\overline{24}$ & 6 & 10 & 11 & 16 & 9 & 8 \\
\hline $\begin{array}{l}n^{\circ} \text { total de tipos diferentes de } \\
\text { gestos }\end{array}$ & 2 & 3 & 2 & 2 & $\overline{0}$ & 3 & 3 & 3 & 2 & 3 & 3 & 3 \\
\hline
\end{tabular}


Quadro 5: Tipos diferentes de ocorrências na comunicação gestual dos quatro sujeitos do GC1 durante as avaliações.

\begin{tabular}{|c|c|c|c|c|c|c|c|c|c|c|c|c|}
\hline & \multicolumn{4}{|c|}{$1^{\mathrm{a}}$ avaliação } & \multicolumn{4}{|c|}{$2^{\mathrm{a}}$ avaliação } & \multicolumn{4}{|c|}{$3^{\mathrm{a}}$ avaliação } \\
\hline Comunicação Gestual & S5 & 56 & S7 & 58 & $\mathbf{S 5}$ & 56 & S7 & $\mathbf{5 8}$ & $\overline{55}$ & 56 & S7 & S8 \\
\hline \multicolumn{13}{|l|}{ Gestos dêiticos: } \\
\hline apontar & 0 & 0 & 0 & 0 & 0 & 1 & 0 & 0 & 0 & 1 & 0 & 1 \\
\hline mostrar & 0 & 0 & 0 & 1 & 0 & 1 & 0 & 0 & 0 & 1 & 0 & 2 \\
\hline alcançar & 0 & 0 & 0 & 0 & 0 & 2 & 0 & 0 & 0 & 0 & 0 & 1 \\
\hline \multicolumn{13}{|l|}{ Gestos representativos: } \\
\hline de conteúdo semântico: & 2 & 13 & 9 & 15 & 4 & 5 & 8 & 10 & 5 & 9 & 7 & 10 \\
\hline convencionais & 0 & 0 & 0 & 0 & 0 & 0 & 2 & 0 & 0 & 0 & 1 & 1 \\
\hline expressivos & 0 & 1 & 0 & 3 & 0 & 0 & 5 & 2 & 3 & 0 & 1 & 1 \\
\hline$n^{\circ}$ total de gestos & 2 & 14 & 9 & 19 & 4 & 9 & 15 & 12 & 8 & 13 & 9 & 16 \\
\hline $\begin{array}{l}n^{\circ} \text { total de tipos diferentes de } \\
\text { gestos }\end{array}$ & 1 & 2 & 1 & 3 & 1 & 4 & 3 & 2 & 2 & 3 & 3 & 6 \\
\hline
\end{tabular}

Quadro 6: Tipos diferentes de ocorrências na comunicação gestual dos quatro sujeitos do GC2 durante as avaliações.

\begin{tabular}{|c|c|c|c|c|c|c|c|c|c|c|c|c|}
\hline \multirow{2}{*}{ Comunicação Gestual } & \multicolumn{4}{|c|}{$1^{\mathrm{a}}$ avaliação } & \multicolumn{4}{|c|}{$2^{\mathrm{a}}$ avaliação } & \multicolumn{4}{|c|}{$3^{\mathrm{a}}$ avaliação } \\
\hline & S9 & $\mathbf{S 1 0}$ & S11 & $\mathbf{S 1 2}$ & S9 & $\mathbf{S 1 0}$ & S11 & S12 & S9 & S10 & S11 & $\mathbf{S 1 2}$ \\
\hline \multicolumn{13}{|l|}{ Gestos dêiticos: } \\
\hline apontar & 0 & 1 & 1 & 0 & 1 & 0 & 1 & 0 & 0 & 0 & 3 & 0 \\
\hline mostrar & 0 & 0 & 0 & 0 & 0 & 1 & 1 & 0 & 0 & 0 & 3 & 0 \\
\hline alcançar & 0 & 0 & 0 & 0 & 2 & 1 & 0 & 1 & 0 & 0 & 1 & 0 \\
\hline \multicolumn{13}{|l|}{ Gestos representativos: } \\
\hline de conteúdo semântico: & 2 & 4 & 2 & 16 & 9 & 10 & 7 & 7 & 5 & 4 & 1 & 6 \\
\hline convencionais & 0 & 0 & 1 & 0 & 1 & 2 & 1 & 2 & 0 & 0 & 0 & 1 \\
\hline expressivos & 0 & 1 & 0 & 0 & 2 & 2 & 0 & 1 & 0 & 1 & 0 & 1 \\
\hline$n^{\circ}$ total de gestos & 2 & 6 & 4 & 16 & 15 & 16 & 10 & 11 & 5 & 5 & 8 & 8 \\
\hline $\begin{array}{l}n^{\circ} \text { total de tipos diferentes de } \\
\text { gestos }\end{array}$ & 1 & 3 & $\overline{3}$ & 1 & 5 & 5 & $\overline{4}$ & 4 & 1 & 2 & 4 & 3 \\
\hline
\end{tabular}

Figura 3: Número de gestos observados durante a comunicação gestual em GP, GC1 e GC

Número total de tipos diferentes de gestos - Número total de gestos

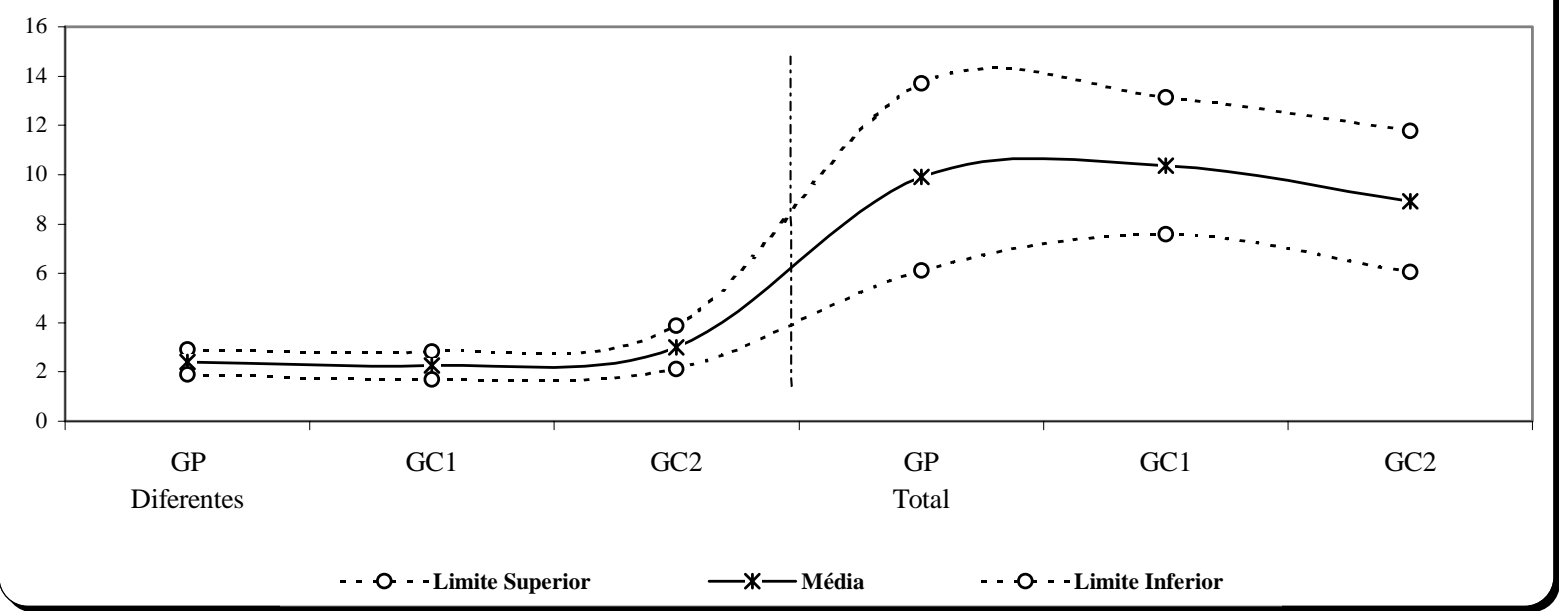




\begin{tabular}{|l|c|c|c|c|c|c|}
\hline \multirow{2}{*}{} & \multicolumn{3}{|c|}{$\begin{array}{c}\text { Número total de tipos } \\
\text { diferentes de gestos }\end{array}$} & \multicolumn{3}{c|}{ Número total de gestos } \\
\cline { 2 - 7 } & GP & GC1 & GC2 & GP & GC1 & GC2 \\
\hline Limite Superior & 2,93 & 2,84 & 3,88 & 13,7 & 13,14 & 11,77 \\
\hline Média & 2,42 & 2,27 & 3 & 9,92 & 10,36 & 8,91 \\
\hline Limite Inferior & 1,91 & 1,7 & 2,12 & 6,13 & 7,59 & 6,05 \\
\hline
\end{tabular}

Ao se observar os p-valores, tanto com relação aos tipos diferentes de gestos como para o número total de gestos apresentados pelos três grupos, verifica-se que não foram encontradas diferenças médias entre os grupos que pudessem ser consideradas estatisticamente significantes.

Portanto, pode-se dizer que os três grupos comportaram-se estatisticamente iguais quanto à comunicação gestual.

\section{Linguagem oral e comunicação gestual simultâneas}

Quadro 7: observação do número de vocábulos diferentes por classe de palavras na linguagem oral simultânea à comunicação gestual dos quatro sujeitos do GP durante as três avaliações.

\begin{tabular}{|c|c|c|c|c|c|c|c|c|c|c|c|c|}
\hline \multirow[b]{2}{*}{ Classes de palavras } & \multicolumn{4}{|c|}{$1^{\circ}$ avaliação } & \multicolumn{4}{|c|}{$2^{\circ}$ avaliação } & \multicolumn{4}{|c|}{$3^{\circ}$ avaliação } \\
\hline & S1 & $\overline{S 2}$ & $\mathrm{S3}$ & S4 & S1 & S2 & S3 & 54 & S1 & $\overline{S 2}$ & S3 & 54 \\
\hline substantivo & 12 & 0 & 1 & 1 & 16 & 0 & 2 & 6 & 10 & 0 & 0 & 11 \\
\hline adjetivo & 0 & 0 & 0 & 0 & 0 & 0 & 0 & 0 & 5 & 0 & 0 & 0 \\
\hline pronome & 2 & 0 & 0 & 0 & 4 & 1 & 0 & 2 & 2 & 0 & 0 & 1 \\
\hline verbo & 3 & 1 & 0 & 0 & 4 & 0 & 0 & 3 & 5 & 0 & 1 & 7 \\
\hline advérbio & 2 & 1 & 1 & 1 & 1 & 1 & 1 & 2 & 2 & 1 & 0 & 4 \\
\hline artigo & 0 & 0 & 0 & 0 & 1 & 0 & 0 & 0 & 1 & 0 & 0 & 0 \\
\hline preposição & 0 & 0 & 0 & 0 & 1 & 0 & 0 & 1 & 1 & 0 & 0 & 1 \\
\hline conjunção & 0 & 0 & 0 & 0 & 0 & 0 & 0 & 0 & 0 & 0 & 0 & 0 \\
\hline numeral & 0 & 0 & 0 & 0 & 4 & 0 & 0 & 0 & 0 & 0 & 0 & 0 \\
\hline interjeição & 3 & 0 & 0 & 0 & 4 & 2 & 0 & 0 & 2 & 1 & 1 & 3 \\
\hline $\begin{array}{l}n^{\circ} \text { total de palavras } \\
\text { diferentes emitidas por } \\
\text { classe }\end{array}$ & 20 & 2 & 2 & 2 & 35 & 4 & 3 & 14 & 28 & 2 & 2 & 27 \\
\hline $\begin{array}{l}n^{\circ} \text { total de classes de } \\
\text { palavras }\end{array}$ & 5 & 2 & 2 & 2 & 8 & 3 & 2 & 5 & 8 & 2 & 2 & 6 \\
\hline
\end{tabular}


Quadro 8: Tipos diferentes de ocorrências de comunicação gestual simultânea à linguagem oral dos quatro sujeitos do GP durante as avaliações, de acordo com a classificação de gestos.

\begin{tabular}{|c|c|c|c|c|c|c|c|c|c|c|c|c|}
\hline \multirow{2}{*}{$\begin{array}{l}\text { Lgg oral e comunicação } \\
\text { gestual simultâneas }\end{array}$} & \multicolumn{4}{|c|}{$1^{\mathrm{a}}$ avaliação } & \multicolumn{4}{|c|}{$2^{\mathrm{a}}$ avaliação } & \multicolumn{4}{|c|}{$3^{\mathrm{a}}$ avaliação } \\
\hline & S1 & $\mathrm{S2}$ & S3 & S4 & S1 & $\mathrm{S2}$ & S3 & S4 & S1 & S2 & S3 & S4 \\
\hline \multicolumn{13}{|l|}{ Gestos dêiticos: } \\
\hline apontar & 0 & 1 & 1 & 0 & 1 & 1 & 1 & 1 & 1 & 1 & 1 & 0 \\
\hline mostrar & 4 & 1 & 0 & 0 & 3 & 1 & 0 & 1 & 8 & 0 & 0 & 3 \\
\hline alcançar & 0 & 0 & 0 & 0 & 0 & 1 & 0 & 0 & 0 & 0 & 0 & 1 \\
\hline \multicolumn{13}{|l|}{ Gestos representativos: } \\
\hline de conteúdo semântico: & 15 & 0 & 4 & 1 & 9 & 4 & 2 & 4 & 12 & 0 & 2 & 4 \\
\hline convencionais & 2 & 1 & 1 & 0 & 3 & 1 & 1 & 1 & 2 & 0 & 0 & 1 \\
\hline expressivos & 1 & 0 & 0 & 0 & 3 & 1 & 0 & 0 & 1 & 2 & 3 & 1 \\
\hline$n^{\circ}$ total de gestos & 22 & 3 & 6 & 1 & 19 & 9 & 4 & 7 & 24 & 3 & 6 & 10 \\
\hline $\begin{array}{l}n^{0} \text { total de tipos diferentes de } \\
\text { gestos }\end{array}$ & 4 & 3 & 3 & 1 & 5 & 6 & 3 & 4 & 5 & 2 & 3 & 5 \\
\hline
\end{tabular}

Quadro 9: observação do número de vocábulos diferentes por classe de palavras na linguagem oral simultânea à comunicação gestual dos quatro sujeitos do GC1 durante as três avaliações.

\begin{tabular}{|c|c|c|c|c|c|c|c|c|c|c|c|c|}
\hline \multirow[b]{2}{*}{ Classes de palavras } & \multicolumn{4}{|c|}{$1^{\circ}$ avaliação } & \multicolumn{4}{|c|}{$2^{\circ}$ avaliação } & \multicolumn{4}{|c|}{$3^{\circ}$ avaliação } \\
\hline & S5 & S6 & S7 & S8 & S5 & S6 & S7 & $\mathbf{S 8}$ & $\mathrm{S5}$ & S6 & S7 & S8 \\
\hline substantivo & 0 & 0 & 0 & 4 & 0 & 4 & 1 & 11 & 0 & 3 & 5 & 10 \\
\hline adjetivo & 0 & 0 & 0 & 1 & 0 & 0 & 0 & 0 & 0 & 0 & 0 & 0 \\
\hline pronome & 0 & 0 & 0 & 0 & 0 & 0 & 0 & 1 & 0 & 0 & 0 & 3 \\
\hline verbo & 0 & 2 & 0 & 9 & 0 & 2 & 0 & 5 & 0 & 2 & 0 & 7 \\
\hline advérbio & 0 & 0 & 0 & 0 & 0 & 0 & 0 & 0 & 0 & 1 & 0 & 5 \\
\hline artigo & 0 & 0 & 0 & 0 & 0 & 0 & 1 & 1 & 0 & 0 & 0 & 1 \\
\hline preposição & 0 & 0 & 0 & 0 & 0 & 0 & 0 & 1 & 0 & 0 & 0 & 0 \\
\hline conjunção & 0 & 0 & 0 & 0 & 0 & 0 & 0 & 0 & 0 & 0 & 0 & 0 \\
\hline numeral & 0 & 0 & 0 & 0 & 0 & 0 & 0 & 0 & 0 & 0 & 0 & 0 \\
\hline interjeição & 0 & 2 & 0 & 3 & 1 & 2 & 0 & 2 & 1 & 3 & 1 & 1 \\
\hline $\begin{array}{l}\mathrm{n}^{\circ} \text { total de palavras } \\
\text { diferentes emitidas por } \\
\text { classe }\end{array}$ & 0 & 4 & 0 & 17 & 1 & 8 & 2 & 21 & 1 & 9 & 6 & 27 \\
\hline $\begin{array}{l}n^{\circ} \text { total de classes de } \\
\text { palavras }\end{array}$ & 0 & 2 & 0 & 4 & 1 & 3 & 2 & 6 & 1 & 4 & 2 & 6 \\
\hline
\end{tabular}


Quadro 10: Tipos diferentes de ocorrências de comunicação gestual simultânea à linguagem oral dos quatro sujeitos do GC1 durante as avaliações, de acordo com a classificação de gestos.

\begin{tabular}{|c|c|c|c|c|c|c|c|c|c|c|c|c|}
\hline \multirow{2}{*}{$\begin{array}{l}\text { Lgg oral e comunicação } \\
\text { gestual simultâneas }\end{array}$} & \multicolumn{4}{|c|}{$1^{\mathrm{a}}$ avaliação } & \multicolumn{4}{|c|}{$2^{\mathrm{a}}$ avaliação } & \multicolumn{4}{|c|}{$3^{\mathrm{a}}$ avaliação } \\
\hline & S5 & 56 & S7 & S8 & S5 & S6 & S7 & 58 & S5 & 56 & S7 & S8 \\
\hline Gestos dêiticos: & \multirow[b]{2}{*}{1} & \multirow[b]{2}{*}{1} & \multirow[b]{2}{*}{0} & \multirow[b]{2}{*}{1} & \multirow[b]{2}{*}{0} & \multirow[b]{2}{*}{2} & \multirow[b]{2}{*}{1} & \multirow[b]{2}{*}{0} & \multirow[b]{2}{*}{0} & \multirow[b]{2}{*}{4} & \multirow[b]{2}{*}{0} & \multirow[b]{2}{*}{0} \\
\hline apontar & & & & & & & & & & & & \\
\hline mostrar & 0 & 3 & 0 & 5 & 2 & 3 & 2 & 5 & 1 & 4 & 1 & 2 \\
\hline alcançar & 0 & 2 & 0 & 2 & 0 & 2 & 0 & 0 & 0 & 2 & 0 & 3 \\
\hline Gestos representativos: & \multirow[b]{2}{*}{3} & \multirow[b]{2}{*}{5} & \multirow[b]{2}{*}{0} & \multirow[b]{2}{*}{11} & \multirow[b]{2}{*}{3} & \multirow[b]{2}{*}{14} & \multirow[b]{2}{*}{1} & \multirow[b]{2}{*}{3} & \multirow[b]{2}{*}{3} & \multirow[b]{2}{*}{3} & \multirow[b]{2}{*}{2} & \multirow[b]{2}{*}{5} \\
\hline de conteúdo semântico: & & & & & & & & & & & & \\
\hline convencionais & 0 & 0 & 0 & 1 & 0 & 0 & 0 & 0 & 0 & 0 & 2 & 0 \\
\hline expressivos & 0 & 3 & 0 & 4 & 0 & 1 & 0 & 0 & 0 & 1 & 0 & 0 \\
\hline $\mathrm{n}^{\circ}$ total de gestos & 4 & 14 & 0 & 24 & 5 & 22 & 4 & 8 & 4 & 14 & 5 & 10 \\
\hline $\begin{array}{l}n^{\circ} \text { total de tipos diferentes de } \\
\text { gestos }\end{array}$ & 2 & 4 & 0 & 6 & 2 & 5 & 3 & 2 & 2 & 22 & 4 & 8 \\
\hline
\end{tabular}

Quadro 11: observação do número de vocábulos diferentes por classe de palavras na linguagem oral simultânea à comunicação gestual dos quatro sujeitos do GC2 durante as três avaliações.

\begin{tabular}{|c|c|c|c|c|c|c|c|c|c|c|c|c|}
\hline \multirow[b]{2}{*}{ Classes de palavras } & \multicolumn{4}{|c|}{$1^{\circ}$ avaliação } & \multicolumn{4}{|c|}{$2^{\circ}$ avaliação } & \multicolumn{4}{|c|}{$3^{\circ}$ avaliação } \\
\hline & S9 & S10 & S11 & S12 & S9 & S10 & S11 & S12 & S9 & S10 & S11 & S12 \\
\hline substantivo & 0 & 0 & 0 & 5 & 4 & 3 & 13 & 14 & 9 & 2 & 4 & 12 \\
\hline adjetivo & 0 & 0 & 0 & 0 & 0 & 0 & 1 & 0 & 0 & 0 & 0 & 1 \\
\hline pronome & 0 & 0 & 0 & 1 & 2 & 1 & 1 & 8 & 2 & 0 & 3 & 4 \\
\hline verbo & 0 & 0 & 0 & 6 & 13 & 5 & 5 & 10 & 17 & 4 & 10 & 11 \\
\hline advérbio & 0 & 0 & 0 & 1 & 5 & 1 & 0 & 4 & 3 & 0 & 5 & 3 \\
\hline artigo & 0 & 0 & 0 & 0 & 1 & 1 & 1 & 1 & 0 & 0 & 1 & 0 \\
\hline preposição & 0 & 0 & 0 & 0 & 2 & 0 & 0 & 3 & 1 & 0 & 2 & 2 \\
\hline conjunção & 0 & 0 & 0 & 0 & 1 & 0 & 0 & 0 & 1 & 0 & 0 & 1 \\
\hline numeral & 0 & 0 & 0 & 0 & 1 & 0 & 0 & 0 & 1 & 0 & 0 & 3 \\
\hline interjeição & 0 & 0 & 0 & 1 & 1 & 1 & 0 & 4 & 1 & 0 & 1 & 3 \\
\hline $\begin{array}{l}\mathrm{n}^{\circ} \text { total de palavras } \\
\text { diferentes emitidas por } \\
\text { classe }\end{array}$ & 0 & 0 & 0 & 14 & 30 & 12 & 21 & 44 & 35 & 6 & 26 & 40 \\
\hline $\begin{array}{l}n^{\circ} \text { total de classes de } \\
\text { palavras }\end{array}$ & 0 & 0 & 0 & 5 & 9 & 6 & 5 & 7 & 8 & 2 & 7 & 9 \\
\hline
\end{tabular}


Quadro 12: Tipos diferentes de ocorrências de comunicação gestual simultânea à linguagem oral dos quatro sujeitos do GC2 durante as avaliações.

\begin{tabular}{|c|c|c|c|c|c|c|c|c|c|c|c|c|}
\hline \multirow{2}{*}{$\begin{array}{l}\text { Lgg oral e comunicação } \\
\text { gestual simultâneas }\end{array}$} & \multicolumn{3}{|c|}{$1^{\mathrm{a}}$ avaliação } & & \multicolumn{4}{|c|}{$2^{\mathrm{a}}$ avaliação } & \multicolumn{4}{|c|}{$3^{\mathrm{a}}$ avaliação } \\
\hline & S9 & $\mathrm{S} 10$ & S11 & $\mathrm{S} 12$ & S9 & S10 & S11 & S12 & S9 & S10 & S11 & $\mathrm{S} 12$ \\
\hline \multicolumn{13}{|l|}{ Gestos dêiticos: } \\
\hline apontar & 0 & 0 & 0 & 0 & 3 & 1 & 1 & 3 & 0 & 1 & 3 & 0 \\
\hline mostrar & 0 & 0 & 0 & 5 & 5 & 10 & 10 & 9 & 11 & 2 & 3 & 11 \\
\hline alcançar & 0 & 0 & 0 & 0 & 2 & 0 & 1 & 0 & 0 & 0 & 1 & 0 \\
\hline \multicolumn{13}{|l|}{ Gestos representativos: } \\
\hline de conteúdo semântico: & 0 & 0 & 0 & 2 & 14 & 1 & 13 & 8 & 8 & 3 & 8 & 9 \\
\hline convencionais & 0 & 0 & 0 & 0 & 2 & 0 & 0 & 1 & 1 & 0 & 0 & 1 \\
\hline expressivos & 0 & 0 & 0 & 1 & 2 & 1 & 0 & 2 & 0 & 0 & 3 & 3 \\
\hline$n^{\circ}$ total de gestos & $\mathbf{0}$ & 0 & $\mathbf{0}$ & 8 & 28 & 13 & 25 & 23 & 20 & 6 & 18 & 24 \\
\hline $\begin{array}{l}n^{\circ} \text { total de tipos diferentes de } \\
\text { gestos }\end{array}$ & 0 & 0 & 0 & 3 & 6 & 4 & 4 & 4 & 3 & 3 & 5 & 4 \\
\hline
\end{tabular}

Figura 4: Ocorrências de linguagem oral simultânea à comunicação gestual dos três grupos segundo o número de vocábulos

\section{Vocábulos Diferentes - Ling. Oral e Comunicação Gestual}

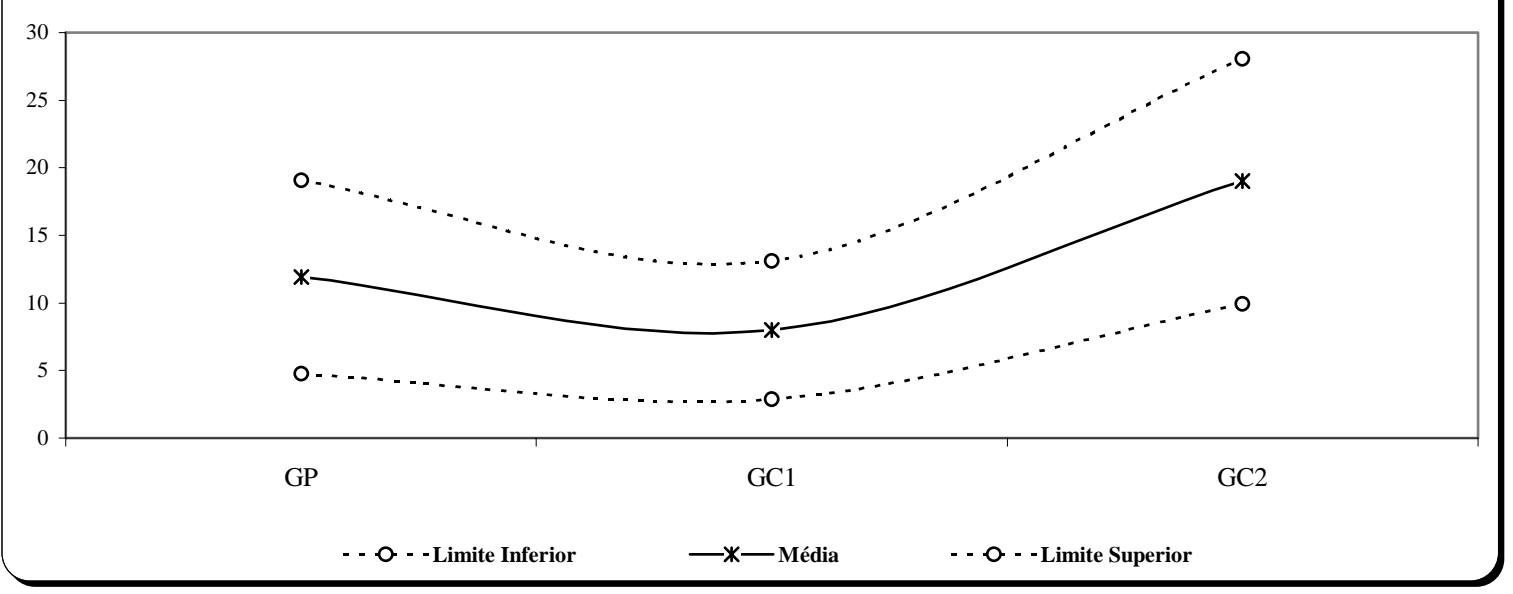

\begin{tabular}{|l|c|c|c|}
\hline Ambas - Vocábulo & GP & GC1 & GC2 \\
\hline Limite Inferior & 4,76 & 2,9 & 9,94 \\
\hline Média & 11,92 & 8 & 19 \\
\hline Limite Superior & 19,07 & 13,1 & 28,06 \\
\hline
\end{tabular}

$p$-valor $=0,300$

Segundo o p-valor, verifica-se que as diferenças encontradas entre os grupos não podem ser consideradas estatisticamente significantes. 
Figura 5: Ocorrências de linguagem oral simultânea à comunicação gestual dos três grupos segundo o número de classes de palavras

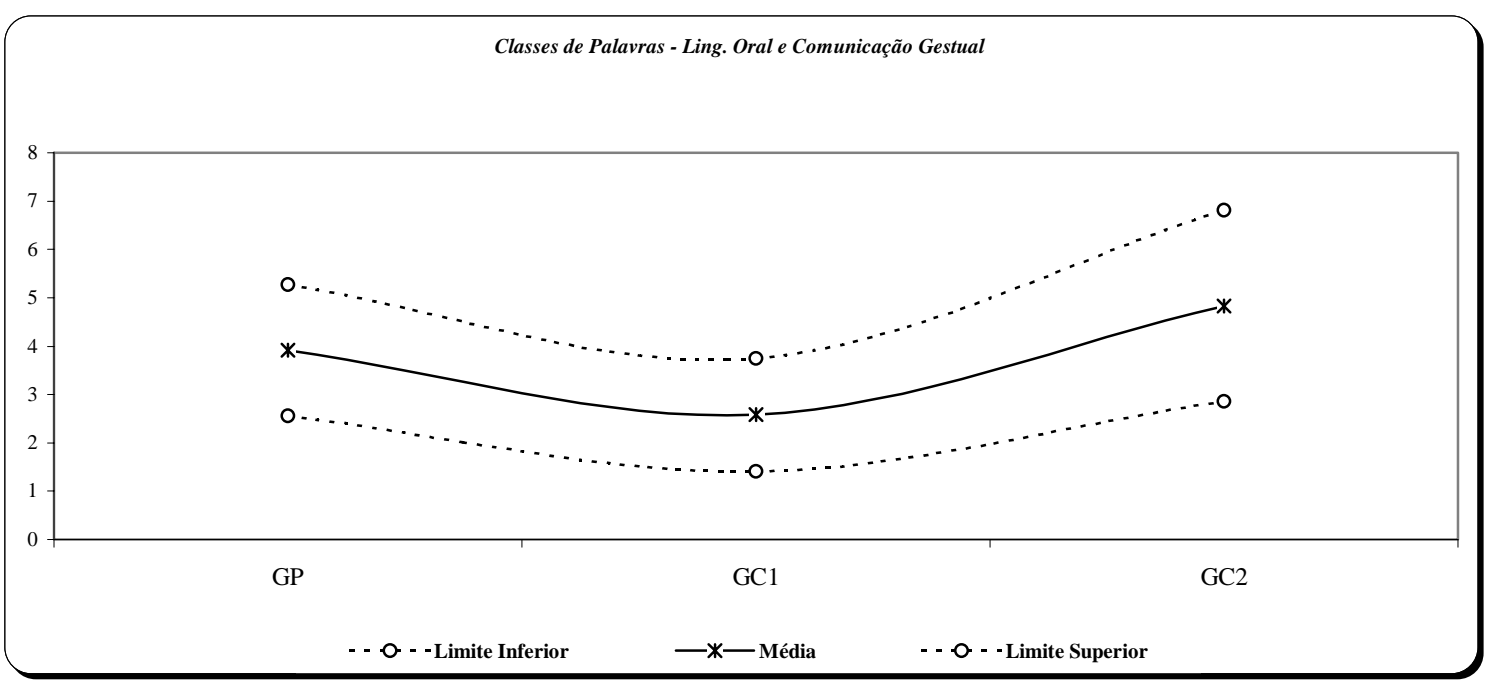

\begin{tabular}{|l|c|c|c|}
\hline \multicolumn{1}{|c|}{ Ambas - Classe } & GP & GC1 & GC2 \\
\hline Limite Inferior & 2,56 & 1,41 & 2,86 \\
\hline Média & 3,92 & 2,58 & 4,83 \\
\hline Limite Superior & 5,27 & 3,75 & 6,81 \\
\hline
\end{tabular}

p-valor $=0,193$

De acordo com o p-valor observado, verifica-se que não foram encontradas diferenças significativas entre os grupos. 
Figura 6: Ocorrências de comunicação gestual e linguagem oral simultâneas dos três grupos segundo o número de gestos

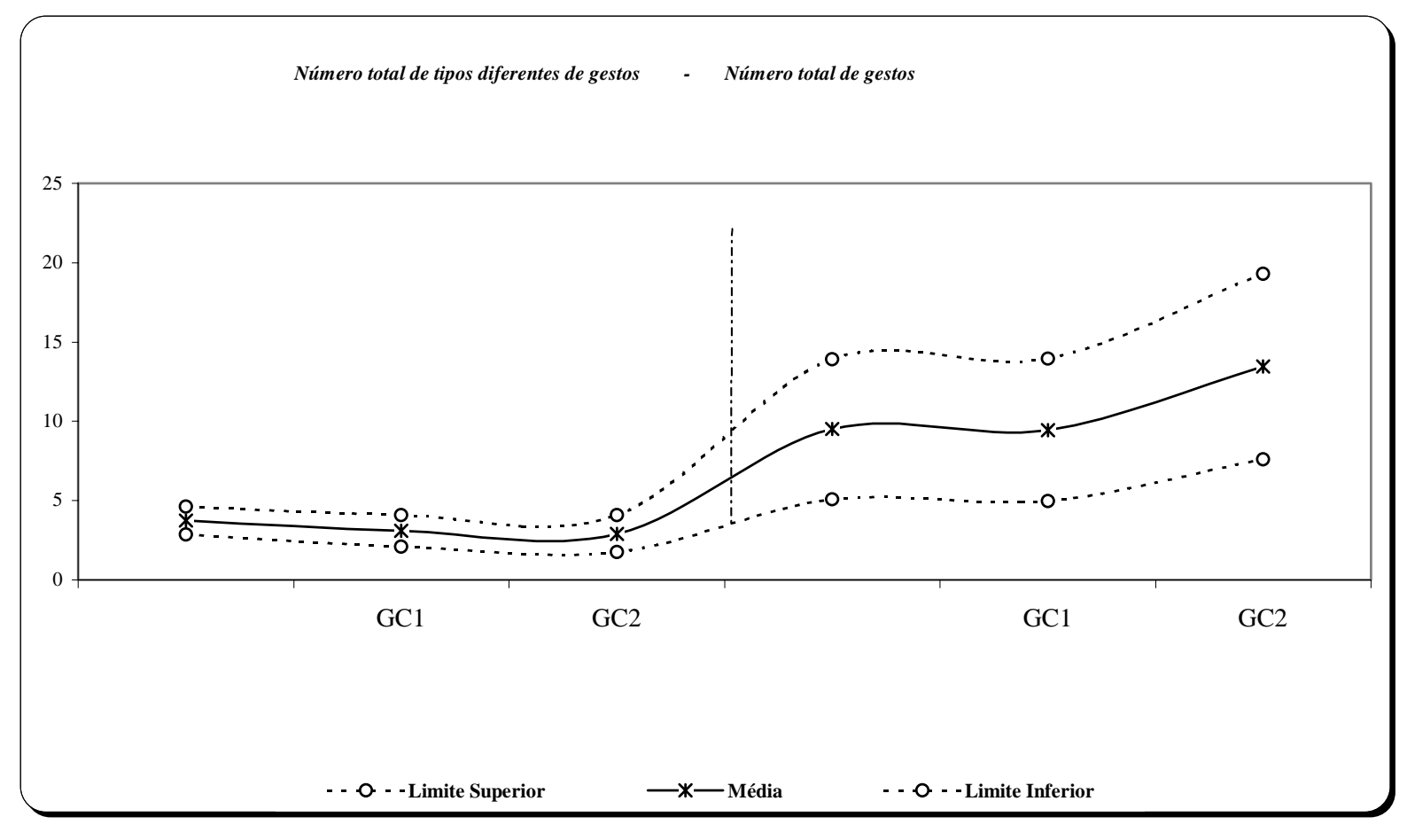

\begin{tabular}{|l|c|c|c|c|c|c|}
\hline & \multicolumn{3}{|c|}{$N^{\circ}$ total de tipos diferentes de } & \multicolumn{3}{c|}{$N^{\circ}$ total de gestos } \\
\cline { 2 - 7 } & GP & GC1 & & GP & GC1 & GC2 \\
\hline Limite Superior & 4,62 & 4,09 & 4,08 & 13,93 & 13,95 & 19,31 \\
\hline Média & 3,75 & 3,09 & 2,91 & 9,5 & 9,45 & 13,45 \\
\hline Limite Inferior & 2,88 & 2,1 & 1,74 & 5,07 & 4,96 & 7,59 \\
\hline
\end{tabular}

Ao se observar os p-valores acima, verifica-se que não existe média estatisticamente significante entre os grupos.

Desse modo, conclui-se que, em todas as análises para a linguagem oral e comunicação gestual simultâneas, não foram encontradas diferenças significativas entre os grupos.

\section{Discussão}


Para facilitar a compreensão dos resultados obtidos, a discussão será abordada a partir da comparação intra-grupal dos GP, GC1 e GC2 e, a seguir, inter-grupal.

Ressalta-se que, na comparação intra-grupal, a discussão terá início pelo GC2, visto que os seus sujeitos apresentavam DT, e os seus resultados foram fundamentais durante a análise dos dados dos outros dois grupos. Em seguida, serão discutidos os resultados dos demais grupos por serem constituídos por sujeitos com SD, o que também facilita a compreensão da comparação entre os dois.

\section{Comparação intra-grupal do GC2}

De um modo geral, pode-se afirmar que todos os resultados obtidos nas avaliações realizadas com os sujeitos do GC2 estiveram de acordo com a literatura.

Observou-se que, durante a emergência da comunicação expressiva dos sujeitos deste grupo, ocorreu uma evolução da comunicação gestual para a linguagem oral, passando pela linguagem oral e comunicação gestual simultâneas.

No decorrer desta evolução, verificou-se que, no início, os gestos mais utilizados por este grupo foram os representativos de conteúdo semântico; depois, observa-se o aumento tanto do número deste tipo de gesto como os dêiticos de mostrar. Paralelamente à esta ocorrência, o número de classes de palavras também aumentou, principalmente as pertencentes às classes substantivo e verbo. Neste período, as expressões comunicativas dos sujeitos deste grupo foram constituídas, basicamente, pela linguagem oral e comunicação gestual simultâneas.

Na última avaliação, verifica-se a diminuição do número de gestos e o aumento de classes de palavras, indicando que os sujeitos deste grupo já estavam 
apresentando a sua comunicação predominantemente por meio da linguagem oral, sendo que, os poucos gestos presentes serviam, apenas, como apoio às palavras. Logo, os gestos estavam diminuindo à medida em que se expandia o vocabulário dos sujeitos deste grupo, tal qual a literatura relatou a respeito (McEachern e Haynes, 2004; Iverson e Goldin-Meadow, 2005; Ozcaliskan e Goldin-Meadow, 2005). A ocorrência do número maior de verbos do que as outras classes de palavras, nesta avaliação, pode ser considerada mais um indício de que este grupo estava em fase da expansão vocabular, confirmando as pesquisas de Camaioni e Longobardi (2001), Colombo e Burani (2002), Abbot-Smith et al. (2004), Theakston et al. (2004), Jones e Smith (2005).

\section{Comparação intra-grupal do GP}

Diferentemente do GC2, a maioria dos sujeitos do GP partiu, basicamente, de uma comunicação predominantemente gestual e, a seguir, enquanto metade deles evoluiu para a emissão de palavras e gestos simultâneos, a outra metade evoluiu para uma maior variação na comunicação gestual.

Tal qual ocorreu com o GC2, inicialmente, os gestos apresentados em maior número pelos sujeitos deste grupo foram os representativos de conteúdo semântico e, depois, quando ocorreu a linguagem oral e a comunicação gestual simultâneas, além deste tipo de gesto, passaram a ocorrer, também, alguns dêiticos.

Quanto à emissão de palavras, substantivo foi a classe mais emitida por alguns sujeitos do GP, sendo seguida de verbo, durante a ocorrência da linguagem oral e comunicação gestual simultâneas, durante as três avaliações. Porém, durante a 
linguagem oral espontânea, a situação apresentada foi oposta, ou seja, verbo foi a classe mais emitida pelos sujeitos, sendo seguida de substantivo. Esta ocorrência difere dos resultados obtidos no GC2, visto que, a maioria dos sujeitos deste último apresentou mais verbos do que substantivos, nesta forma de comunicação, somente na última avaliação e de acordo com a literatura (Camaioni e Longobardi, 2001; Colombo e Burani, 2002; Grela, 2003; Jones e Smith, 2005).

No decorrer das avaliações, observou-se que S1 comunicou-se, predominantemente, por meio da linguagem oral e comunicação gestual simultâneas. Contudo, observa-se que, dentro desta forma de comunicação, houve a evolução do número da emissão de palavras, indicando que este sujeito estava evoluindo para a emissão de frases compostas somente por palavras, sendo que, os gestos, aos poucos, estavam sendo substituídos pelas palavras, tal qual afirmaram McEachern e Haynes (2004), Iverson e Goldin-Meadow (2005) e Ozcaliskan e Goldin-Meadow (2005) em seus estudos.

Dentre os sujeitos do GP, S2 foi o único a apresentar a evolução predominante da comunicação gestual durante as três avaliações realizadas, cujos gestos variaram de acordo com o contexto em que se desenrolaram as situações e modo compreensível para o interlocutor. As poucas palavras emitidas por S2 tiveram, somente, a função de acompanhar os gestos como apoio lingüístico. Os resultados apresentados por este sujeito confirmaram os estudos abordados na literatura sobre a preferência de alguns sujeitos com SD desenvolverem a sua linguagem neste sentido (Franco e Wishart, 1995; Chan e Iacono, 2001; Iverson et al., 2003; Iverson e Goldin-Meadow, 2005). 
S3 iniciou a sua comunicação predominantemente por meio da linguagem oral e comunicação gestual simultâneas, porém, evoluiu para a comunicação gestual, a qual ocorreu de modo mais atrasado do que em S2.

S4, por sua vez, apresentou as suas expressões comunicativas partindo da predominância da comunicação gestual e evoluiu para a linguagem oral e comunicação gestual simultâneas. Com relação à emissão de classes de palavras, durante as três avaliações, S4 apresentou número maior de verbos do que substantivos na ocorrência da linguagem oral espontânea, enquanto que, na linguagem oral e comunicação gestual simultâneas, ocorreu a situação inversa. Observa-se que estes resultados diferem do que ocorreu com os sujeitos do GC2 e do que geralmente ocorre no desenvolvimento da linguagem oral da criança com DT, segundo a literatura (Camaioni e Longobardi, 2001; Colombo e Burani, 2002; Grela, 2003; Abbot-Smith, 2004; Jones e Smith, 2005).

\section{Comparação intra-grupal do GC1}

Os sujeitos do GC1 apresentaram a emergência da comunicação expressiva semelhante ao do GP, porém, de modo ainda mais lento e atrasado do que este.

Embora eles tivessem desenvolvido as suas expressões comunicativas predominantemente por meio de gestos, observou-se, de um modo geral, que eles não evoluíram no desenvolvimento de linguagem da mesma forma que o GP. Em outras palavras, os gestos apresentados pelos sujeitos deste grupo ocorreram em menor número do que os do GP, bem como, apresentaram-se menos variados. A razão para este fato pode estar relacionada à defasagem cognitiva destes sujeitos, a qual, de um 
modo geral, esteve mais comprometida do que para o GP, e que, consequentemente, interferiu de forma significativa no seu desenvolvimento de linguagem. Vale lembrar que todos estavam na mesma fase de desenvolvimento cognitivo, no início da pesquisa.

Neste sentido, pode-se dizer que os resultados apresentados pelos sujeitos do GC1 confirmaram os estudos de alguns autores sobre a relação entre os desenvolvimentos cognitivo e o de linguagem na criança com SD (Limongi et al., 2000; Johnson-Glenberg e Chapman, 2004; Laws e Bishop, 2004).

Observa-se que os gestos de maior ocorrência nas expressões comunicativas dos sujeitos do GC1 foram os representativos de conteúdo semântico quando ocorria somente a comunicação gestual. Por outro lado, na ocorrência da linguagem oral e comunicação gestual simultâneas, além dos primeiros, a presença dos gestos dêiticos foi maior do que quando ocorria somente a comunicação gestual, como aconteceu com o GP e de acordo com as pesquisas de Franco e Wishart (1995) sobre o uso prolongado dos gestos dêiticos na criança com SD.

S5 e S7 apresentaram, predominantemente, a comunicação gestual nas suas expressões, com pouca variedade de tipos de gestos.

S6 e S8 comunicaram-se mais por meio da linguagem oral e a comunicação gestual simultâneas, porém, observa-se que, neste tipo de comunicação, S6 apresentou mais gestos do que palavras desde a primeira avaliação, ao passo que S8 evoluiu do número maior de gestos para o de palavras. Tais dados podem indicar que S6 ainda utilizava parte de sua linguagem oral como apoio à sua comunicação gestual, como relataram alguns autores sobre este tipo de ocorrência na criança com 
SD (Franco e Wishart, 1995; Chan e Iacono, 2001; Iverson et al., 2003; Iverson e Goldin-Meadow, 2005).

Com relação à presença da linguagem oral nos sujeitos deste grupo, S8 foi o que mais emitiu palavras, acompanhando ou não os gestos.

A ocorrência das classes de palavras mais presentes no repertório lingüístico de alguns sujeitos do GC1 foram substantivo e verbo, sendo que a primeira classe foi mais emitida do que a segunda durante a linguagem oral e comunicação gestual simultâneas, ao passo que, durante a presença da linguagem oral espontânea, foram verbo e substantivo, respectivamente. Este fato confirmou os dados obtidos nos sujeitos do GP, porém, também contrariaram os achados da literatura (Camaioni e Longobardi, 2001; Colombo e Burani, 2002; Grela, 2003; Jones e Smith, 2005).

\section{Comparação inter-grupal dos GP, GC1 e GC2}

De acordo com o estudo estatístico sobre a comparação entre os grupos, no decorrer das três avaliações realizadas, foi observado que somente existiu diferença significante no p-valor do GC2 em relação à linguagem oral, demonstrando a evolução crescente deste grupo nesta forma de comunicação quando comparado com os demais grupos, os quais, estatisticamente, comportaram-se de modo semelhante para todos os aspectos avaliados na pesquisa.

Por outro lado, não ocorreram diferenças estatísticas significantes entre os $p$ valores para os três grupos no que se referiu à comunicação gestual e na linguagem oral e comunicação gestual simultâneas. 
A análise mais cuidadosa sobre esses fatos mostra que são dados complementares e que se justificam por si mesmos, pois o GC2 não apresentou diferenças estatísticas significantes com relação aos demais grupos justamente por ter evoluído na sua expressão oral, indicando que os seus sujeitos estavam diminuindo o número de gestos à medida em que aumentavam o de palavras, tal qual apontou a literatura (Namy e Waxman, 2002; McEachern e Haynes, 2004; Ozcaliskan e Goldin-Meadow, 2005; Iverson e Goldin-Meadow, 2005).

Segundo as comparações intra-grupais realizadas anteriormente e os estudos de Limongi et al. (2000), Johnson-Glenberg e Chapman (2004) e Laws e Bishop (2004), verifica-se que, apesar dos GP e GC1 serem constituídos por sujeitos com SD e de apresentarem idades cronológicas aproximadas entre si e estarem na mesma fase do desenvolvimento cognitivo, este desenvolvimento apresentou-se diferente em ambos os grupos, o que, consequentemente, interferiu no desenvolvimento de suas expressões comunicativas no decorrer das avaliações.

Estas diferenças podem ser justificadas por meio da própria evolução das expressões comunicativas apresentada pelos sujeitos de ambos os grupos, independente se foram realizadas predominantemente por meio de gestos, palavras e gestos simultâneos ou somente palavras. Como exemplo, pode-se citar o fato de que, embora alguns sujeitos do GP tivessem se comunicado predominantemente por meio de gestos, foi observado que as suas expressões comunicativas foram mais variadas e inteligíveis do que as de alguns sujeitos do GC1.

Tais resultados estão de acordo com a literatura, confirmando que, apesar dos atrasos cognitivo e de linguagem presentes na criança com SD, o desenvolvimento cognitivo ocorre de modo mais eficiente do que o de linguagem e que, nesta, a 
compreensão é melhor do que a expressão (Limongi et al., 2000; Miles e Chapman, 2002; Johnson-Glenberg e Chapman, 2004; Laws e Bishop, 2004).

Outro fato que contribui para justificar a melhor evolução do GP em relação ao GC1 fundamenta-se na utilização do método dialético-didático (Parrat-Dayan, 1996) realizado durante o processo terapêutico fonoaudiológico com o primeiro grupo. No decorrer deste processo, diante de cada dificuldade apresentada pelos sujeitos na realização das atividades propostas pela terapeuta, ocorria a intervenção desta última, incentivando-os a resolver o “problema”, mostrando-lhes parte de sua resolução para que eles percebessem o seu processo e, a seguir, repetia-se a ação realizada naquele momento e nas terapias seguintes, até que a terapeuta tivesse a certeza da compreensão e aprendizado dos sujeitos sobre o que lhes tinha sido proposto. Neste sentido, a terapeuta foi capaz de intervir respeitando o limite de resposta de cada sujeito, de acordo com o seu potencial naquele momento.

Por meio do método dialético-didático, foi possível observar a capacidade que os sujeitos do GP tiveram de construir representações, segundo o desenvolvimento cognitivo de cada um, as quais manifestaram-se pelos gestos, palavras ou ambos (Piaget, 1990, eidção original de 1946; Iverson et al., 2003; Iverson e GoldinMeadow, 2005).

\section{Conclusão}

Com base nos resultados obtidos dos sujeitos dos GP, GC1 e GC2, pode-se concluir: 
- quanto à emergência da linguagem oral e sua relação com a comunicação gestual, verificou-se que na criança com SD, os gestos desenvolveram-se antes da linguagem oral, tal qual ocorre com a criança com DT, mas se prolongaram por mais tempo. Em alguns casos foi observado que os gestos foram utilizados acompanhando as palavras e, com o decorrer do desenvolvimento lexical, houve diminuição do seu número de ocorrências; em outros, sua utilização foi em substituição à linguagem oral, mas de modo compreensível para o interlocutor, por variarem de acordo com o contexto.

- no que se refere à evolução dos gestos e à sua qualificação, foi verificado que as crianças com SD que apresentaram linguagem oral e comunicação gestual simultâneas diminuíram a quantidade de gestos à medida que ampliaram o seu vocabulário sem, contudo, deixá-los de apresentar por um período longo. Por outro lado, outras ampliaram a quantidade de gestos em detrimento do desenvolvimento da linguagem oral e, neste caso, a comunicação gestual apresentou variedade tanto com relação ao número de gestos quanto aos tipos apresentados.

- o método dialético-didático favoreceu o desenvolvimento de linguagem e sua expressão oral nas crianças com SD, a partir da comunicação gestual, o que foi verificado ao se constatar a evolução apresentada pelo GP durante e após o período a que se submeteram à intervenção fonoaudiológica, comparando-se seu desempenho com as crianças do GC1.

\section{Referências Bibliográficas}


ABBOT-SMITH, K.; LIEVEN, E.; TOMASELLO, M. Training 2;6-years-olds to produce the transitive construction: the role of frequency, semantic similarity and shared syntatic distribution. Dev Sci. v. 7, n. 1, p. 48-55, feb. 2004.

ANDRADE, R. V.; LIMONGI, S. C. O. O processo terapêutico fonoaudiológico de crianças pequenas portadoras de síndrome de Down e a orientação à família. Revista da Sociedade Brasileira de Fonoaudiologia. São Paulo, n.2, p. 29-33, 2001.

ANDRADE, R.V. Trabalho de reeducação quanto à comunicação oral de crianças com alterações sensório-motoras de origem sindrômica ( 0 a 3 anos): enfoque na orientação às mães. 2002. 204 f. Dissertação (Mestrado em Educação) - Faculdade de Educação, Universidade de São Paulo, São Paulo.

ARAUJO, K. Aspectos do desempenho gramatical de crianças pré-escolares em desenvolvimento normal de linguagem. 2003. Dissertação (Mestrado em Lingüística) - Faculdade de Filosofia, Letras e Ciências Humanas, Universidade de São Paulo.

BERGLUND, E.; ERIKSON, M.; JOHANSON, I. Parental reports of spoken language skills in children with Down syndrome. Journal of Speech, Language, and Hearing Research. v. 44, p. 179-191, feb. 2001.

BLACKWELL, A. A. Acquiring the english adjective lexicon: relationships with input properties and adjectival semantic typology. J Child Lang. v. 32, n. 3, p. 535562, aug. 2005. 
BROCK, J.; JARROLD, C. Language influences on verbal short-term memory performance in Down syndrome: item and order recognition. J. Speech Lang Hear Res. v. 47, n. 6, p. 1334-1346, dec. 2004.

CAMAIONI, L.; LONGOBARDI, E. Noun versus verb emphasis in italian motherto-child speech. J. Child Lang. v. 28, n. 3, p. 773-785, oct. 2001.

CHAN, J. B.; IACONO, T. Gesture and production in children with Down syndrome. AAC Augmentative and Alternative Communication. v. 17, p. 73-87, jun. 2001.

CHAPMAN, R. S.; HESKETH, L. J.; KISTLER, D.J. Predicting longitudinal change in language production and comprehension in individuals with Down syndrome: hierarchial linear modeling. Journal of Speech, Language, and Hearing Research. v. 45, p. 902-915, oct. 2002.

COLOMBO, L.; BURANI, C. The influence of age of acquisition, root frequency, and context availability in processing nouns and verbs. Brain Language. v. 81, n. 13, p. 398-411, apr-jun. 2002.

DODD, B.; THOMPSON, L. Speech disorder in children with Down’s syndrome. $J$ Intellect Disabil Res. v. 45, n. Pt 4, p. 308-316, aug. 2001. 
FONSECA, J. S.; MARTINS, G. A. Curso de estatística. São Paulo: Editora Atlas, 320p., $6^{\mathrm{a}}$ ed.,1996.

FRANCO, F.; WISHART, J. G. Use of pointing and other gestures by young children with Down syndrome. American Journal on Mental Retardation. v. 100, n. 2, p. 160-182, 1995.

GOMES, R. C. G.; ANDRADE, R. V.; LIMONGI, S. C. O. Trabalho de orientação fonoaudiológica a mães de crianças com síndrome de Down (0 a 3 anos) - estudo clínico de dois casos. Pró-Fono Revista de Atualização Científica. v. 4, n. 2, p. $22-$ 28, 1992.

GRELA, B. G. Do children with Down syndrome have difficulty with argument structure?. J. Commun. Disord. v. 36, n. 4, p. 263-279, jul-aug. 2003.

HICK, R. F.; BOTTING, N.; CONTI-RAMSDEN, G. Short-term memory and vocabulary development in children with Down syndrome and children with specific language impairment. Dev Med Child Neurol. v. 47, n. 8, p. 532-538, aug. 2005.

IDERIHA, P. N. Eficácia do tratamento fonoaudiológico em síndrome de Down: avaliação eletromiográfica de superfície. 2005. 123 f. Dissertação (Mestrado em Ciências) - Faculdade de Medicina, Universidade de São Paulo, São Paulo.

IVERSON, J. M.; LONGOBARDI, E.; CASELLI, M.C. Relationship between gestures and words in children with Down's syndrome and typically developing 
children in the early stges of communicative development. Int. J. Lang. Comm. Dis. v. 38, n. 2, p. 179-197, 2003.

IVERSON, J. M.; GOLDIN-MEADOW, S. Gesture paves the way for language development. Psychol Sci. v. 16, n. 5, p. 367-371, may 2005.

JOHNSON-GLENBERG, M.C.; CHAPMAN, R.S. Predictors of parent-child language during novel task play: comparison between typically developing children and individual with Down syndrome. J Intellect Disabil. Res. v. 48, n. Pt 3, p. 225238, mar. 2004.

JONES, S. S.; SMITH, L. B. Object name learning and object perception: a deficit in late talkers. J Child Lang. v. 32, n. 1, p. 223-240, feb. 2005.

LAWS, G.; BISHOP, D. V. Verbal deficits in Down's syndrome and specific language impairment: a comparison. Int J Lang Commun Disord. v. 39, n. 4, p. 423451, oct-dec. 2004.

LIMONGI, S. C. O.; ANDRADE, R. V.; LIMA, F. A.G. F.; ALABARSE, V. M.; PEREZ, V. M. Processo terapêutico fonoaudiológico realizado com um par de gêmeos portadores de síndrome de Down. Pró-Fono Revista de Atualização Científica, Barueri, v.12, n. 1, p. 24-33, 2000. 
MCEACHERN, D.; HAYNES, W.O. Gesture-speech combinations as a transition multiword utterances. Am J Speech Lang Pathol. v. 13, n. 3, p. 227-235, aug. 2004.

MILES, S.; CHAPMAN, R. S. Narrative content as described by individuals with Down syndrome and typically developing children. Journal of Speech, Language, and Hearing Research. v. 45, p. 175-189, feb. 2002.

MPURSER, H. R.; JARROLD, C. Impaired verbal short-term memory in Down syndrome reflects a capacity limitation rather than atypically rapid forgetting. $J$ Exp Child Psychol. v. 91, n. 1, p. 1-23, may 2005.

MUSTACCHI, Z. Síndrome de Down. In: MUSTACCHI, Z; PERES, S. Genética baseada em evidências - síndromes e heranças. São Paulo: CID Editora, 2000. cap. 21, p. 817-894.

NAMY, L. L.; WAXMAN, S. R. Patterns of spontaneous production of novel words and gestures within an experimental setting in children ages 1;6 and 2;2. J Child Lang. v. 29, n. 4, p. 911-921, nov. 2002.

NINIO, A. Testing the role of semantic similarity in syntatic development. J Child Lang. v. 32, n. 1, p. 35-61, feb. 2005.

OZCALISKAN, S.; GOLDIN-MEADOW, S. Gesture is at the cutting edge of early language development. Cognition. v. 96, n. 3, p. B101-113, jul. 2005. 
PARRAT-DAYAN, S. Processos internos y externos en la construcción de una explicación causal. In: ASSIS, M. C.; ASSIS, O. Z. M.; RAMOZZICHIAROTTINO, Z. (org.). Piaget: teoria e prática - IV simpósio internacional de epistemologia genética, XIII encontro nacional de professores do PROEPRE. p. 2845, 1996.

PIAGET, J. A formação do símbolo na criança. Rio de Janeiro: LTC Editora, 1990, edição original de 1946.

SCARSELLONE, J. M. Analysis of observational data in speech and language research using generalizability theory. Journal of Speech, Language and Hearing Research. v. 41, p. 1341-1347, dec. 1998.

SPINELLI M.; GARCEZ, E. M. C. B. M.; SARRUF, M.; ENDSFELDZ, A. A.; MARIN, A.; AYUSO, M. T. S. C.; MANTOVANI, L.; CINTRA, A. C. M.; MARCHETTI, P.; PASCALICHIO, M. C. A. Inteligibilidade da fala em portadores da síndrome de Down: relações com praxia motora oral, memória auditiva verbal, idade, sexo e nível intelectual. Distúrbios da Comunicação. São Paulo, v. 12, n. 2, p. 141-160, jun. 2001.

STEINKE, E. E. Use of videotaped interventions in research. West J Nurs Res. v. 23, n. 6, p. 627-643, oct. 2001. 
THEAKSTON, A. L.; LIEVEN, E. V.; PINE, J. M.; ROWLAND, C. F. Semantic generality, input frequency and the acquisition of syntax. $J$ Child Lang. v. 31, n. 1, p. 61-99, feb. 2004.

YODER, P. J.; WARREN, S. F. Early predictors of language in children with and without Down syndrome. American Journal on Mental Retardation. v. 109, n.4, p. 285-300, 2004.

YPSILANTI, A.; GROUIOS, G. ALEVRIADOU, A., TSAPKINI, K. Expressive and receptive vocabulary in children with Williams and Down syndromes. J. Intellect Disabil Res. v. 49, n. Pt 5, p. 353-364, may 2005. 